\title{
Evaluation of the TORE® Lance for Radioactive Waste Mobilization and Retrieval from Underground Storage Tanks
}

\author{
J. A. Bamberger \\ C. J. Bates \\ J. M. Bates \\ M. White
}

September 2002

Prepared for the U.S. Department of Energy

under Contract DE-AC06-76RLO 1830

Pacific Northwest National Laboratory

Richland, Washington 99352 


\title{
DISCLAIMER
}

This report was prepared as an account of work sponsored by an agency of the United States Government. Neither the United States Government nor any agency thereof, nor Battelle Memorial Institute, nor any of their employees, makes any warranty, express or implied, or assumes any legal liability or responsibility for the accuracy, completeness, or usefulness of any information, apparatus, product, or process disclosed, or represents that its use would not infringe privately owned rights. Reference herein to any specific commercial product, process, or service by trade name, trademark, manufacturer, or otherwise does not necessarily constitute or imply its endorsement, recommendation, or favoring by the United States Government or any agency thereof, or Battelle Memorial Institute. The views and opinions of authors expressed herein do not necessarily state or reflect those of the United States Government or any agency thereof.

\author{
PACIFIC NORTHWEST NATIONAL LABORATORY \\ operated by \\ BATTELLE \\ for the \\ UNITED STATES DEPARTMENT OF ENERGY \\ under Contract DE-AC06-76RLO 1830
}

\author{
Printed in the United States of America \\ Available to DOE and DOE contractors from the \\ Office of Scientific and Technical Information, P.O. Box 62, Oak Ridge, TN 37831; \\ prices available from (615) 576-8401. \\ Available to the public from the National Technical Information Service, \\ U.S. Department of Commerce, 5285 Port Royal Rd., Springfield, VA 22161
}

This document was printed on recycled paper. 


\title{
Evaluation of the TORE® Lance for Radioactive Waste Mobilization and Retrieval from Underground Storage Tanks
}

\author{
J. A. Bamberger \\ C. J. Bates \\ J. M. Bates \\ M. White
}

September 2002

Prepared for the U.S. Department of Energy

under Contract DE-AC06-76RLO 1830

Pacific Northwest National Laboratory

Richland, Washington 99352 



\section{Acknowledgments}

The TORE® Lance testing required a team of dedicated researchers. Bill Combs operated the handheld TORE® Lance during its performance evaluation in the 336 building 1/4-scale tank. He also coordinated operation of process equipment including the pressurized water skid and the compressor. Staff under his guidance include Franz Nigl, in tank and Cameron Bates, out of tank. Special recognition is given to Cameron Bates for his data processing and photo and video compilations of the test results.

The success of the tests and the TORE® Lance evaluation is due in part to participation of project sponsor, Dave Smet, CH2M Hill, Inc. Dave's prior experience with the technology at the vendor's site was critical to enhanced understanding of the system fine tuning and obtaining the most useful operating conditions for the TORE® Lance. His valuable insight provided us the ability to operate the system in regimes not specified by the TORE® Lance literature. 



\section{Summary}

The TORE $^{\circledR}$ Lance is a hand-held hydro transportation device with the ability to mobilize and convey solids at pre-determined slurry concentrations over great distances. The TORE® Lance head generates a precessing vortex core to mobilize solids. Solids retrieval is accomplished using an eductor. The device contains no moving parts and requires pressurized fluid to operate the eductor and produce mobilization. Three process fluids for TORE® Lance operation were evaluated for mobilization and eduction during these tests: compressed air, water, and air and water mixtures.

\section{Compressed Air Mobilization and Retrieval}

Stationary mobilization and retrieval tests conducted using gravel and sand simulants showed that

- The zone of influence of the mobilizing fluid from the TORE® Lance head was $~ 18$ in. in diameter for tests conducted with the TORE® Lance head in contact with or submerged in the simulant. This was observed with the head oriented vertically or at angles of 30, 60 or $\sim 90 \mathrm{deg}$ from the vertical. This measured zone of influence for the precessing vortex confirms predictions by Parkinson and Delves (1999) that the diameter of the zone of influence should be 6 times the diameter of the discharge line.

- When compared to a baseline of pneumatic conveyance, addition of compressed air eduction coupled with pneumatic conveyance significantly enhances retrieval rate.

- When compared to a baseline of air eduction coupled with pneumatic conveyance, addition of the precessing vortex significantly enhances solids mobilization and provides a more uniform loading of particulate in the retrieved stream.

Tests of mobilization and retrieval of sand from a drum-shaped container showed that:

- Optimal solids retrieval rates were obtained when the inlet air pressure from the compressor was set at 45 psig. At this condition, the average retrieval rate observed was $\sim 20 \mathrm{lbm} / \mathrm{min}$; the peak retrieval rate obtained was $\sim 45 \mathrm{lbm} / \mathrm{min}$ for these short duration tests.

Mobilization and retrieval of kaolin clay sludge using compressed air was not effective.

- During these tests the compressed air emanating from the TORE® Lance head took the path of least resistance, channeling between the sludge and the TORE® Lance assembly or the sludge and the sides of the container. After this occurred no additional dislodging of sludge was observed.

\section{Water Mobilization and Retrieval}

Tests with water used for eduction and mobilization were conducted both with the pneumatic conveyance line attached and with no pneumatic conveyance with the flow routed through a short hose attached to the TORE® Lance discharge.

- The high water flow rate through the eductor tended to overwhelm the retrieval capability of the pneumatic conveyance line.

- Mobilization and retrieval tests with the pneumatic conveyance line removed showed qualitative mobilization and retrieval at inlet water flow rates of 50 and $70 \mathrm{gpm}$. The retrieved flow was steady and significant amounts of solids were mobilized and transported as indicated by the 
extremely dark color of the retrieved fluid. Tests with an inlet flow rate of $10 \mathrm{gpm}$ showed that this flow rate was too low to induce eduction to support retrieval.

- A companion test at 70 gpm inlet flow rate with no precessing vortex showed the importance of the flow to the TORE® Lance head for mobilizing solids. Without this mobilization, the retrieval flow pulsated between white and dark color as slugs of solids were intermittently introduced into the retrieval line by eduction.

Mobilization and retrieval of kaolin clay sludge was not effective.

- The water took the path of least resistance, channeling between the sludge and the assembly.

- For tests with the TORE® Lance head in contact with the sludge layer, some slow dislodging of the sludge beneath the water jets was observed.

\section{Air and Water Mobilization and Retrieval Test Results}

The air-water combination was the most effective combination for dislodging sludge simulant.

- Tests with the compressed air set at 100 psig at the inlet from the compressor and a $\sim 5$ gpm flow rate of water did penetrate into the sludge. With the TORE® Lance head submerged in the simulant, the air water combination cut small-diameter channels through the sludge to form a radial cut path in the interior of the sludge block. Additional dislodging of sludge occurred along these paths.

\section{Implementation}

These tests have shown that the TORE® Lance is a tool that can be used at Hanford for mobilization and retrieval of wastes. The system is versatile and can be configured for many types of applications. These studies showed that the diverse applications require unique solutions so care is recommended for TORE® Lance or other TORE®-based equipment selection for each application.

The two components of the TORE® Lance are the precessing vortex for mobilization and the eductor for retrieval. The precessing vortex is sensitive to fluid flow rate and pressure. In the hand-held unit these parameters are controlled both internally, by changing shim spacing, and externally by controlling

the flow split between the eductor and the head. For in-tank applications out-of-tank control of both these parameters is recommended. 


\section{Contents}

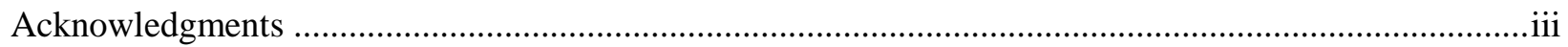

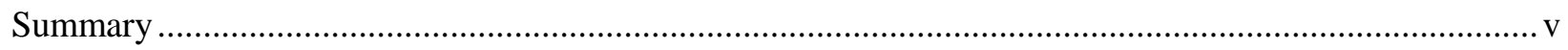

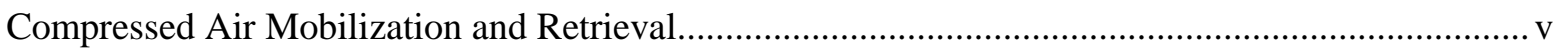

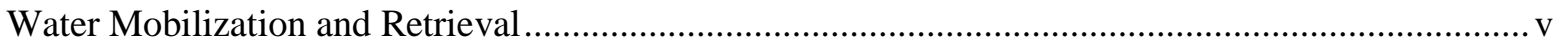

Air and Water Mobilization and Retrieval Test Results ................................................................. vi

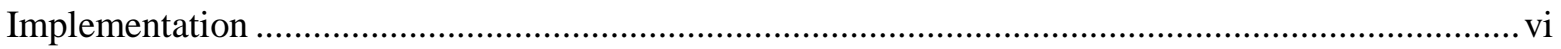

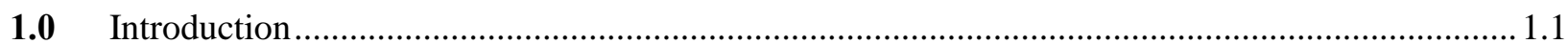

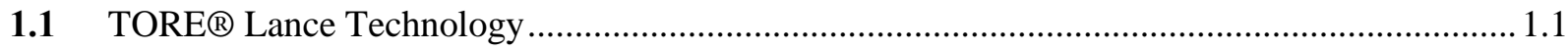

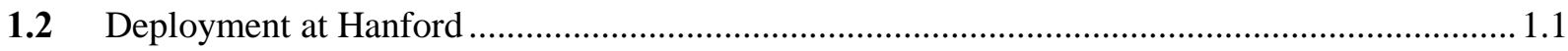

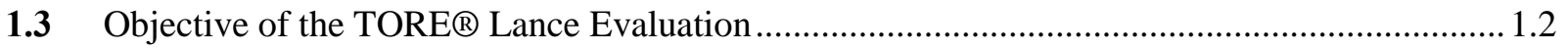

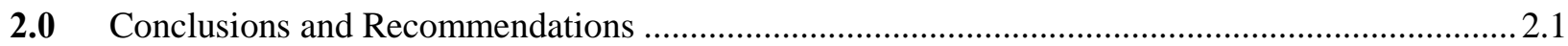

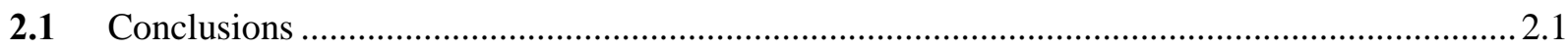

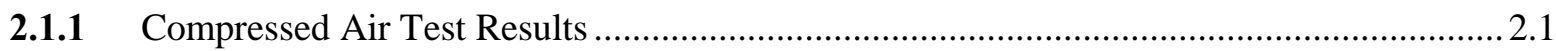

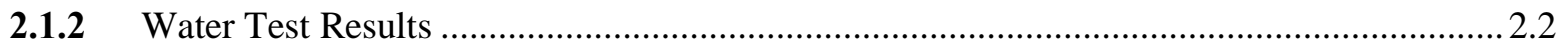

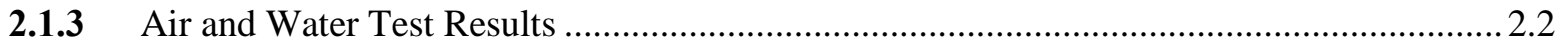

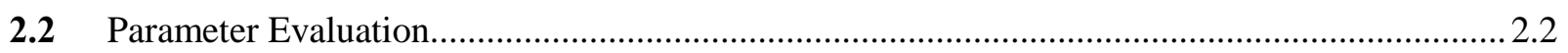

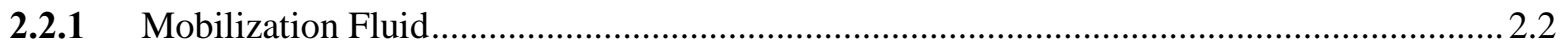

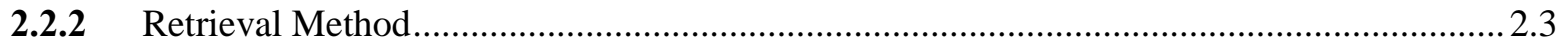

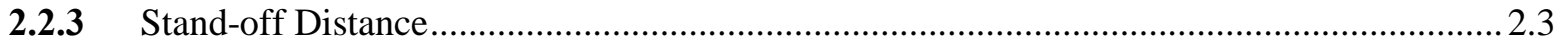

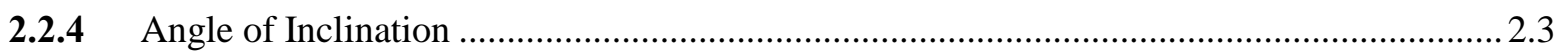

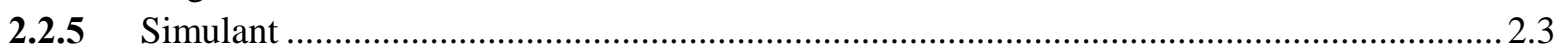

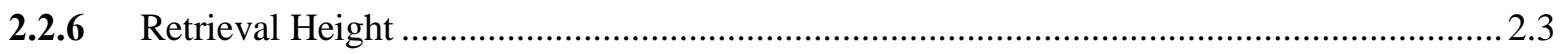

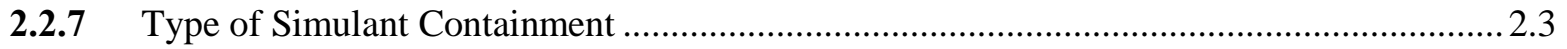

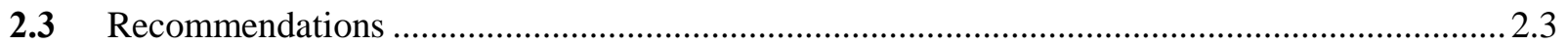

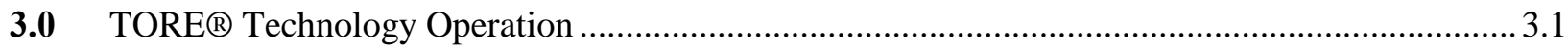

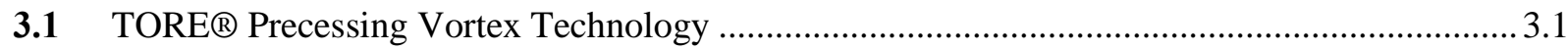

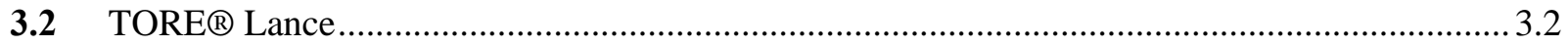

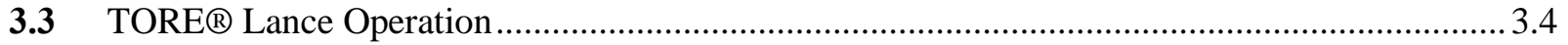

3.3.1 Externally Adjustable Parameters ............................................................................... 3.5

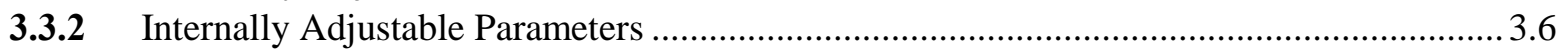

3.4 TORE® Lance Demonstration at Vendor's ......................................................................... 3.7

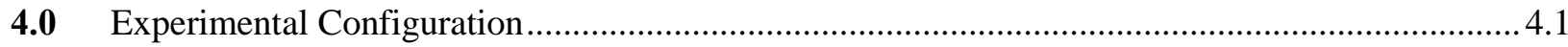

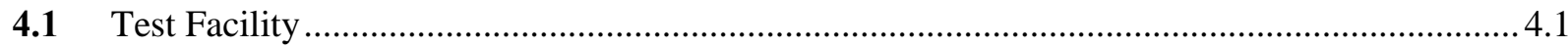

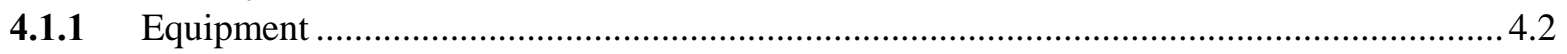

4.1.1.1 Solids Separation System and Blower .................................................................... 4.2

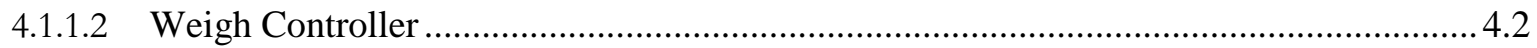

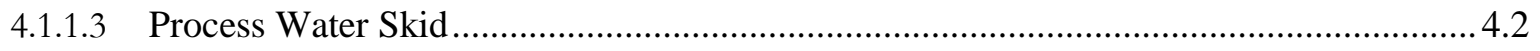

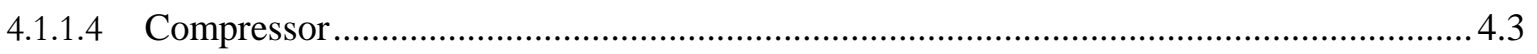

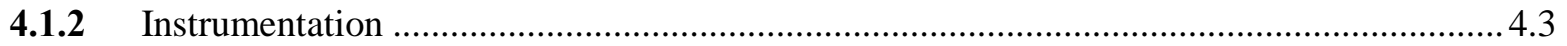

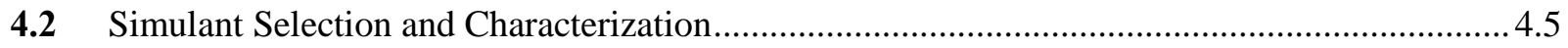




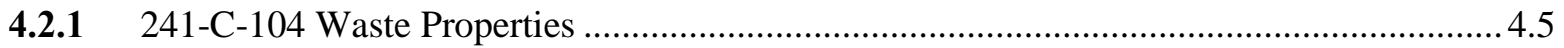

4.2.2 Recommended Simulant for MRS Factory Acceptance Test........................................... 4.6

4.2.3 Simulants Selected for TORE® Lance Evaluation ........................................................... 4.6

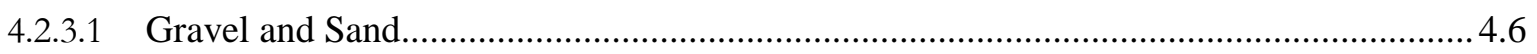

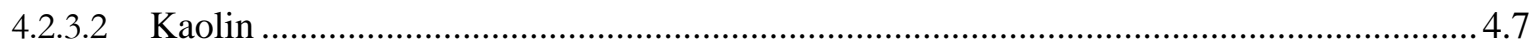

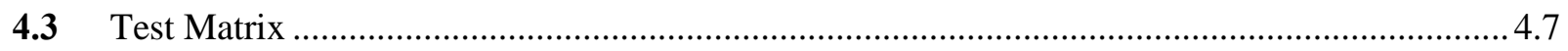

5.0 TORE® Lance Mobilization and Retrieval of Gravel ........................................................... 5.1

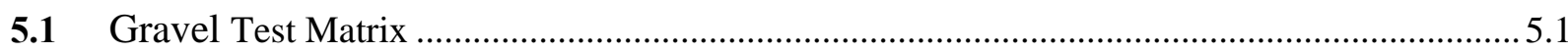

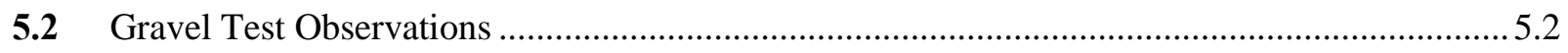

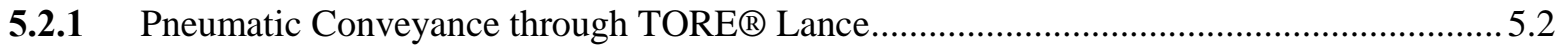

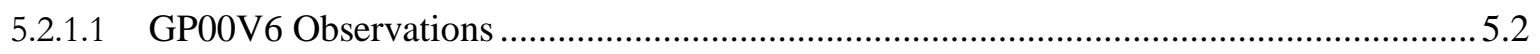

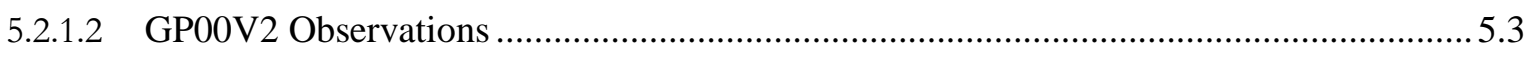

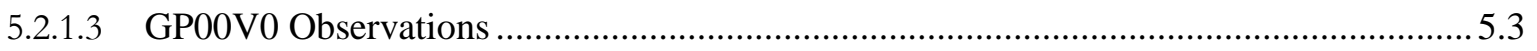

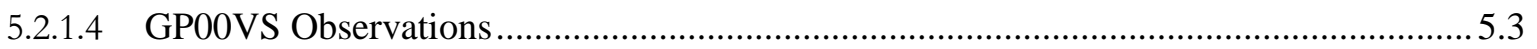

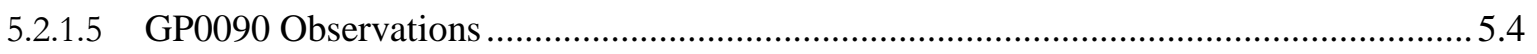

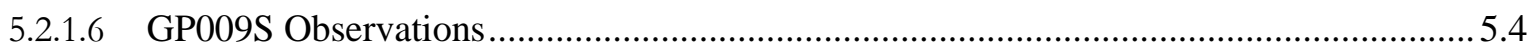

5.2.2 TORE® Lance Operation with Air Eduction-Enhanced Conveyance ................................5.5

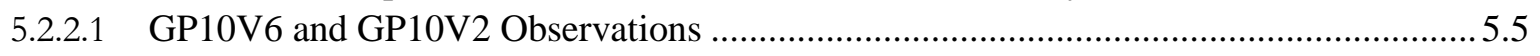

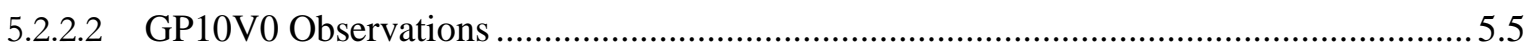

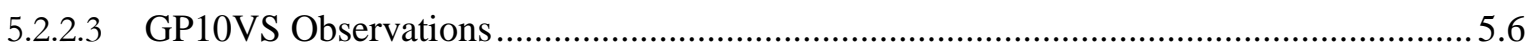

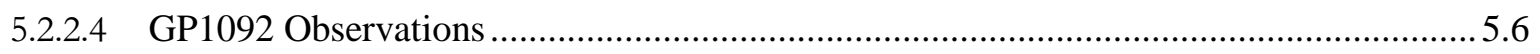

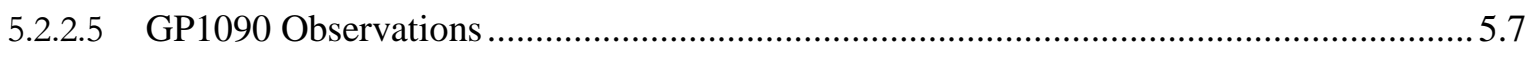

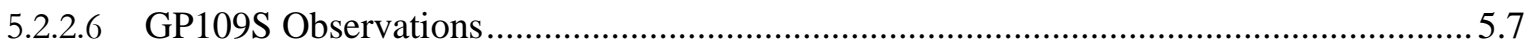

5.2.3 TORE® Lance Full Operation with Air Precessing Vortex Mobilization and Eduction-

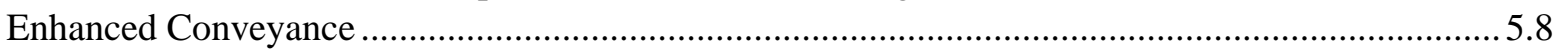

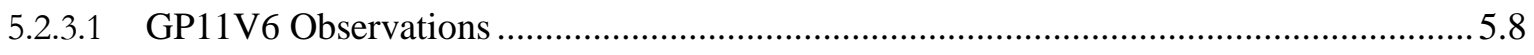

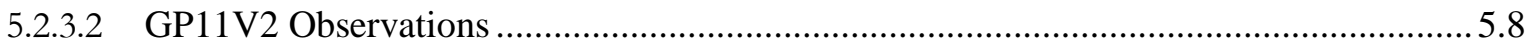

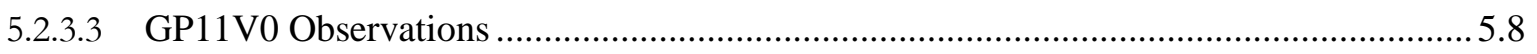

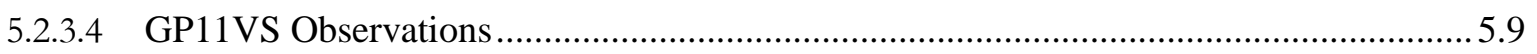

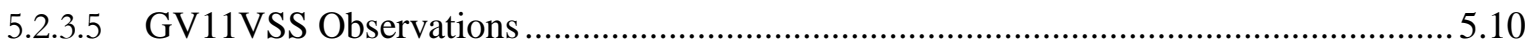

5.2.3.6 GP119S Observations...................................................................................... 5.10

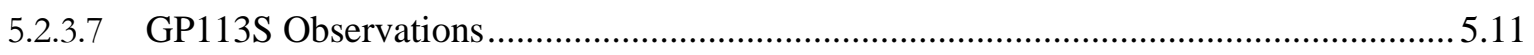

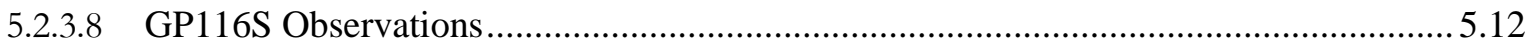

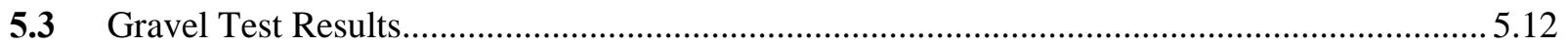

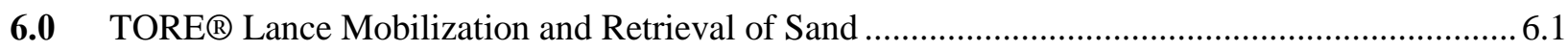

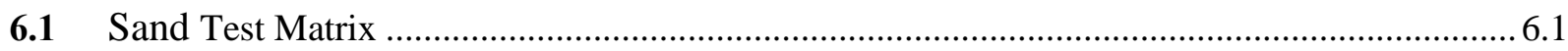

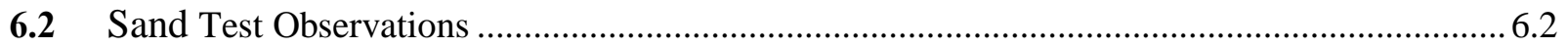

6.2.1 TORE® Lance Operation with No Head Feed or Blower Induced Pneumatic Conveyance6.2

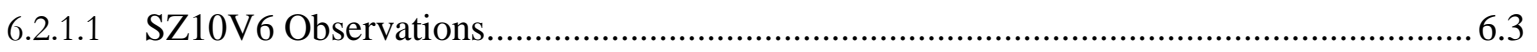

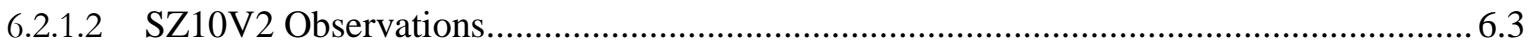

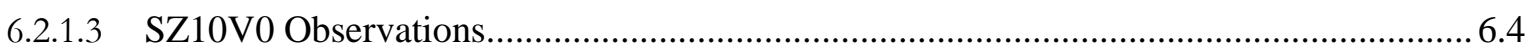

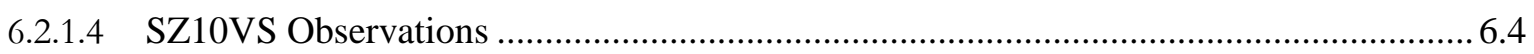

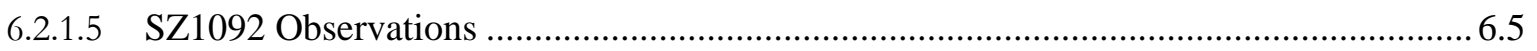

viii 


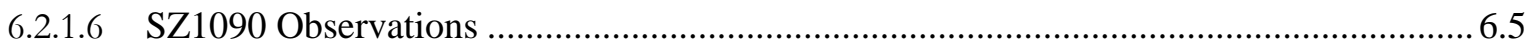

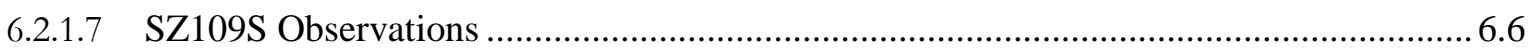

6.2.2 TORE® Lance Operation with Head Feed but No Pneumatic Conveyance ..........................6.6

6.2.2.1 SZ11V6 Observations............................................................................................. 6.6

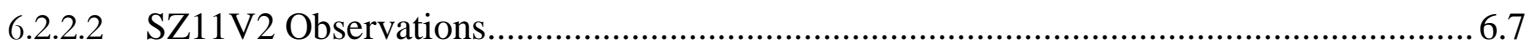

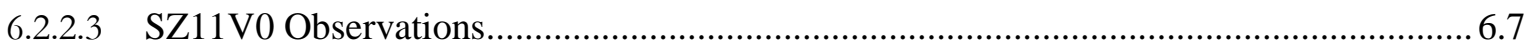

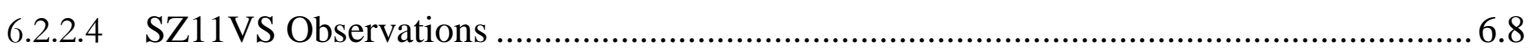

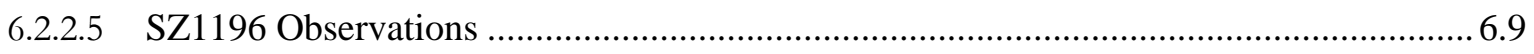

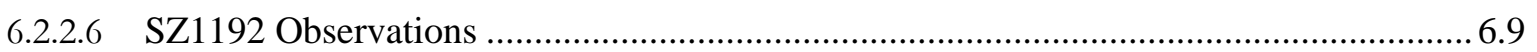

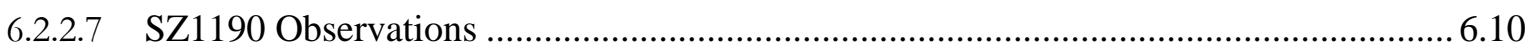

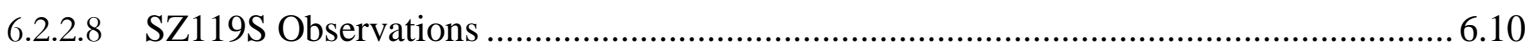

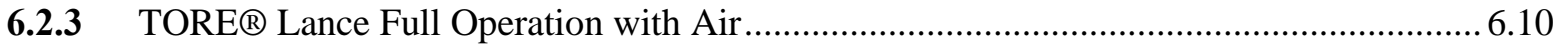

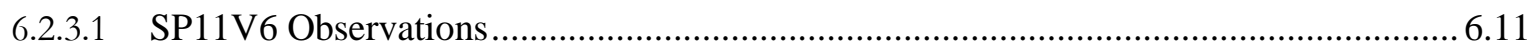

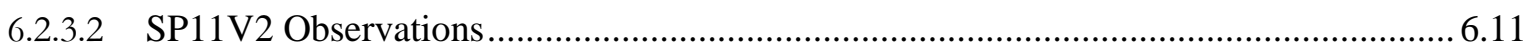

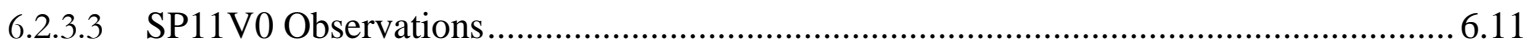

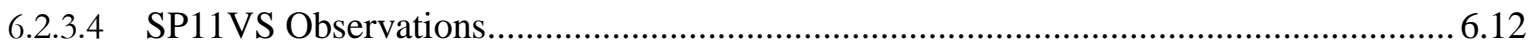

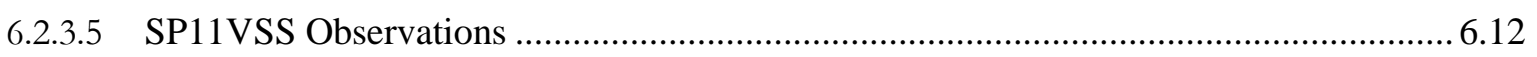

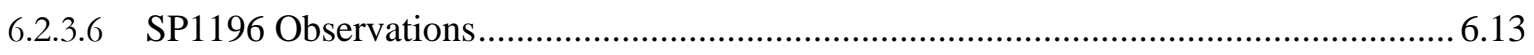

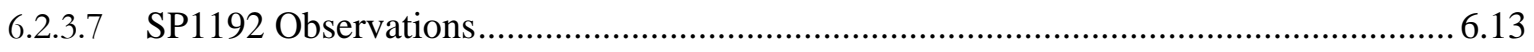

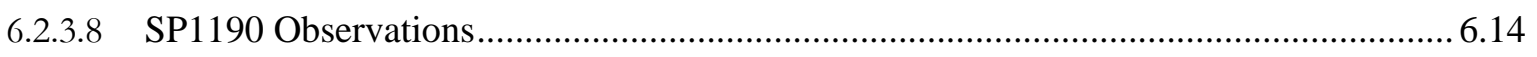

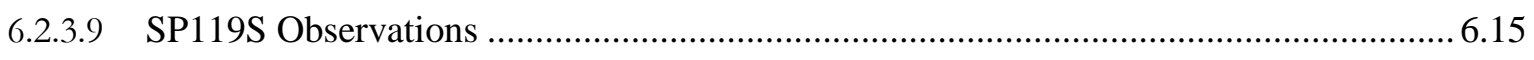

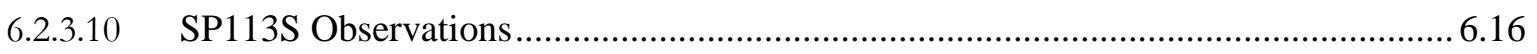

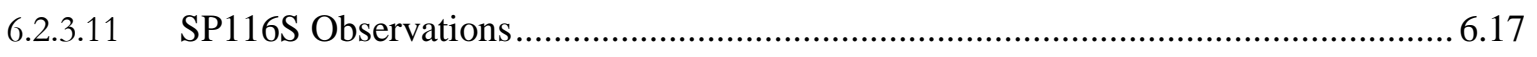

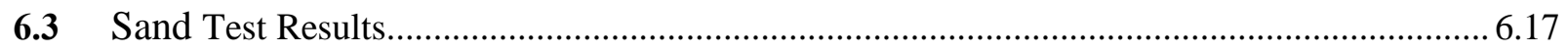

7.0 TORE® Lance Mobilization and Retrieval of Sludge ….......................................................... 7.1

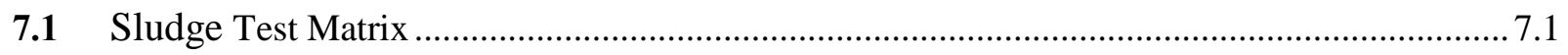

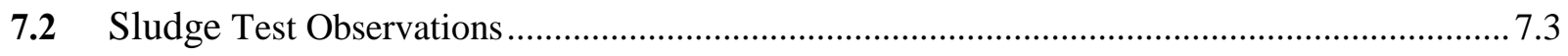

7.2.1 TORE® Lance Operation with Extremely Strong Sludge Simulant .................................. 7.3

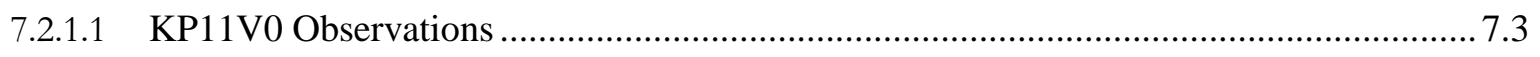

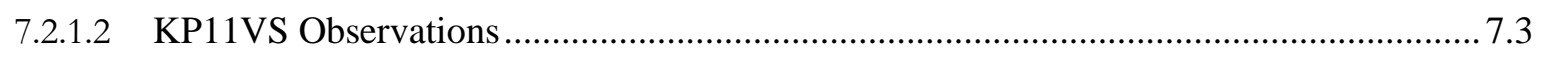

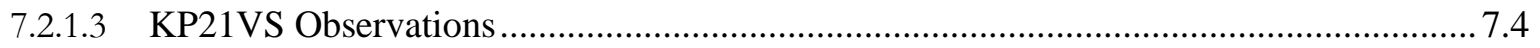

7.2.2 TORE® Lance Full Operation with Air Precessing Vortex Mobilizing and Eductor-

Enhanced Conveyance for Retrieval of Sludge ........................................................................ 7.4

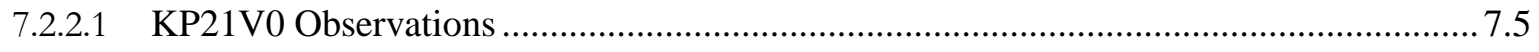

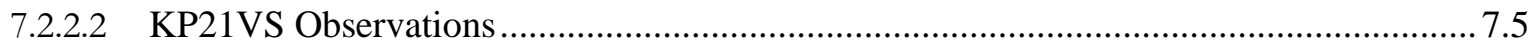

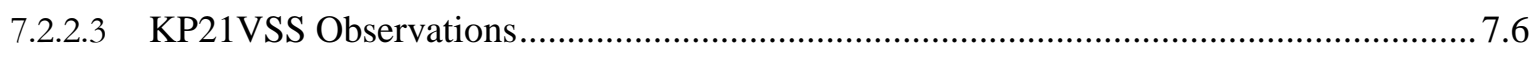

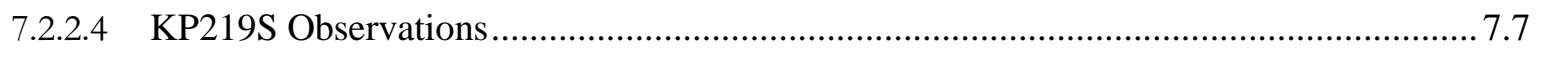

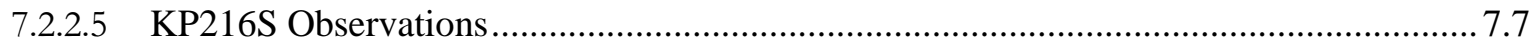

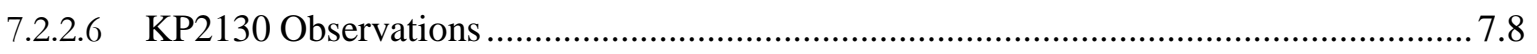

7.2.3 TORE® Lance Full Operation with Combined Air and Water......................................... 7.8

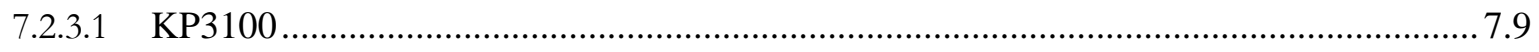

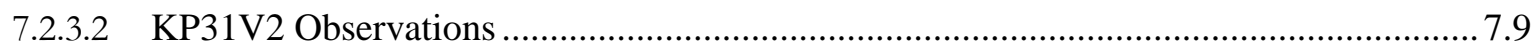

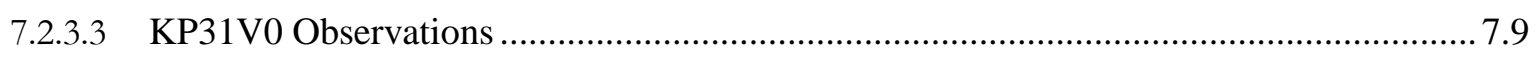




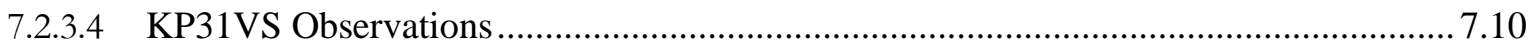

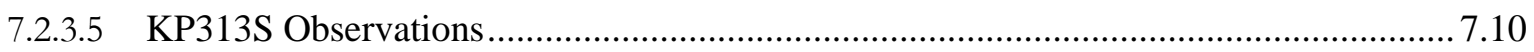

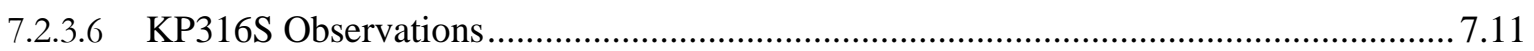

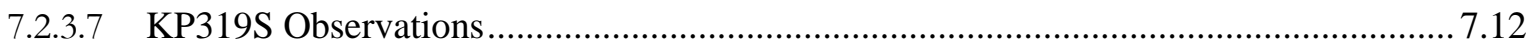

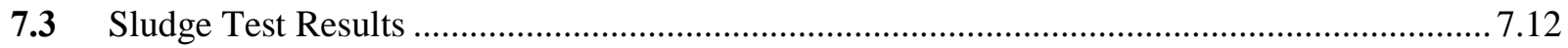

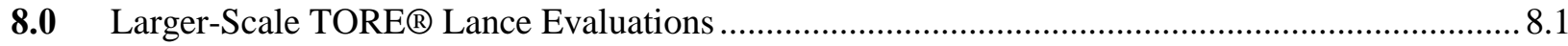

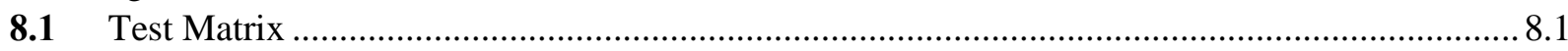

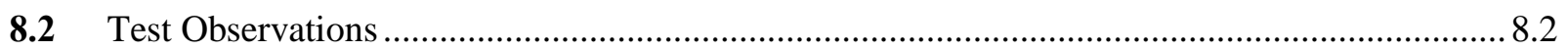

8.2.1 Initial TORE® Lance Retrieval of Solids from a Drum ................................................... 8.2

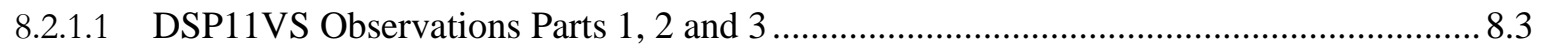

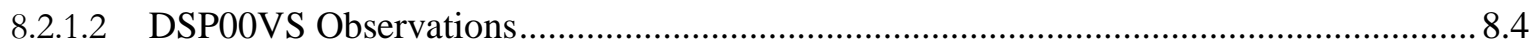

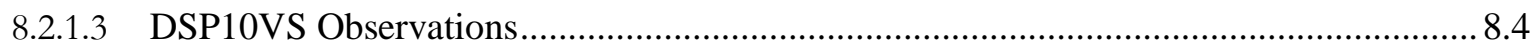

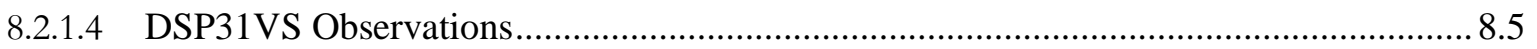

8.2.2 Evaluating Changes in Inlet Air Pressure ..................................................................... 8.5

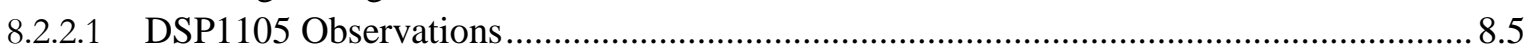

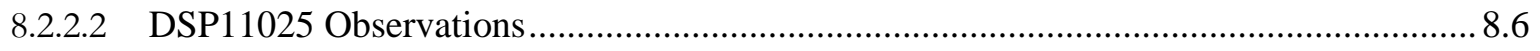

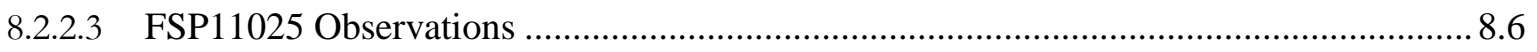

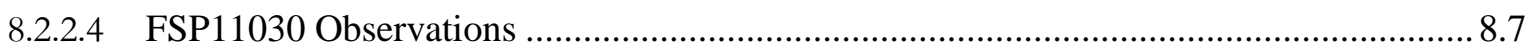

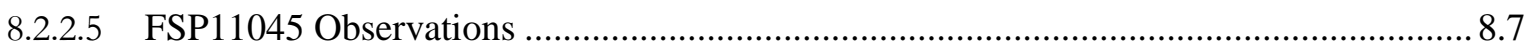

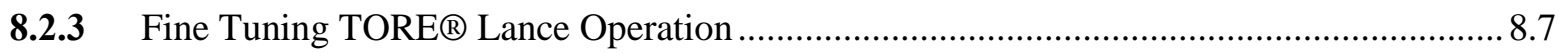

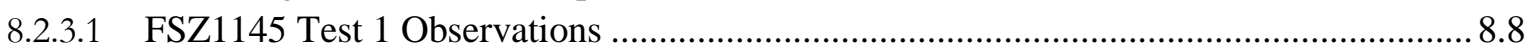

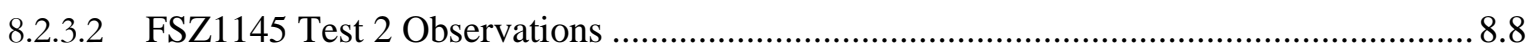

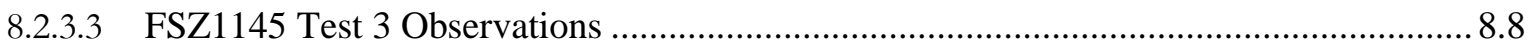

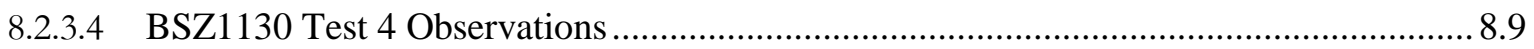

8.2.3.5 BSZ1145 Test 5 Observations ................................................................................ 8.9

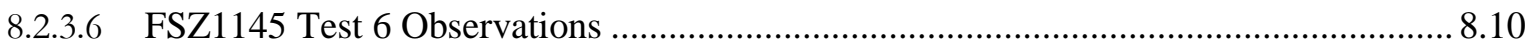

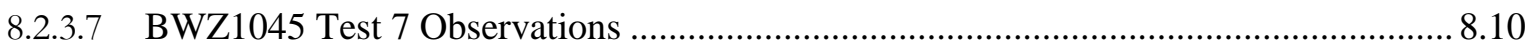

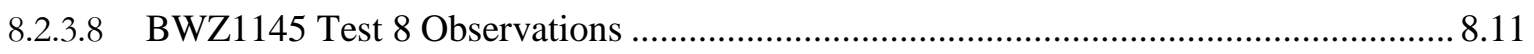

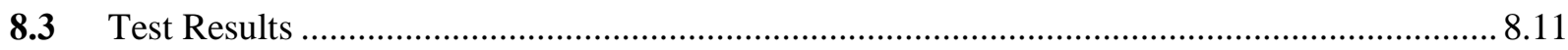

9.0 TORE® Lance Retrieval of Bulk Solids from a Drum .......................................................... 9.1

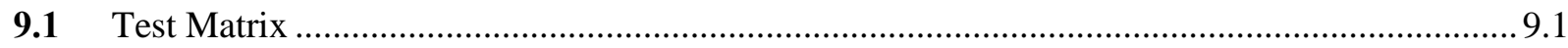

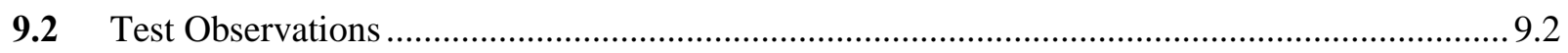

9.2.1 Sand Mobilization and Retrieval from a Drum ................................................................ 9.2

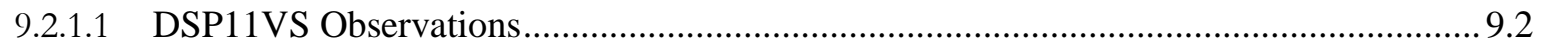

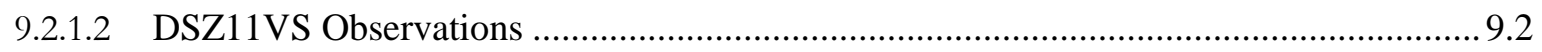

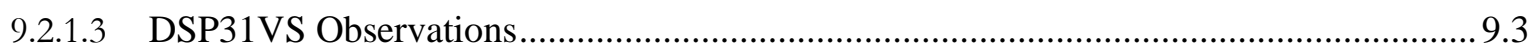

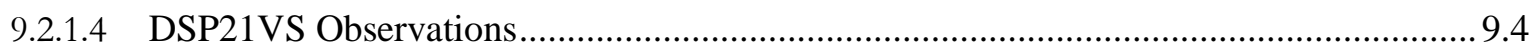

9.2.2 Evaluating Effects of Water Flow Rate on Water-Only Mobilization and Retrieval...........9.4

9.2.2.1 DSZ21VS10 Observations ...................................................................................... 9.4

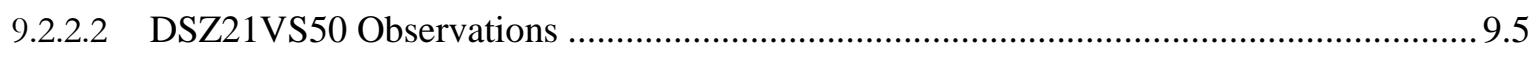

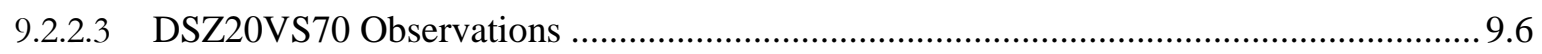

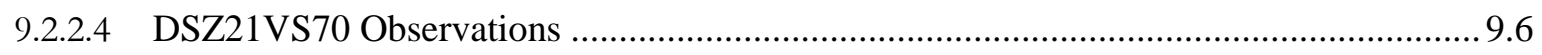

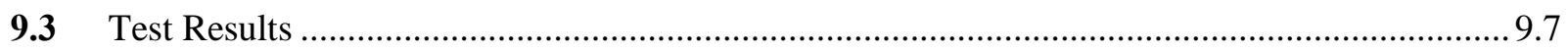




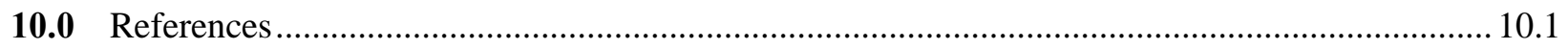

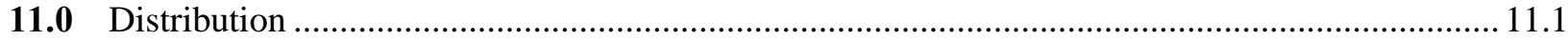





\section{Figures}

Figure 1.1. Waste removal system configuration for deployment in tank 241-C-104 ........................... 1.2

Figure 3.1. TORE ${ }^{\circledR}$ configuration for solids suspension and retrieval ................................................. 3.1

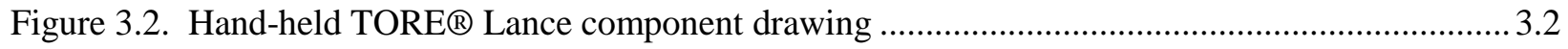

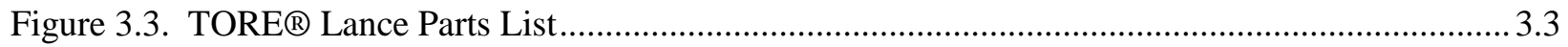

Figure 3.4. View of the TORE® Lance head showing the slits used to develop the precessing vortex ... 3.4

Figure 3.5. TORE® Lance performance curves. ............................................................................. 3.5

Figure 3.6. TORE® Lance flow rate with and without bypassing flow to the head................................ 3.5

Figure 3.7. View inside the flow control manifold showing the connection between the upper and lower

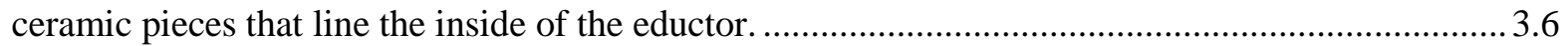

Figure 3.8. Eductor ceramic liner showing black O-ring and white spacer.......................................... 3.6

Figure 3.9. Plot showing how the spacer thickness affects the flow split between the eductor and the

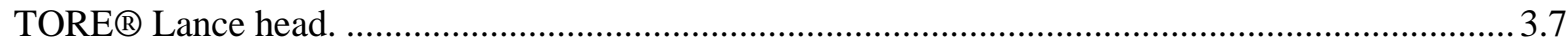

Figure 3.10. Demonstration of operation of a 1-in. diameter TORE® Lance at the vendor's facility. .... 3.8

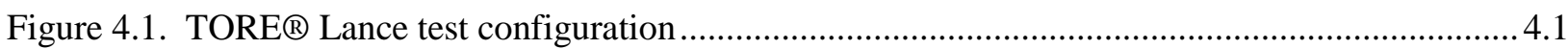

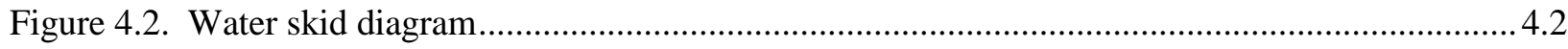

Figure 4.3. Properties of kaolin water simulants and comparison with sludge-type wastes................... 4.7

Table 4.4. Test number column definition for tests described in Sections 5, 6 and 7 ..........................4.8

Table 4.5. Test number column definition for tests described in Section 8.......................................... 4.8

Figure 5.1 Test GP00V6 Sequence May 31, 2002: Gravel simulant, pneumatic conveyance, no air or water, no head feed, TORE® oriented vertically 6 in. above the simulant. ....................................5.3

Figure 5.2. Test GP00V2 Sequence May 31, 2002: Gravel simulant, pneumatic conveyance, no air or water, no head feed, TORE® oriented vertically 2 in. above the simulant. .................................... 5.3

Figure 5.3. Test GP00V0 Sequence May 31, 2002: Gravel simulant, pneumatic conveyance, no air or water, no head feed, TORE® oriented vertically 0 in. above the simulant. ......................................5.3

Figure 5.4. Test GP00VS Sequence May 31, 2002: Gravel simulant, pneumatic conveyance, no air or water, no head feed, TORE® oriented vertically with the head submerged in the simulant..............5.4

Figure 5.5. Test GP0090 Sequence May 31, 2002: Gravel simulant, pneumatic conveyance, no air or water, no head feed, TORE® oriented horizontally $\left(90^{\circ}\right) 0$ in. above the simulant..........................5.4

Figure 5.6. Test GP009S Sequence May 31, 2002: Gravel simulant, pneumatic conveyance, no air or water, no head feed, TORE® oriented horizontally $\left(90^{\circ}\right)$ with the head submerged in the simulant.5.5

Figure 5.7. Test GP10V0 Sequence May 31, 2002: Gravel simulant, pneumatic conveyance, air, no water, no head feed, TORE® oriented vertically 0 in. above the simulant. ...................................5.6

Figure 5.8. Test GP10VS Sequence May 31, 2002: Gravel simulant, pneumatic conveyance, air, no water, no head feed, TORE® oriented vertically with the head submerged in the simulant..............5.6

Figure 5.9. Test GP1092 Sequence May 31, 2002: Gravel simulant, pneumatic conveyance, air, no water, no head feed, TORE® oriented horizontally 2 in. above the simulant.......................................... 5.7

Figure 5.10. Test GP1090 Sequence May 31, 2002: Gravel simulant, pneumatic conveyance, air, no water, no head feed, TORE® oriented horizontally 0 in. above the simulant. .................................5.7

Figure 5.11. Test GP109S Sequence May 31, 2002: Gravel simulant, pneumatic conveyance, air, no water, no head feed, TORE® oriented horizontally with the head submerged in the simulant..........5.7 
Figure 5.12. Test GP11V6 Sequence May 31, 2002: Gravel simulant, pneumatic conveyance, air, no water, head feed, TORE® oriented vertically 6 in. above the simulant.

Figure 5.13. Test GP11V0 Sequence May 31, 2002: Gravel simulant, pneumatic conveyance, air, no water, head feed, TORE® oriented vertically 2 in. above the simulant. .....

Figure 5.14. Test GP11V0 Sequence May 31, 2002: Gravel simulant, pneumatic conveyance, air, no water, head feed, TORE® oriented vertically 0 in. above the simulant.

Figure 5.15. Test GP11VS Sequence May 31, 2002: Gravel simulant, pneumatic conveyance, air, no water, head feed, TORE® oriented vertically with head submerged in the simulant.......................5.9

Figure 5.16. Test GP11VSS Sequence May 31, 2002: Gravel simulant, pneumatic conveyance, air, no water, head feed, TORE® oriented vertically with head submerged deeper into the simulant........5.10

Figure 5.17. Test GP119S Sequence May 31, 2002: Gravel simulant, pneumatic conveyance, air, no water, head feed, TORE® oriented horizontally (at $90^{\circ}$ ) with the head submerged in the simulant.

Figure 5.18. Test GP113S Sequence May 31, 2002: Gravel simulant, pneumatic conveyance, air, no water, head feed, TORE® oriented at $30^{\circ}$ with the head submerged in the simulant.

Figure 5.19. Test GP116S Sequence May 31, 2002: Gravel simulant, pneumatic conveyance, air, no water, head feed, TORE® oriented at $60^{\circ}$ with the head submerged in the simulant.

Figure 6.1. Test SZ10V6 Sequence June 3, 2002: Sand simulant, no pneumatic conveyance, air, no water, no head feed, TORE® oriented vertically 6 in. above the simulant. 6.3

Figure 6.2. Disassembly and removal of solids from the TORE® Lance manifold...............................6.3

Figure 6.3. Test SZ10V2 Sequence June 3, 2002: Sand simulant, no pneumatic conveyance, air, no water, no head feed, TORE® oriented vertically 2 in. above the simulant. 6.4

Figure 6.4. Test SZ10V0 Sequence June 3, 2002: Sand simulant, no pneumatic conveyance, air, no water, no head feed, TORE® oriented vertically 0 in. above the simulant. 6.4

Figure 6.5. Test SZ10VS Sequence June 3, 2002: Sand simulant, no pneumatic conveyance, air, no water, no head feed, TORE® oriented vertically with head submerged in the simulant

Figure 6.6. Test SZ1092 Sequence June 3, 2002: Sand simulant, no pneumatic conveyance, air, no water, no head feed, TORE® oriented horizontally $\left(\right.$ at $\left.90^{\circ}\right) 2$ in. above the simulant.......

Figure 6.7. Test SZ1090 Sequence June 3, 2002: Sand simulant, pneumatic conveyance, air, no water, no head feed, TORE® oriented horizontally (at $\left.90^{\circ}\right) 0$ in. above the simulant.

Figure 6.8. Test SZ109S Sequence June 3, 2002: Sand simulant, no pneumatic conveyance, air, no water, no head feed, TORE® oriented horizontally $\left(\right.$ at $\left.90^{\circ}\right)$ with head submerged in the simulant. 6.6

Figure 6.9. Test SZ11V6 Sequence June 3, 2002: Sand simulant, no pneumatic conveyance, air, no water, head feed, TORE® oriented vertically 6 in. above the simulant. ....

Figure 6.10. Test SZ11V2 Sequence June 3, 2002: Sand simulant, no pneumatic conveyance, air, no water, head feed, TORE® oriented vertically 2 in. above the simulant.

Figure 6.11. Test SZ11V0 Sequence June 3, 2002: Sand simulant, no pneumatic conveyance, air, no water, head feed, TORE® oriented vertically 0 in. above the simulant.

Figure 6.12. Test SZ11VS Sequence June 3, 2002: Sand simulant, no pneumatic conveyance, air, no water, head feed, TORE® oriented vertically submerged deeper into the simulant......

Figure 6.13. Test SZ1196 Sequence June 3, 2002: Sand simulant, no pneumatic conveyance, air, no water, head feed, TORE® oriented horizontally (at $90^{\circ}$ ) with head 6 in. above the simulant.

Figure 6.14. Test SZ1192 Sequence June 3, 2002: Sand simulant, no pneumatic conveyance, air, no water, head feed, TORE® oriented horizontally (at $90^{\circ}$ ) with head 2 in. above the simulant. 
Figure 6.15. Test SZ1190 Sequence June 3, 2002: Sand simulant, no pneumatic conveyance, air, no water, head feed, TORE® oriented horizontally (at $90^{\circ}$ ) with head 0 in. above the simulant. ........ 6.10 Figure 6.16. Test SZ119S Sequence June 3, 2002: Sand simulant, no pneumatic conveyance, air, no water, head feed, TORE® oriented horizontally $\left(\right.$ at $90^{\circ}$ ) with head submerged in the simulant. .... 6.10 Figure 6.17. Test SP11V6 Sequence June 4, 2002: Sand simulant, pneumatic conveyance, air, no water, head feed, TORE® oriented vertically 6 in. above the simulant............................................... 6.11

Figure 6.17. Test SP11V2 Sequence June 4, 2002: Sand simulant, pneumatic conveyance, air, no water, head feed, TORE® oriented vertically 2 in. above the simulant. .............................................. 6.11

Figure 6.18. Test SP11V0 Sequence June 4, 2002: Sand simulant, pneumatic conveyance, air, no water, head feed, TORE® oriented vertically 0 in. above the simulant. ................................................ 6.12

Figure 6.19. Test SP11VS Sequence June 4, 2002: Sand simulant, pneumatic conveyance, air, no water, head feed, TORE® oriented vertically submerged in the simulant............................................... 6.12

Figure 6.20. Test SP11VSS Sequence June 4, 2002: Sand simulant, pneumatic conveyance, air, no water, head feed, TORE® oriented vertically submerged deeper into the simulant. ............................... 6.13

Figure 6.21. Test SP1196 Sequence June 4, 2002: Sand simulant, pneumatic conveyance, air, no water, head feed, TORE® oriented horizontally, suspended 6 in. above the simulant. 6.13

Figure 6.22. Test SP1192 Sequence June 4, 2002: Sand simulant, pneumatic conveyance, air, no water, head feed, TORE® oriented horizontally (at $90^{\circ}$ ) with head 2 in. above the simulant 6.14

Figure 6.23. Test SP1190 Sequence June 4, 2002: Sand simulant, pneumatic conveyance, air, no water, head feed, TORE® oriented horizontally $\left(\right.$ at $90^{\circ}$ ) with head 0 in. above the simulant. 6.15

Figure 6.24. Test SP119S Sequence June 4, 2002: Sand simulant, pneumatic conveyance, air, no water, head feed, TORE® oriented horizontally $\left(\right.$ at $90^{\circ}$ ) with head submerged in the simulant. .............. 6.16

Figure 6.25. Test SP113S Sequence June 4, 2002: Sand simulant, pneumatic conveyance, air, no water, head feed, TORE ${ }^{\circledR}$ oriented at $30^{\circ}$ with head submerged in the simulant.

Figure 6.26. Test SP116S Sequence June 4, 2002: Sand simulant, pneumatic conveyance, air, no water, head feed, TORE® oriented at $60^{\circ}$ with head submerged in the simulant. 6.17

Figure 7.1. Test KP11V0 Sequence June 5, 2002: Kaolin clay simulant, pneumatic conveyance, air, no water, head feed, TORE $®$ oriented vertically with head 0 in. above the simulant............................ 7.3

Figure 7.2. Test KP11VS Sequence June 5, 2002: Kaolin clay simulant, pneumatic conveyance, air, no water, head feed, TORE® oriented vertically with head submerged in the simulant...... 7.4

Figure 7.3. Test KP21VS Sequence June 5, 2002: Kaolin clay simulant, pneumatic conveyance, air, water, head feed, TORE® oriented vertically with head submerged in the simulant.

Figure 7.4. Test KP21V0 (updated from KP11V0) ( $2^{\text {nd }}$ time with new clay) Sequence June 18, 2002 : Kaolin clay simulant, pneumatic conveyance, no air, water, head feed, TORE® oriented vertically with head $0 \mathrm{in}$. above the simulant.

Figure 7.5. Test KP21VS (updated from KP1VS) ( $2^{\text {nd }}$ time with new clay) Sequence June 18, 2002 : Kaolin clay simulant, pneumatic conveyance, no air, water, head feed, TORE® oriented vertically with head submerged in the simulant.

Figure 7.6. Test KP21VSS (updated from KP11VSS) Sequence June 18, 2002: Kaolin clay simulant, pneumatic conveyance, no air, water, head feed, TORE® oriented vertically with head submerged deeper in the simulant

Figure 7.7. Test KP219S (updated from KP119S) Sequence June 18, 2002: Kaolin clay simulant, pneumatic conveyance, no air, water, head feed, TORE® oriented horizontally (at $90^{\circ}$ ) with head submerged in the simulant. 
Figure 7.8. Test KP216S (updated from KP116S) Sequence June 18, 2002: Kaolin clay simulant, pneumatic conveyance, no air, water, head feed, TORE® oriented at $60^{\circ}$ with head submerged in the simulant.

Figure 7.9. Test KP213S Sequence June 18, 2002: Kaolin clay simulant, pneumatic conveyance, no air, water, head feed, TORE® oriented at $30^{\circ}$ with head submerged into the simulant......................... 7.8

Figure 7.10. Flow of water through the TORE® Lance head............................................................. 7.9

Figure 7.11. Test KP31V2 (updated from KP12V2)Sequence June 18, 2002: Kaolin clay simulant, pneumatic conveyance, air, water, head feed, TORE® oriented at vertically with head $2 \mathrm{in}$. above the simulant.

Figure 7.12. Test KP31V0 (updated from KP12V0) Sequence June 18, 2002: Kaolin clay simulant, pneumatic conveyance, air, water, head feed, TORE® oriented at vertically with head 0 in. above the simulant

Figure 7.13. Test KP31VS (updated from KP12VS) Sequence June 18, 2002: Kaolin clay simulant, pneumatic conveyance, air, water, head feed, TORE® oriented at vertically with head submerged in the simulant

Figure 7.14. Test KP313S (updated from KP123S) Sequence June 18, 2002: Kaolin clay simulant, pneumatic conveyance, air, water, head feed, TORE® oriented at $30^{\circ}$ with head submerged in the simulant.

Figure 7.15. Test KP316S (updated from KP126S) Sequence June 18, 2002: Kaolin clay simulant, pneumatic conveyance, air, water, head feed, TORE® oriented at $60^{\circ}$ with head submerged in the simulant.

Figure 7.16. Test KP319S Sequence June 18, 2002: Kaolin clay simulant, pneumatic conveyance, air, water, head feed, TORE® oriented at horizontally (at $90^{\circ}$ ) with head submerged in the simulant. 7.12

Figure 8.1. Test DSP11VS (a+b) Sequence July 22, 2002: Wet sand/water simulant, pneumatic conveyance, air, no water, head feed, TORE® oriented vertically with head submerged into the simulant.

Figure 8.2. Test DSP11VS (c) Sequence July 22, 2002: Wet sand/water simulant, pneumatic conveyance, air, no water, head feed, TORE® oriented vertically with head submerged into the simulant. ......... 8.4

Figure 8.3. Test DSP00VS Sequence July 22, 2002: Wet sand/water simulant, pneumatic conveyance, no air, no water, no head feed, TORE® oriented vertically with head submerged into the simulant. ....8.4

Figure 8.4. Test DSP10VS Sequence July 22, 2002: Wet sand/water simulant, pneumatic conveyance, air, no water, no head feed, TORE® oriented vertically with head submerged into the simulant. ....8.5

Figure 8.5. Test DSP11005 Sequence July 24, 2002: Wet sand simulant, pneumatic conveyance, air, no water, head feed, TORE® oriented vertically with head submerged into the simulant

Figure 8.6. Test DSP11025 Sequence July 24, 2002: Wet sand/water simulant, pneumatic conveyance, air, no water, head feed, TORE® oriented vertically with head submerged in the simulant. ............ 8.6

Figure 8.7. Test FSP11025 (updated from DSP11025-Floor Sequence) July 24, 2002: Wet sand/water simulant, pneumatic conveyance, air, no water, head feed, TORE® oriented vertically with head 0 in. above the simulant. (25 psig.)

Figure 8.8. Test FSP11030 (updated from DSP11030-Floor Sequence) July 24, 2002: Wet sand/water simulant, pneumatic conveyance, air, no water, head feed, TORE® oriented vertically with head 0 in. above the simulant. (30 psig.) 
Figure 8.9. Test FSP11045 (updated from DSP11045-Floor Sequence) July 24, 2002: Wet sand/water simulant, pneumatic conveyance, air, no water, head feed, TORE® oriented vertically with head 0 in. above the simulant. (45 psig)

Figure 8.10. FSZ1145 Test 1 Sequence July 31, 2002: Wet sand/water simulant on floor, no pneumatic conveyance, air, no water, head feed, TORE® operated manually.

Figure 8.11. FSZ1145 Test 2 Sequence July 31, 2002: Wet sand/water simulant on floor, no pneumatic conveyance, air, no water, head feed, TORE® operated manually................................................ 8.8

Figure 8.12. FSZ1145 Test 3 Sequence July 31, 2002: Wet sand/water simulant on floor, no pneumatic conveyance, air, no water, head feed, TORE® operated manually.

Figure 8.13. BSZ1130 Test 4 Sequence July 31, 2002: Wet sand/water simulant in bucket, no pneumatic conveyance, air (at 30psig), no water, head feed, TORE® operated manually

Figure 8.14. BSZ1145 Test 5 Sequence July 31, 2002: Wet sand/water simulant in bucket, no pneumatic conveyance, air (at $45 \mathrm{psig}$ ), no water, head feed, TORE® operated manually............................. 8.10

Figure 8.15. FSZ1145 Test 6 Sequence July 31, 2002: Wet sand/water simulant in pile on floor, no pneumatic conveyance, air, no water, head feed, TORE® operated manually.

Figure 8.16. BWZ1045 Test 7 Sequence July 31, 2002: Water without solids in bucket, no pneumatic conveyance, air, no water, no head feed, TORE® operated manually.

Figure 8.17. BWZ1145 Test 8 Sequence July 31, 2002: Water without solids in bucket, no pneumatic conveyance, air, no water, head feed, TORE® operated manually

Figure 9.1. Test DSP11VS (updated from DSP01VS) Sequence August 7, 2002: Wet sand/water simulant, pneumatic conveyance, air, no water, head feed, TORE® oriented vertically with head submerged into the simulant.

Figure 9.2. Test DSZ01VS Sequence August 7, 2002: Wet sand/water simulant, no pneumatic conveyance, air, no water, head feed, TORE® oriented vertically with head submerged into the simulant.

Figure 9.3. Test DSP31VS (updated from DSP21VS) Sequence August 7, 2002: Wet sand/water simulant, pneumatic conveyance, air, water, head feed, TORE® oriented vertically with head submerged into the simulant.

Figure 9.4. Test DSP21VS (updated from DSP11VS) Sequence August 7, 2002: Wet sand/water simulant, pneumatic conveyance, no air, water, head feed, TORE® oriented vertically with head submerged into the simulant.

Figure 9.5. Test DSZ21VS10 (updated from DSZ11VS10) Sequence August 7, 2002: Wet sand/water simulant, no pneumatic conveyance, no air, water, head feed, TORE® oriented vertically with head submerged into the simulant. (10 gpm water flow rate.).

Figure 9.6. Test DSZ21VS50 (updated from DSZ11VS50) Sequence August 7, 2002: Wet sand/water simulant, no pneumatic conveyance, no air, water, head feed, TORE® oriented vertically with head submerged into the simulant. (50 gpm water flow rate).

Figure 9.7. Test DSZ20VS70 (update of DSZ10VS70) Sequence August 7, 2002: Wet sand/water simulant, no pneumatic conveyance, no air, water, no head feed, TORE® oriented vertically with head submerged into the simulant. (70 gpm).

Figure 9.8. Test DSZ21VS70 (update of DSZ11VS70) Sequence August 7, 2002: Wet sand/water simulant, no pneumatic conveyance, no air, water, head feed, TORE® oriented vertically with head submerged into the simulant. (70 gpm). 


\section{Tables}

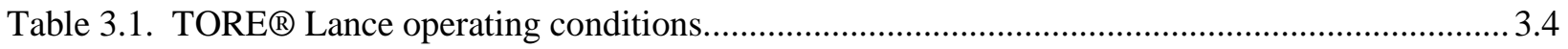

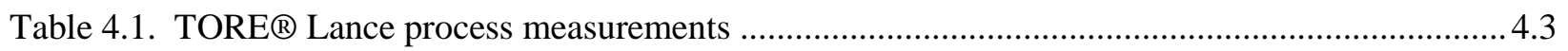

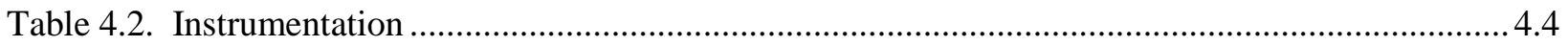

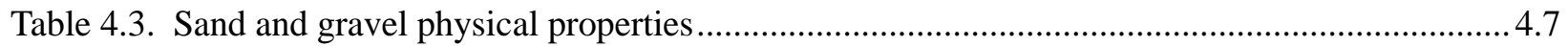

Table 4.4. Physical properties of kaolin-water sludge simulants..................................................... 4.7

Table 5.1 Test matrix for evaluation of TORE® Lance mobilizing and retrieval of gravel....................5.1

Table 5.2. Results of TORE® Lance retrieval of gravel using compressed air enhanced mobilizing and

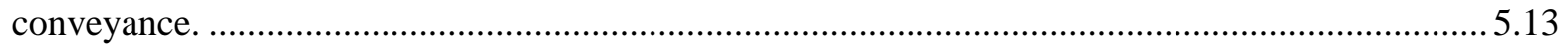

Table 6.1 Test matrix for evaluation of TORE® Lance mobilizing and retrieval of sand. ...................... 6.1

Table 6.2. Results of TORE® Lance retrieval of sand using compressed air enhanced mobilizing and

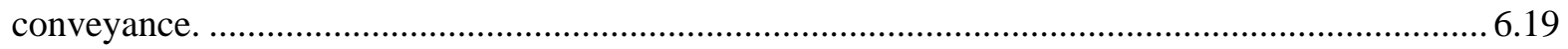

Table 7.1. Test matrix for evaluation of TORE® Lance mobilizing and retrieval of sludge. .................7.1

Table 7.2. Results of TORE® Lance retrieval of sludge using air, water, and air-water for mobilizing coupled with pneumatic conveyance .......................................................................................... 7.13

Table 8.1. Test matrix for TORE® Lance larger-scale evaluations...................................................... 8.1

Table 8.2. Results of TORE® Lance mobilizing and retrieval of sand in confined and unconfined

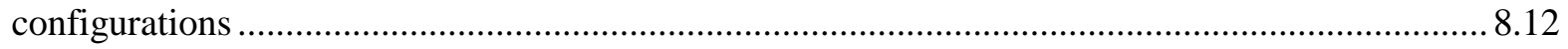

Table 9.1. Test matrix for TORE® Lance larger-scale evaluations.................................................... 9.1

Table 9.2. Results of TORE® Lance mobilizing and retrieval of bulk solids from a drum .................... 9.8 


\subsection{Introduction}

\subsection{TORE@ Lance Technology}

The $\mathrm{TORE}^{\circledR}$ Lance is a patented hydro transportation device with the ability to convey solids at predetermined slurry concentrations over great distances. ${ }^{a}$ The system is designed to transport slurries containing concentration from $1 \%$ to $70 \%$ or more solids by weight. Because the device has no moving parts it contains no parts to wear out and simply requires pressurized fluid to operate the eductor and produce mobilization. In FY 2001, this technology was evaluated as a potential method for enhancing retrieval from potentially leaking tanks (Bamberger et al 2001).

\subsection{Deployment at Hanford}

The TORE® Lance technology is being incorporated as a part of the mobile retrieval system (MRS) for deployment at Hanford Tank 241-C-104 to facilitate retrieval of radioactive waste stored in the tank and expedite the eventual closure of the tank (Holm 2001). The system configuration being developed for Hanford deployment is shown in Figure 1.1. It incorporates two applications of TORE® precessing vortex technology:

- A unit (A) attached to the movable mast to retrieve solids from the tank

- A unit (B) submerged in the collection tank at the top of the tank to mobilize retrieved solids prior to transport.

The unit attached to the base of the mobile mast must transport solids out of the tank, an elevation change of $\sim 40$ to $60 \mathrm{ft}$. The TORE® head at the end of the mast may be oriented anywhere from horizontal, to inclined to vertical. The head may be submerged in the waste, partially submerged, on or slightly above the waste.

The batch transfer TORE® is expected to operate with the TORE® fully submerged in fluid. Its purpose is to mobilize the settled solids that have been transferred to the batch tank prior to retrieval and transport.

The functional description of the mobile retrieval system (MRS) is to retrieve waste from tank 241-C104 (Holm 2001). The performance characteristics goal is to remove $99 \%$ of the tank contents by volume. The waste volume includes all liquids remaining in the tank at the completion of the retrieval operations. Metal tapes, rocks, debris, abandoned equipment, waste transfer line flush water, and final decontamination water are excluded from the waste volume. Additionally, the MRS shall be capable of completing retrieval of tank 241-C-104 waste within 145 days.

\footnotetext{
${ }^{a}$ Dave Smet, CH2MHill Hanford Group, identified Merpro, Ltd. and their TORE® technology as a potential method for enhancing waste retrieval. He led a workshop July 16-17, 2001 to introduce others at Hanford to the Merpro Ltd. team and the potential applications of this technology.
} 


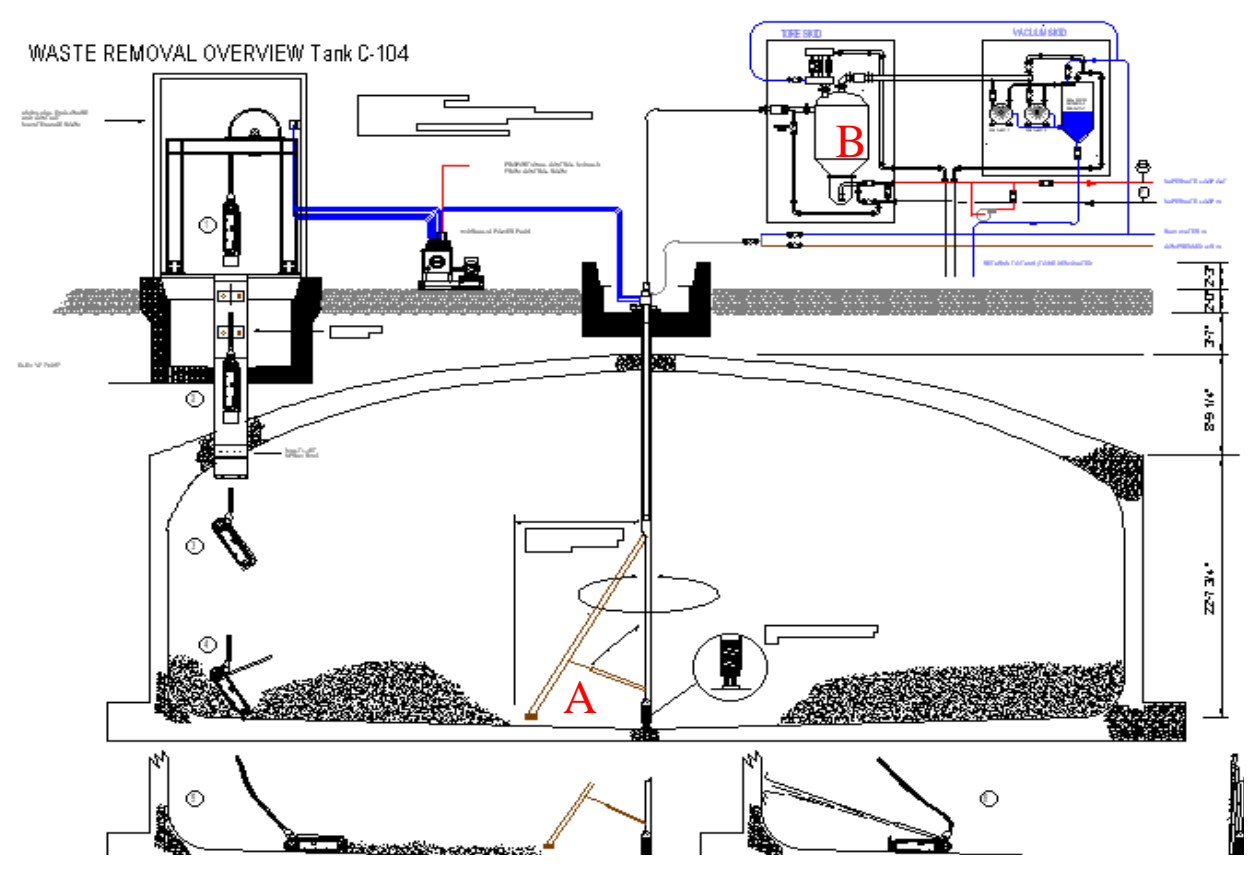

Figure 1.1. Waste removal system configuration for deployment in tank 241-C-104

\subsection{Objective of the TORE® Lance Evaluation}

The objective of the TORE® Lance evaluation is to qualitatively evaluate the ability of TORE® Lance technology for use for in mobilizing and retrieving waste from underground storage tanks at Hanford. The purpose of these tests is to investigate changes in the following parameters, which represent potential configurations for deployment at Hanford.

- $\quad$ Mobilization fluid: air, water, a mixture of air and water

- $\quad$ Retrieval method: pneumatic conveyance, eduction, or combined pneumatic conveyance and eduction

- $\quad$ Stand-off distance: 6 in. above the surface to $\sim 6$ in. submergence depth

- $\quad$ Angle of inclination: vertical and 30, 60 and 90 degree inclination from the vertical.

- $\quad$ Simulant: gravel, sand, or sludge

- $\quad$ Retrieval height: no elevation change or $\sim 25 \mathrm{ft}$ elevation change. (This elevation represents the capability and configuration of the existing conveyance system).

- $\quad$ Type of simulant container: retrieval from a shallow tub, a deep drum or from an unconfined pile.

Evaluation of these parameters provides a broad overview of the applicability of this technology for a range of retrieval deployment opportunities at Hanford. The TORE® Lance technology could be applied for retrieval of many of the Hanford tanks.

To support retrieval of tank 241-C-104, the Hanford Site staff have worked with Merpro and Non Entry Systems Limited to develop special configurations of the TORE® precessing vortex technology for evaluation and use at this tank. The TORE® Lance evaluation described in this report differs from that 
project. This investigation focuses on evaluating the ability of a commercially available hand-held TORE® Lance for approximating these applications at Hanford. Some of the results from this investigation may support the equipment deployment at tank 241-C-104, others may not be relevant to that tank based on differences in configuration, deployment method, dislodging and retrieval fluid, retrieval method, or simulant. 



\subsection{Conclusions and Recommendations}

Conclusions and recommendations based on tests conducted to evaluate the operation of the handheld TORE® Lance for retrieval of gravel, sand, and sludge simulants are presented.

\subsection{Conclusions}

Three process fluid combination for TORE® Lance operation were evaluated for mobilization and retrieval of granular sand and gravel and kaolin clay sludge:

- Compressed air mobilization and eduction

- Water mobilization and eduction

- Air and water mixture for mobilization and eduction.

Tests were conducted to evaluate several types of retrieval:

- Stationary retrieval of simulant from a tub

- Bulk mobilization and retrieval of simulant from a drum

- Unconfined mobilization and dislodging of simulant from the floor.

Each of these evaluations uncovered useful configurations applicable for mobilization and retrieval of granular and sludge simulants. Details are described below.

\subsubsection{Compressed Air Test Results}

Stationary mobilization and retrieval tests conducted using gravel and sand simulants showed that

- The zone of influence of the mobilizing fluid from the TORE® Lance head was $~ 18$ in. in diameter for tests conducted with the TORE® Lance head in contact with or submerged in the simulant. This was observed with the head oriented vertically or at angles of 30,60 or $\sim 90 \mathrm{deg}$ from the vertical. This measured zone of influence for the precessing vortex confirms predictions by Parkinson and Delves (1999) that the diameter of the zone of influence should be 6 times the diameter of the discharge line. The TORE® Lane tested had a 2-in. diameter discharge line attached to a 3-in. diameter fitting.

- When compared to a baseline of pneumatic conveyance, addition of compressed air eduction coupled with pneumatic conveyance significantly enhances retrieval rate.

- When compared to a baseline of air eduction coupled with pneumatic conveyance, addition of the precessing vortex significantly enhances solids mobilization and provides a more uniform loading of particulate in the retrieved stream.

Tests of retrieval of sand from a drum showed that:

- Optimal solids retrieval rates were obtained when the inlet air pressure from the compressor was set at $45 \mathrm{psig}$. At this condition, the average retrieval rate observed was $\sim 20 \mathrm{lbm} / \mathrm{min}$; the peak retrieval rate obtained was $\sim 45 \mathrm{lbm} / \mathrm{min}$ in these short duration tests.

Retrieval of kaolin clay sludge using compressed air was not observed. 
- During these tests the compressed air emanating from the TORE® Lance head took the path of least resistance, channeling between the sludge and the TORE® Lance tube or the sludge and the sides of the container. After this occurred no additional dislodging of sludge was observed.

\subsubsection{Water Test Results}

Tests with water used for eduction and mobilization were conducted both with the pneumatic conveyance line attached and with no pneumatic conveyance with the flow routed through a short hose attached to the TORE® Lance discharge and discharged directly to tank containment.

- The high water flow rate through the eductor tended to overwhelm the retrieval capability of the pneumatic conveyance line (a limitation of the existing conveyance system).

- Retrieval tests with the pneumatic conveyance line removed showed excellent qualitative mobilization and retrieval at inlet water flow rates of 50 and $70 \mathrm{gpm}$. The retrieved flow was steady and significant amounts of solids were transported as indicated by the extremely dark color of the retrieved fluid. Tests with an inlet flow rate of $10 \mathrm{gpm}$ showed that this flow rate was too low to induce retrieval.

- A companion test at $70 \mathrm{gpm}$ inlet flow rate with no precessing vortex showed the importance of the flow to the TORE® Lance head for mobilizing solids. Without this mobilization, the retrieval flow pulsated between white and dark color as slugs of solids were intermittently introduced into the retrieval line by eduction only.

Mobilization and retrieval of kaolin clay sludge was not effective.

- The water took the path of least resistance, channeling between the sludge and the assembly.

- For tests with the TORE® Lance head in contact with the sludge layer, some slow dislodging of the sludge beneath the water jets was observed.

\subsubsection{Air and Water Test Results}

The air-water combination was the most effective combination for dislodging sludge simulant.

- Tests were conducted with the compressed air set at 100 psig at the inlet from the compressor and a $\sim 5$ gpm flow rate of water. With the TORE® Lance head submerged in the simulant, the air water combination cut small-diameter channels through the sludge to form a radial cut path in the interior of the sludge block. Additional dislodging of sludge occurred along these paths. No evidence of development of a precessing vortex was observed

\subsection{Parameter Evaluation}

A brief synopsis for each of the parameters follows.

\subsubsection{Mobilization Fluid}

Three process fluids: air, water, and an air-water combination were considered for mobilization. Air or water worked well for mobilizing sand or gravel. The air-water combination worked best for sludge mobilization. 


\subsubsection{Retrieval Method}

The retrieval methods evaluated included pneumatic conveyance, eduction or a combination of pneumatic conveyance and eduction. Pneumatic conveyance performance was significantly enhanced by the addition of compressed air eduction. Pneumatic conveyance performance was significantly degraded by the addition of water eduction. Water eduction worked well when the pneumatic conveyance line was removed and flow was directly discharged through a short hose attached to the discharge of the TORE® Lance.

\subsubsection{Stand-off Distance}

The TORE® Lance performance was best when the TORE® Lance head was either submerged or in contact with the simulant. Operation with a 2 in. or greater spacing between the head and the simulant surface was not effective.

\subsubsection{Angle of Inclination}

The TORE® Lance orientation was evaluated with it oriented vertically or at angles of 30, 60, or $\sim 90$ deg from the vertical. The most uniform zone of influence was obtained with the unit oriented vertically. At other orientations, the zone of influence changed from a circle to a slit (see Figures 6.23 or 6.24) with the range unchanged by orientation.

\subsubsection{Simulant}

Three simulants: gravel, sand, and sludge were evaluated for combined mobilization and retrieval using the TORE® Lance. Air mobilization and retrieval was most effective for use with sand or gravel, a combination of air and water for mobilization was most effective for use with sludge. Water-induced mobilization and retrieval was not as effective because excess water volume overloaded the pneumatic conveyance system and hindered retrieval.

\subsubsection{Retrieval Height}

The retrieval height significantly affects the method of retrieval. This parameter must be analyzed for each application to ensure that adequate transport can be provided.

\subsubsection{Type of Simulant Containment}

The TORE® Lance was able to retrieve both confined and unconfined sand and gravel simulants. The depth of the head submergence in the material must be considered for each type of simulant containment.

\subsection{Recommendations}

These tests have shown that the TORE® Lance is a tool that can be used at Hanford for mobilization and retrieval of wastes. The system is versatile and can be configured for many types of applications. 
These studies showed that the diverse applications require unique solutions so care is recommended in TORE® Lance or TORE® equipment selection for each unique application.

The two components of the TORE® Lance are the precessing vortex inducing head for mobilizing and the eductor for retrieval. The precessing vortex is sensitive to fluid flow rate and pressure. In the hand-held TORE® Lance unit these parameters are controlled both internally, by changing shim spacing, and externally by controlling the flow split between the eductor and the head. For in-tank applications out-of-tank control of both these parameters is recommended. 


\subsection{TORE® Technology Operation}

\subsection{TORE® Precessing Vortex Technology}

The TORE ${ }^{\circledR}$ is a hydraulic conveyor of solids that contains no moving parts marketed by MerPro Limited. It consists of a concentric feed section having a central discharge assembly, where a motive fluid such as water is used to displace the process material, depicted in Figure 3.1. The TORE ${ }^{\circledR}$ can be installed in any orientation to ensure it is buried in solids. A phenomenon known as a precessing vortex core (PVC) occurs beneath the head of the TORE ${ }^{\circledR}$ central assembly and is responsible for fluidization of solids, leading to their subsequent transport (Chard et al 1996). A PVC is an unstable, time dependent, three-dimensional vortex core, which precesses about the geometrical center. Its occurrence results from shear between the driving vortex (swirling flow exiting the TORE ${ }^{\circledR}$ into the vessel) and the forced vortex (swirling flow entering the $\mathrm{TORE}^{\circledR}$ via the inner tube). The pressure drop across the TORE ${ }^{\circledR}$ is minimal.
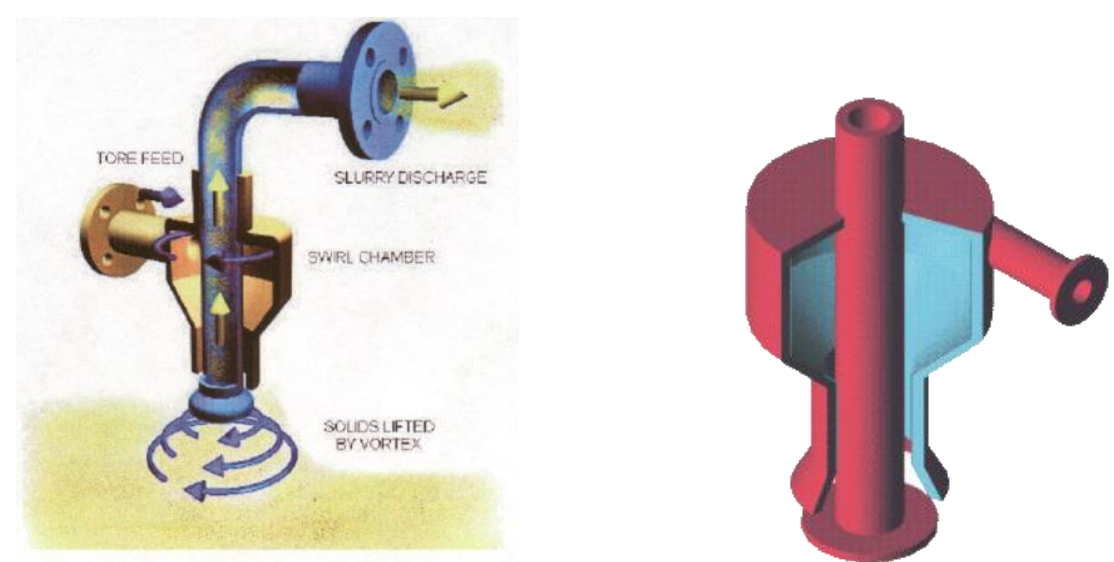

Figure 3.1. TORE $^{\circledR}$ configuration for solids suspension and retrieval

The TORE ${ }^{\circledR}$ must be installed as part of a system and motive pressure for transporting the solids must be provided by another source. Currently, the TORE ${ }^{\circledR}$, by nature of its operation, is best suited to applications in which it is placed in a pressure vessel (Faram et al 1996). For TORE ${ }^{\circledR} \mathrm{s}$ installed internally/externally in a pressure vessel the motive pressure is due to the operating pressure of the vessel. For TORE ${ }^{\circledR}$ s installed in atmospheric vessels compressed air or a jet pump must be connected to the $\mathrm{TORE}^{\circledR}$ inlet line to provide the motive pressure. The flow in the discharge line is provided by a jet pump or other pump. In each case the discharge flow rate from the TORE ${ }^{\circledR}$ should be controlled to ensure that the slurry velocity does not exceed the erosional limits of the materials used to construct the piping.

It is favorable to install a TORE ${ }^{\circledR}$ in a vessel which concentrates the solids within the TORE ${ }^{\circledR}$ zone of influence but this may not always be practical, especially for retrofits (Parkinson and Delves 1999). For cases where the $\mathrm{TORE}^{\circledR}$ is installed in large diameter vessels the degree of solids removal can be calculated using a series of cones, with a suitable angle of repose, extending from the edge of the TORE ${ }^{\circledR} \mathrm{S}$ maximum zone of influence. For general design the zone of influence is considered as six times the TORE $^{\circledR}$ discharge pipe diameter. 


\subsection{TORE® Lance}

The TORE® Lance shown in Figures 3.2-4 is a hand-held unit that incorporates the TORE® precessing vortex technology designed to be operated by a single operator. The unit is available with 1in. and 2-in. diameter bores. The unit supplied for these tests and performance evaluation is the 2-in. diameter model, Serial No. TL-2-009. Based on the "rule of thumb' stated by Parkinson and Delves (1999) and the TORE® Lance discharge line diameter of 3 in., the expected zone of influence is $\sim 18$ in. in diameter. A close up view of the head is shown in Figure 3.4.

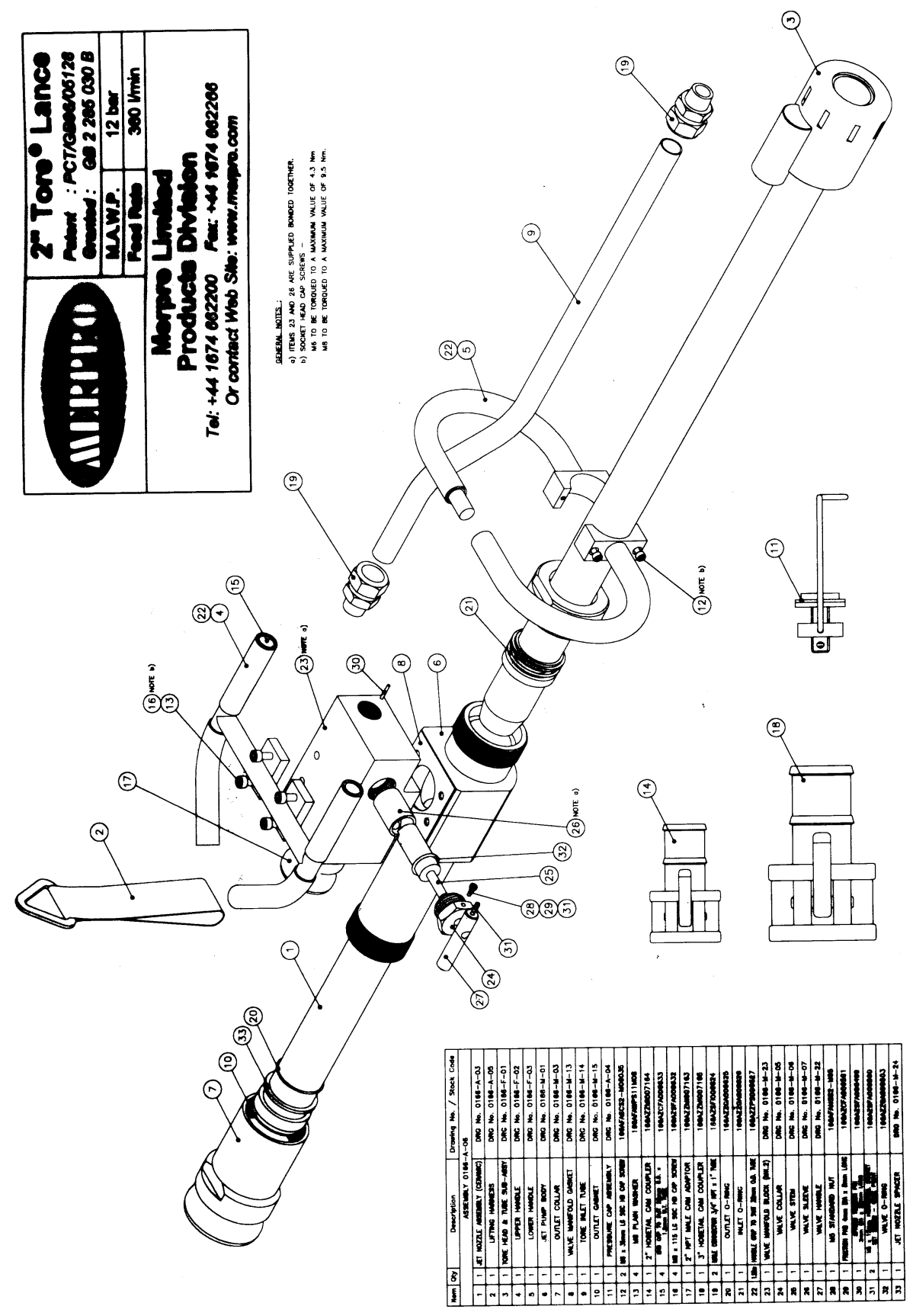

Figure 3.2. Hand-held TORE® Lance component drawing 


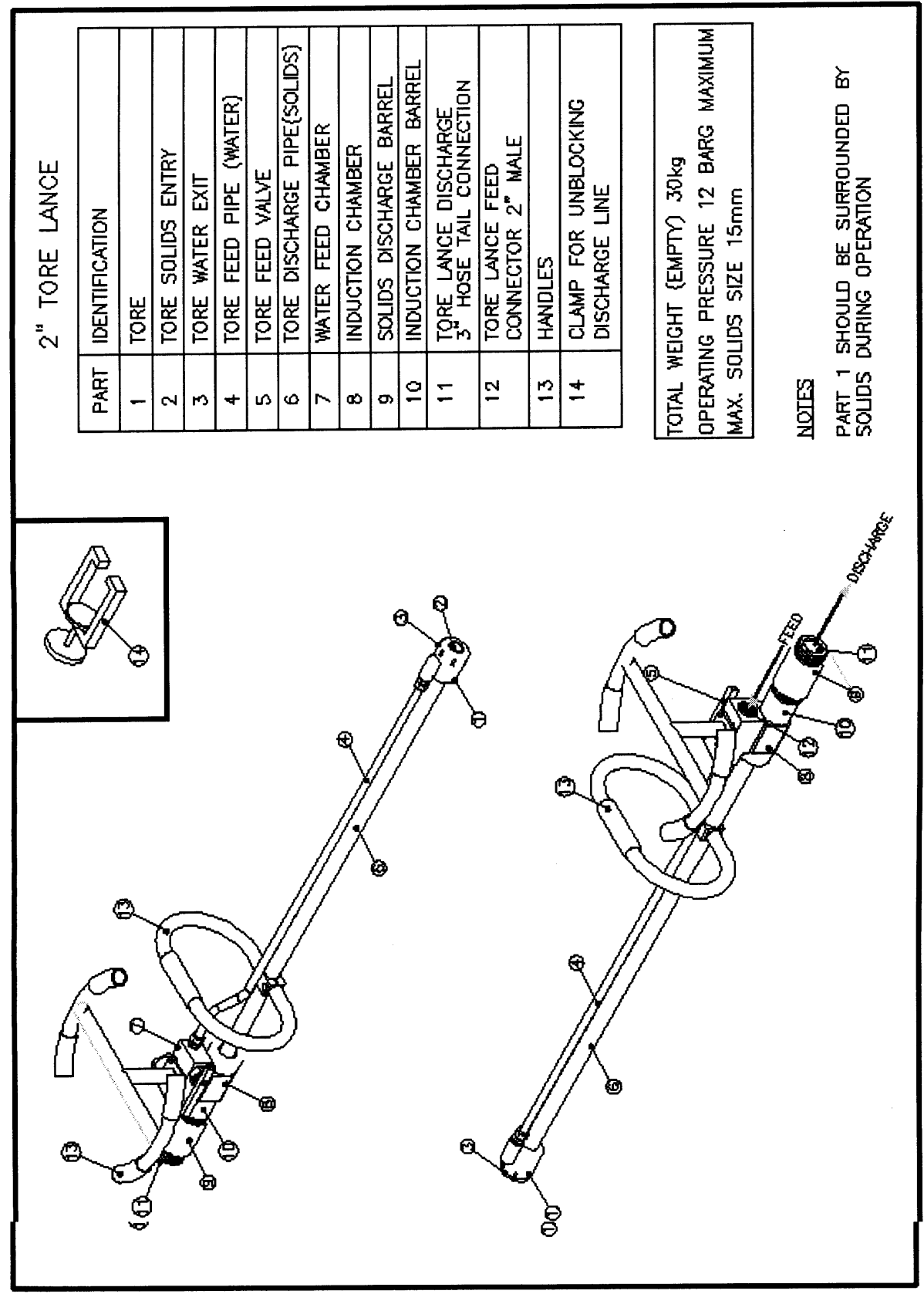

Figure 3.3. TORE@ Lance Parts List

When operational, the TORE® Lance inlet must be supplied with the fluid used for mobilization and eduction, and the outlet must be attached to the retrieval line. This type of unit is usually operated in the submerged mode such as would be encountered when using the TORE® Lance to mobilize settled solids in a tank or a drum for transport to a nearby vessel. In this case pressurized water could be supplied to the TORE® inlet with some of the flow exiting the TORE® head to mobilize the solids and the remainder of 
the water flowing through the balance valve into the eductor to retrieve the solids from the tank and deposit them nearby.

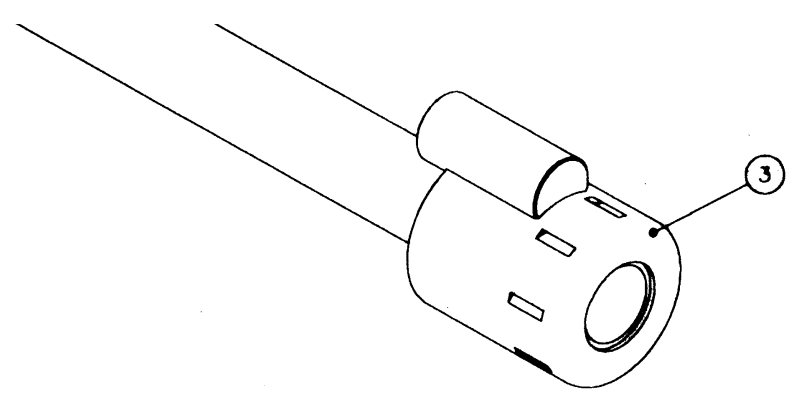

Figure 3.4. View of the TORE® Lance head showing the slits used to develop the precessing vortex

\subsection{TORE® Lance Operation}

The TORE® Lance operating limits are listed in Table 3.1. For initial operation using water as the mobilizing and eductor fluid, Merpro recommends that operations start at a pressure of 4 to 5 bar (58 to 73 psig). Performance curves for the TORE® Lance rated operation are shown in Figure 3.5. ${ }^{\mathrm{a}}$

Table 3.1. TORE® Lance operating conditions.

\begin{tabular}{|l|l|}
\hline Parameter & Operating Condition \\
\hline Operating Pressure & 12 barg maximum $(174 \mathrm{psig}, 11.6 \mathrm{~atm})$ \\
\hline Operating temperature & $5-40 \mathrm{C}$ \\
\hline Maximum solids size & $15 \mathrm{~mm}(0.059 \mathrm{in})$. \\
\hline Recommended initial water supply pressure & $4-5 \mathrm{barg}(58-73 \mathrm{psig})$ \\
\hline Maximum retrieval rate & 12 metric Tonnes $/ \mathrm{hr}(440 \mathrm{lbm} / \mathrm{min})$ \\
\hline
\end{tabular}

a Merpro Limited - Process \& Products Division, TORE® Lance Development, 2 inch TORE® Lance Operating Manual, Rev. 1., Document No: D012/OM/001. 

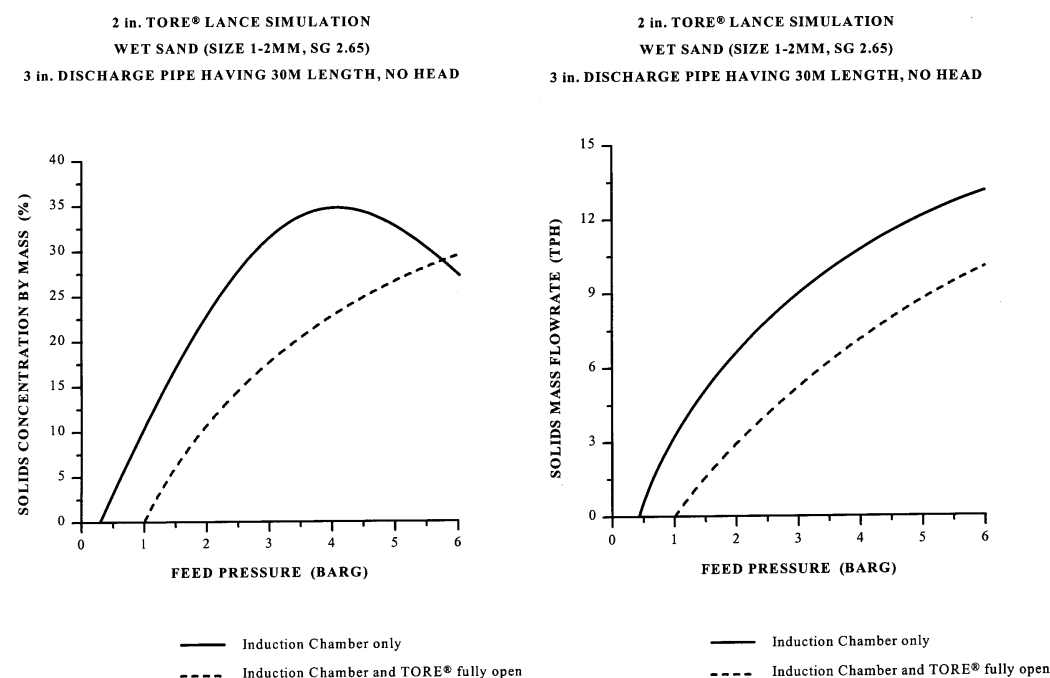

WET SAND (SIZE 1-2MM, SG 2.65)

3 in. DISCHARGE PIPE HAVING 30M LENGTH, NO HEAD

.... Induction Chamber and TORE ${ }^{\infty}$ fully open

-..- Induction Chamber and TORE ${ }^{\circledR}$ fully open

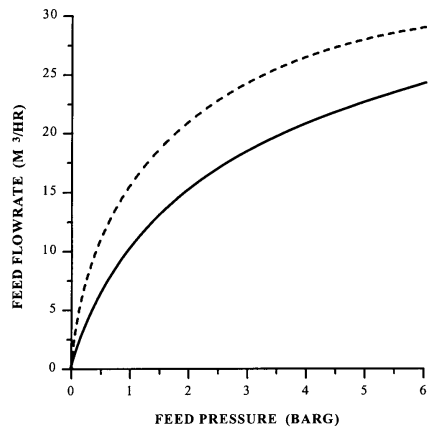

- Induction Chamber only -..-- Induction Chamber and TORE® fully oper

Figure 3.5. TORE® Lance performance curves.

\subsubsection{Externally Adjustable Parameters}

Two TORE® Lance operational adjustments may be made during operation.

- Inlet fluid pressure: the inlet fluid pressure can vary from atmospheric up to 12 bar (174 psi).

Performance curves in Figure 3.5 show operation over a range from 0 to 6 bar ( $87 \mathrm{psig}$ ). Measurement of the flow as a function of compressor supply pressure for our unit is shown in Figure 3.6. The compressor supply pressures evaluated ranged from 5 to 100 psig.

\section{Air Flow to TORE $\circledast$ Lance}

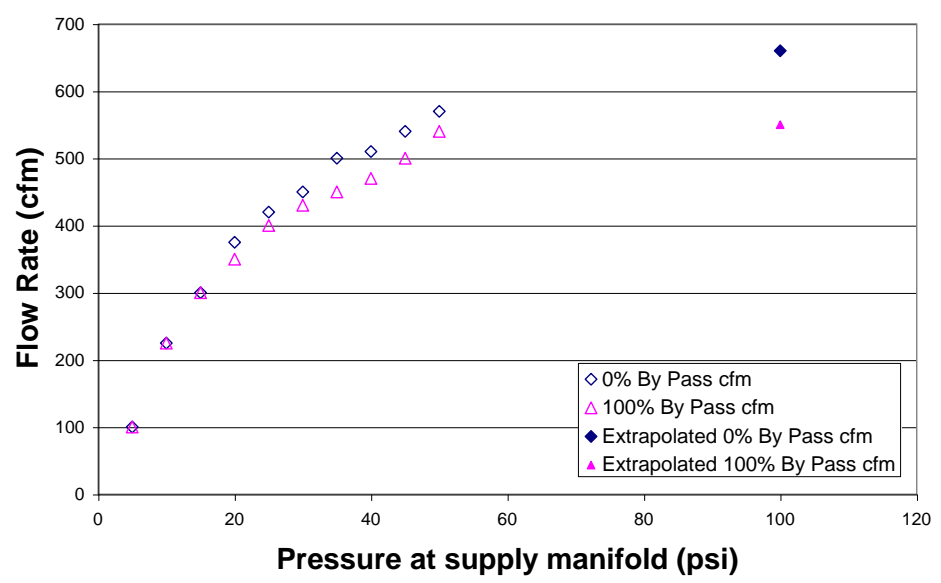

Figure 3.6. TORE® Lance flow rate with and without bypassing flow to the head. 
- Flow split between the eductor and the TORE® Lance head.

This flow split is adjusted using the manually operated bypass flow balance valve located on the manifold near the center of the TORE® Lance. The internal components of this valve are shown in Figure 3.7.
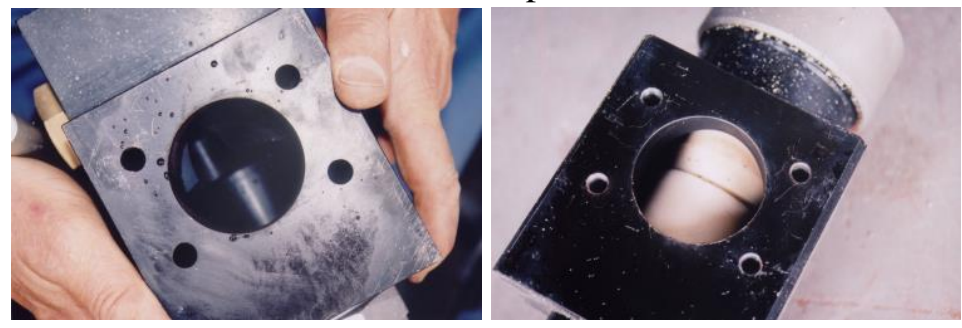

Figure 3.7. View inside the flow control manifold showing the connection between the upper and lower ceramic pieces that line the inside of the eductor.

\subsubsection{Internally Adjustable Parameters}

The TORE® Lance incorporates a series of spacers to fine tune the flow split between the head and the eductor by creating a larger or smaller gap between the ceramic inserts shown in Figure 3.7. In this unit, adjustment is made manually by inserting the correct height spacer at the top of the ceramic insert that forms the upper liner of the eductor, as shown in Figure 3.8. To evaluate the effect of the spacer thickness, the flow through the TORE® Lance was measured with each of the spacers and several spacer combinations. This plot is shown in Figure 3.9. An increase in the spacer thickness decreases the flow available to the TORE® Lance head for establishing the precessing vortex for solids mobilization. The TORE® Lance was received from MerPro with the 1-mm spacer installed in the unit.

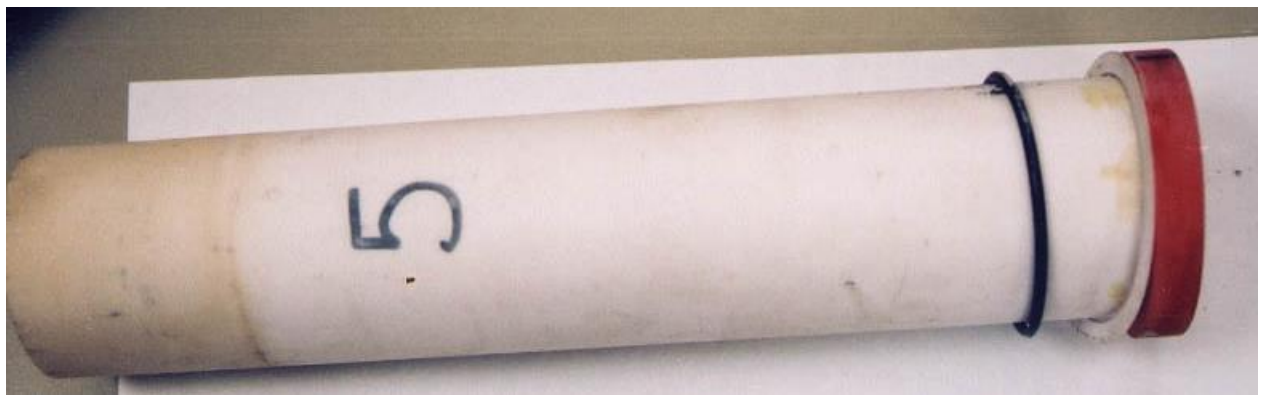

Figure 3.8. Eductor ceramic liner showing black O-ring and white spacer. 


\section{Evaluation of Spacer Performance}

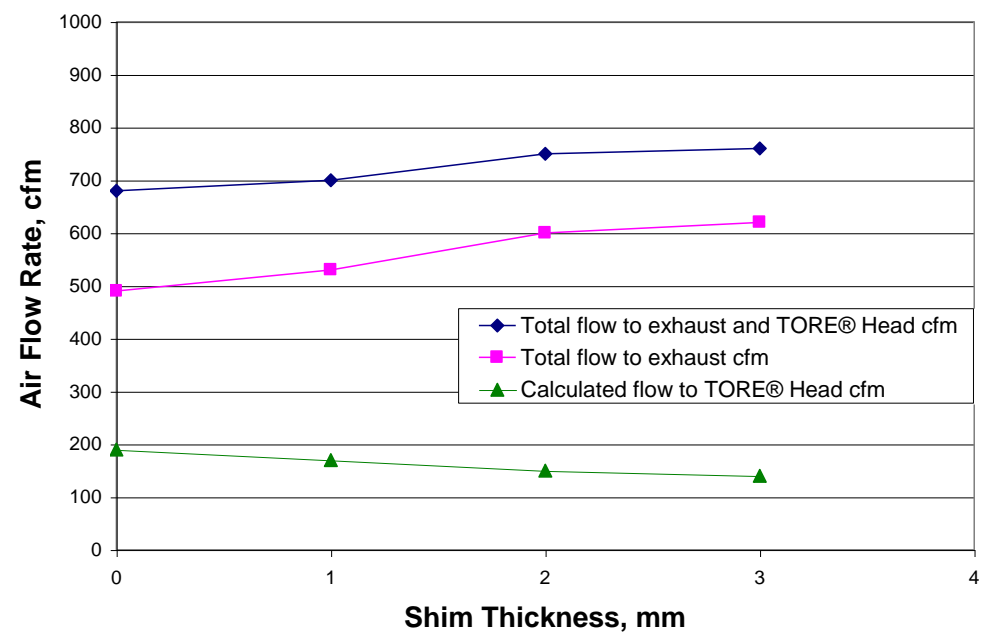

Figure 3.9. Plot showing how the spacer thickness affects the flow split between the eductor and the TORE® Lance head.

\subsection{TORE® Lance Demonstration at Vendor's Site}

A smaller TORE® Lance with a 1-in. diameter bore was demonstrated at the vendor's site and observed by the project sponsor. The application was to remove sand from a series of channels. The operating conditions were not specified; however, pressurized water was fed to the TORE® Lance inlet and used for solids mobilization and to power the eductor. No discharge line was attached to the outlet of the TORE® Lance. A photo taken during the demonstration is shown in Figure 3.10. It is important to observe the steadiness of the flow stream and the color of the retrieved water. The darker the color, the more solids in the retrieval stream. The flow does look quite steady and solids are definitely being retrieved. 


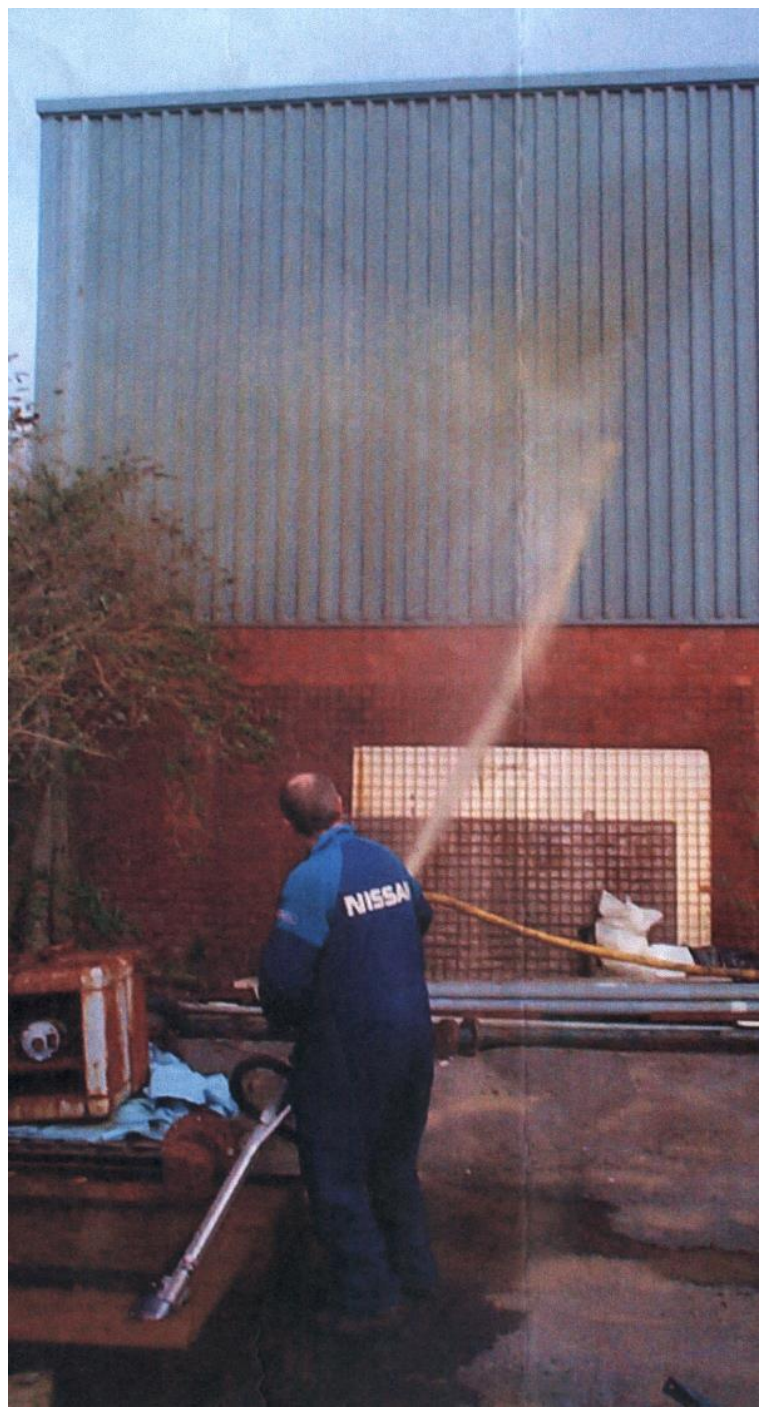

Figure 3.10. Demonstration of operation of a 1-in. diameter TORE® Lance at the vendor's facility. 


\subsection{Experimental Configuration}

To evaluate the performance of the TORE® Lance, a series of small-scale tests were conducted to investigate different system configurations, operating configurations, and the ability to mobilize and retrieve different simulants. The test facility, instrumentation, and test matrix used during these tests are described in this section. In addition, the details of the simulant selection and the simulant physical properties are presented.

\subsection{Test Facility}

The TORE® Lance evaluation was conducted at Hanford in the 336 Building Fluid Dynamics Laboratory using selected equipment, shown in Figure 1. This figure shows equipment, process connections, and instrumentation.

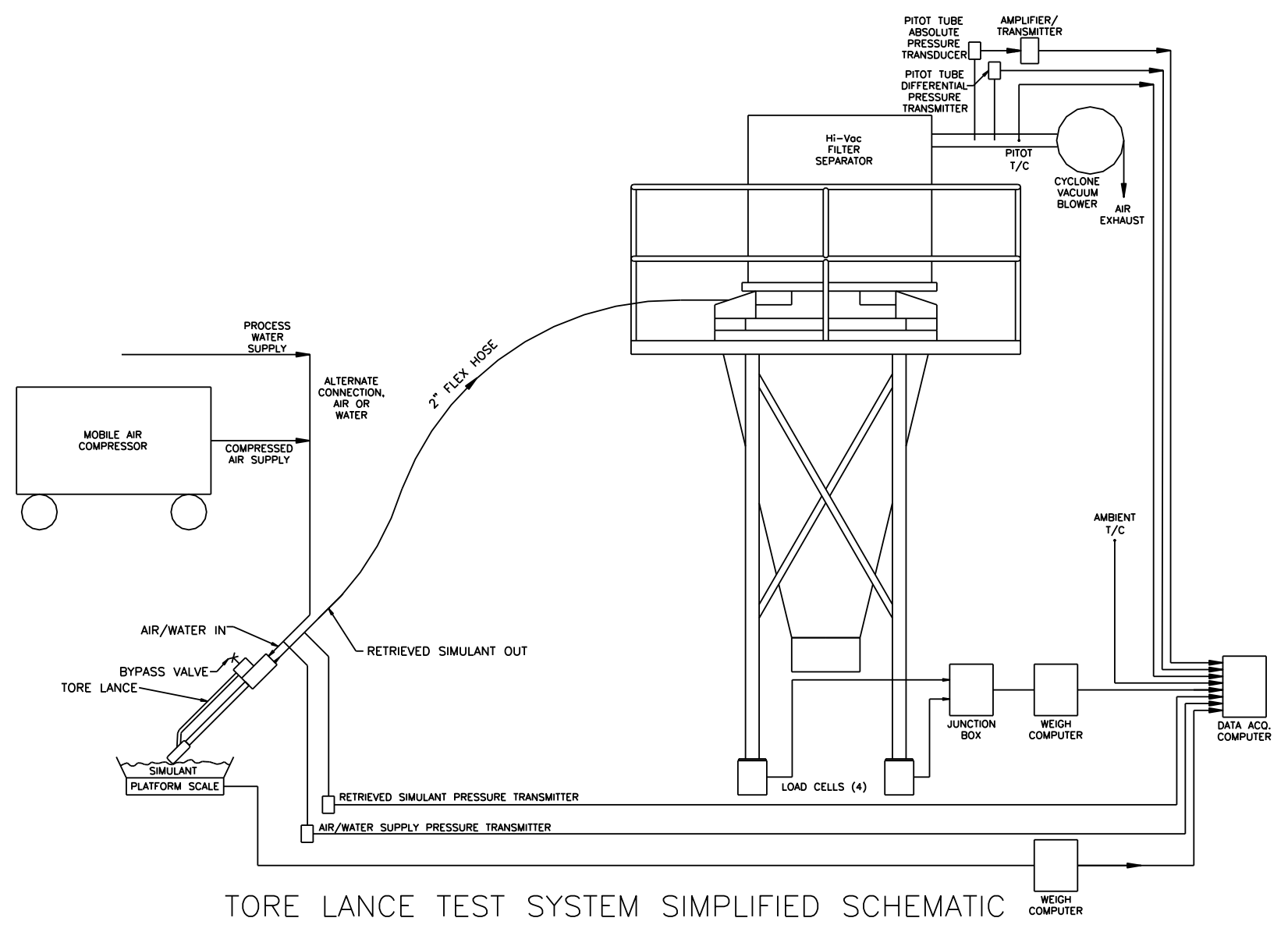

Figure 4.1. TORE® Lance test configuration 


\subsubsection{Equipment}

Major equipment includes the: TORE® Lance tool (described in Section 3.0), solids separation system (Hi-Vac) and blower, weigh controller (Hardy), water skid, compressor, and data acquisition.

\subsubsection{Solids Separation System and Blower}

The Hi-Vac ${ }^{a}$ solids separation system includes a bag house and cyclone separation system to remove solids and water from the conveyance line process stream. The Hi-Vac control panel is used to control the Gardner-Denver ${ }^{\mathrm{b}}$ roots type blower that is located outside the building. The blower can be started or stopped from the Hi-Vac Control Panel, from the Remote Control Panel located in the control panel, or from the blower start stop remote control box on a $50 \mathrm{ft}$ cable that connects to the Hi-Vac Control Panel.

\subsubsection{Weigh Controller}

The Hardy ${ }^{\mathrm{c}}$ weigh controller and load cells are used to measure the weight of the Hi-Vac system.

\subsubsection{Process Water Skid}

The process water skid, on loan from $\mathrm{CH} 2 \mathrm{M}$ Hill Hanford Group was used to provide pressurized water flow to the TORE® Lance. The water skid components are shown in Figure 4.2.

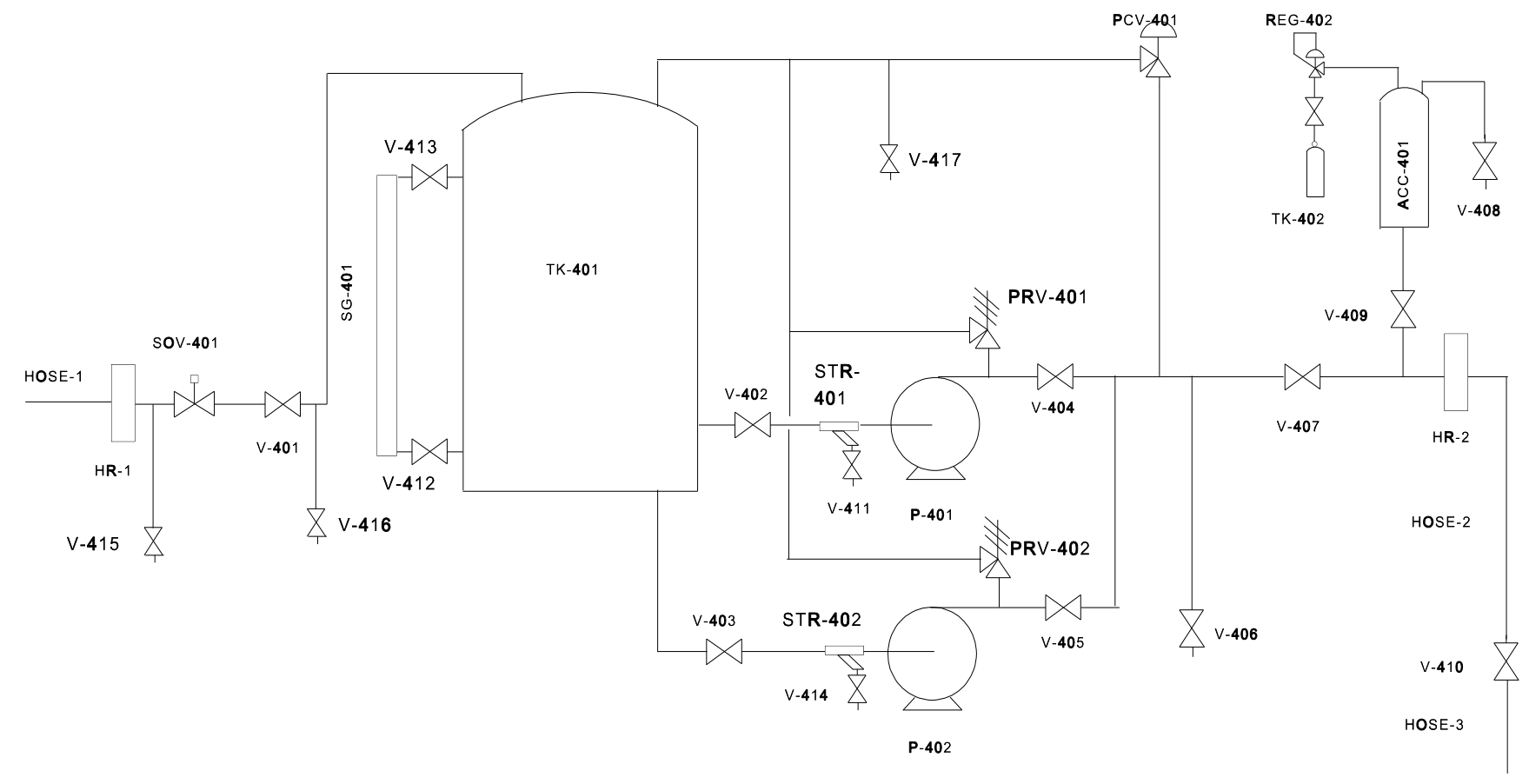

Figure 4.2. Water skid diagram

a Hi-Vac Corporation, Marietta, Ohio. http://www.hi-vac.com

b Gardner-Denver, Inc., Peachtree City, Georgia. http://www.gardner-denver.com

c Hardy Instruments, Inc., San Diego, California. http://www.hardyinst.com 


\subsubsection{Compressor}

A Sullair ${ }^{a}$ Model 1050 diesel-powered air compressor was located outside the east wall of 336 building. The compressor provides $1000 \mathrm{cfm}$ at $100 \mathrm{psig}$.

\subsubsection{Instrumentation}

Process parameters measured during the TORE® Lance tests are listed in Table 4.1. The components of the instrumentation system are listed in Table 4.2.

Table 4.1. TORE® Lance process measurements

\begin{tabular}{|l|l|l|l|}
\hline Parameter and Measurement & Range & Units \\
\hline Mobilizing Fluid & Water Pressure & & \\
\hline & Water Flow Rate & $0 \sim 200$ & psig \\
\hline & Air Pressure & $0 \sim 100 \mathrm{max}$ & gpm \\
\hline & Air Flow Rate & $0 \sim 200$ & psig \\
\hline & Throttled Supply Air/Water Pressure & $0-800$ & scfm \\
\hline Simulant & $0 \sim 200$ & psig \\
\hline \multicolumn{2}{l}{} & & \\
\hline & Weight & $0 \sim 1000$ & lb \\
\hline & Hopper weight Conveyance & $0-4000$ & lb \\
\hline & $\begin{array}{l}\text { Air Flow Rate - calculated from } \\
\text { measurements of }\end{array}$ & $0-1000$ & scfm \\
\hline & Vacuum Supply Pressure Differential (Pitot) & $0 \sim 10$ & in. $\mathrm{H}_{2} \mathrm{O}$ differential \\
\hline & Vacuum Supply Absolute Pressure & $0 \sim 15$ & psia \\
\hline & Vacuum Supply Temperature & $0 \sim 100$ & C \\
\hline Ambient Conditions & Atmospheric Pressure (from weather station) & $0 \sim 30$ & in $\mathrm{Hg}$ \\
\hline & Ambient Temperature & $0 \sim 50$ & C \\
\hline
\end{tabular}

a Sullair Corporation, Michigan City, Indiana. http://www.sullair.com 
Table 4.2. Instrumentation

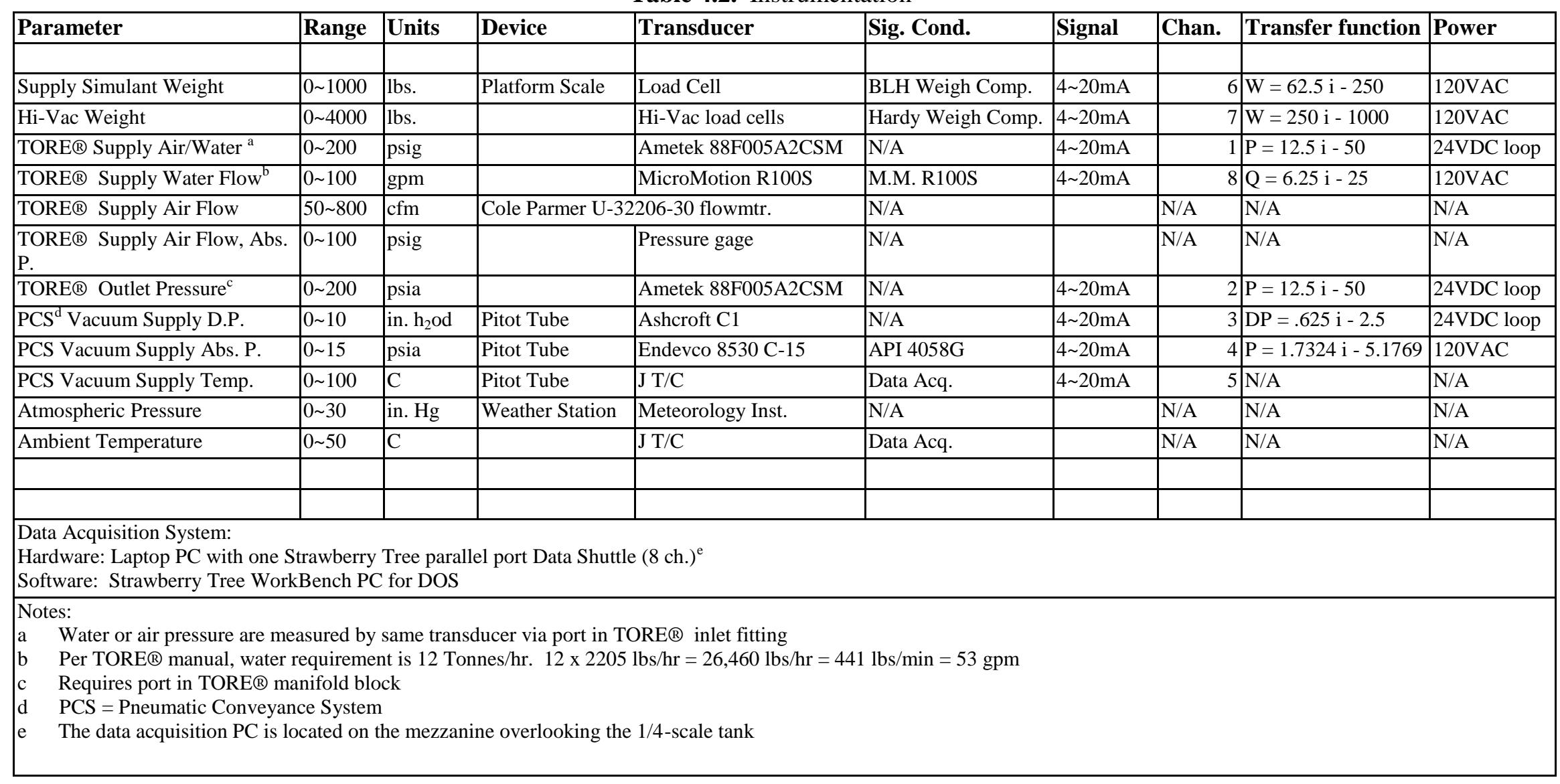




\subsection{Simulant Selection and Characterization}

The simulant selection took into account

- Anticipated waste types expected to be found in tank 241-C-104

- Guidance from Merpro literature regarding types of solids transported

- Recommendations for the MRS system qualification.

\subsubsection{1-C-104 Waste Properties}

Analysis of existing physical and chemical property data of the waste in tank 241-C-104 provided guidance for simulant selection. Property values of slurried tank waste during retrieval include:

- Liquid density - 1.1 to $1.4 \mathrm{~kg} / \mathrm{l}$

- Liquid viscosity - 10 to $100 \mathrm{cP}$

- Slurry temperature 80 to $120 \mathrm{~F}$

- Solids density 2.5 to $3.0 \mathrm{~kg} / \mathrm{l}$

- In tank operating temperature $20.8 \mathrm{C}(80 \mathrm{~F})$ to $45.7 \mathrm{C}(100 \mathrm{~F})$.

Waste property data from Estey (2001) recommends:

- Using a conservative solids density of $3.00 \mathrm{~kg} / \mathrm{l}$, the bulk physical composition of tank C-104 sludge is about $72 \%$ by volume liquid and $28 \%$ by volume solids with a bulk density of $1.67 \mathrm{~kg} / \mathrm{l}$ and a liquid phase density of $1.19 \mathrm{~kg} / \mathrm{l}$.

- Analyzed particle sizes ranged from 5 to $6350 \mu \mathrm{m}$. $6350 \mu \mathrm{m}$ represents the largest minimal dimension of a particle that could pass through a $1 / 4$ in. filter screen. Laboratory analysis suggests that the vast majority of particles derived from tank 241-C-104 sludge have mean diameters $\leq 275 \mu \mathrm{m}$ in diameter.

Jewett et al. (2002) recommended values for three waste properties, particle size distribution, particle density, and slurry viscosity, to be used for planned waste feed delivery system analysis. The particle size distributions were obtained from analysis of samples from 7 of 10 Phase 1 high level waste feed tanks. The particle size data show

- $7.5 \mu \mathrm{m} \pm 4.2 \mu \mathrm{m}$ mean

- the one sided $95 / 95$ tolerance limit value for the $50^{\text {th }}$ percentile is $22 \mu \mathrm{m}$. This means that with 95 percent confidence at least 95 percent of the tanks will have a median particle size no larger than $22 \mu \mathrm{m}$.

- the 95\% UL (upper limit to a one-sided 95 percent confidence limit on the mean) is $11 \mu \mathrm{m}$. The 95\% UL means that we are $95 \%$ confident that the true mean for all the wastes will be less than the computed value.

The average of the dry-basis densities of the solids in eight high level waste tanks is calculated to be $2.9 \mathrm{~kg} / \mathrm{l}$. This is a conservative value because the value ignores the beneficial effect of agglomeration, which probably reduces the effective density of the solids to a value of around $2.2 \mathrm{~kg} / \mathrm{l}$. The solids density is the least known waste property required for pipeline transfer assessment. A curve fit that is a function of the volume fraction is provided for density. The report (Jewett et al. 2002) also states that 
only tank 241-C-104 had a viscosity greater than $10 \mathrm{cP}$. This data shows that the maximum viscosity measured ranged up to $60 \mathrm{cP}$ at 0.2 volume fraction solids.

O'Rourke (2001 Rev 0B) reports that shear strength measurements were made on twelve undisturbed portions of core-sampled 241-C-104 sludge. Before starting any other tests, shear strength measurements were completed on the undisturbed sludge. The shear strengths ranged from 289 to $7077 \mathrm{~Pa}$ and tended to increase with sample depth in the tank. The shear strength could not be measured for the two samples collected from the lowest segment. These two samples were sufficiently hard that the shear vane could not be pushed into the sample material.

\subsubsection{Recommended Simulant for MRS Factory Acceptance Test}

The following simulant recipe

- $66 \mathrm{wt} \%$ EPK pulverized kaolin clay

- $34 \mathrm{wt} \%$ water

was recommended as the simulant for the AMS lift test. ${ }^{a}$ The simulant was selected based on cost, ease of handling and preparation, non-hazardous nature, and no particular disposal requirements. This simulant was initially developed to support evaluation of retrieval processes. Additional data about the simulant is presented in Golcar et al (1997) and Powell et al. (1997). The properties of such a simulant are: very sticky with a shear strength of approximately $3.5 \mathrm{kPa}$. The bulk density of the simulant is about $1.650 \mathrm{~kg} / \mathrm{l}$. The mean diameter of particle is $1.2 \mu \mathrm{m}$. The kaolin particles are smaller than the waste particle but the plate-like shape of the kaolin particles is expected to render the kaolin conservatively cohesive (more sticky and difficult to retrieve than the waste). Rheological analysis demonstrated that kaolin (A12O3.2 SiO2.2H2O) is a Bingham plastic as well as most of Hanford sludge.

\subsubsection{Simulants Selected for TORE® Lance Evaluation}

With concurrence from the project sponsor three physical simulants were selected for TORE® Lance evaluation tests conducted at PNNL: two particulates: gravel and sand, and a sludge simulant made from kaolin clay and water. All of these simulants are non-hazardous and relatively easy to dispose or recycle after test completion.

\subsubsection{Gravel and Sand}

The gravel and sand were selected for simulants since Merpro uses sand to characterize TORE® Lance performance because the solids are easy to handle and are relatively easy to dislodge, even when moist. The particle size is large enough that the majority of the solids won't aerosolize during dislodging. Physical properties of the sand and gravel are listed in Table $4.3^{\mathrm{b}}$.

\footnotetext{
a Creze, Chantho M. 2002. Simulant for the AMS Lift Test. Email to D. B. Smet and K. E. Carpenter, February 12, 2002 11:58 AM. CH2M Hill Hanford Group, Inc. From Numatec Hanford Company.

b Bamberger, J. A. et al. 1995. FY 95 Retrieval Process Development and Enhancements Three-Phase Flow Conveyance for Transport of Scarified Waste and Instrumentation for In-Situ Slurry Measurements. Draft.
} 
Table 4.3. Sand and gravel physical properties

\begin{tabular}{|l|l|l|l|l|}
\hline Material & Sieve Range & Mean Diameter & Solids Density & Bulk Density \\
\hline & $\mathbf{m m}$ & $\mathbf{m m}$ & $\mathbf{k g} / \mathbf{m}^{\mathbf{3}}$ & $\mathbf{k g} / \mathbf{m}^{\mathbf{3}}$ \\
\hline Large gravel & 4.00 to 5.60 & 4.80 & 2730 & 1680 \\
\hline Gravel & 1.40 to 2.00 & 1.70 & 2730 & $1585^{\mathbf{a}}$ \\
\hline Sand & 0.05 to 0.71 & 0.61 & 2730 & 1490 \\
\hline a) Average of large gravel and sand & \\
\hline
\end{tabular}

\subsubsection{Kaolin}

The kaolin simulant selected to model sludge was described in Section 4.2.2. Physical properties are listed in Table 4.4 (Bamberger et al. 1994). Additional properties of kaolin and water sludges are listed in Figure 4.3.

Table 4.4. Physical properties of kaolin-water sludge simulants

\begin{tabular}{|l|l|l|l|l|}
\hline Simulant & Kaolin & Water & Bulk Density & Shear Strength \\
\hline & $\mathbf{w t} \%$ & $\mathbf{w t \%}$ & $\mathbf{k g} / \mathbf{m}^{\mathbf{3}}$ & $\mathbf{k P a}$ \\
\hline Slurry & 20 & 80 & 1090 & \\
\hline Sludge & 66 & 34 & 1634 & 4.1 to 4.9 \\
\hline Extremely hard sludge & 75 & 25 & & $>12$ \\
\hline
\end{tabular}
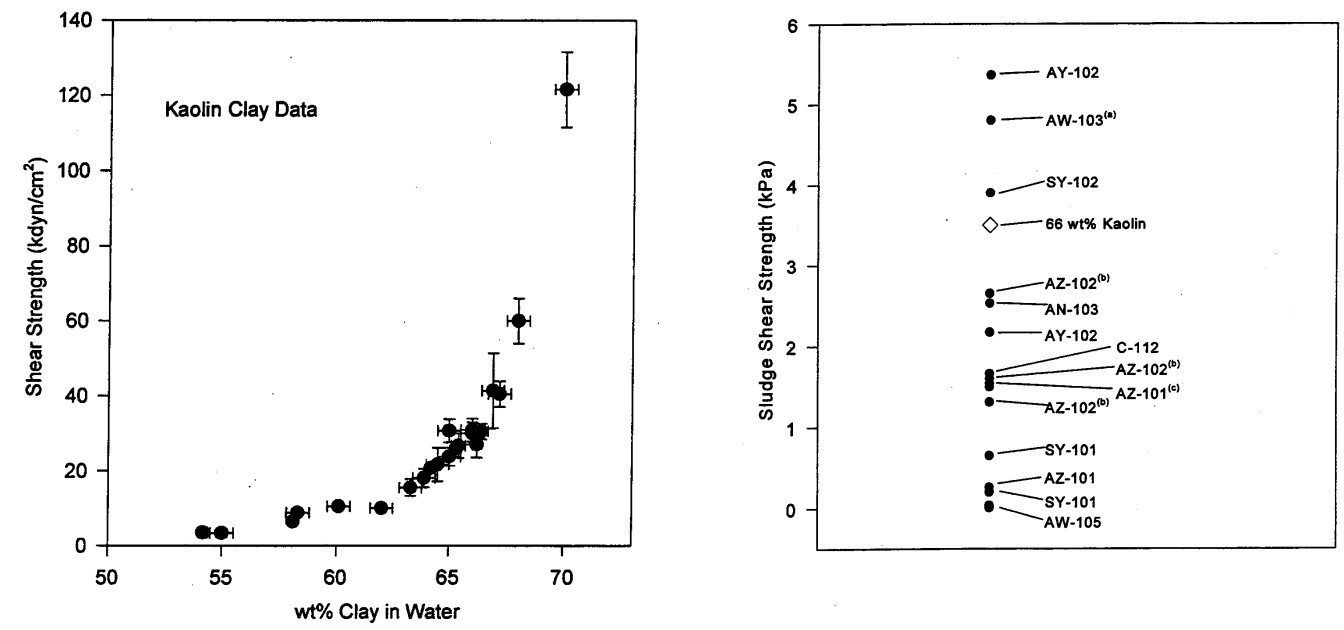

Figure 4.3. Properties of kaolin water simulants and comparison with sludge-type wastes

\subsection{Test Matrix}

The initial test matrix was developed to evaluate TORE® Lance performance over a range of anticipated operating conditions. To identify these tests a unique 6-digit test number was developed to identify tests described in Sections 5, 6 and 7, see Table 4.4. This test number was modified to include two additional parameters used to identify tests in Sections 8 and 9; see Table 4.5. 
Table 4.4. Test number column definition for tests described in Sections 5, 6 and 7.

\begin{tabular}{|l|l|l|l|l|l|}
\hline \multicolumn{7}{|c|}{$\mathbf{2}$} & \multicolumn{1}{|c|}{$\mathbf{3}$} & \multicolumn{1}{c|}{$\mathbf{4}$} & \multicolumn{1}{c|}{$\mathbf{5}$} & \multicolumn{1}{c|}{ 6 } \\
\hline Simulant & \multicolumn{1}{|c|}{$\begin{array}{l}\text { Conveying } \\
\text { Fluid }\end{array}$} & $\begin{array}{l}\text { Mobilizing } \\
\text { Fluid }\end{array}$ & $\begin{array}{l}\text { Head } \\
\text { Feed }\end{array}$ & Orientation & Stand-off Distance \\
\hline G: gravel & $\begin{array}{l}\text { P: Pneumatic } \\
\text { conveyance }\end{array}$ & 1: Air & 0: OFF & V: Vertical & $\begin{array}{l}\text { 6: } 6 \text { in. above the } \\
\text { simulant }\end{array}$ \\
\hline S: sand & $\begin{array}{l}\text { Z: No } \\
\text { conveyance }\end{array}$ & 2: Water & 1: ON & $\begin{array}{l}30: 30 \text { degrees } \\
\text { from vertical }\end{array}$ & $\begin{array}{l}\text { 2: } 2 \text { in. above the } \\
\text { simulant }\end{array}$ \\
\hline K: kaolin & & $\begin{array}{l}\text { 3: A mixture of } \\
\text { air and water }\end{array}$ & & $\begin{array}{l}\text { 60: } 60 \text { degrees } \\
\text { from vertical }\end{array}$ & $\begin{array}{l}\text { 0: contacting the } \\
\text { simulant }\end{array}$ \\
\hline & & & $\begin{array}{l}\text { 90: Near } \\
\text { horizontal }\end{array}$ & $\begin{array}{l}\text { S: submerged } ~ 6 \text { in. in } \\
\text { the simulant }\end{array}$ \\
\hline
\end{tabular}

Table 4.5. Test number column definition for tests described in Section 8 .

\begin{tabular}{|l|l|l|l|l|l|}
\hline \multicolumn{1}{|c|}{$\mathbf{1}$} & \multicolumn{1}{|c|}{$\mathbf{2}$} & \multicolumn{1}{|c|}{$\mathbf{3}$} & \multicolumn{1}{c|}{$\mathbf{4}$} & \multicolumn{1}{c|}{$\mathbf{5}$} & \multicolumn{1}{c|}{ 6-7 } \\
\hline Container & Simulant & Conveying Fluid & Mobilizing Fluid & $\begin{array}{l}\text { Head } \\
\text { Feed }\end{array}$ & $\begin{array}{l}\text { Inlet Supply Pressure } \\
\text { or Flow Rate }\end{array}$ \\
\hline B: bucket & S: sand & $\begin{array}{l}\text { P: Pneumatic } \\
\text { conveyance }\end{array}$ & 1: Air & $0:$ OFF & $5,30,45 \mathrm{psig}$ \\
\hline D: drum & K: kaolin & Z: No conveyance & 2: Water & 1: ON & $10,50,70 \mathrm{gpm}$ \\
\hline F: floor & W: water & & $\begin{array}{l}\text { 3: A mixture of } \\
\text { air and water }\end{array}$ & & \\
\hline & & & & & \\
\hline
\end{tabular}




\subsection{TORE@ Lance Mobilization and Retrieval of Gravel}

Initial TORE® Lance performance evaluation tests were conducted using air as the mobilizing and retrieval fluid and gravel as the material to be mobilized and retrieved. The larger particle diameter of the gravel was expected to be advantageous during these tests because we were attempting to keep the solids in the container or inside the conveyance line.

\subsection{Test Matrix}

The initial test matrix was developed to evaluate TORE® Lance performance over a range of anticipated operating conditions. To identify these tests a unique 6-digit test number was developed. The components of this number were defined in Section 4.5. The gravel tests were conducted in three parts; each part was selected with the specific goal to evaluate separate facets of the TORE® Lance system.

- $\quad$ To evaluate transport of solids through the TORE® Lance assembly to the conveyance hopper using only pneumatic conveyance. This test provides a baseline to define mobilizing and retrieval that could be accomplished with only the TORE® Lance hardware with no enhancement from either the eductor or precessing vortex.

- $\quad$ To evaluate the transport of solids through the TORE® Lance assembly to the conveyance hopper using compressed air through the TORE® Lance assembly to enhance the pneumatic conveyance. This test evaluates the increased performance obtained by using compressed air to power the eductor to enhance retrieval.

- $\quad$ To evaluate the transport of solids through the TORE® Lance assembly to the conveyance hopper using compressed air through the TORE® Lance head to mobilize the solids and through the TORE® Lance assembly to enhance the pneumatic conveyance. These tests evaluate the full performance of the TORE® Lance using the precessing vortex to mobilize the gravel and the eduction to enhance retrieval.

The test matrix is listed in Table 5.1.

Table 5.1 Test matrix for evaluation of TORE® Lance mobilizing and retrieval of gravel.

\begin{tabular}{|l|l|l|l|l|l|l|}
\hline $\begin{array}{l}\text { Test } \\
\text { Number }\end{array}$ & $\begin{array}{l}\text { Simu- } \\
\text { lant }\end{array}$ & Conveying Fluid & $\begin{array}{l}\text { Mobiliz } \\
\text {-ing } \\
\text { Fluid }\end{array}$ & $\begin{array}{l}\text { Head } \\
\text { Feed }\end{array}$ & Orientation & $\begin{array}{l}\text { Stand-off } \\
\text { Distance }\end{array}$ \\
\hline Objective & \multicolumn{6}{|l|}{$\begin{array}{l}\text { To evaluate the transport of solids through the TORE® Lance assembly to the conveyance } \\
\text { hopper using only pneumatic conveyance }\end{array}$} \\
\hline GP00V6 & Gravel & Air: pneumatic conveyance & None & None & Vertical & 6 in. \\
\hline GP00V2 & Gravel & Air: pneumatic conveyance & None & None & Vertical & 2 in. \\
\hline GP00V0 & Gravel & Air: pneumatic conveyance & None & None & Vertical & 0 in. \\
\hline GP00VS & Gravel & Air: pneumatic conveyance & None & None & Vertical & Submerged 6 in. \\
\hline GP0090 & Gravel & Air: pneumatic conveyance & None & None & Horizontal & 0 in. \\
\hline GP009S & Gravel & Air: pneumatic conveyance & None & None & Horizontal & Submerged 6 in. \\
\hline
\end{tabular}




\begin{tabular}{|c|c|c|c|c|c|c|}
\hline Objective & \multicolumn{6}{|c|}{$\begin{array}{l}\text { To evaluate the transport of solids through the TORE® Lance assembly to the conveyance } \\
\text { hopper using compressed air through the TORE® Lance assembly to enhance the pneumatic } \\
\text { conveyance }\end{array}$} \\
\hline GP10V6 & Gravel & Air: pneumatic conveyance & Air & None & Vertical & 6 in. \\
\hline GP10V2 & Gravel & Air: pneumatic conveyance & Air & None & Vertical & 2 in. \\
\hline GP10V0 & Gravel & Air: pneumatic conveyance & Air & None & Vertical & 0 in. \\
\hline GP10VS & Gravel & Air: pneumatic conveyance & Air & None & Horizontal & Submerged 6 in. \\
\hline GP1092 & Gravel & Air: pneumatic conveyance & Air & None & Horizontal & 2 in. \\
\hline GP1090 & Gravel & Air: pneumatic conveyance & Air & None & Horizontal & 0 in. \\
\hline GP109S & Gravel & Air: pneumatic conveyance & Air & None & Horizontal & Submerged 6 in. \\
\hline Objective & \multicolumn{6}{|c|}{$\begin{array}{l}\text { To evaluate the transport of solids through the TORE® Lance assembly to the conveyance } \\
\text { hopper using compressed air through the TORE® Lance head to mobilize the solids and } \\
\text { through the TORE® Lance assembly to enhance the pneumatic conveyance }\end{array}$} \\
\hline GP11V6 & Gravel & Air: pneumatic conveyance & Air & Air & Vertical & 6 in. \\
\hline GP11V2 & Gravel & Air: pneumatic conveyance & Air & Air & Vertical & 2 in. \\
\hline GP11V0 & Gravel & Air: pneumatic conveyance & Air & Air & Vertical & 0 in. \\
\hline GP11VS & Gravel & Air: pneumatic conveyance & Air & Air & Vertical & Submerged 6 in. \\
\hline GP11VSS & Gravel & Air: pneumatic conveyance & Air & Air & Vertical & $\begin{array}{l}\text { Submerged > } 6 \\
\text { in. }\end{array}$ \\
\hline GP119S & Gravel & Air: pneumatic conveyance & Air & Air & Horizontal & Submerged 6 in. \\
\hline GP113S & Gravel & Air: pneumatic conveyance & Air & Air & $\begin{array}{l}\text { Inclined } 30 \\
\text { degrees } \\
\text { from } \\
\text { vertical }\end{array}$ & Submerged 6 in. \\
\hline GP116S & Gravel & Air: pneumatic conveyance & Air & Air & $\begin{array}{l}\text { Inclined } 60 \\
\text { degrees } \\
\text { from } \\
\text { vertical }\end{array}$ & Submerged 6 in. \\
\hline
\end{tabular}

\subsection{Gravel Test Observations}

\subsubsection{Pneumatic Conveyance through TORE® Lance}

During these tests, pneumatic conveyance was the only mechanism used to retrieve solids. This test provides a baseline to define mobilizing and retrieval that could be accomplished with only the TORE® Lance hardware with no enhancement from either the eductor or precessing vortex.

\subsubsection{GP00V6 Observations}

No solids were mobilized or conveyed during this test. 


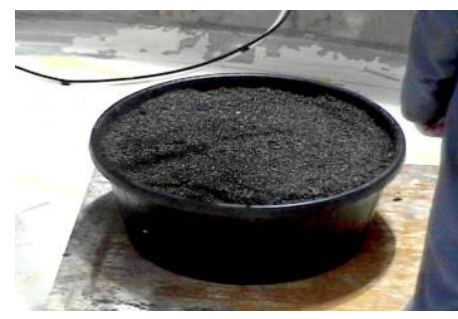

Prior to test start.

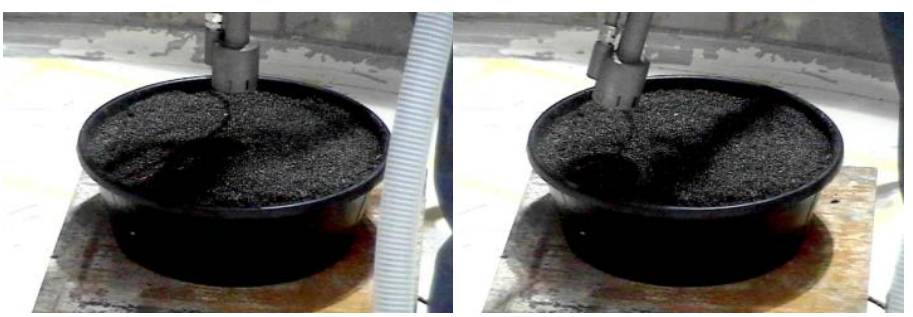

During TORE® Lance operation. After test conclusion.

Figure 5.1 Test GP00V6 Sequence May 31, 2002: Gravel simulant, pneumatic conveyance, no air or water, no head feed, TORE® oriented vertically 6 in. above the simulant.

\subsubsection{GP00V2 Observations}

No solids were mobilized or conveyed during this test.

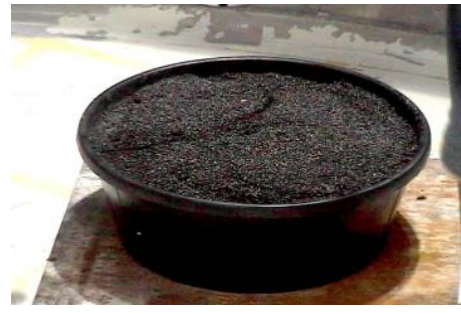

Prior to test start.

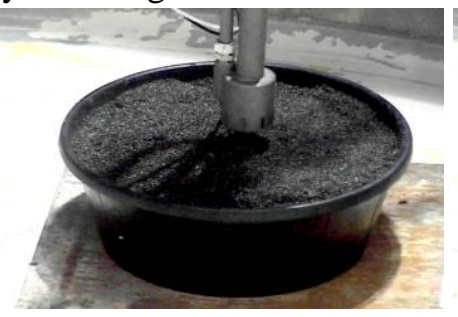

During TORE® Lance operation. After test conclusion.

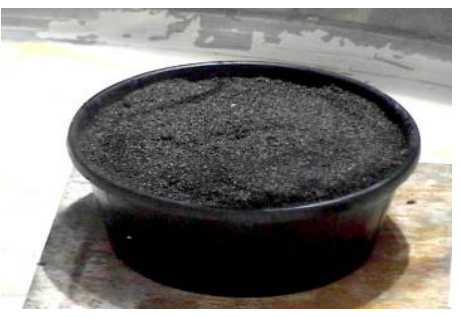

Figure 5.2. Test GP00V2 Sequence May 31, 2002: Gravel simulant, pneumatic conveyance, no air or water, no head feed, TORE® oriented vertically 2 in. above the simulant.

\subsubsection{GP00V0 Observations}

With only pneumatic conveyance a dish-shaped impression, $\sim 5$ in. wide $\mathrm{x} 1 \mathrm{in}$. deep was uncovered.

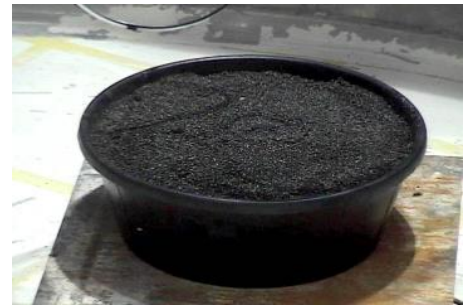

Prior to test start.

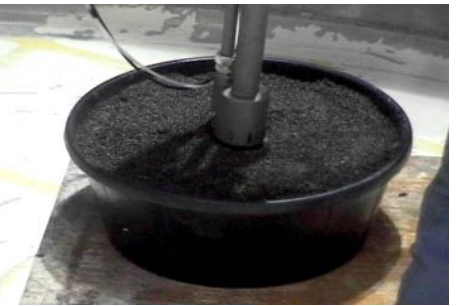

During TORE® Lance operation. After test conclusion.

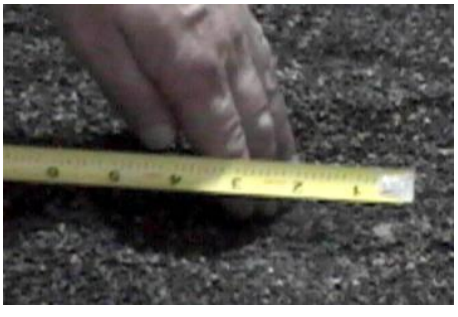

Figure 5.3. Test GP00V0 Sequence May 31, 2002: Gravel simulant, pneumatic conveyance, no air or water, no head feed, TORE® oriented vertically 0 in. above the simulant.

\subsubsection{GP00VS Observations}

The TORE® Lance head was buried in the gravel prior to test start. During operation pneumatic conveyance excavated a cylindrical hole $\sim 6$ in. in diameter and $\sim 6$ in. deep. 


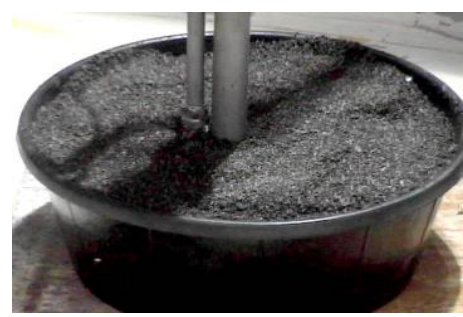

Prior to test start.

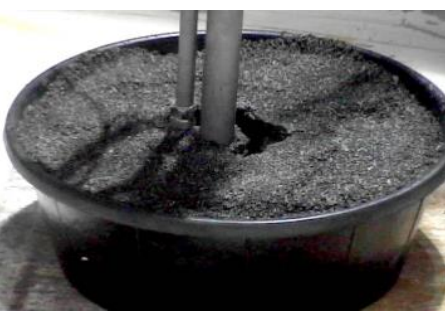

During TORE® Lance operation. After conclusion of test.

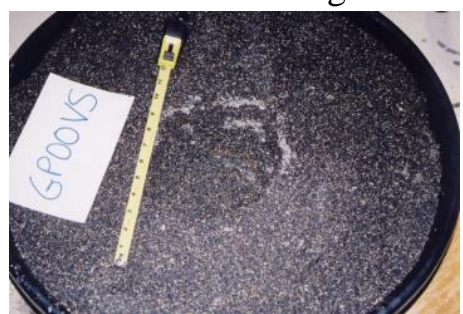

After conclusion of test.

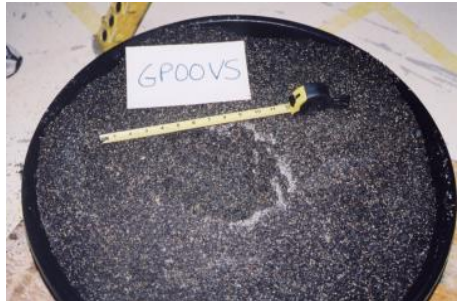

After conclusion of test.

Figure 5.4. Test GP00VS Sequence May 31, 2002: Gravel simulant, pneumatic conveyance, no air or water, no head feed, TORE® oriented vertically with the head submerged in the simulant.

\subsubsection{GP0090 Observations}

No solids were mobilized or conveyed during this test.

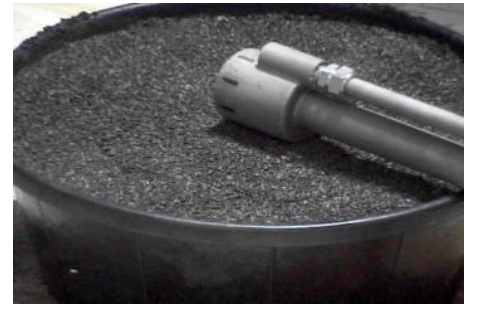

Prior to test start (no change during test).

Figure 5.5. Test GP0090 Sequence May 31, 2002: Gravel simulant, pneumatic conveyance, no air or water, no head feed, TORE® oriented horizontally $\left(90^{\circ}\right) 0$ in. above the simulant.

\subsubsection{GP009S Observations}

Pneumatic conveyance suction removed some solids surrounding the TORE® Lance inlet. The void is visible in the second and third photos. 


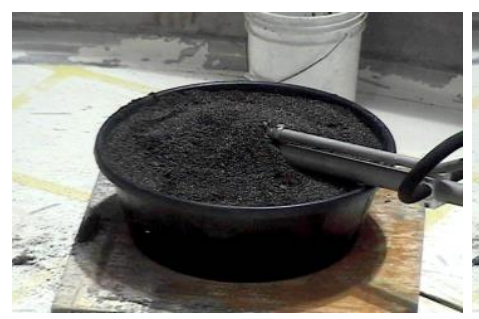

Prior to test start.

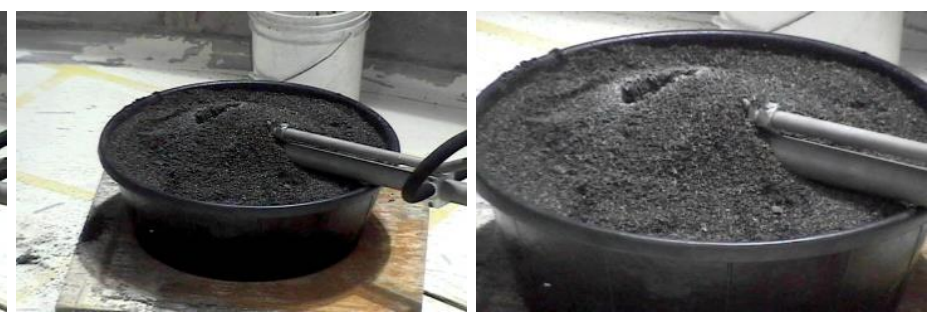

During TORE® Lance operation.

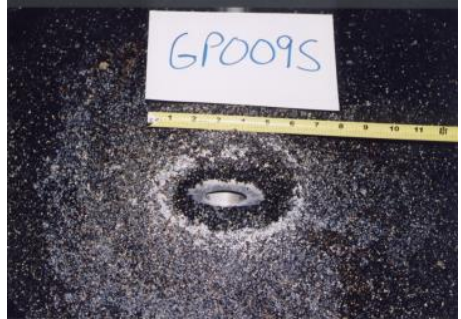

After test conclusion.

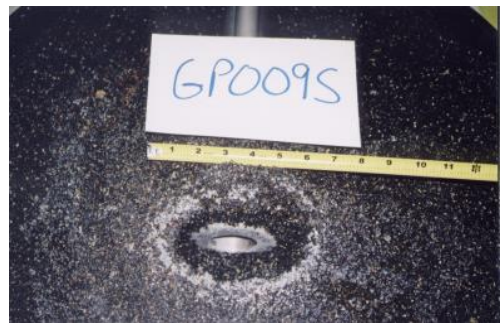

After test conclusion.

Figure 5.6. Test GP009S Sequence May 31, 2002: Gravel simulant, pneumatic conveyance, no air or water, no head feed, TORE® oriented horizontally $\left(90^{\circ}\right)$ with the head submerged in the simulant.

\subsubsection{TORE® Lance Operation with Air Eduction-Enhanced Conveyance}

During these tests $\sim 100$ psig compressed air was supplied to the TORE® Lance. The balance valve was set at $100 \%$ bypass so no compressed air was routed through the TORE® Lance head. The purpose of these tests was to determine the type of retrieval enhancement provided by the eductor.

\subsubsection{GP10V6 and GP10V2 Observations}

No solids retrieval was observed during the tests with stand-off distances of 2 and 6 in.

\subsubsection{GP10V0 Observations}

Addition of eduction flow produced a dish-shaped depression $\sim 6$ in. in diameter and $\sim 2$ in. deep. Slightly deeper depression than obtained without compressed air flow.

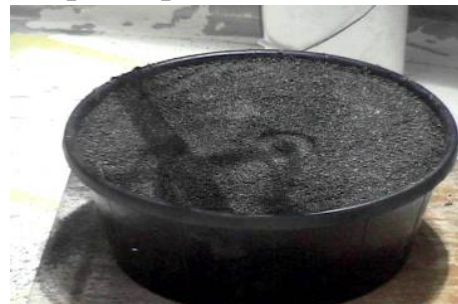

Prior to test start.

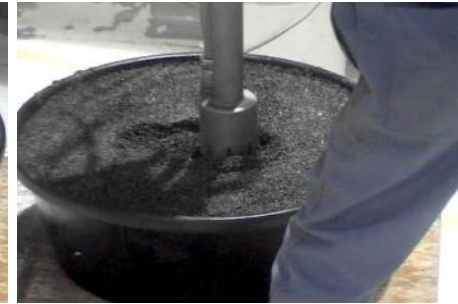

During TORE® Lance operation. After test conclusion.

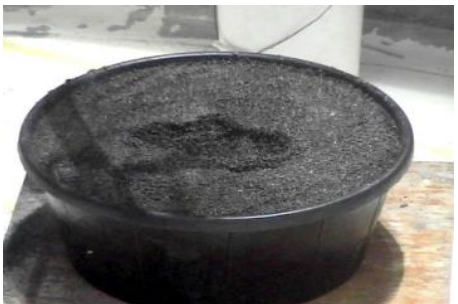




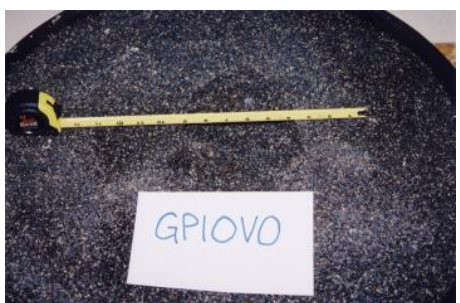

After test conclusion.

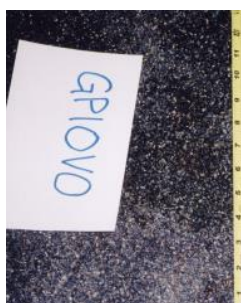

After test conclusion.

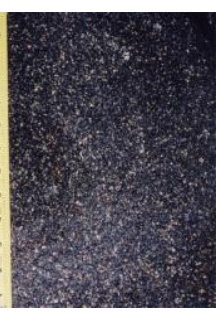

Figure 5.7. Test GP10V0 Sequence May 31, 2002: Gravel simulant, pneumatic conveyance, air, no water, no head feed, TORE® oriented vertically 0 in. above the simulant.

\subsubsection{GP10VS Observations}

Addition of eduction flow produced a cylindrical hole $\sim 7.5 \mathrm{in}$. in diameter and $\sim 6.5 \mathrm{in}$. deep. Slightly wider and deeper depression than obtained without compressed air flow.

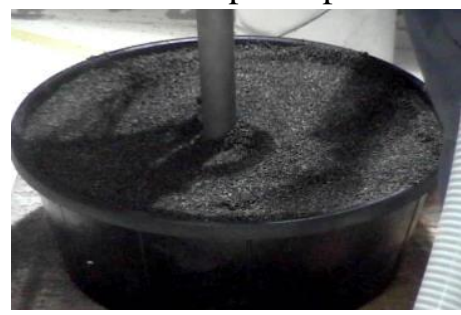

Prior to test start.

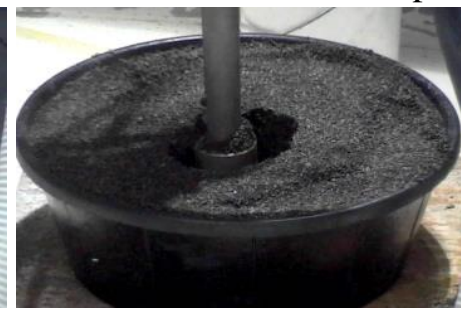

During TORE® Lance operation. After test conclusion.

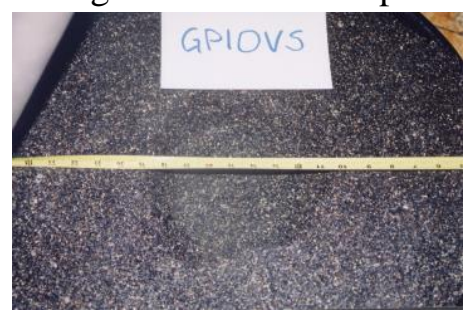

After test conclusion.

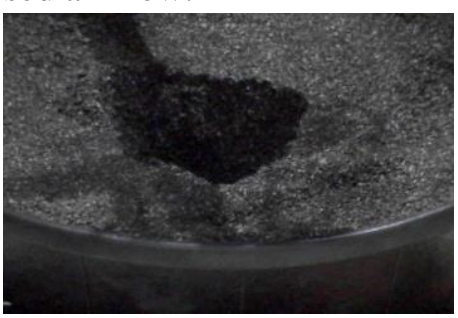




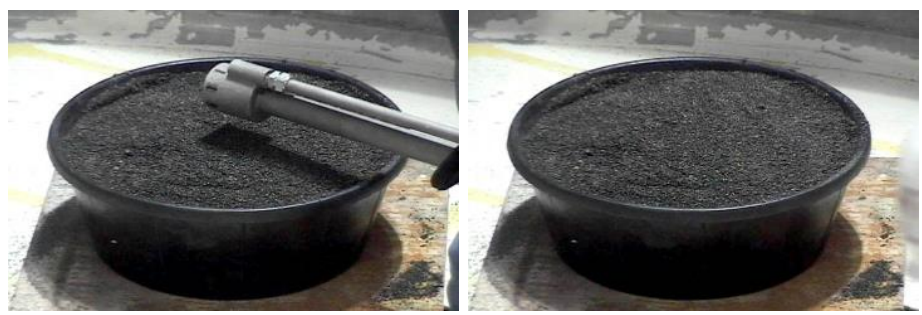

Prior to test start (no change during test). After test conclusion.

Figure 5.9. Test GP1092 Sequence May 31, 2002: Gravel simulant, pneumatic conveyance, air, no water, no head feed, TORE® oriented horizontally 2 in. above the simulant.

\subsubsection{GP1090 Observations}

No solids were mobilized or conveyed during this test.

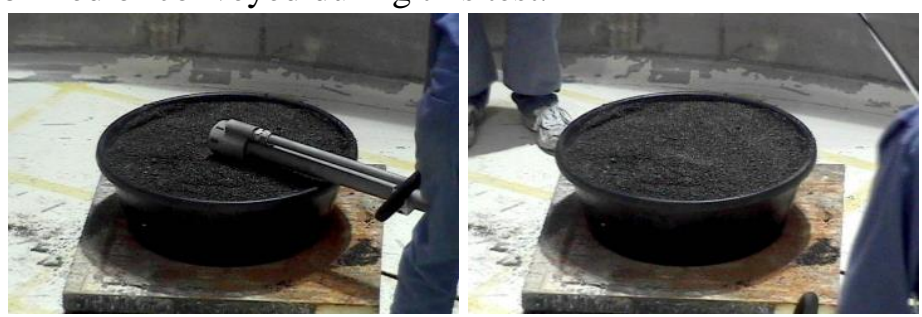

Prior to test start (no change during test). After test conclusion.

Figure 5.10. Test GP1090 Sequence May 31, 2002: Gravel simulant, pneumatic conveyance, air, no water, no head feed, TORE® oriented horizontally 0 in. above the simulant.

\subsubsection{GP109S Observations}

Solids were removed by enhanced suction almost instantaneously as the retrieval was initiated. The resulting hole was $\sim 5$ in. in diameter and $\sim 4$ in. deep.

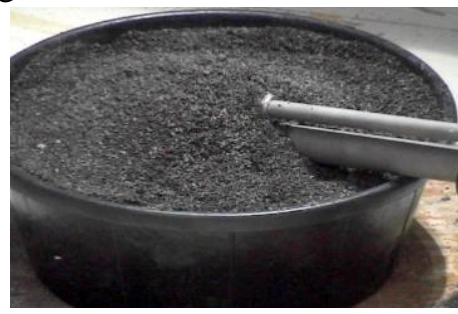

Prior to test start.
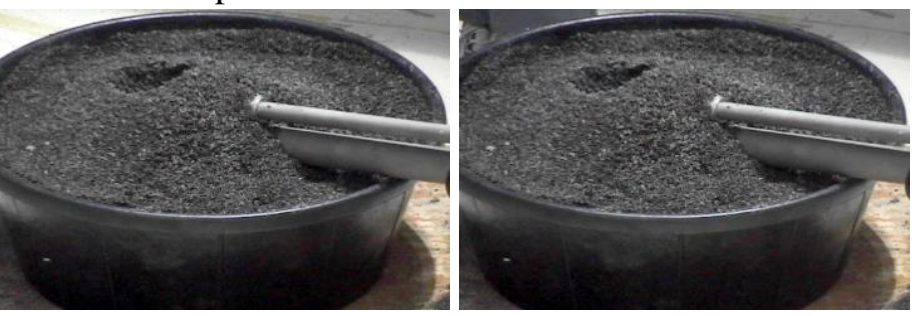

During TORE® Lance operation. After test conclusion.

Figure 5.11. Test GP109S Sequence May 31, 2002: Gravel simulant, pneumatic conveyance, air, no water, no head feed, TORE® oriented horizontally with the head submerged in the simulant. 


\subsubsection{TORE@ Lance Full Operation with Air Precessing Vortex Mobilization and Eduction-Enhanced Conveyance}

During these tests, first pneumatic conveyance was initiated. Then $\sim 100$ psig compressed air was started with the TORE® Lance flow control valve in the $0 \%$ bypass configuration. This ensured that a maximum amount of compressed air was routed through the TORE® Lance head.

\subsubsection{GP11V6 Observations}

No solids mobilizing or retrieval was observed.

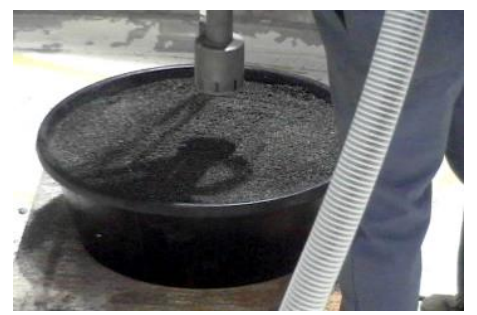

Prior to test start (no change during test).

Figure 5.12. Test GP11V6 Sequence May 31, 2002: Gravel simulant, pneumatic conveyance, air, no water, head feed, TORE® oriented vertically 6 in. above the simulant.

\subsubsection{GP11V2 Observations}

The force of air flow through the TORE® Lance head blew gravel from the container.
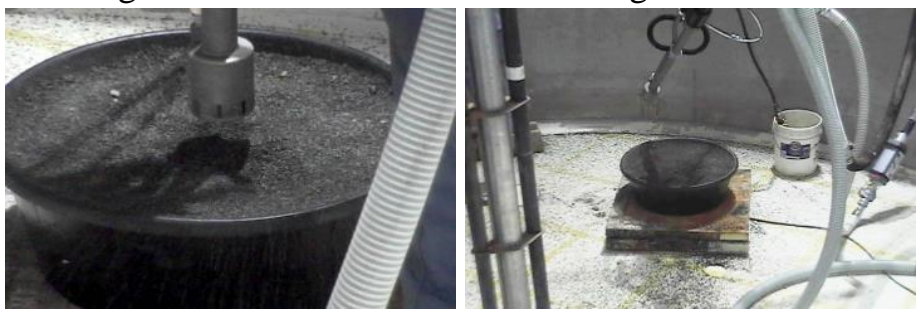

During TORE® Lance operation. After test conclusion.

Figure 5.13. Test GP11V0 Sequence May 31, 2002: Gravel simulant, pneumatic conveyance, air, no water, head feed, TORE® oriented vertically 2 in. above the simulant.

\subsubsection{GP11V0 Observations}

Significant solids were ejected from the container by the air flow through the TORE® Lance head. The resulting depression was $17 \mathrm{in}$. in diameter and dish shaped with an average depth of $3.5 \mathrm{in}$. and a maximum depth of $6.5 \mathrm{in}$. This maximum diameter approaches the $18 \mathrm{in}$. diameter predicted as the zone of influence based on obtaining six times the 3 -in. diameter discharge line. 


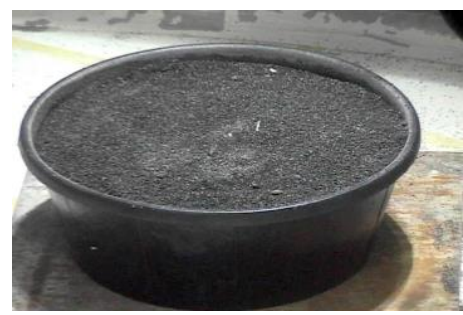

Prior to test start.
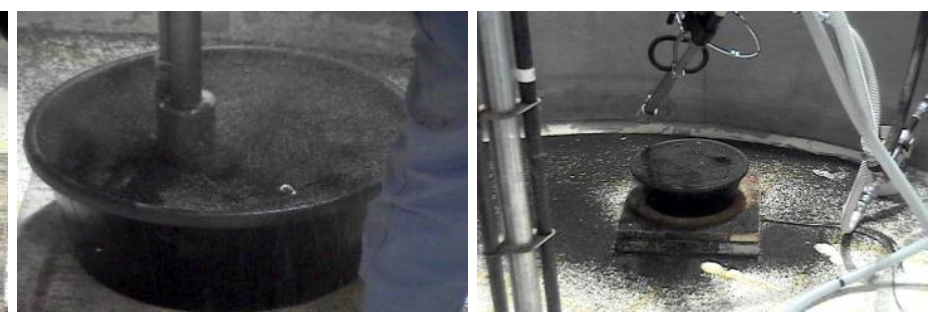

During TORE® Lance operation. After test conclusion.

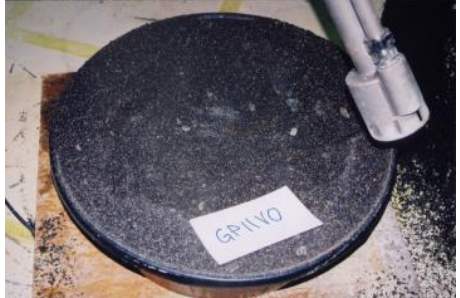

After test conclusion.

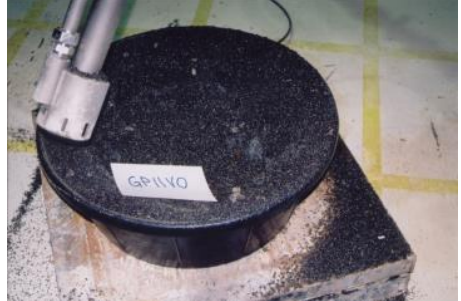

After test conclusion.

Figure 5.14. Test GP11V0 Sequence May 31, 2002: Gravel simulant, pneumatic conveyance, air, no water, head feed, TORE® oriented vertically 0 in. above the simulant.

\subsubsection{GP11VS Observations}

Significant solids mobilizing occurred during this test. The resulting depression was $\sim 7.5$ in. in diameter and $\sim 9.5 \mathrm{in}$. maximum depth. The photos also show that the maximum diameter of influence is also $\sim 18$ in.

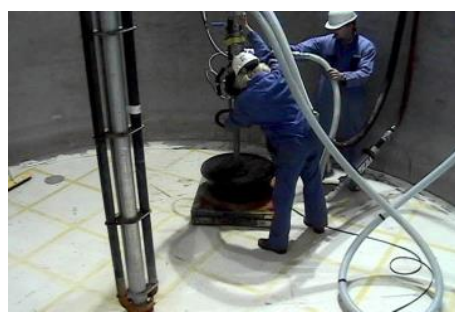

Prior to test start.

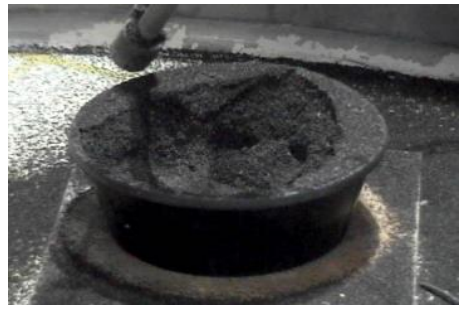

After test conclusion.

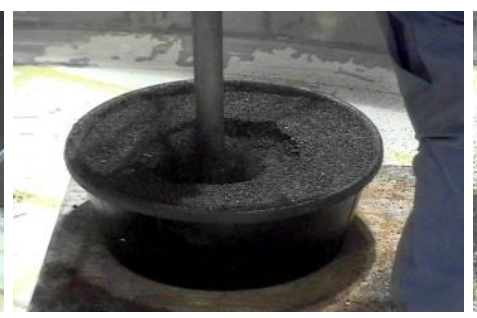

During TORE@ Lance operation.

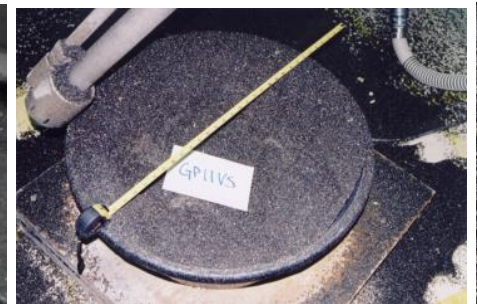

After test conclusion.

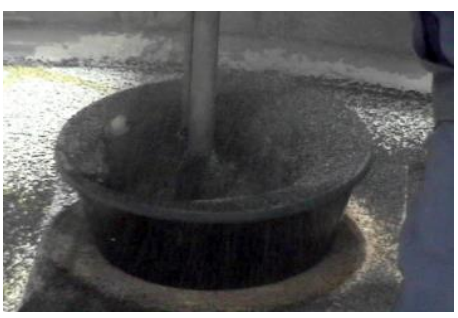

. During TORE® Lance operation.

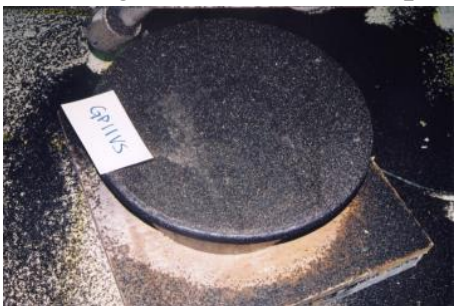

After test conclusion.

Figure 5.15. Test GP11VS Sequence May 31, 2002: Gravel simulant, pneumatic conveyance, air, no water, head feed, TORE® oriented vertically with head submerged in the simulant 


\subsubsection{GV11VSS Observations}

At the start of this test the TORE® Lance head was very close to the bottom of the container. The suction caused the container bottom to deform and restrict flow to the TORE® Lance retrieval line. The head was raised slightly and significant mobilizing and retrieval occurred.
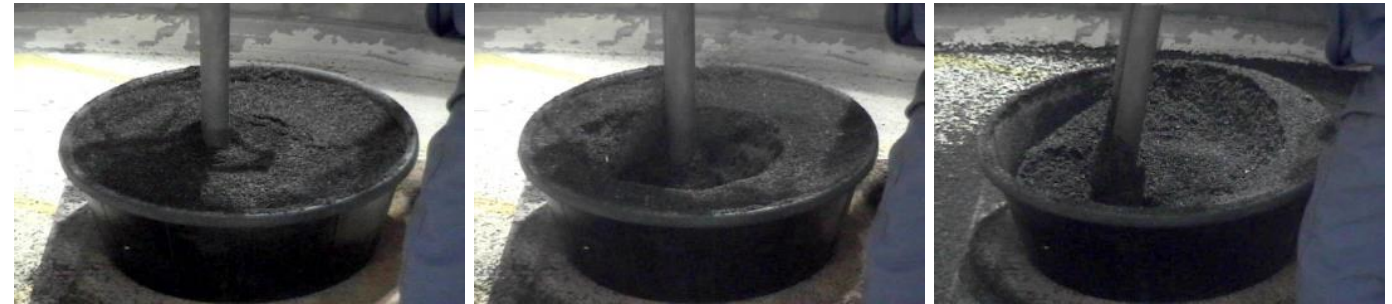

Prior to test start.

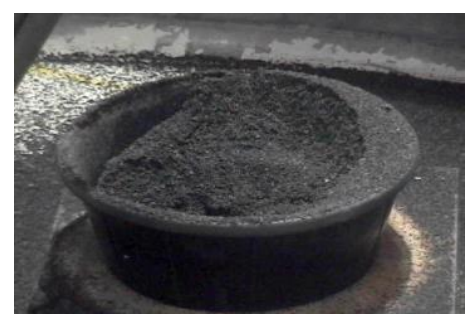

After test conclusion.
During TORE® Lance operation. During TORE® Lance operation.

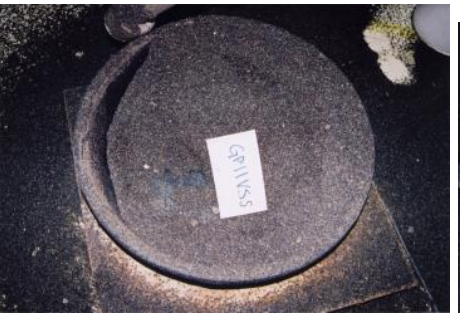

After test conclusion.

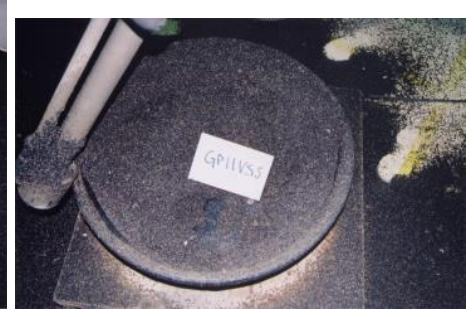

After test conclusion.

Figure 5.16. Test GP11VSS Sequence May 31, 2002: Gravel simulant, pneumatic conveyance, air, no water, head feed, TORE® oriented vertically with head submerged deeper into the simulant.

\subsubsection{GP119S Observations}

With the TORE® Lance head at $\sim 90$ degrees to the gravel a slit-shaped hole resulted immediately after start of operation. 

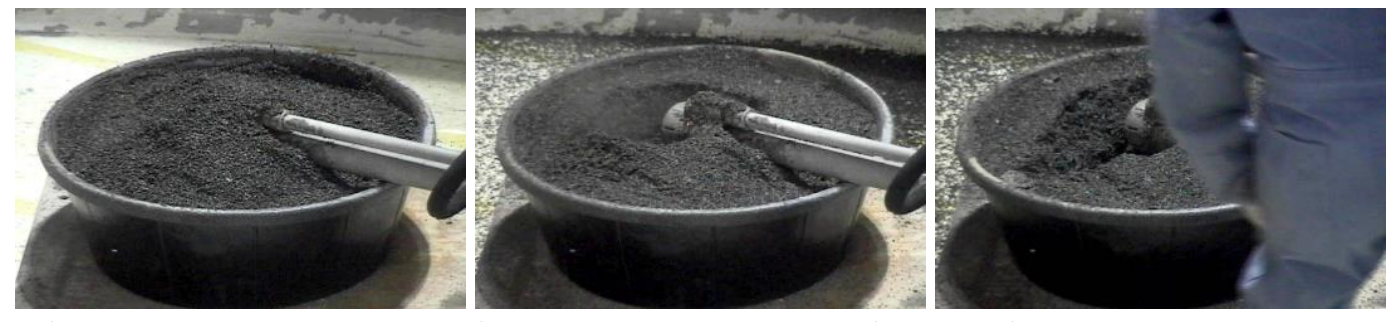

Prior to test start.

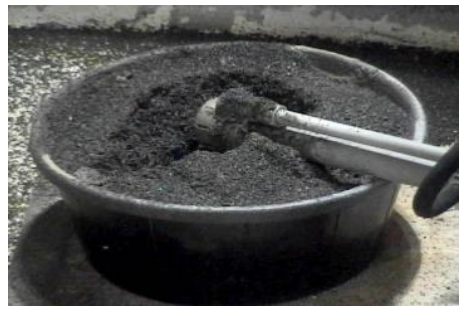

During TORE® Lance operation. After test conclusion.

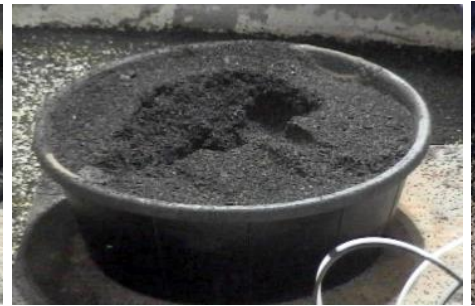

After test conclusion.

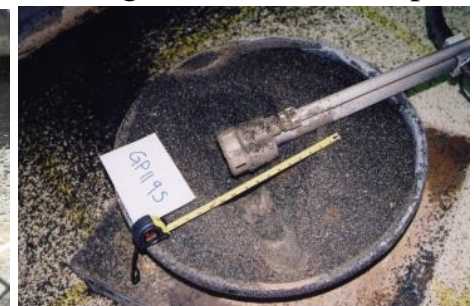

Figure 5.17. Test GP119S Sequence May 31, 2002: Gravel simulant, pneumatic conveyance, air, no water, head feed, TORE® oriented horizontally $\left(\right.$ at $\left.90^{\circ}\right)$ with the head submerged in the simulant.

\subsubsection{GP113S Observations}

Significant mobilizing occurred with the TORE® Lance head oriented at 30 and 60 degrees from the vertical. In both cases, oval holes were excavated with an average depth of $5 \mathrm{in}$. and a maximum depth of $9.5 \mathrm{in}$. The $30 \mathrm{deg}$ orientation oval was 17 in. $\mathrm{x} 14 \mathrm{in.}$
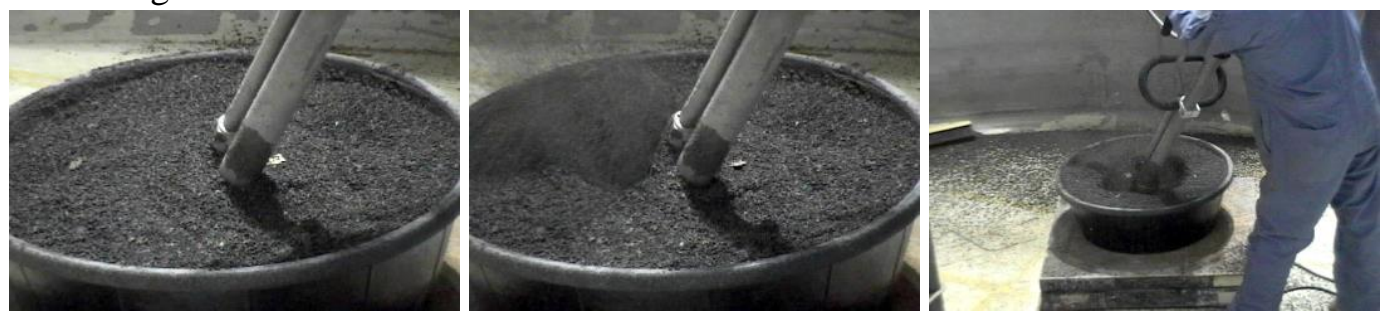

Prior to test start.

During TORE® Lance operation. During TORE® Lance operation.
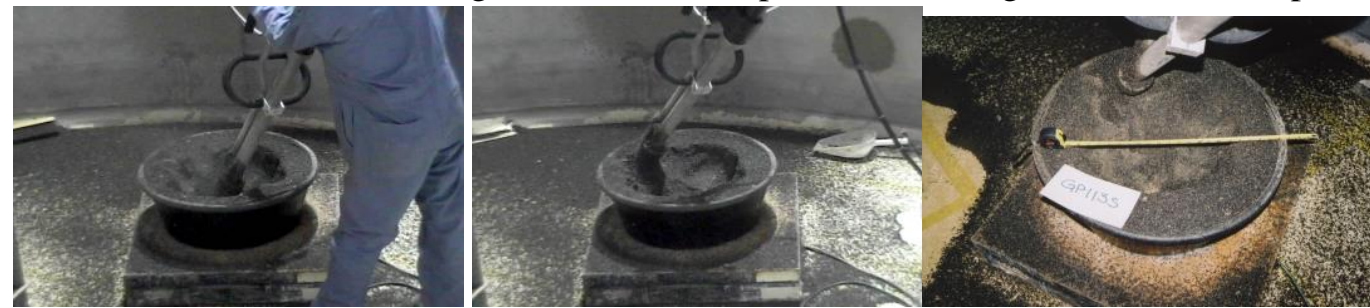

During TORE® Lance operation. After test conclusion. After test conclusion.

Figure 5.18. Test GP113S Sequence May 31, 2002: Gravel simulant, pneumatic conveyance, air, no water, head feed, TORE® oriented at $30^{\circ}$ with the head submerged in the simulant. 


\subsubsection{GP116S Observations}

Significant mobilizing occurred with the TORE® Lance head oriented at 30 and 60 degrees from the vertical. In both cases, oval holes were excavated with an average depth of $5 \mathrm{in}$. and a maximum depth of 9.5 in. The 60 deg orientation oval was 20 in. $x 14$ in.
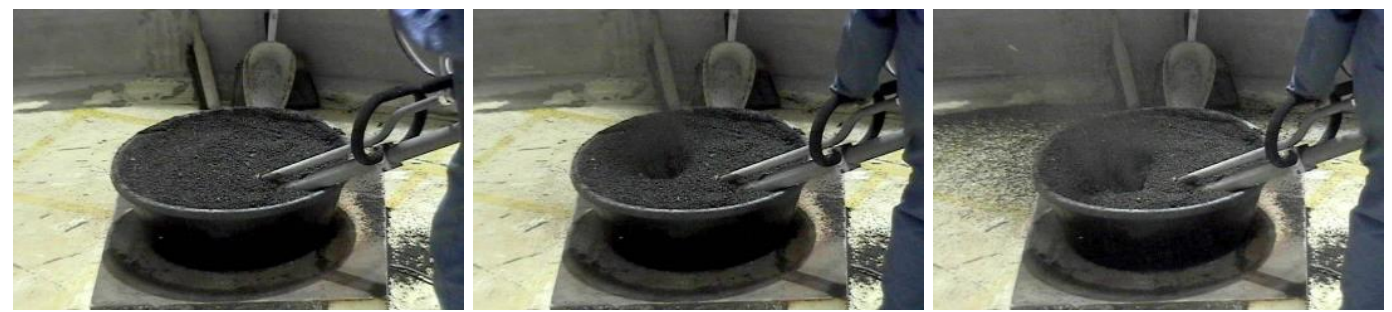

Prior to test start.

During TORE® Lance operation. During TORE® Lance operation.
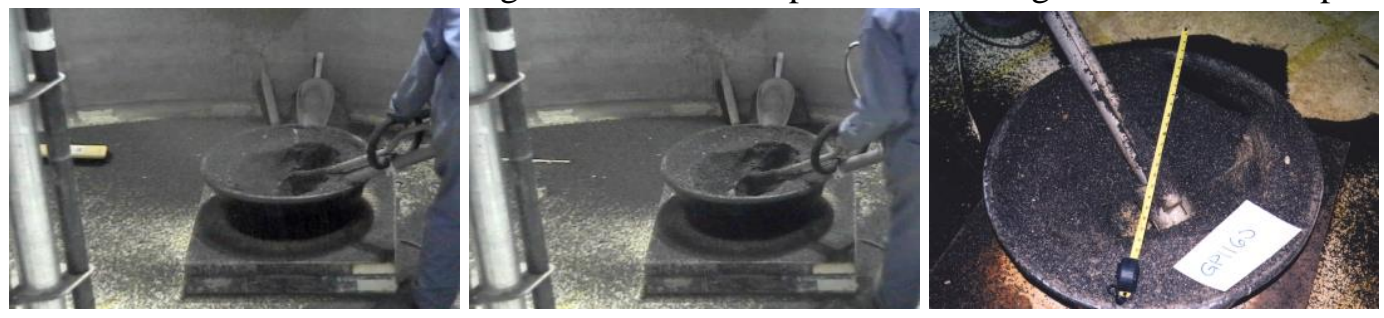

During TORE® Lance operation. After test conclusion.

After test conclusion.

Figure 5.19. Test GP116S Sequence May 31, 2002: Gravel simulant, pneumatic conveyance, air, no water, head feed, TORE® oriented at $60^{\circ}$ with the head submerged in the simulant.

\subsection{Gravel Test Results}

Data from the gravel tests are summarized in Table 5.2. As expected the best mobilization and retrieval was observed when the TORE® Lance was operated in the $0 \%$ bypass mode with all possible flow through the head. Retrieval with the TORE® Lance operated in the eductor mode (100\% bypass) was significantly better than operation with only pneumatic conveyance. This is to be expected. With the pneumatic conveyance the available pressure drop for transport is $\sim 0.5 \mathrm{~atm}$. Addition of $\sim 100 \mathrm{psig}$ compressed air increases the available inlet pressure at the TORE® Lance to $\sim 48$ psig with the TORE® Lance in the $100 \%$ bypass mode and $~ 35$ psig with the TORE® Lance in the $0 \%$ bypass mode. This additional available pressure significantly enhances TORE® Lance retrieval over pneumatic conveyance.

With the TORE® Lance operated either submerged in or in contact with the gravel, an $\sim 18$ in. zone of influence from the air emanating from the head was observed. This zone of influence for the precessing vortex agrees with that predicted by Parkinson and Delves (1999). 
Table 5.2. Results of TORE® Lance retrieval of gravel using compressed air enhanced mobilizing and conveyance.

\begin{tabular}{|c|c|c|c|c|c|c|c|c|}
\hline \begin{tabular}{|c|} 
Test \\
Number
\end{tabular} & Data Interval & $\begin{array}{c}\text { Simulant Mobilized } \\
\text { (LRB) }\end{array}$ & \begin{tabular}{|c|} 
Simulant \\
Mobilized
\end{tabular} & $\begin{array}{c}\text { Simulant Addition } \\
\text { to Hopper }\end{array}$ & $\begin{array}{c}\text { Air Flow through } \\
\text { Conveyance Line Avg }\end{array}$ & $\begin{array}{c}\text { TORE@ Head } \\
\text { Feed Pressure } \\
\text { Avg }\end{array}$ & $\begin{array}{l}\text { TORE® Supply } \\
\text { Pressure Avg }\end{array}$ & $\begin{array}{c}\text { Pitot Probe } \Delta \mathbf{P} \\
\text { Avg }\end{array}$ \\
\hline & & Ibm & Ibm & Ibm & scfm & psi & psi & psi \\
\hline GP00V6 & $13: 55: 01$ to $13: 55: 51$ & 0 & 0 & 1 & 191 & 0.0 & 0.0 & 0.8 \\
\hline GP00V2 & $13: 56: 51$ to $13: 57: 31$ & 0 & 0 & 2 & 194 & 0.0 & 0.0 & 0.8 \\
\hline GP00V0 & $13: 58: 31$ to $13: 59: 31$ & 3 & 2 & 0 & 186 & 0.0 & 0.0 & 0.8 \\
\hline GP00VS & 14:04:21 to $14: 06: 01$ & 11 & 10 & 6 & 176 & 0.0 & 0.0 & 0.7 \\
\hline GP0090 & $14: 12: 31$ to $14: 13: 11$ & 0 & 20 & -1 & 210 & 0.0 & 0.0 & 1.0 \\
\hline GP009S & 14:16:01 to $14: 16: 41$ & 2 & 0 & 3 & 186 & 0.0 & 0.0 & 0.8 \\
\hline GP10V6 & $14: 26: 02$ to $14: 30: 12$ & 0 & 0 & 5 & 426 & 0.0 & 49.4 & 4.5 \\
\hline GP10V2 & $14: 29: 32$ to $14: 29: 52$ & 0 & 0 & 2 & 480 & 0.0 & 48.3 & 4.4 \\
\hline GP10V0 & $14: 32: 32$ to $14: 33: 02$ & 2 & 2 & 2 & 330 & 0.0 & 47.6 & 2.5 \\
\hline GP10VS & $14: 36: 22$ to $14: 36: 52$ & 7 & 9 & 5 & 411 & 0.0 & 47.5 & 3.4 \\
\hline GP1092 & $14: 41: 02$ to $14: 41: 32$ & 0 & 0 & -5 & 412 & 0.0 & 47.5 & 3.6 \\
\hline GP1090 & $14: 42: 52$ to $14: 43: 02$ & 0 & 4 & 3 & 481 & 0.0 & 47.3 & 4.4 \\
\hline GP109S & $14: 45: 32$ to $14: 45: 52$ & 2 & 1 & 1 & 460 & 0.0 & 39.6 & 4.1 \\
\hline GP11V6 & $14: 54: 22$ to $14: 54: 32$ & 0 & 2 & 2 & 438 & 15.9 & 35.8 & 3.7 \\
\hline GP11V2 & $14: 55: 42$ to $14: 56: 02$ & $\begin{array}{l}\text { 8=before sweep }{ }^{\text {a) }} \\
0=\text { after sweep }^{\text {b) }}\end{array}$ & 5 & 2 & 434 & 16.3 & 36.9 & 3.7 \\
\hline GP11V0 & $15: 04: 32$ to $15: 04: 52$ & $\begin{array}{c}35=\text { before sweep } \\
6=\text { after sweep }\end{array}$ & 29 & 0 & 420 & 16.0 & 36.3 & 3.4 \\
\hline GP11VS & $15: 13: 52$ to $15: 14: 32$ & $\begin{array}{c}45=\text { before sweep } \\
\text { ?=after sweep }\end{array}$ & 43 & 12 & 352 & 15.4 & 32.9 & 2.6 \\
\hline $\begin{array}{l}\text { GP11VS } \\
S\end{array}$ & $15: 26: 52$ to $15: 28: 12$ & $\begin{array}{c}67=\text { before sweep } \\
27=\text { after sweep }\end{array}$ & 56 & 19 & 383 & 15.4 & 35.4 & 2.9 \\
\hline GP119S & $15: 47: 47$ to $15: 48: 17$ & $\begin{array}{c}\text { 31=before sweep } \\
\text { 4=after sweep }\end{array}$ & 32 & 7 & 404 & 16.2 & 36.9 & 3.2 \\
\hline GP113S & $16: 00: 57$ to $16: 01: 07$ & $\begin{array}{c}29=\text { before sweep } \\
7=\text { after sweep }\end{array}$ & 14 & 4 & 387 & 15.3 & 35.5 & 2.9 \\
\hline GP116S & 16:08:07 to $16: 08: 37$ & $\begin{array}{c}51=\text { before sweep } \\
10=\text { =after sweep }\end{array}$ & 68 & 3 & 342 & 16.4 & 37.4 & 2.4 \\
\hline a) & \multicolumn{8}{|c|}{$\begin{array}{l}\text { Before sweep refers to the actual weight of the simulant container at the end of the test. This shows the amount of solids that were removed from the container. The } \\
\text { solids were either retrieved through the pneumatic conveyance line or dislodged from the container and scattered on the tank floor. } \\
\text { After sweep refers to the weight of the simulant container after solids scattered on the floor were swept up and returned to the container. This weight is more indicative } \\
\text { of the amount of solids that were retrieved from the container. }\end{array}$} \\
\hline
\end{tabular}





\subsection{TORE® Lance Mobilization and Retrieval of Sand}

After preliminary tests to determine the TORE® Lance ability to mobilize and retrieve gravel, tests with the sand were conducted. The sand is a finer grade of gravel, just sieved to provide a smaller mean particle size. These tests were also conducted using air as the mobilizing and retrieval fluid.

\subsection{Sand Test Matrix}

A similar series of tests conducted with gravel were repeated using sand. To identify each test a unique 6-digit test number was developed. The components of this number were defined in Section 4.5. The sand tests were conducted in three parts; each part was selected with the specific goal to evaluate separate facets of the TORE® Lance system.

- $\quad$ To evaluate transport of solids through the TORE® Lance assembly to the conveyance hopper using only compressed air introduced at the TORE® Lance inlet with no head feed or pneumatic conveyance. This test provides a baseline to define mobilizing and retrieval that could be accomplished with only the TORE® Lance eductor with no enhancement from either the precessing vortex or pneumatic conveyance.

- $\quad$ To evaluate the transport of solids through the TORE® Lance assembly to the conveyance hopper using compressed air through the TORE® Lance head to mobilize the solids and through the TORE® Lance assembly with no pneumatic conveyance. This test evaluates whether the eductor and precessing vortex, without pneumatic conveyance, could retrieve solids and transport them to the pneumatic conveyance hopper.

- $\quad$ To evaluate the transport of solids through the TORE® Lance assembly to the conveyance hopper using compressed air through the TORE® Lance head to mobilize the solids and through the TORE@ Lance assembly to enhance the pneumatic conveyance. These tests evaluate the full performance of the TORE® Lance using the precessing vortex to mobilize the sand and the eduction to enhance retrieval.

The test matrix is listed in Table 6.1.

Table 6.1 Test matrix for evaluation of TORE® Lance mobilizing and retrieval of sand.

\begin{tabular}{|l|l|l|l|l|l|l|}
\hline $\begin{array}{l}\text { Test } \\
\text { Number }\end{array}$ & $\begin{array}{l}\text { Simu- } \\
\text { lant }\end{array}$ & Conveying Fluid & $\begin{array}{l}\text { Mobil } \\
\text { izing } \\
\text { Fluid }\end{array}$ & $\begin{array}{l}\text { Head } \\
\text { Feed }\end{array}$ & Orientation & $\begin{array}{l}\text { Stand-off } \\
\text { Distance }\end{array}$ \\
\hline Objective & \multicolumn{1}{|l|}{$\begin{array}{l}\text { To evaluate the transport of solids through the TORE® Lance assembly to the conveyance } \\
\text { hopper using only compressed air introduced at the TORE® Lance inlet with no head feed or } \\
\text { pneumatic conveyance }\end{array}$} \\
\hline SZ10V6 & Sand & Air: no conveyance & Air & None & Vertical & 6 in. \\
\hline SZ10V2 & Sand & Air: no conveyance & Air & None & Vertical & 2 in. \\
\hline SZ10V2 & Sand & Air: no conveyance & Air & None & Vertical & 2 in. \\
\hline SZ10V0 & Sand & Air: no conveyance & Air & None & Vertical & 0 in. \\
\hline SZ10VS & Sand & Air: no conveyance & Air & None & Vertical & Submerged 6 in. \\
\hline SZ1092 & Sand & Air: no conveyance & Air & None & Horizontal & 2 in. \\
\hline
\end{tabular}




\begin{tabular}{|c|c|c|c|c|c|c|}
\hline SZ0090 & Sand & Air: no conveyance & Air & None & Horizontal & 0 in. \\
\hline SZ009S & Sand & Air: no conveyance & Air & None & Horizontal & Submerged 6 in. \\
\hline Objective & \multicolumn{6}{|c|}{$\begin{array}{l}\text { To evaluate the transport of solids through the TORE® Lance assembly to the conveyance } \\
\text { hopper using compressed air through the TORE® Lance head to mobilize the solids and } \\
\text { through the TORE® Lance assembly with no pneumatic conveyance. }\end{array}$} \\
\hline SZ11V6 & Sand & Air: no conveyance & Air & Air & Vertical & 6 in. \\
\hline SZ11V2 & Sand & Air: no conveyance & Air & Air & Vertical & 2 in. \\
\hline SZ11V0 & Sand & Air: no conveyance & Air & Air & Vertical & 0 in. \\
\hline SZ11VS & Sand & Air: no conveyance & Air & Air & Vertical & Submerged 6 in. \\
\hline SZ1196 & Sand & Air: no conveyance & Air & Air & Horizontal & 6 in. \\
\hline SZ1192 & Sand & Air: no conveyance & Air & Air & Horizontal & 2 in. \\
\hline SZ1190 & Sand & Air: no conveyance & Air & Air & Horizontal & 0 in. \\
\hline SZ119S & Sand & Air: no conveyance & Air & Air & Horizontal & Submerged 6 in. \\
\hline Objective & \multicolumn{6}{|c|}{$\begin{array}{l}\text { To evaluate the transport of solids through the TORE® Lance assembly to the conveyance } \\
\text { hopper using compressed air through the TORE® Lance head to mobilize the solids and } \\
\text { through the TORE® Lance assembly to enhance the pneumatic conveyance }\end{array}$} \\
\hline SP11V6 & Sand & Air: pneumatic conveyance & Air & Air & Vertical & 6 in. \\
\hline SP11V2 & Sand & Air: pneumatic conveyance & Air & Air & Vertical & 2 in. \\
\hline SP11V0 & Sand & Air: pneumatic conveyance & Air & Air & Vertical & 0 in. \\
\hline SP11VS & Sand & Air: pneumatic conveyance & Air & Air & Vertical & Submerged 6 in. \\
\hline SP11VSS & Sand & Air: pneumatic conveyance & Air & Air & Vertical & $\begin{array}{l}\text { Submerged >6 } \\
\text { in. }\end{array}$ \\
\hline SP1196 & Sand & Air: pneumatic conveyance & Air & Air & Horizontal & 6 in. \\
\hline SP1192 & Sand & Air: pneumatic conveyance & Air & Air & Horizontal & 2 in. \\
\hline SP1190 & Sand & Air: pneumatic conveyance & Air & Air & Horizontal & 0 in. \\
\hline SP119S & Sand & Air: pneumatic conveyance & Air & Air & Horizontal & Submerged 6 in. \\
\hline SP113S & Sand & Air: pneumatic conveyance & Air & Air & $\begin{array}{l}\text { Inclined } 30 \\
\text { degrees from } \\
\text { vertical }\end{array}$ & Submerged 6 in \\
\hline SP116S & Sand & Air: pneumatic conveyance & Air & Air & $\begin{array}{l}\text { Inclined } 60 \\
\text { degrees from } \\
\text { vertical }\end{array}$ & Submerged 6 in \\
\hline
\end{tabular}

\subsection{Sand Test Observations}

\subsubsection{TORE® Lance Operation with No Head Feed or Blower Induced Pneumatic Conveyance}

The purpose of these tests is to provide a baseline to define dislodging and retrieval that could be accomplished with only the TORE® Lance hardware using the eductor with no enhancement from either the precessing vortex or pneumatic conveyance. 


\subsubsection{SZ10V6 Observations}

No solids were mobilized or conveyed during this test.
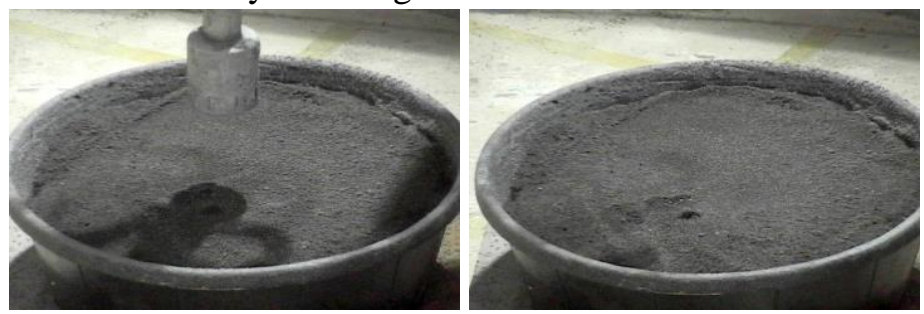

Prior to test start (no change during test). After test completion.

Figure 6.1. Test SZ10V6 Sequence June 3, 2002: Sand simulant, no pneumatic conveyance, air, no water, no head feed, TORE® oriented vertically 6 in. above the simulant.

\subsubsection{SZ10V2 Observations}

During this test, a check on the TORE® Lance air flow revealed an unexplained drop. The unit was disassembled and solids, $\sim 38 \mathrm{~g}$ of gravel and sand were removed from the area outside the ceramic casing. It is speculated that the solids were sucked into this area while pneumatic conveyance was operating and the compressed air was off. After removal, the flow rate through the unit returned to the expected value. Note, this was the only occurrence of solids accumulation in this area.
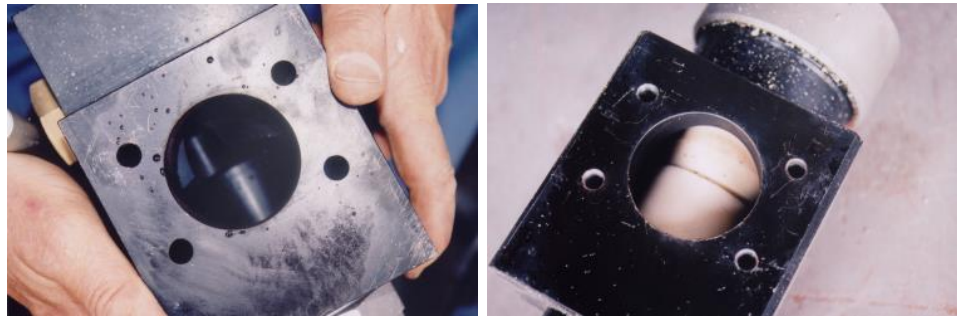

Inside of TORE® Lance control manifold.

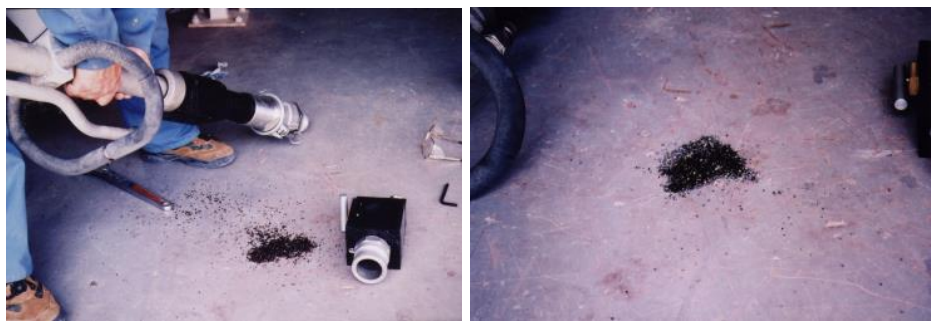

Solids removed from inside manifold

Figure 6.2. Disassembly and removal of solids from the TORE® Lance manifold. 
The test was repeated and again no solids were mobilized or conveyed during this test.
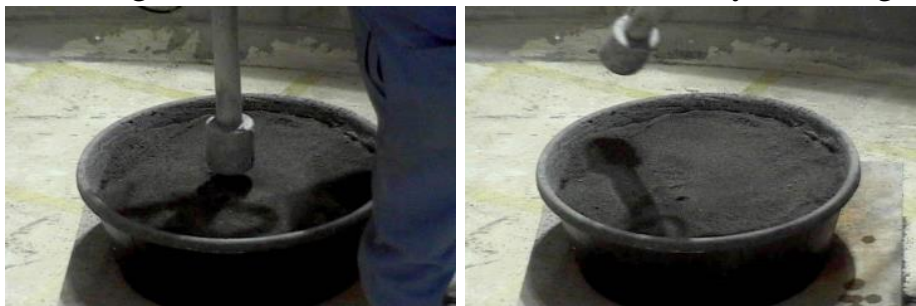

During TORE® Lance operation (no change during test). After test completion.

Figure 6.3. Test SZ10V2 Sequence June 3, 2002: Sand simulant, no pneumatic conveyance, air, no water, no head feed, TORE® oriented vertically 2 in. above the simulant.

\subsubsection{SZ10V0 Observations}

With only eductor conveyance solids were removed to create a dish-shaped impression $\sim 6$ in. wide $\mathrm{x}$ 2 in. deep.
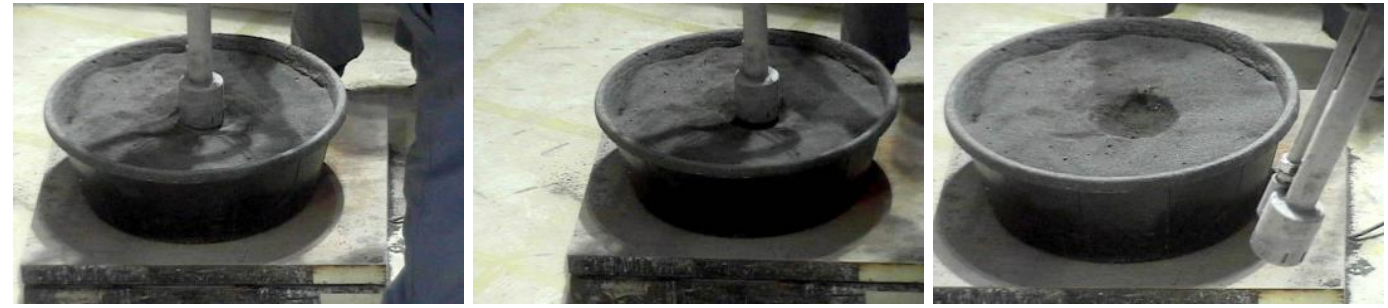

Prior to test start.

During TORE® Lance operation. After test conclusion.

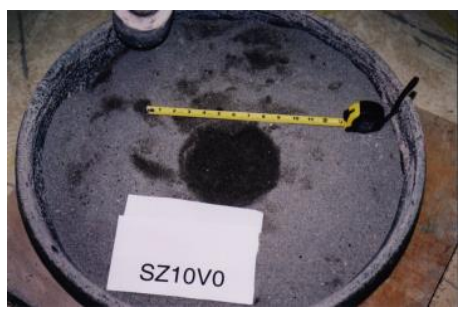

After test conclusion.

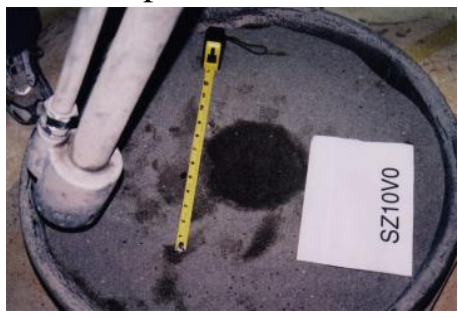

After test conclusion.

Figure 6.4. Test SZ10V0 Sequence June 3, 2002: Sand simulant, no pneumatic conveyance, air, no water, no head feed, TORE® oriented vertically 0 in. above the simulant.

\subsubsection{SZ10VS Observations}

The TORE® Lance head was buried in gravel prior to test start. During operation eduction excavated a cylindrical hole $\sim 6.5$ in. in diameter and 6.5 in. deep. 

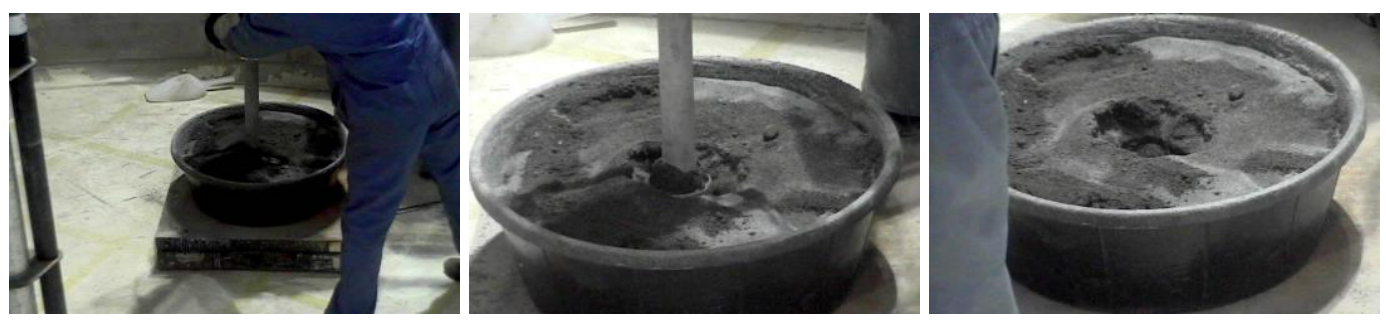

Prior to test start.

During TORE® Lance operation. After test completion.

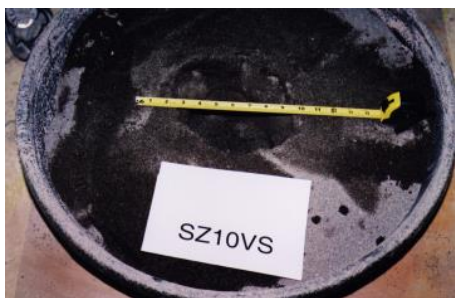

After test completion.

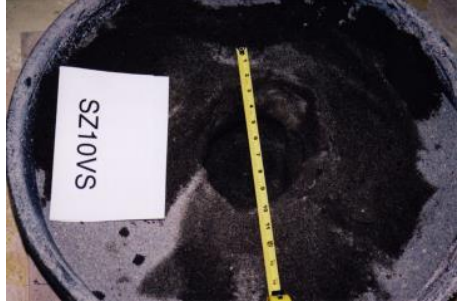

After test completion.

Figure 6.5. Test SZ10VS Sequence June 3, 2002: Sand simulant, no pneumatic conveyance, air, no water, no head feed, TORE® oriented vertically with head submerged in the simulant.

\subsubsection{SZ1092 Observations}

No solids were mobilized or conveyed during this test.
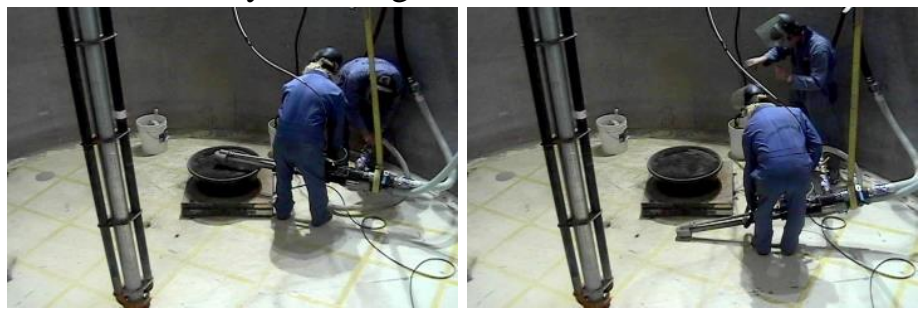

Prior to test start (no change during test). After test conclusion.

Figure 6.6. Test SZ1092 Sequence June 3, 2002: Sand simulant, no pneumatic conveyance, air, no water, no head feed, TORE® oriented horizontally (at $\left.90^{\circ}\right) 2$ in. above the simulant.

\subsubsection{SZ1090 Observations}

No solids were mobilized or conveyed during this test. 


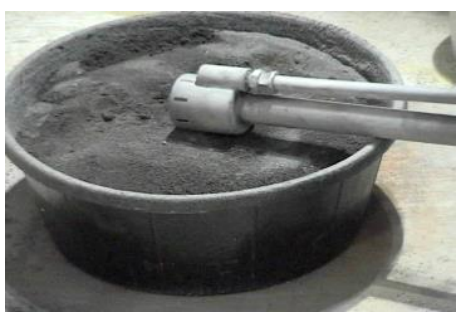

Prior to test start.

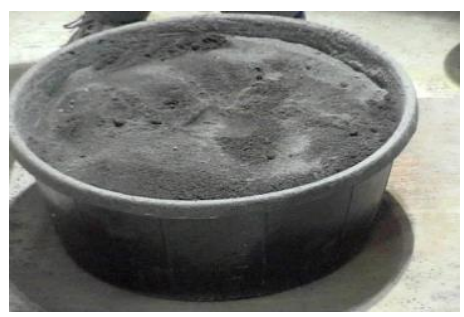

After test conclusion.

Figure 6.7. Test SZ1090 Sequence June 3, 2002: Sand simulant, pneumatic conveyance, air, no water, no head feed, TORE® oriented horizontally $\left(\right.$ at $\left.90^{\circ}\right) 0$ in. above the simulant.

\subsubsection{SZ109S Observations}

Eduction removed some solids surrounding the TORE® Lance inlet. The void is visible in the first three figures.
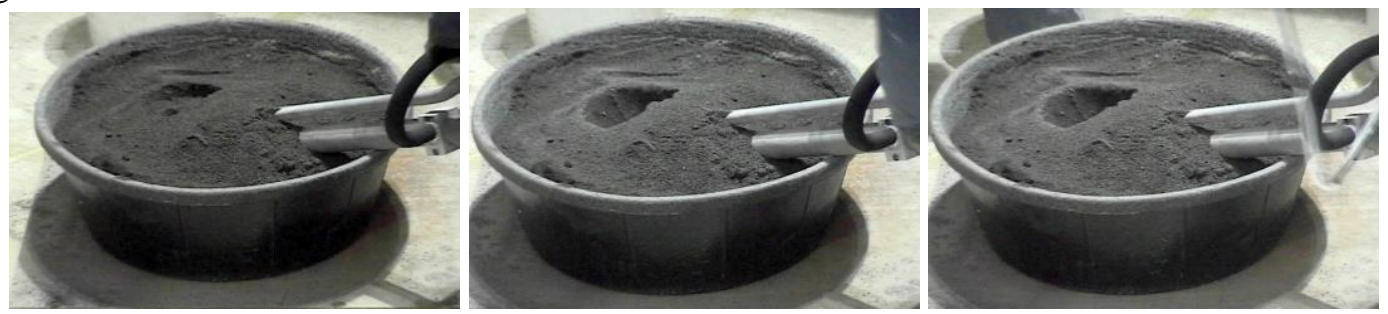

During TORE® Lance operation. During TORE® Lance operation. After test conclusion.

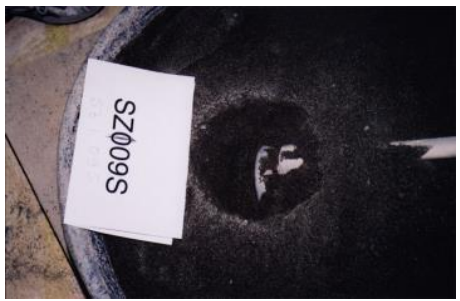

After test conclusion.

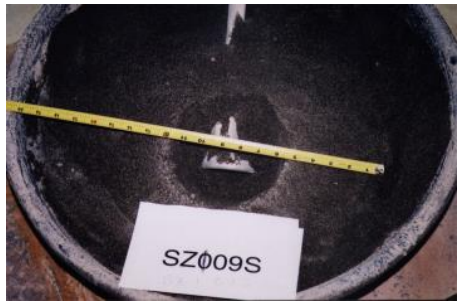

After test conclusion.

Figure 6.8. Test SZ109S Sequence June 3, 2002: Sand simulant, no pneumatic conveyance, air, no water, no head feed, TORE® oriented horizontally (at $90^{\circ}$ ) with head submerged in the simulant.

\subsubsection{TORE® Lance Operation with Head Feed but No Pneumatic Conveyance}

The purpose of these tests is to evaluate whether the eductor and precessing vortex, without pneumatic conveyance, could retrieve solids and transport them to the pneumatic conveyance hopper.

\subsubsection{SZ11V6 Observations}

The precessing vortex above the sand container did displace some solids from the container. 


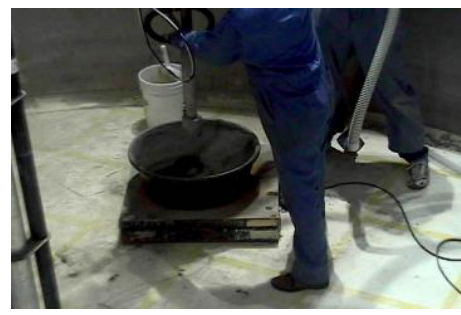

Prior to test start.

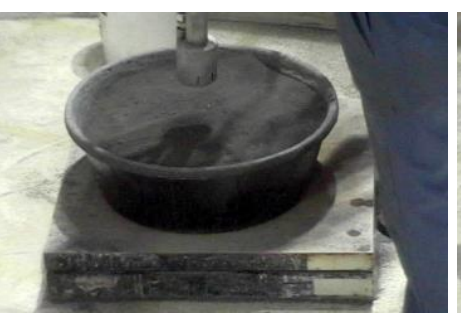

During TORE® Lance operation. After test completion.

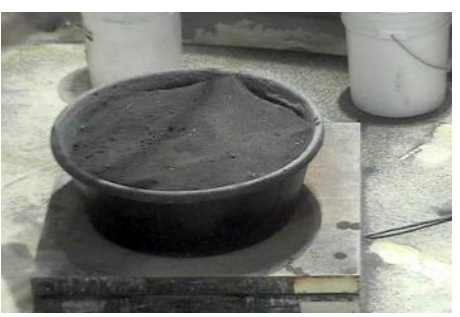

Figure 6.9. Test SZ11V6 Sequence June 3, 2002: Sand simulant, no pneumatic conveyance, air, no water, head feed, TORE® oriented vertically 6 in. above the simulant.

\subsubsection{SZ11V2 Observations}

A significant amount of solids were blown out of the container by the flow through the TORE® Lance head.
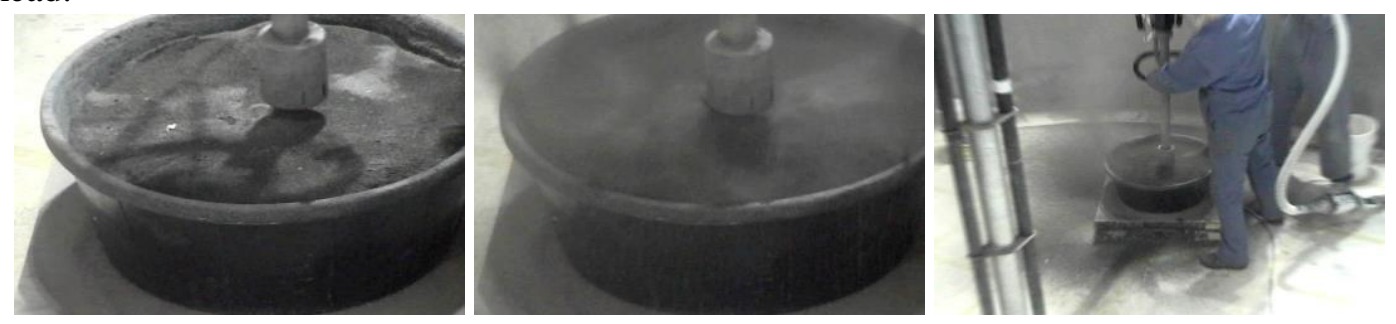

Prior to test start.

During TORE® Lance operation. During TORE® Lance operation.

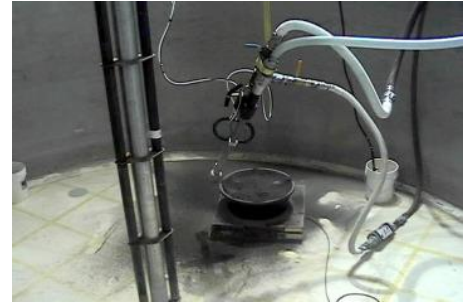

After test completion.

Figure 6.10. Test SZ11V2 Sequence June 3, 2002: Sand simulant, no pneumatic conveyance, air, no water, head feed, TORE® oriented vertically 2 in. above the simulant.

\subsubsection{SZ11V0 Observations}

With the TORE® Lance head touching the sand, solids were mobilized in a scalloped pattern corresponding to the locations of the slots in the head. 

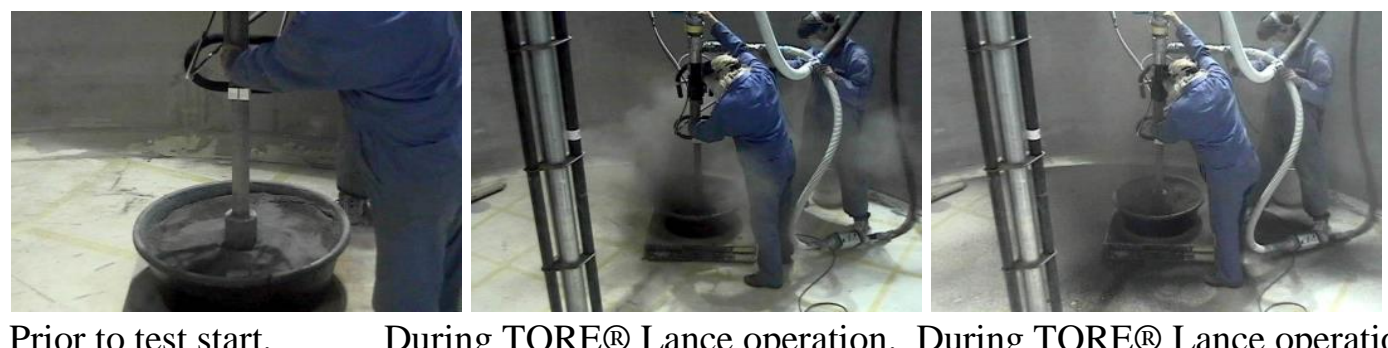

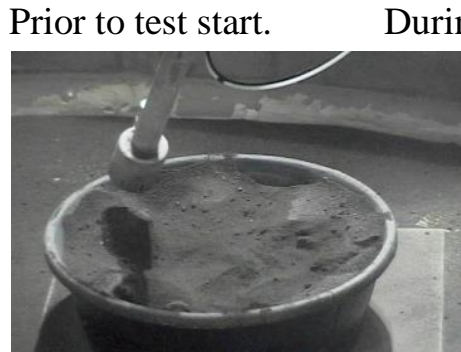

After test completion.

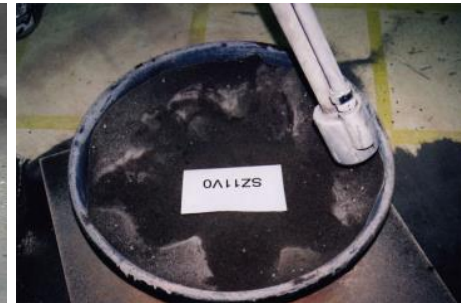

After test completion.

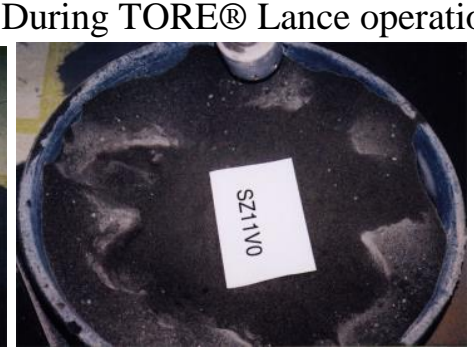

After test completion.

Figure 6.11. Test SZ11V0 Sequence June 3, 2002: Sand simulant, no pneumatic conveyance, air, no water, head feed, TORE® oriented vertically 0 in. above the simulant.

\subsubsection{SZ11VS Observations}

This test was conducted with the TORE® Lance head buried in the sand. Operation produced a 19 in. diameter hole and exposed the bottom of the container. Some sand slumped to the bottom of the container after the TORE® Lance was removed. The container maximum diameter is 24 in.; the minimum diameter is $19.5 \mathrm{in}$. and the depth is $9.5 \mathrm{in}$. This maximum diameter is greater than the $18 \mathrm{in}$. diameter predicted as the zone of influence based on obtaining six times the 3-in. diameter discharge line.
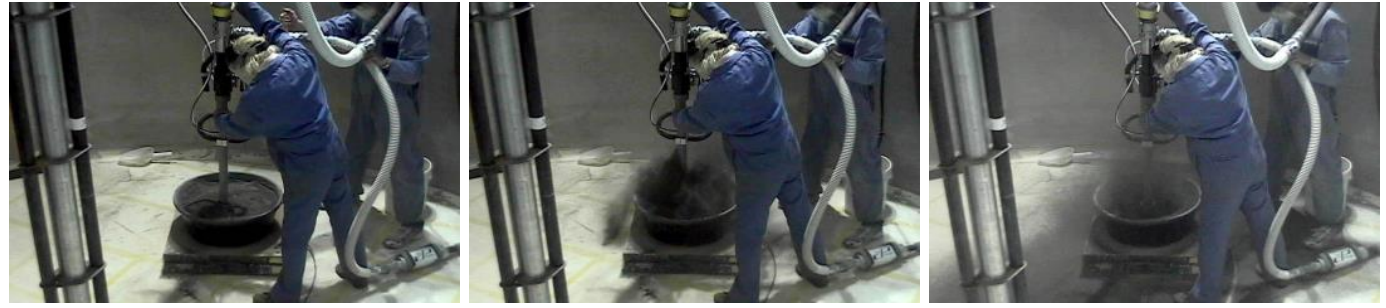

Prior to test start

During TORE® Lance operation. During TORE® Lance operation.
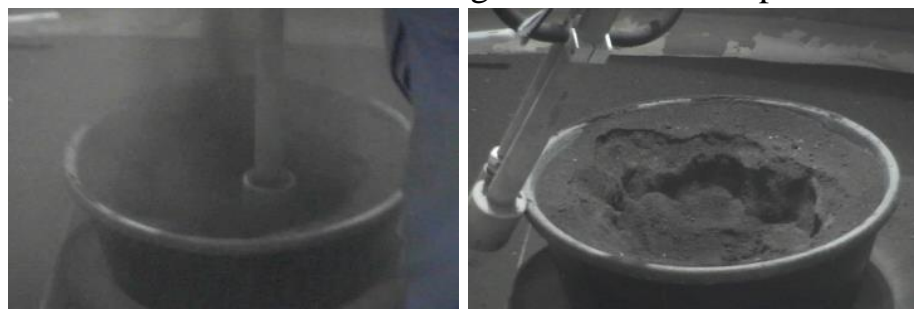

During TORE® Lance operation. After test conclusion.

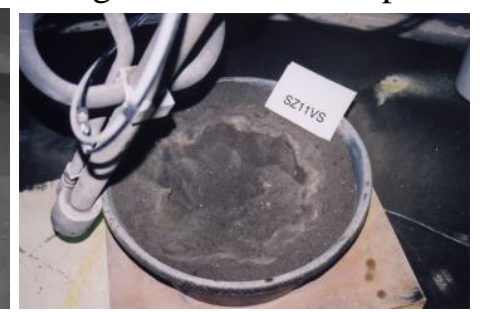

After test conclusion.

Figure 6.12. Test SZ11VS Sequence June 3, 2002: Sand simulant, no pneumatic conveyance, air, no water, head feed, TORE® oriented vertically submerged deeper into the simulant. 


\subsubsection{SZ1196 Observations}

During this test with the TORE® Lance oriented horizontally at $\sim 6$ in. above the sand, significant solids were displaced by the air flow through the head.

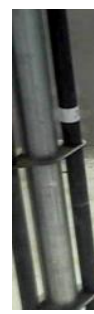

Prior to test start.

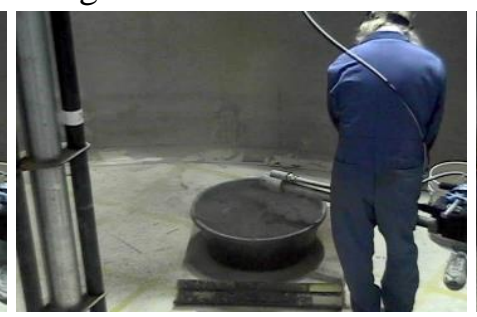

During TORE® Lance operation. During TORE® Lance operation

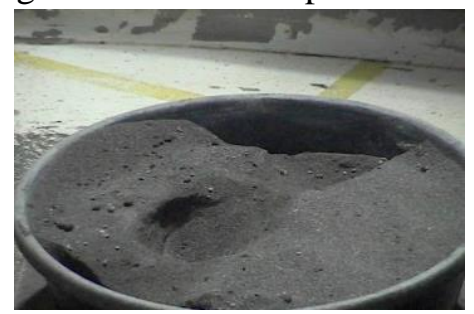

After test completion.

Figure 6.13. Test SZ1196 Sequence June 3, 2002: Sand simulant, no pneumatic conveyance, air, no water, head feed, TORE® oriented horizontally (at $\left.90^{\circ}\right)$ with head 6 in. above the simulant.

\subsubsection{SZ1192 Observations}

With the TORE® Lance head 2 in. above the simulant, the jets from slots projecting toward the solids excavated large holes in the path of the air flow and excavated one side of the container.
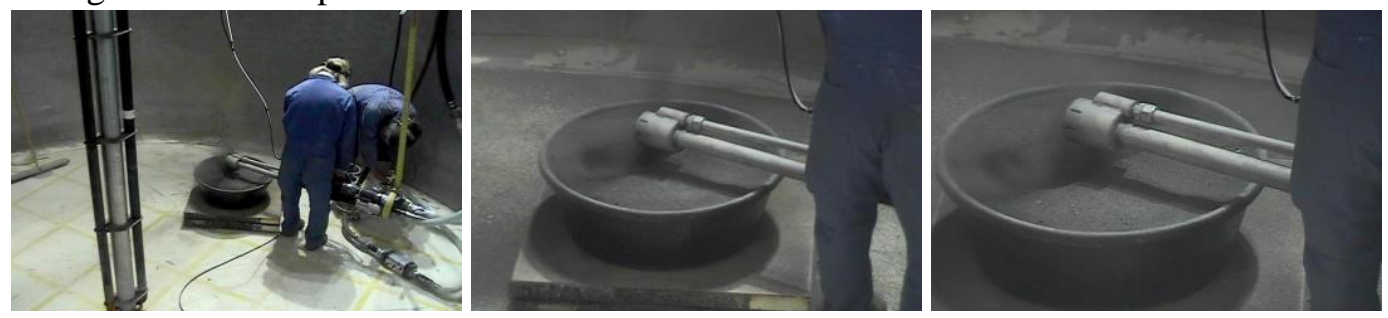

During TORE® Lance operation. During TORE® Lance operation. During TORE® Lance operation

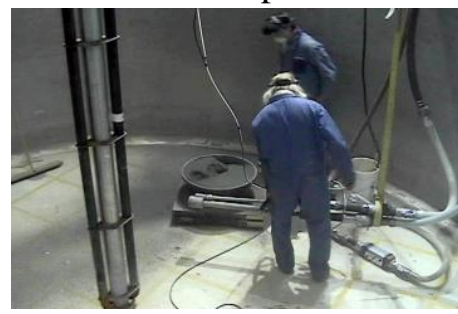

After test completion.

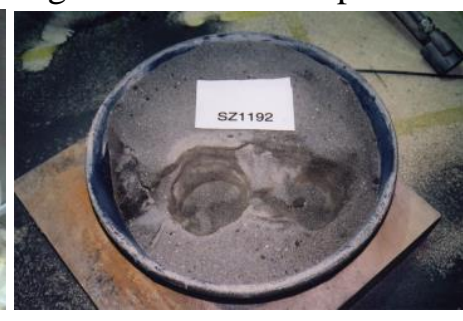

After test completion.

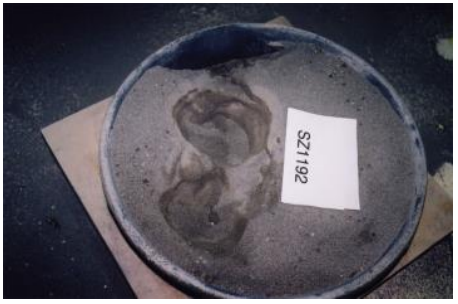

After test completion.

Figure 6.14. Test SZ1192 Sequence June 3, 2002: Sand simulant, no pneumatic conveyance, air, no water, head feed, TORE® oriented horizontally $\left(\right.$ at $90^{\circ}$ ) with head 2 in. above the simulant. 


\subsubsection{SZ1190 Observations}

With no stand-off distance the TORE® Lance head flow was able to excavate additional material. The view of the room shows the solids dispersed to the floor.
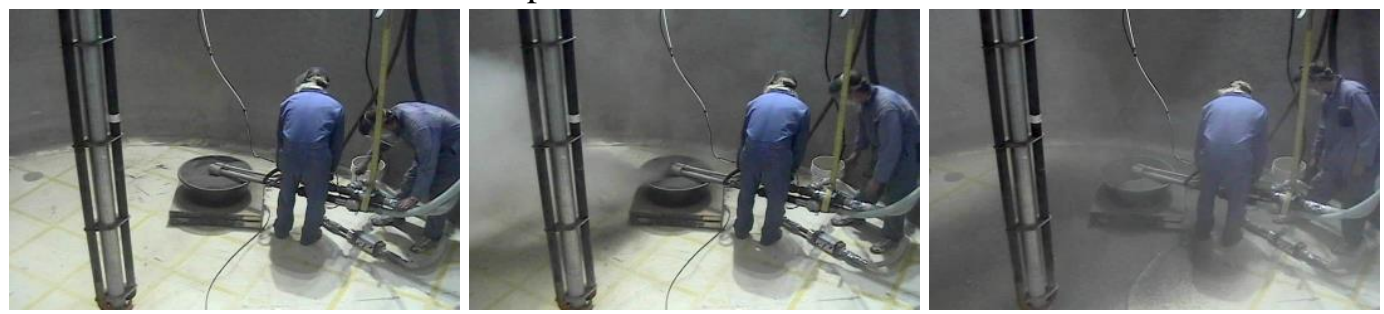

Prior to test start. During TORE® Lance operation. During TORE® Lance operation.

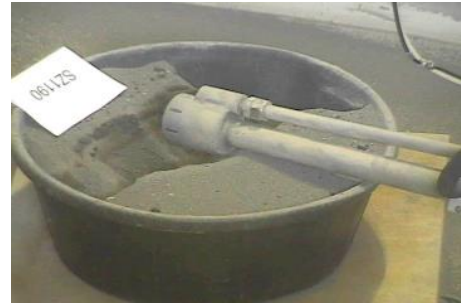

After test completion.

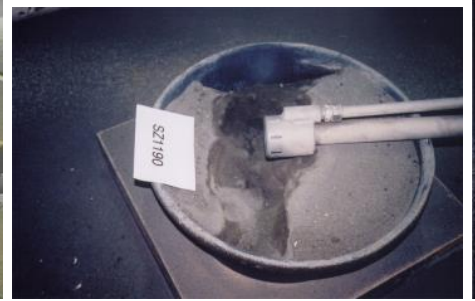

After test completion.

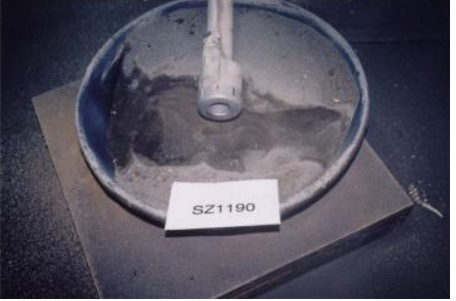

After test completion.

Figure 6.15. Test SZ1190 Sequence June 3, 2002: Sand simulant, no pneumatic conveyance, air, no water, head feed, TORE® oriented horizontally (at $90^{\circ}$ ) with head 0 in. above the simulant.

\subsubsection{SZ119S Observations}

With the TORE® Lance head submerged, additional solids were dispersed.

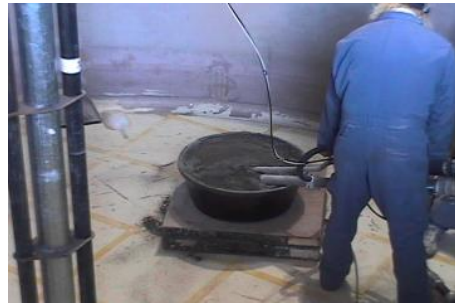

Prior to test start.

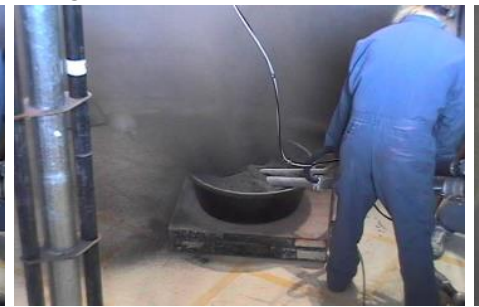

During TORE® Lance operation. After test completion.

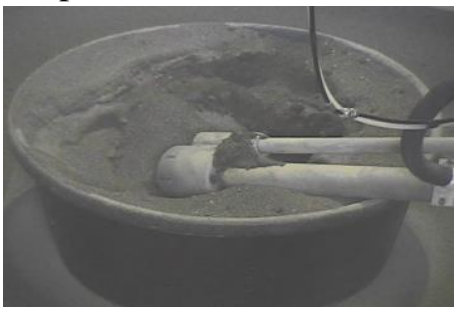

Figure 6.16. Test SZ119S Sequence June 3, 2002: Sand simulant, no pneumatic conveyance, air, no water, head feed, TORE® oriented horizontally $\left(\right.$ at $\left.90^{\circ}\right)$ with head submerged in the simulant.

\subsubsection{TORE® Lance Full Operation with Air}

The purpose of these tests was to evaluate the full performance of the TORE® Lance coupled with pneumatic conveyance. The precessing vortex was activated to mobilize the gravel and the flow from the eductor was used to enhance retrieval. 


\subsubsection{SP11V6 Observations}

During this tests the TORE® Lance head feed dislodged sand from the container; however no solids transport was visible in the conveyance line.

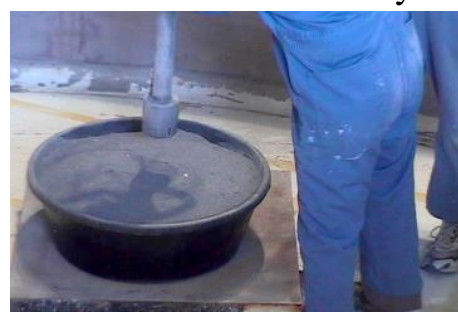

Prior to test start.
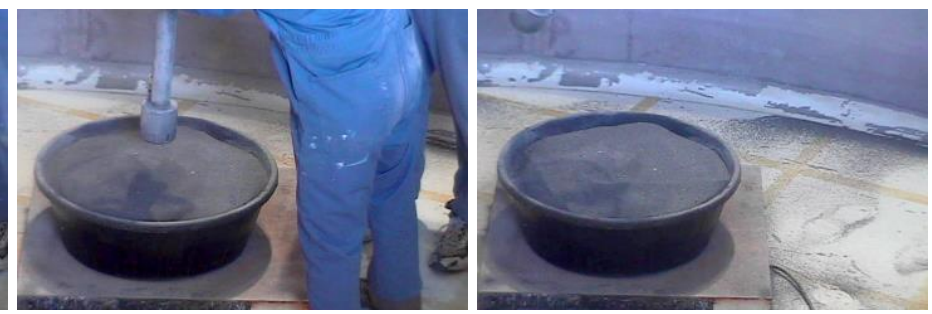

During TORE® Lance operation. After test conclusion.

Figure 6.17. Test SP11V6 Sequence June 4, 2002: Sand simulant, pneumatic conveyance, air, no water, head feed, TORE® oriented vertically 6 in. above the simulant.

\subsubsection{SP11V2 Observations}

During this tests the TORE® Lance head feed dislodged sand from the container; however no solids transport was visible in the conveyance line. During this series of photos the solids deposition on the floor is visible.

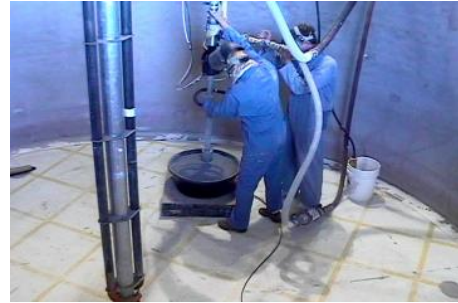

Prior to test start.

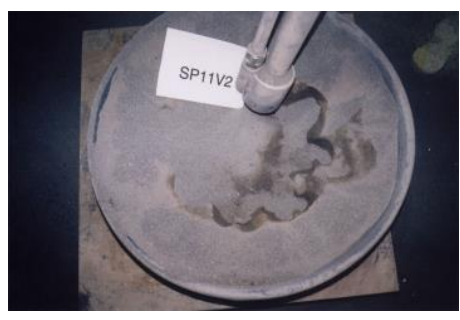

After test conclusion.

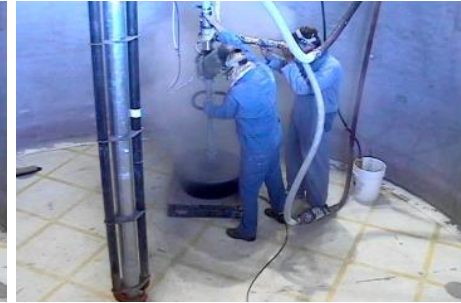

During TORE® Lance operation. After test conclusion.

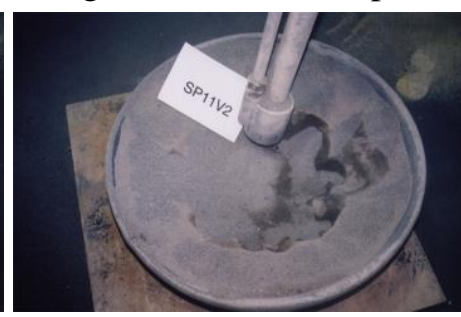

After test conclusion.
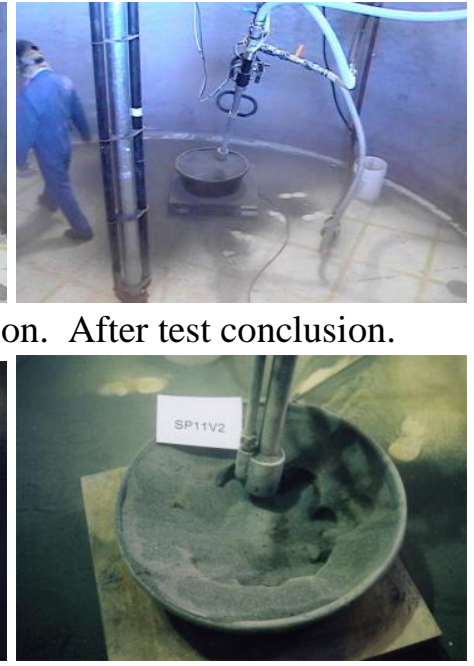

After test conclusion.

Figure 6.17. Test SP11V2 Sequence June 4, 2002: Sand simulant, pneumatic conveyance, air, no water, head feed, TORE® oriented vertically 2 in. above the simulant.

\subsubsection{SP11V0 Observations}

Significant amounts of sand were blown out of the container during this test which started with the TORE® Lance head positioned on top of the sand. 

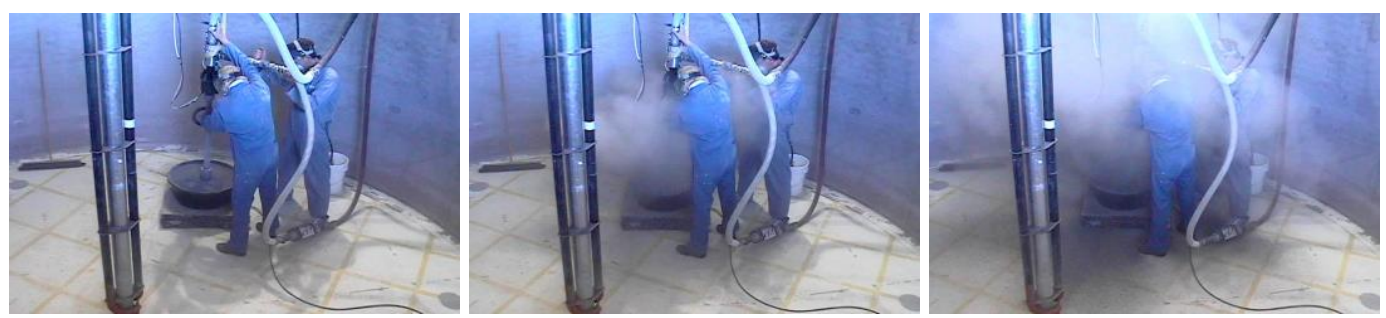

Prior to test start.

During TORE® Lance operation. During TORE® Lance operation

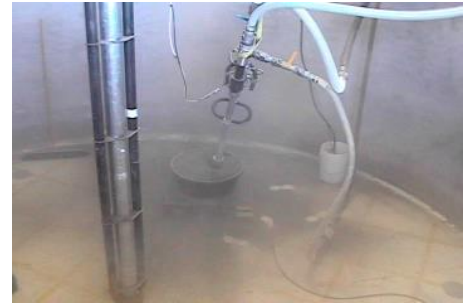

After test conclusion.

Figure 6.18. Test SP11V0 Sequence June 4, 2002: Sand simulant, pneumatic conveyance, air, no water, head feed, TORE® oriented vertically 0 in. above the simulant.

\subsubsection{SP11VS Observations}

Significant amounts of sand were blown out of the container during this test which started with the TORE® Lance head submerged in the sand.

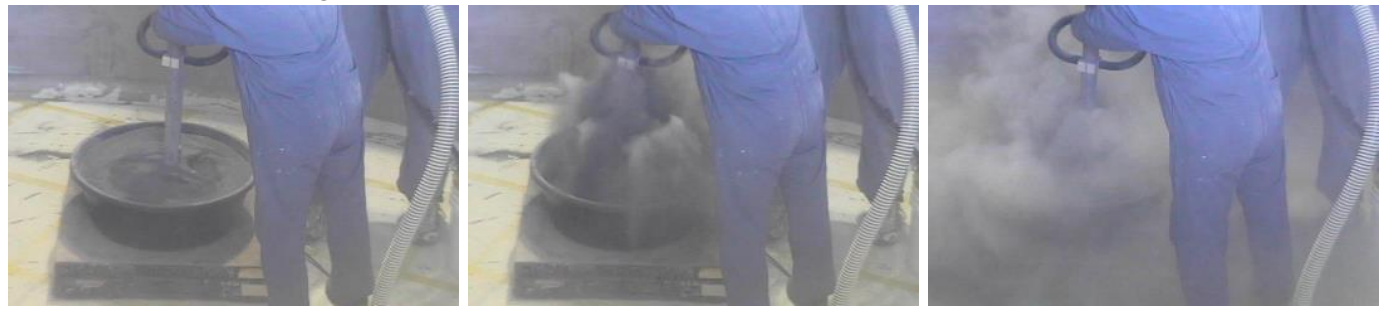

Prior to test start.

During TORE® Lance operation. During TORE® Lance operation

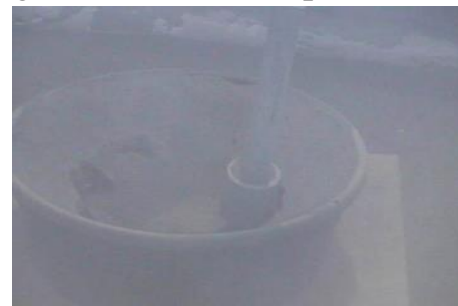

After test conclusion.

Figure 6.19. Test SP11VS Sequence June 4, 2002: Sand simulant, pneumatic conveyance, air, no water, head feed, TORE® oriented vertically submerged in the simulant.

\subsubsection{SP11VSS Observations}

During this test, the TORE® Lance head was placed within 1/2 in. from the container bottom. 


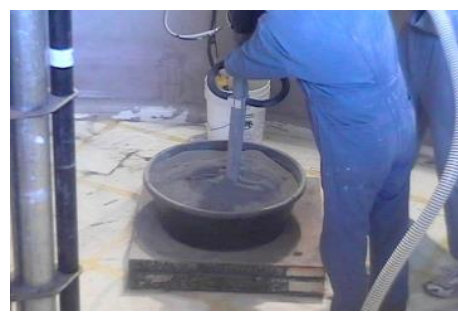

Prior to test start.
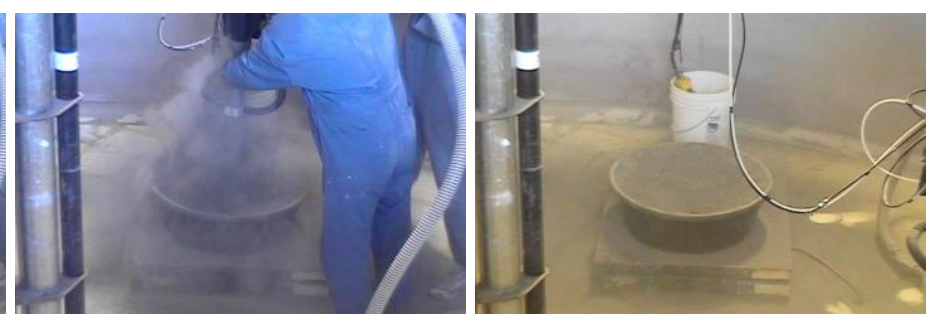

During TORE® Lance operation. After test conclusion

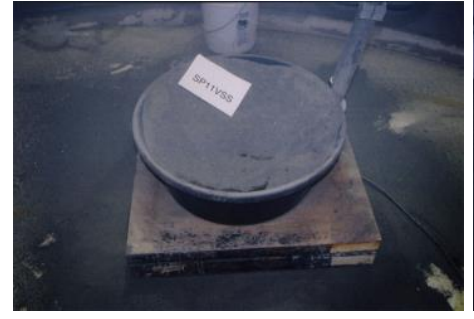

After test conclusion

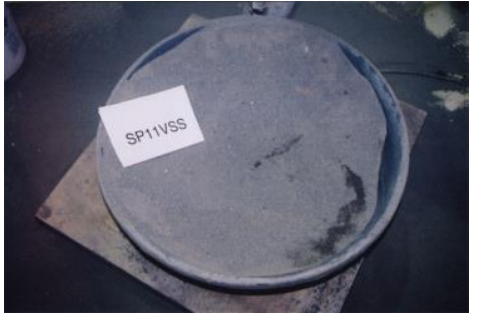

After test conclusion

Figure 6.20. Test SP11VSS Sequence June 4, 2002: Sand simulant, pneumatic conveyance, air, no water, head feed, TORE® oriented vertically submerged deeper into the simulant.

\subsubsection{SP1196 Observations}

The excavation resulting from this TORE® Lance operation was 17 in. long, 4 in. wide and 1.5 in. deep.

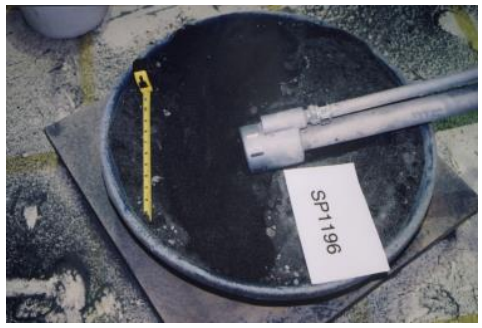

After test conclusion

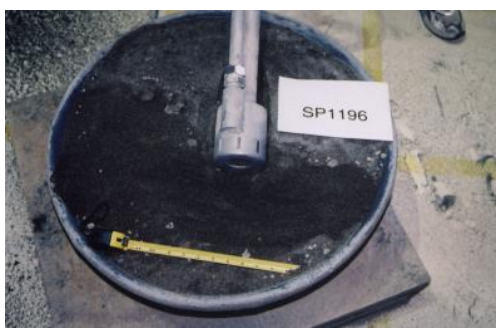

After test conclusion

Figure 6.21. Test SP1196 Sequence June 4, 2002: Sand simulant, pneumatic conveyance, air, no water, head feed, TORE® oriented horizontally, suspended 6 in. above the simulant.

\subsubsection{SP1192 Observations}

A distinctive dislodging pattern is visible in the sand after completion of this test. Some dust was generated during this test. 


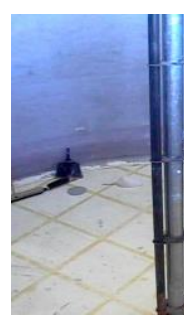

Prior to test start.

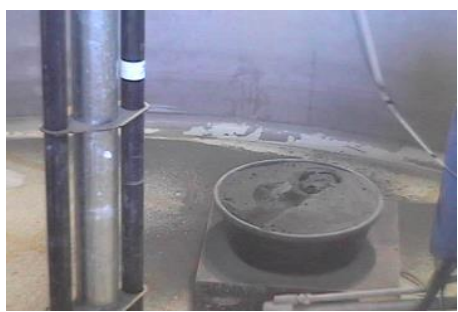

After test conclusion.

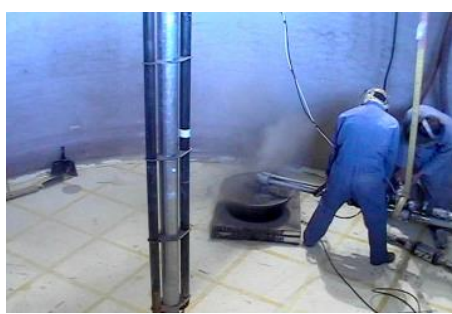

During TORE® Lance operation. During TORE® Lance operation.

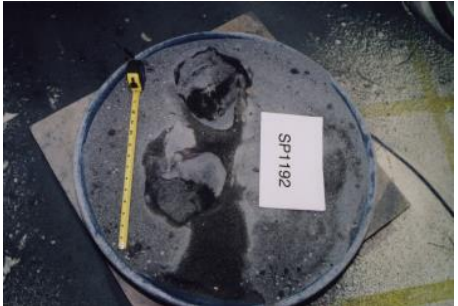

After test conclusion.
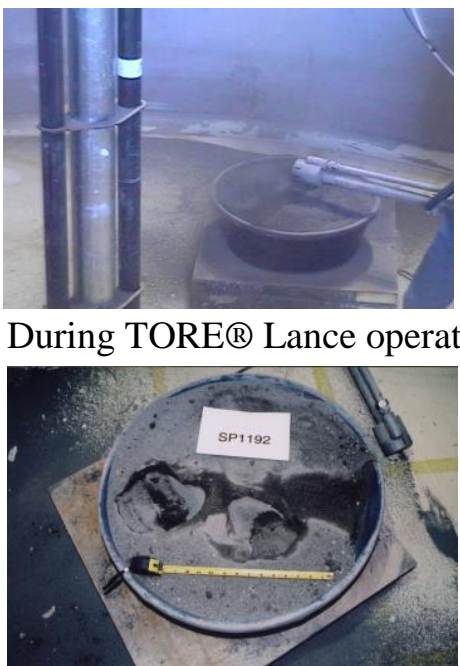

After test conclusion.

Figure 6.22. Test SP1192 Sequence June 4, 2002: Sand simulant, pneumatic conveyance, air, no water, head feed, TORE® oriented horizontally (at $90^{\circ}$ ) with head 2 in. above the simulant.

\subsubsection{SP1190 Observations}

The resulting excavation from the sand dislodged from this test was 23 in. long, 12 in. maximum width, 5, in. minimum width, 6 in. maximum depth, and 3 in. in average depth. Some dust was generated during this test. 

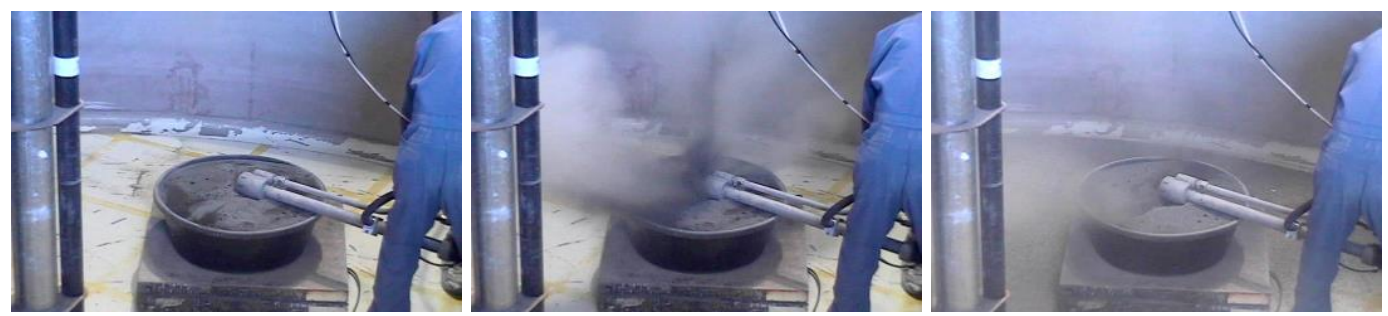

Prior to test start.

During TORE® Lance operation. During TORE® Lance operation.
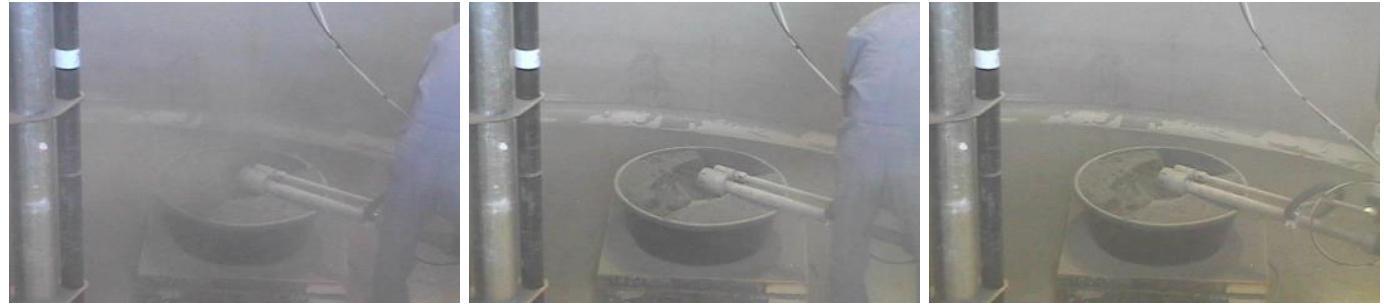

During TORE® Lance operation. During TORE® Lance operation. After test conclusion.
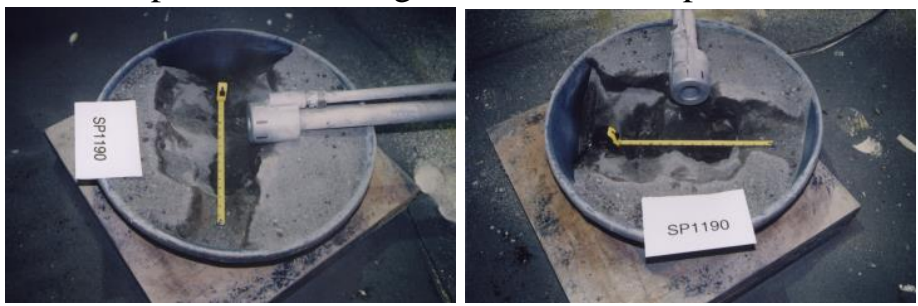

After test conclusion.

After test conclusion.

Figure 6.23. Test SP1190 Sequence June 4, 2002: Sand simulant, pneumatic conveyance, air, no water, head feed, TORE® oriented horizontally (at $90^{\circ}$ ) with head 0 in. above the simulant.

\subsubsection{SP119S Observations}

The resulting excavation from the sand dislodged from this test was 24 in. long, 13 in. maximum width, 6 in. minimum width, and 6.5 in. maximum depth. Some dust was generated during this test. 

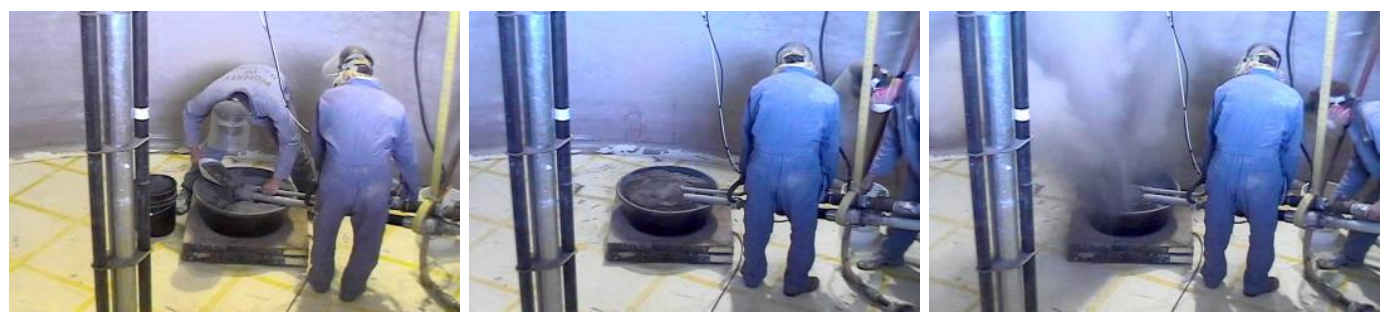

Prior to test start.

Prior to test start.

During TORE® Lance operation.
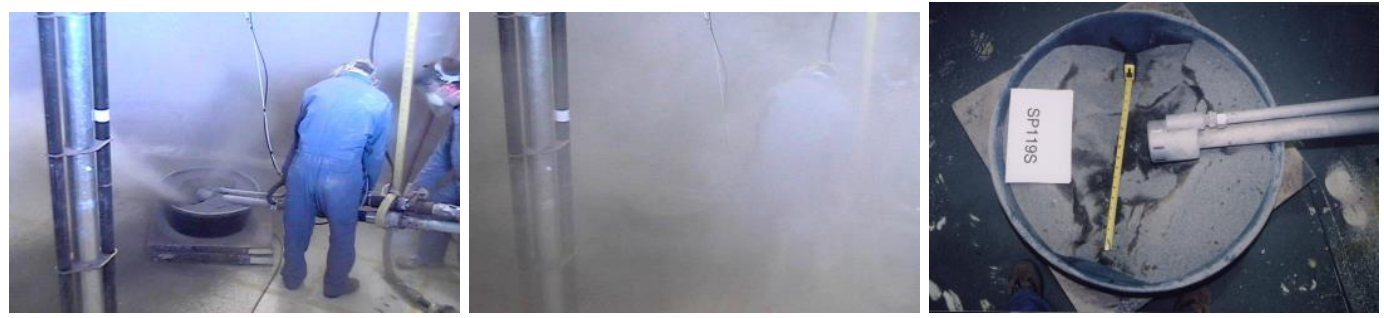

During TORE® Lance operation. After test conclusion.

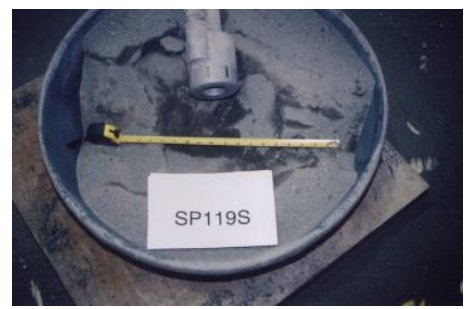

After test conclusion.

After test conclusion.

Figure 6.24. Test SP119S Sequence June 4, 2002: Sand simulant, pneumatic conveyance, air, no water, head feed, TORE® oriented horizontally (at $90^{\circ}$ ) with head submerged in the simulant.

\subsubsection{SP113S Observations}

With the TORE® Lance oriented at 30 deg from the vertical, significant dust was generated during the test. In addition, conveyance of slugs of sand was visible through the hose during the test initiation. 

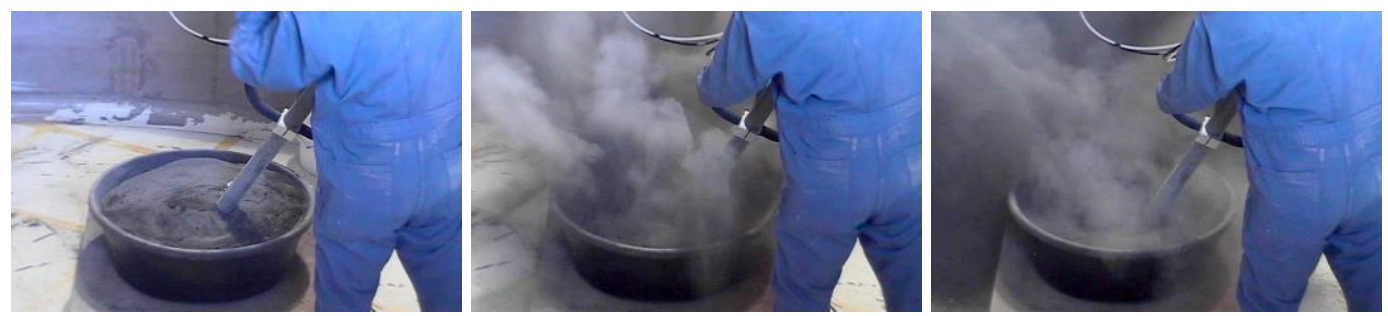

Prior to test start. During TORE® Lance operation. During TORE® Lance operation.
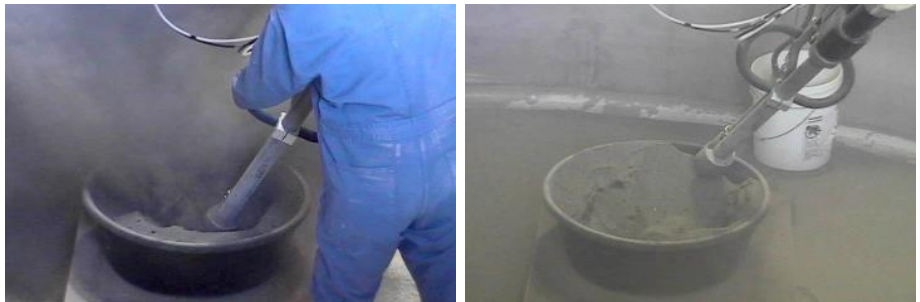

During TORE® Lance operation. After test conclusion

Figure 6.25. Test SP113S Sequence June 4, 2002: Sand simulant, pneumatic conveyance, air, no water, head feed, TORE® oriented at $30^{\circ}$ with head submerged in the simulant.

\subsubsection{SP116S Observations}

The resulting excavation from the sand dislodged from this test was an oval $20 \mathrm{in.}$ long and $16 \mathrm{in}$. wide, 9.5 in. deep. Some dust was generated during this test.
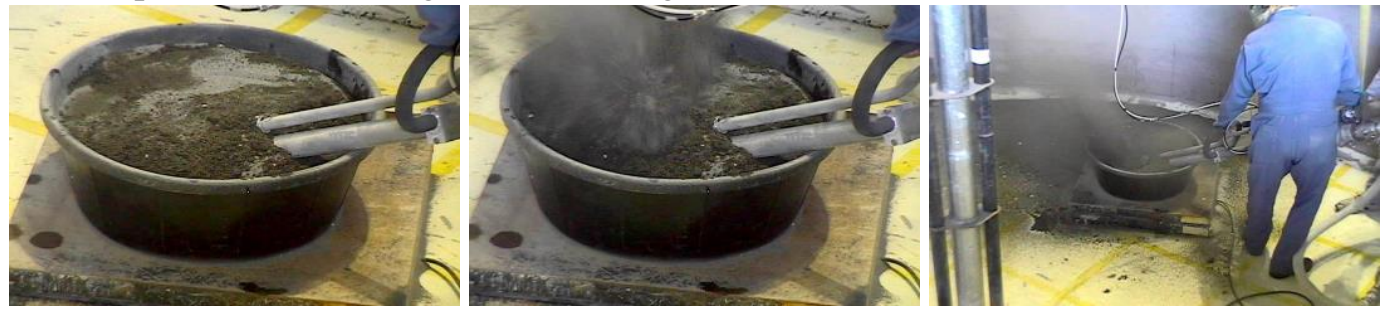

Prior to test start.

During TORE® Lance operation. During TORE® Lance operation.
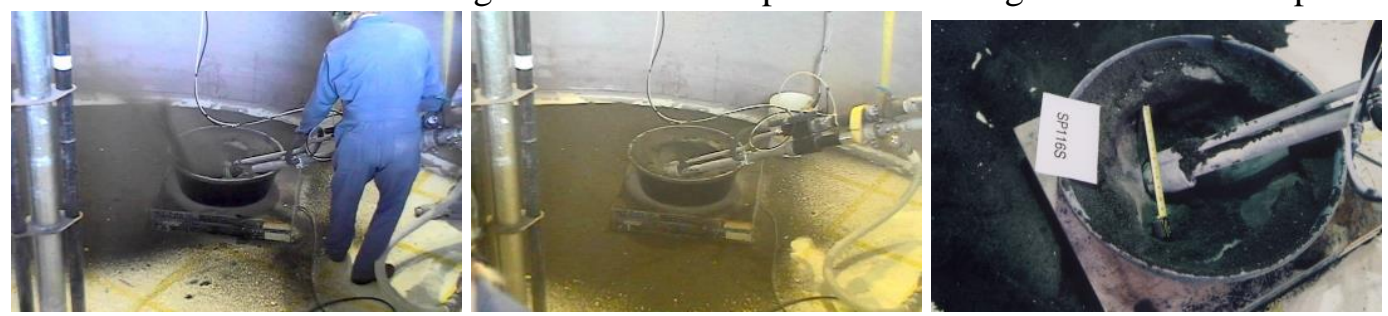

During TORE® Lance operation. After test conclusion.

After test conclusion.

Figure 6.26. Test SP116S Sequence June 4, 2002: Sand simulant, pneumatic conveyance, air, no water, head feed, TORE® oriented at $60^{\circ}$ with head submerged in the simulant.

\subsection{Sand Test Results}

Data from the sand tests are summarized in Table 6.2. Retrieval tests using only eduction to transport the solids from the TORE® Lance inlet to the hopper showed that some transport of solids in direct 
contact with the head was accomplished. The air pressure delivered to the inlet of the eductor was $\sim 50$ psig.

For tests that included both eduction and feed to the TORE® Lance head for mobilization, the pressure delivered to the inlet of the eductor was $\sim 39 \mathrm{psig}$ and the pressure delivered to the inlet of the head was $\sim 17$ psig. These pressures were very similar to tests with addition of pneumatic conveyance.

The best mobilization and retrieval occurred when the TORE® Lance head was submerged in the sand. Because the tests were initiated with $0 \%$ bypass (all available flow to the TORE® Lance head) some solids were dislodged (blown) from the container. A reduction of the flow to the TORE® Lance head would reduce the amount of solids spread. The tests were conducted with full flow to the TORE® Lance head based on the premise that when the system is operated in the tank, the air feed to the system head may occur when the head is not fully submerged. So these tests were able to provide information about what type and amount of solids dispersal could occur.

With the TORE® Lance operated either submerged or in contact with the sand, an $\sim 18$ in. zone of influence from the air emanating from the head was observed. This zone of influence for the precessing vortex agrees with that predicted by Parkinson and Delves (1999) based on obtaining mobilization at a diameter six times the 3-in. diameter discharge line. 
Table 6.2. Results of TORE® Lance retrieval of sand using compressed air enhanced mobilizing and conveyance.

\begin{tabular}{|c|c|c|c|c|c|c|c|c|}
\hline \begin{tabular}{|l|} 
Test Number \\
\end{tabular} & Data Interval & $\begin{array}{c}\text { Simulant Mobilized } \\
\text { (LRB) }\end{array}$ & $\begin{array}{c}\text { Simulant } \\
\text { Mobilized }\end{array}$ & $\begin{array}{c}\text { Simulant } \\
\text { Addition to } \\
\text { Hopper } \\
\end{array}$ & $\begin{array}{c}\text { Air Flow through } \\
\text { Conveyance Line } \\
\text { Avg } \\
\end{array}$ & $\begin{array}{c}\text { TORE® Head } \\
\text { Feed Pressure } \\
\text { Avg } \\
\end{array}$ & $\begin{array}{c}\text { TORE® Supply } \\
\text { Pressure Avg }\end{array}$ & $\begin{array}{c}\text { Pitot Probe } \Delta \mathbf{P} \\
\text { Avg }\end{array}$ \\
\hline & & lbm & lbm & lbm & scfm & psi & psi & psi \\
\hline SZ10V2 & 12:01:06 & 0 & 0 & 0 & 189 & 21.4 & 46.1 & 0.7 \\
\hline SZ10V2b & 14:05:35 & 1 & 0 & 0 & 399 & 0.0 & 49.4 & 2.9 \\
\hline SZ10V0 & 14:08:45 & 1 & 1 & 0 & 397 & 0.0 & + & 2.9 \\
\hline SZ10VS & $14: 11: 55$ to $14: 12: 05$ & 6 & 4 & 5 & 306 & 0.0 & 52.5 & 1.8 \\
\hline SZ1090 & $4: 17: 25$ & 0 & 0 & 0 & 357 & 0.0 & 56.0 & 2.4 \\
\hline SZ109S & $14: 19: 35$ to $14: 19: 45$ & 5 & 2 & 3 & 373 & 0.0 & 50.1 & 2.6 \\
\hline \begin{tabular}{|l|} 
SZ11V6 \\
\end{tabular} & $14: 23: 25$ to $14: 23: 35$ & 2 & 0 & 1 & 349 & 17.1 & 38.2 & 2.3 \\
\hline SZ11V2 & 14:27:15 & 10 & 10 & 1 & 293 & 16.5 & 37.5 & 1.6 \\
\hline SZ11V0 & $14: 34: 15$ & $\begin{array}{c}23=\text { before sweep }{ }^{\text {a0 }} \\
4=\text { after sweep }^{b)}\end{array}$ & 23 & 2 & 284 & 2.0 & 8.5 & 1.6 \\
\hline SZ11VS & $14: 39: 25$ to $14: 39: 35$ & $\begin{array}{c}\text { 39=before sweep } \\
6=\text { after sweep }\end{array}$ & 18 & 2 & 188 & 16.3 & 36.9 & 0.7 \\
\hline SZ1196 & $14: 46: 35$ to $14: 46: 45$ & $\begin{array}{c}7=\text { before } \text { sweep } 0=\text { after } \\
\text { sweep }\end{array}$ & 4 & 0 & 337 & 17.1 & 39.0 & 2.1 \\
\hline SZ1192 & $14: 51: 55$ to $14: 52: 05$ & $\begin{array}{c}15=\text { before sweep } \\
0=\text { after sweep }\end{array}$ & 7 & 0 & 325 & 17.1 & 38.8 & 2.0 \\
\hline SZ1190 & $14: 56: 45$ to $14: 57: 05$ & $\begin{array}{c}\text { 31=before sweep } \\
7=\text { after sweep }\end{array}$ & 22 & 3 & 295 & 16.8 & 37.9 & 1.7 \\
\hline SZ119S & $15: 11: 05$ to $15: 11: 25$ & $\begin{array}{c}\text { 49=before sweep } \\
9=\text { after sweep }\end{array}$ & 39 & 5 & 248 & 17.4 & 39.0 & 1.2 \\
\hline \multicolumn{9}{|l|}{$6 / 4 / 2002$} \\
\hline SP11V6 & $13: 44: 16$ to $13: 44: 27$ & $\begin{array}{c}2=\text { before } \text { sweep } 0=\text { after } \\
\text { sweep }\end{array}$ & 1 & 2 & 452 & 16.2 & 36.7 & 3.9 \\
\hline SP11V2 & $13: 50: 46$ to $13: 50: 58$ & $\begin{array}{c}17=\text { before sweep } \\
2=\text { after sweep }\end{array}$ & 13 & 4 & 417 & 15.1 & 34.7 & 3.5 \\
\hline SP11V0 & $13: 55: 27$ to $13: 55: 36$ & $\begin{array}{c}27=\text { before sweep } \\
5=\text { after sweep }\end{array}$ & 21 & 4 & 374 & 16.4 & 37.2 & 2.8 \\
\hline SP11VS & $14: 00: 15$ to $14: 00: 32$ & $\begin{array}{c}27=\text { before sweep } \\
5=\text { after sweep }\end{array}$ & 40 & 8 & 355 & 16.0 & 36.6 & 2.5 \\
\hline \multicolumn{9}{|l|}{$6 / 5 / 2002$} \\
\hline SP116S & 9:53:11 to $9: 53: 38$ & $\begin{array}{c}56=\text { before sweep } \\
12=\text { after sweep }\end{array}$ & 66 & 9 & 380 & 16.0 & 37.0 & 2.9 \\
\hline
\end{tabular}




\begin{tabular}{|c|c|c|c|c|c|c|c|c|}
\hline Test Number & Data Interval & $\begin{array}{c}\text { Simulant Mobilized } \\
\text { (LRB) }\end{array}$ & $\begin{array}{l}\text { Simulant } \\
\text { Mobilized }\end{array}$ & $\begin{array}{c}\text { Simulant } \\
\text { Addition to } \\
\text { Hopper }\end{array}$ & $\begin{array}{c}\text { Air Flow through } \\
\text { Conveyance Line } \\
\text { Avg }\end{array}$ & $\begin{array}{c}\text { TORE® Head } \\
\text { Feed Pressure } \\
\text { Avg }\end{array}$ & $\begin{array}{c}\text { TORE® Supply } \\
\text { Pressure Avg }\end{array}$ & $\begin{array}{c}\text { Pitot Probe } \Delta \mathbf{P} \\
\text { Avg }\end{array}$ \\
\hline & & lbm & lbm & lbm & scfm & psi & psi & psi \\
\hline \\
\hline \multicolumn{9}{|c|}{$\begin{array}{l}\text { After sweep refers to the weight of the simulant container after solids scattered on the floor were swept up and returned to the container. This weight is more indicative } \\
\text { of the amount of solids that were retrieved from the container. }\end{array}$} \\
\hline
\end{tabular}




\subsection{TORE® Lance Mobilization and Retrieval of Sludge}

Sludge is one type of waste form that could be encountered during retrieval of radioactive waste from underground storage tanks. Two types of sludge simulant were evaluated: an extremely hard sludge and one developed to simulate some types of tank waste. All the TORE® Lance performance evaluations were conducted using pneumatic conveyance to assist retrieval. The tests did vary the mobilizing fluid. Tests were conducted using $100 \%$ compressed air, 100\% pressurized water, and a mix of air with addition of $\sim 6$ gpm water.

\subsection{Sludge Test Matrix}

The test series to evaluate dislodging of sludge was expanded to include using three types of mobilizing fluids: $100 \%$ air, $100 \%$ water, and a mixture of mostly air with $\sim 6$ gpm water addition. To identify each test a unique test number was developed. The components of this number were defined in Section 4.5. The tests were conducted in three parts.

- $\quad$ To evaluate the dislodging and retrieval of extremely strong sludge simulant. Selected tests were conducted with either compressed air as the mobilizing and eductor fluid or pressurized water as the mobilizing and eductor fluid to enhance the pneumatic conveyance. These tests document evaluations of TORE® Lance ability to dislodge and retrieve a sludge type simulant that is much stronger than anticipated to be found in the waste tanks.

- $\quad$ To evaluate dislodging of sludge simulant using pressurized water through the TORE® Lance head to mobilize the sludge and through the TORE® Lance eductor assembly to complement pneumatic conveyance. These tests evaluate the ability of the TORE® Lance to dislodge and mobilize a more typical sludge simulant using water for dislodging and eduction. These tests also show how $100 \%$ water dislodging and eduction can be coupled with pneumatic conveyance.

- $\quad$ To evaluate the transport of solids through the TORE® Lance assembly to the conveyance hopper using a combination of pressurized water through the TORE@ Lance head to mobilize the solids and through the TORE® Lance assembly in conjunction with pneumatic conveyance. These tests show how a combination of compressed air and pressurized water dislodging and eduction can be coupled with pneumatic conveyance.

The test matrix is listed in Table 7.1.

Table 7.1. Test matrix for evaluation of TORE® Lance mobilizing and retrieval of sludge.

\begin{tabular}{|l|l|l|l|l|l|l|}
\hline $\begin{array}{l}\text { Test } \\
\text { Number }\end{array}$ & Simulant & Conveying Fluid & $\begin{array}{l}\text { Dis- } \\
\text { lodging } \\
\text { Fluid }\end{array}$ & $\begin{array}{l}\text { Head } \\
\text { Feed }\end{array}$ & $\begin{array}{l}\text { Orien- } \\
\text { tation }\end{array}$ & $\begin{array}{l}\text { Stand-off } \\
\text { Distance }\end{array}$ \\
\hline Objective & \multicolumn{5}{|l|}{$\begin{array}{l}\text { To evaluate the dislodging and retrieval of extremely strong sludge simulant. Selected tests } \\
\text { were conducted with either compressed air as the mobilizing and eductor fluid or } \\
\text { pressurized water as the mobilizing and eductor fluid to enhance the pneumatic conveyance }\end{array}$} \\
\hline KP11V0 & $\begin{array}{l}\text { Strong } \\
\text { kaolin }\end{array}$ & Air: pneumatic conveyance & Air & Air & Vertical & 0 in. \\
\hline KP11VS & $\begin{array}{l}\text { Strong } \\
\text { kaolin }\end{array}$ & Air: pneumatic conveyance & Air & Air & Vertical & Submerged 6 in. \\
\hline
\end{tabular}




\begin{tabular}{|c|c|c|c|c|c|c|c|c|}
\hline $\begin{array}{l}\text { Test } \\
\text { Number }\end{array}$ & Simulant & Conveying Fluid & $\begin{array}{l}\text { Dis- } \\
\text { lodging } \\
\text { Fluid }\end{array}$ & $\begin{array}{l}\text { Head } \\
\text { Feed }\end{array}$ & \multicolumn{2}{|c|}{$\begin{array}{l}\text { Orien- } \\
\text { tation }\end{array}$} & \multicolumn{2}{|c|}{$\begin{array}{l}\text { Stand-off } \\
\text { Distance }\end{array}$} \\
\hline KP21VS & $\begin{array}{l}\text { Strong } \\
\text { kaolin }\end{array}$ & $\begin{array}{l}\text { Water eductor and } \\
\text { pneumatic conveyance }\end{array}$ & Water & Water & \multicolumn{2}{|c|}{ Vertical } & \multicolumn{2}{|c|}{ Submerged 6 in. } \\
\hline Objective & \multicolumn{8}{|c|}{$\begin{array}{l}\text { To evaluate dislodging of sludge simulant using pressurized water through the TORE® } \\
\text { Lance head to mobilize the sludge and through the TORE® Lance eductor assembly to } \\
\text { complement pneumatic conveyance. }\end{array}$} \\
\hline KP21V0 & Kaolin & Air: pneumatic conveyance & Air & Air & \multicolumn{2}{|c|}{ Vertical } & \multicolumn{2}{|c|}{0 in. } \\
\hline KP21VS & Kaolin & Air: pneumatic conveyance & Air & Air & \multicolumn{2}{|c|}{ Vertical } & \multicolumn{2}{|c|}{ Submerged 6 in. } \\
\hline KP21VSS & Kaolin & Air: pneumatic conveyance & Air & Air & \multicolumn{2}{|c|}{ Vertical } & \multicolumn{2}{|c|}{ Submerged $>6$ in. } \\
\hline KP219S & Kaolin & Air: pneumatic conveyance & Air & Air & \multicolumn{2}{|c|}{ Vertical } & \multicolumn{2}{|c|}{ Submerged 6 in. } \\
\hline KP2160 & Kaolin & Air: pneumatic conveyance & Air & Air & \multicolumn{2}{|c|}{ Vertical } & \multicolumn{2}{|c|}{0 in. } \\
\hline KP216S & Kaolin & Air: pneumatic conveyance & Air & Air & \multicolumn{2}{|c|}{$\begin{array}{l}\text { Inclined } \\
60 \text { deg } \\
\text { from } \\
\text { vertical }\end{array}$} & \multicolumn{2}{|c|}{ Submerged 6 in. } \\
\hline KP213S & Kaolin & Air: pneumatic conveyance & Air & Air & \multicolumn{2}{|c|}{$\begin{array}{l}\text { Inclined } \\
30 \text { deg } \\
\text { from } \\
\text { vertical }\end{array}$} & \multicolumn{2}{|c|}{ Submerged 6 in. } \\
\hline Objective & \multicolumn{8}{|c|}{$\begin{array}{l}\text { To evaluate the transport of solids through the TORE® Lance assembly to the conveyance } \\
\text { hopper using a combination of pressurized water through the TORE® Lance head to } \\
\text { mobilize the solids and through the TORE® Lance assembly in conjunction with pneumatic } \\
\text { conveyance }\end{array}$} \\
\hline KP3100 & None & Just testing water flow & & & & & & \\
\hline KP31V2 & Kaolin & $\begin{array}{l}\text { Water: pneumatic } \\
\text { conveyance }\end{array}$ & Air/wates & & & Ver & & 2 in. \\
\hline KP31V0 & Kaolin & $\begin{array}{l}\text { Water: pneumatic } \\
\text { conveyance }\end{array}$ & Air/wates & & & Ver & & 0 in. \\
\hline KP31VS & Kaolin & $\begin{array}{l}\text { Water: pneumatic } \\
\text { conveyance }\end{array}$ & Air/wate & & & Ver & & $\begin{array}{l}\text { Submerged } \\
6 \mathrm{in.}\end{array}$ \\
\hline KP313S & Kaolin & $\begin{array}{l}\text { Water: pneumatic } \\
\text { conveyance }\end{array}$ & Air/water & & & $\begin{array}{l}\text { Incl } \\
30 \mathrm{~d} \\
\text { fron } \\
\text { vert }\end{array}$ & & $\begin{array}{l}\text { Submerged } \\
6 \text { in. }\end{array}$ \\
\hline KP316S & Kaolin & $\begin{array}{l}\text { Water: pneumatic } \\
\text { conveyance }\end{array}$ & Air/wate & & & $\begin{array}{l}\text { Incl } \\
60 \mathrm{~d} \\
\text { fron } \\
\text { vert }\end{array}$ & & $\begin{array}{l}\text { Submerged } \\
6 \text { in. }\end{array}$ \\
\hline KP319S & Kaolin & $\begin{array}{l}\text { Water: pneumatic } \\
\text { conveyance }\end{array}$ & Air/wate & & & & & $\begin{array}{l}\text { Submerged } \\
6 \text { in. }\end{array}$ \\
\hline
\end{tabular}




\subsection{Sludge Test Observations}

\subsubsection{TORE® Lance Operation with Extremely Strong Sludge Simulant}

These initial tests with sludge were conducted with an extremely strong sludge simulant. The kaolin clay simulant was composed of $\sim 25 \mathrm{wt} \%$ water and $75 \mathrm{wt} \%$ kaolin clay. This was a much stronger simulant than the $34 \mathrm{wt} \%$ water and $66 \mathrm{wt} \%$ kaolin clay mixture proposed. Only three tests were conducted to dislodge and retrieve this simulant. The results are presented here not because the sludge is representative of what would be expected in the tank, but because the results could be informative for other scenarios.

\subsubsection{KP11V0 Observations}

During this test, the TORE® Lance head was directly on top of the strong sludge simulant. During operation the sludge deformed to show an ill-defined depression $\sim 1.5 \mathrm{in}$. in diameter and $\sim 1.5 \mathrm{in}$. deep. The sludge deformed but no dislodging or retrieval was accomplished.

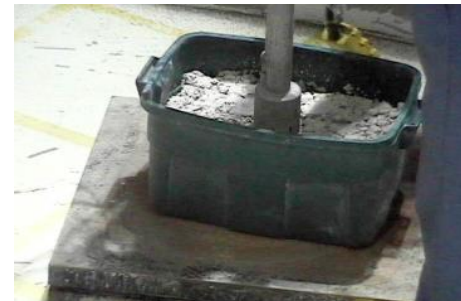

Prior to test start.

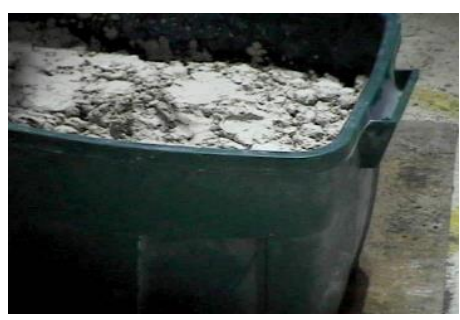

After test conclusion.

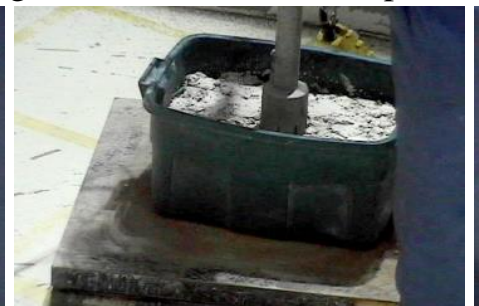

During TORE® Lance operation. After test conclusion

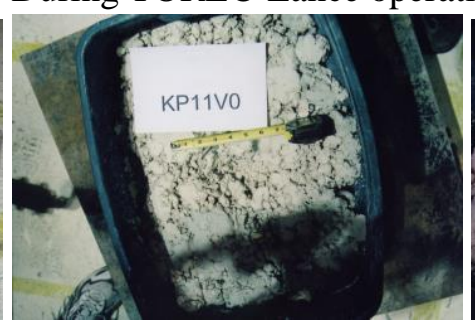

After test conclusion
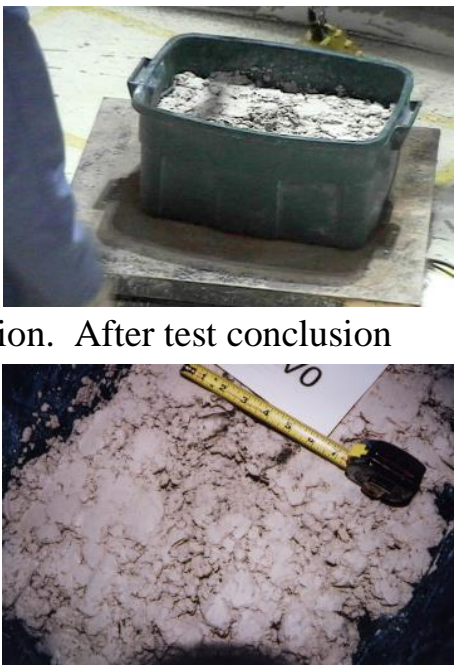

After test conclusion

Figure 7.1. Test KP11V0 Sequence June 5, 2002: Kaolin clay simulant, pneumatic conveyance, air, no water, head feed, TORE® oriented vertically with head 0 in. above the simulant.

\subsubsection{KP11VS Observations}

Prior to the start of this test the TORE® Lance head was submerged into the strong sludge simulant. After insertion, the sludge was compressed to make a seal around the assembly. During the test, the compressed air from the head broke the seal of the kaolin around the edge of the head and the air blew straight up, bypassing any solids mobilization. 


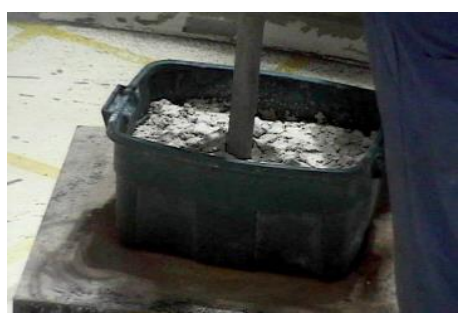

Prior to test start.

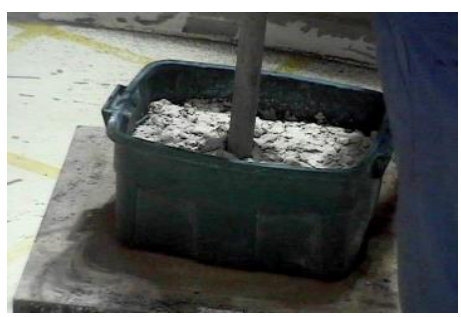

After test conclusion.

Figure 7.2. Test KP11VS Sequence June 5, 2002: Kaolin clay simulant, pneumatic conveyance, air, no water, head feed, TORE® oriented vertically with head submerged in the simulant.

\subsubsection{KP21VS Observations}

One test was conducted with water as the dislodging fluid that emanated from the TORE® Lance head. The water was split in the manifold so water was also used to enhance conveyance through eduction. Pneumatic conveyance provided additional lift. During this test water was injected into the strong sludge simulant. The injected water broke the seal between the clay and the assembly and bubbled up into the container.

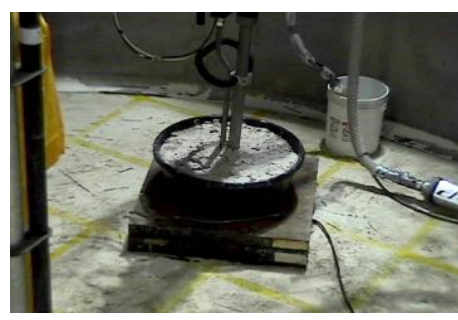

Prior to test start.
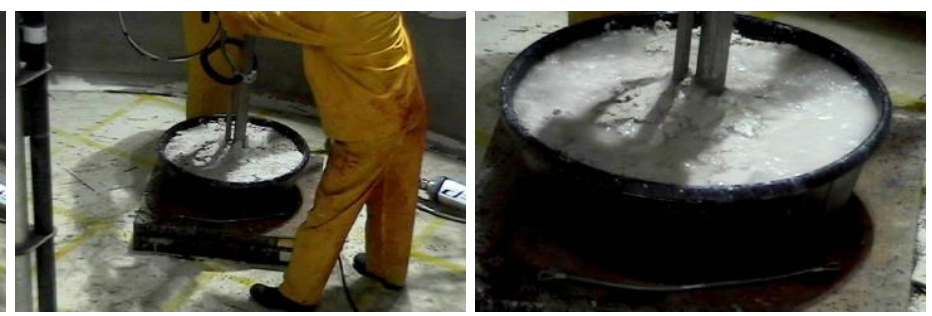

During TORE® Lance operation. During TORE® Lance operation.
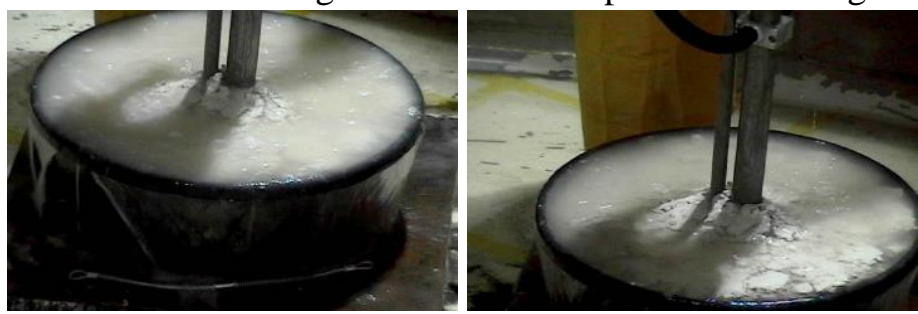

During TORE® Lance operation. After test conclusion

Figure 7.3. Test KP21VS Sequence June 5, 2002: Kaolin clay simulant, pneumatic conveyance, air, water, head feed, TORE® oriented vertically with head submerged in the simulant.

\subsubsection{TORE® Lance Full Operation with Air Precessing Vortex Mobilization and Eductor-Enhanced Conveyance for Retrieval of Sludge}

The purpose of these tests was to evaluate dislodging of sludge simulant using pressurized water through the TORE® Lance head to mobilize the sludge and through the TORE® Lance eductor assembly to complement pneumatic conveyance. These tests evaluate the ability of the TORE® Lance to dislodge and mobilize a more typical sludge simulant using water for dislodging and eduction. These tests also 
show how $100 \%$ water dislodging and eduction can be coupled with pneumatic conveyance. The sludge simulant was developed to represent a typical strength sludge.

\subsubsection{KP21V0 Observations}

This test was conducted with the TORE® Lance positioned at the top of the sludge. During the test water sprayed out of the slits slightly above the surface of the waste. After the test was completed and the standing water was removed from the container, some deformation of the top of the sludge was observed.

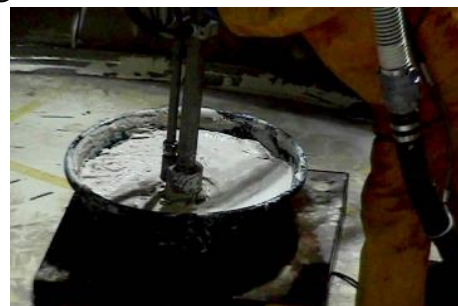

Prior to test start.
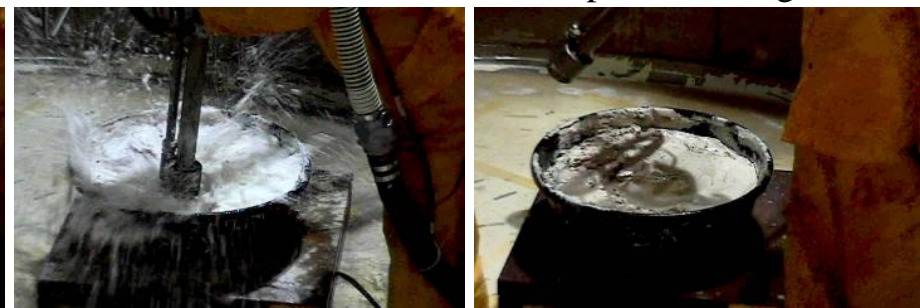

During TORE® Lance operation. After test conclusion

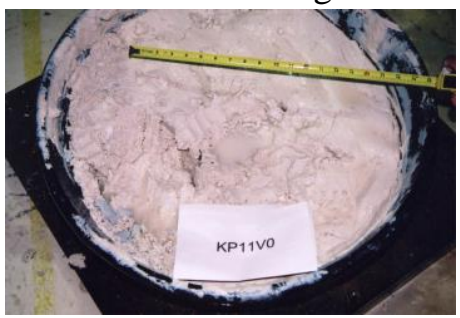

After test conclusion.

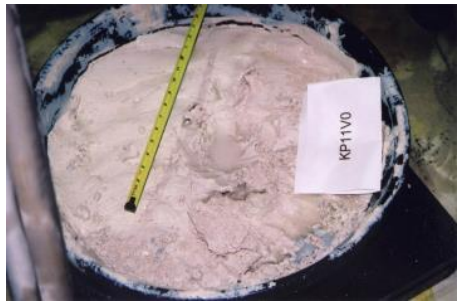

After test conclusion

Figure 7.4. Test KP21V0 (updated from KP11V0) ( $2^{\text {nd }}$ time with new clay) Sequence June 18, 2002: Kaolin clay simulant, pneumatic conveyance, no air, water, head feed, TORE® oriented vertically with head 0 in. above the simulant.

\subsubsection{KP21VS Observations}

The test started with the TORE® Lance head inserted into the sludge with sludge sealed around the assembly. After the test started, pressurized water broke that seal and started to develop a fluid layer on the top of the sludge. In the conveyance line, slugs of fluid were visible during upward transport to the conveyance hopper. 


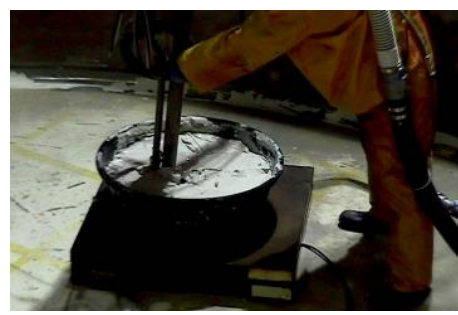

Prior to test start.
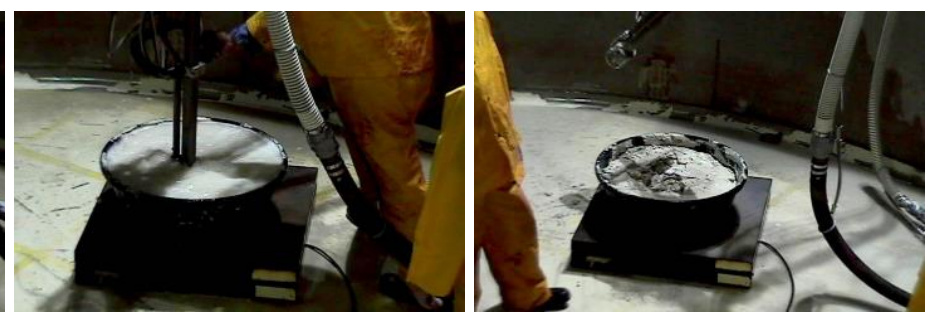

During TORE® Lance operation. After test conclusion

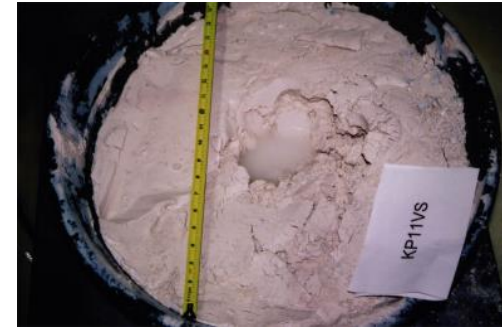

After test conclusion.

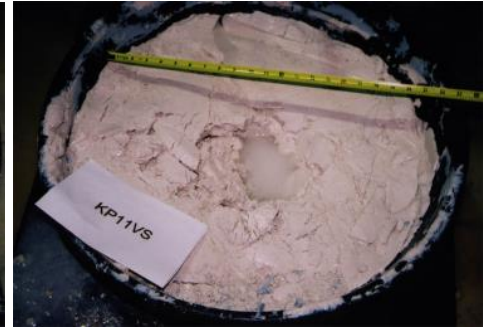

After test conclusion.

Figure 7.5. Test KP $21 \mathrm{VS}$ (updated from KP1VS) ( $2^{\text {nd }}$ time with new clay) Sequence June 18 , 2002: Kaolin clay simulant, pneumatic conveyance, no air, water, head feed, TORE® oriented vertically with head submerged in the simulant.

\subsubsection{KP21VSS Observations}

During this test the TORE® Lance head was submerged to near the bottom of the container. When the test started water first bubbled around the head and a few seconds later water bubbled up around the walls of the container. So the water appeared to take the path of least resistance, instead of cutting through the sludge it penetrated along the sludge container or sludge assembly interface.

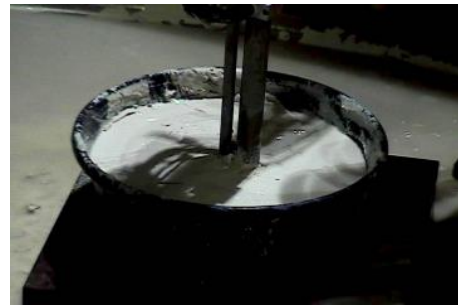

Prior to test start.

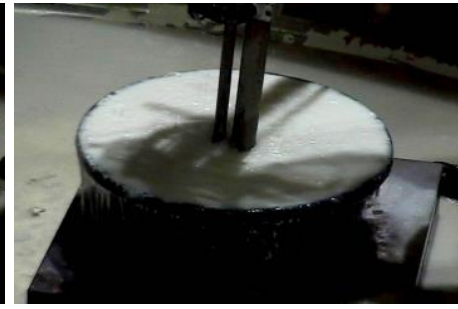

During TORE® Lance operation. After test conclusion.
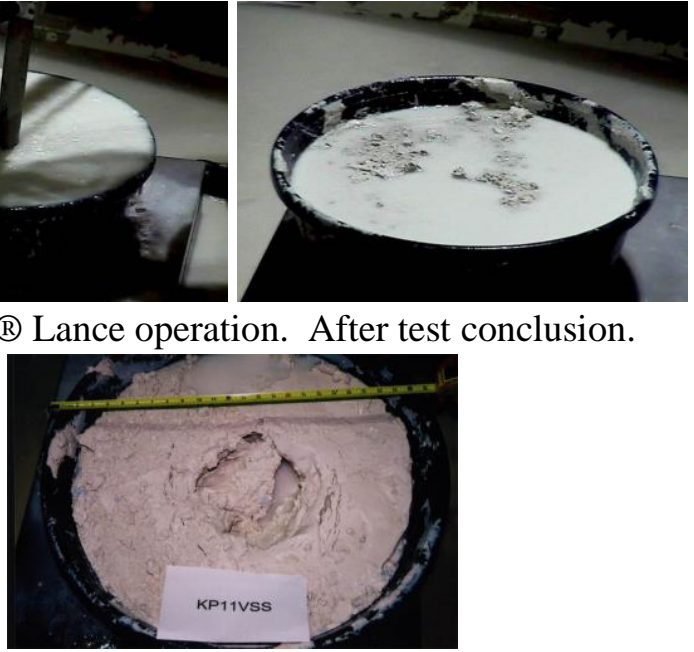

After test conclusion.

Figure 7.6. Test KP21VSS (updated from KP11VSS) Sequence June 18, 2002: Kaolin clay simulant, pneumatic conveyance, no air, water, head feed, TORE® oriented vertically with head submerged deeper in the simulant. 


\subsubsection{KP219S Observations}

During this test with the TORE® Lance head submerged horizontally fluid first penetrated the sludge directly above the slots of the TORE® Lance head as shown in the third photo from the test sequence.
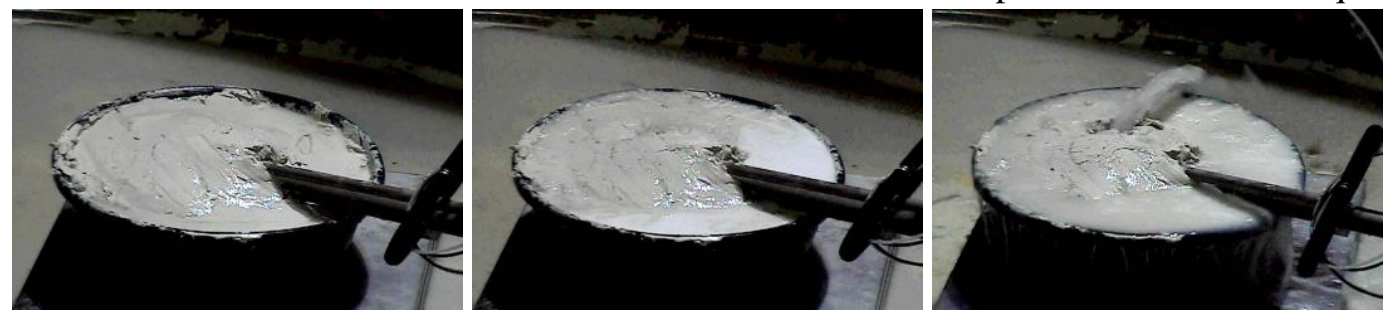

Prior to test start.

During TORE® Lance operation. During TORE® Lance operation.

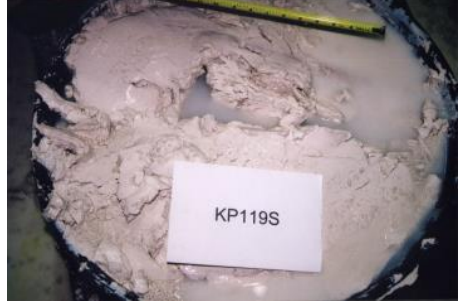

After test conclusion.

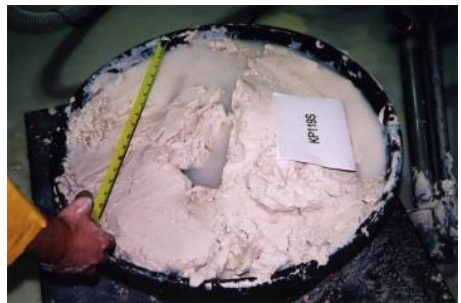

After test conclusion.

Figure 7.7. Test KP219S (updated from KP119S) Sequence June 18, 2002: Kaolin clay simulant, pneumatic conveyance, no air, water, head feed, TORE® oriented horizontally (at $90^{\circ}$ ) with head submerged in the simulant.

\subsubsection{KP216S Observations}

During this test with the TORE® Lance head oriented at 60 degrees from the vertical, the fluid first penetrated the sludge at the location of the slots on the head, followed by sludge contraction near the head as sludge and fluid is sucked into the conveyance line. Then additional fluid penetrated along the side of the container directly opposite the head.

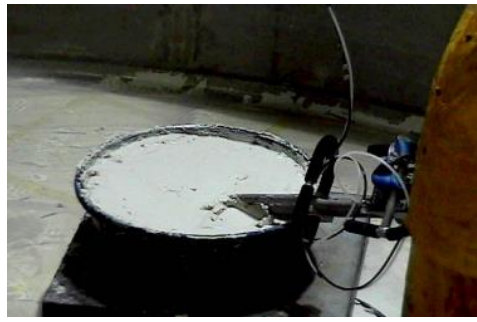

Prior to test start.
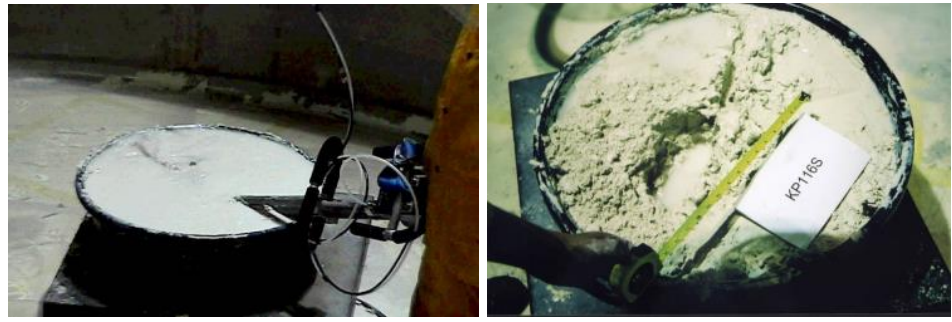

During TORE® Lance operation. After test conclusion 


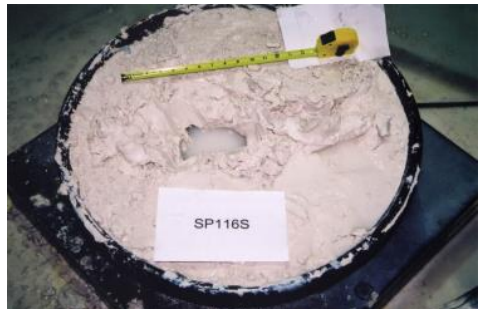

After test conclusion.

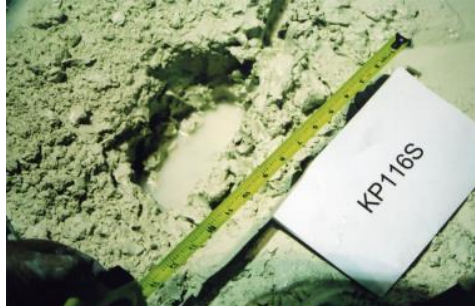

After test conclusion.

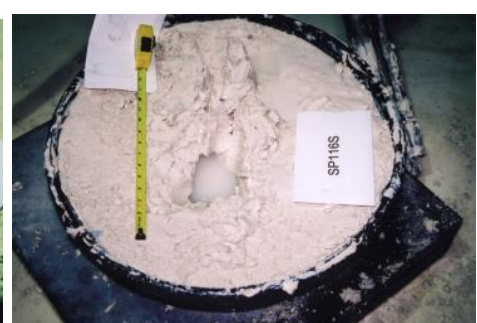

After test conclusion.

Figure 7.8. Test KP216S (updated from KP116S) Sequence June 18, 2002: Kaolin clay simulant, pneumatic conveyance, no air, water, head feed, TORE® oriented at $60^{\circ}$ with head submerged in the simulant.

\subsubsection{KP2130 Observations}

During this test with the TORE® Lance head oriented at 30 degrees from the vertical, first the sludge bed contracts near the head as sludge is sucked into the conveyance line, then fluid penetrates the surface of the sludge near the location of the head.

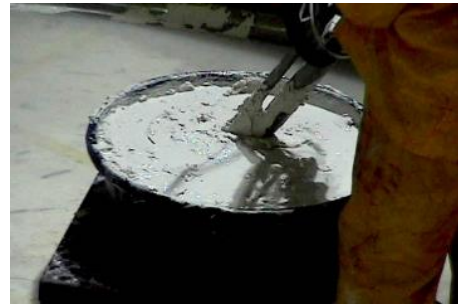

Prior to test start.

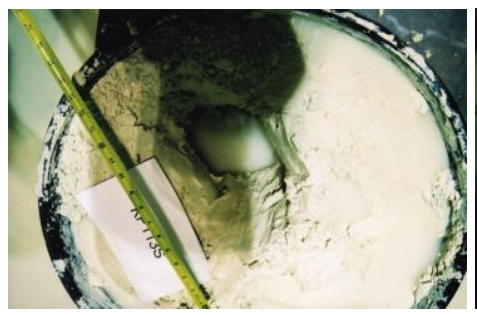

After test conclusion.
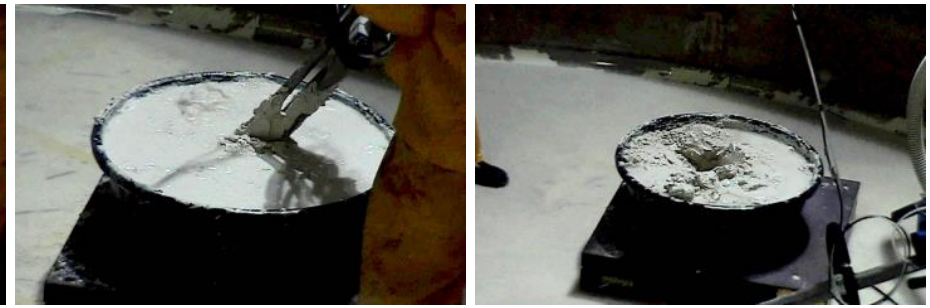

During TORE® Lance operation. After test conclusion

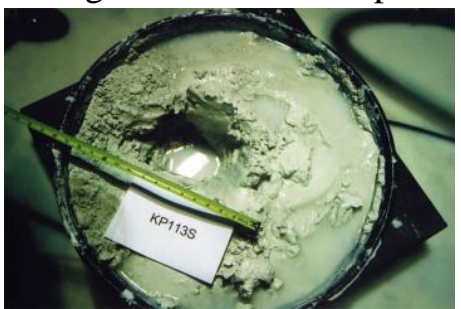

After test conclusion

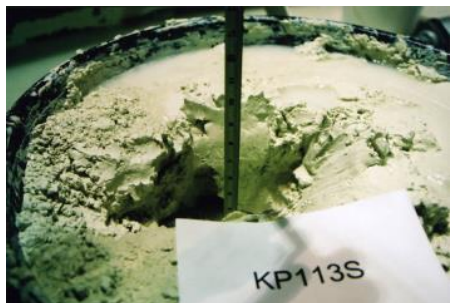

After test conclusion

Figure 7.9. Test KP213S Sequence June 18, 2002: Kaolin clay simulant, pneumatic conveyance, no air, water, head feed, TORE@ oriented at $30^{\circ}$ with head submerged into the simulant.

\subsubsection{TORE® Lance Full Operation with Combined Air and Water}

The purpose of these tests is to evaluate the transport of solids through the TORE® Lance assembly to the conveyance hopper using a combination of pressurized water through the TORE® Lance head to mobilize the solids and through the TORE® Lance assembly in conjunction with pneumatic conveyance. These tests show how a combination of compressed air and pressurized water dislodging and eduction can be coupled with pneumatic conveyance. 


\subsubsection{KP3100}

Prior to the start of the combined air-water tests, the flow rates for both air and water were measured. With no air flow, the water flow rate to the TORE® Lance head was set at $\sim 6.5 \mathrm{gpm}$. Then with no water flow, the air flow was measured. In the $100 \%$ bypass mode, with no flow to the TORE® Lance head the flow rate was $550 \mathrm{scfm}$; with $0 \%$ by pass mode, with all permissible flow to the TORE® Lance head the flow rate was $650 \mathrm{scfm}$. With combined air and water flow, the water flow rate was measured to be $\sim 6.5$ to $6.9 \mathrm{gpm}$. An example of water flow through the TORE® Lance head is shown below.

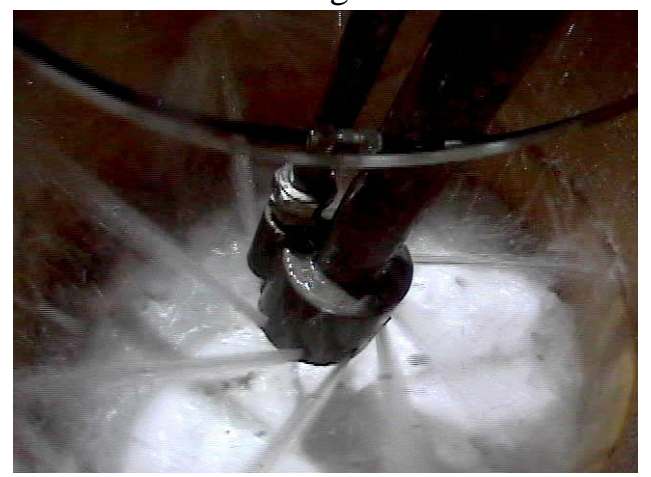

Figure 7.10. Flow of water through the TORE® Lance head.

\subsubsection{KP31V2 Observations}

During this test, the TORE® Lance head was positioned $\sim 2$ in. above the sludge. In the center photo the air-water "mist" is visible. It does not penetrate down, it stays above the sludge in the container. So no active dislodging occurs.

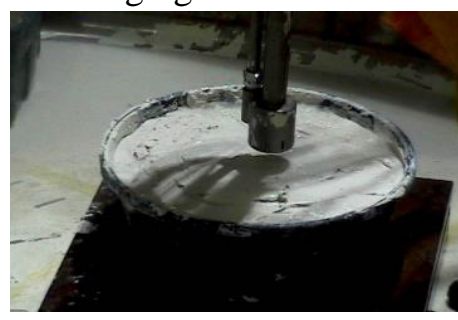

Prior to test start.
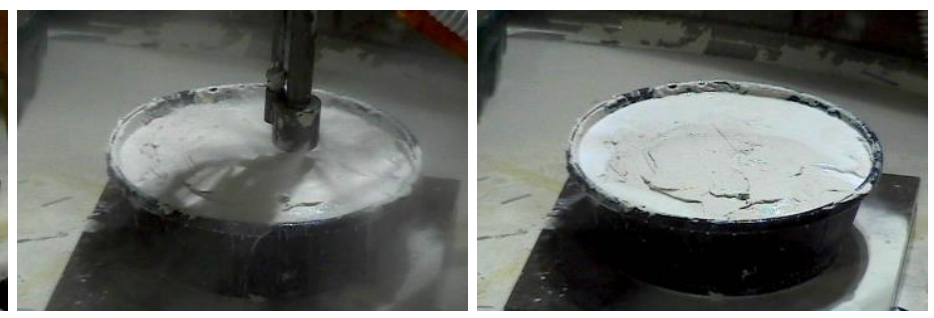

During TORE® Lance operation. After test conclusion.

Figure 7.11. Test KP31V2 (updated from KP12V2)Sequence June 18, 2002: Kaolin clay simulant, pneumatic conveyance, air, water, head feed, TORE® oriented at vertically with head 2 in. above the simulant.

\subsubsection{KP31V0 Observations}

With the TORE® Lance positioned on top of the sludge some water from the head does contact the sludge and some conveyance occurs. After the test completion an impression from the head was visible in the sludge.
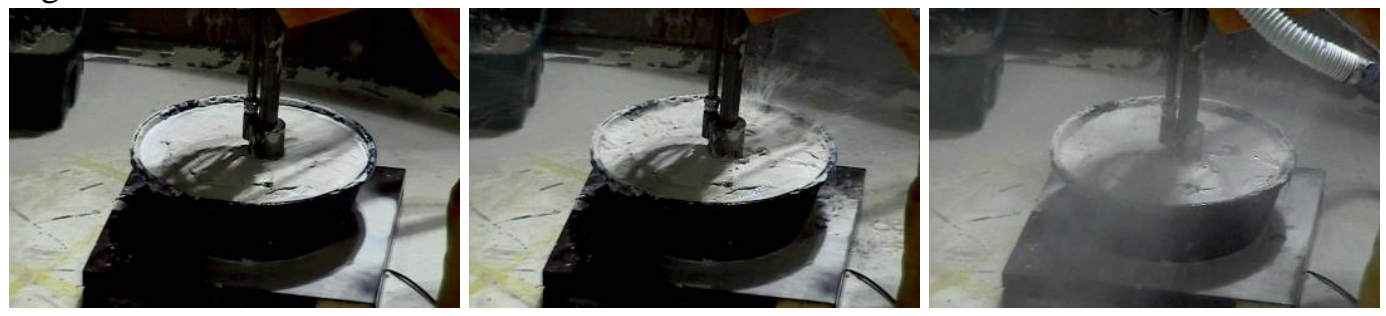
Prior to test start.

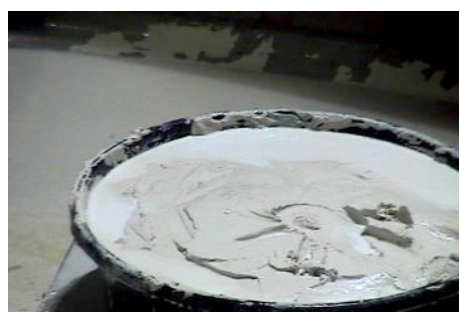

After test conclusion.
During TORE® Lance operation. During TORE® Lance operation

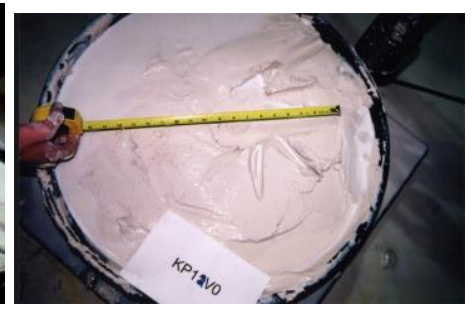

After test conclusion.

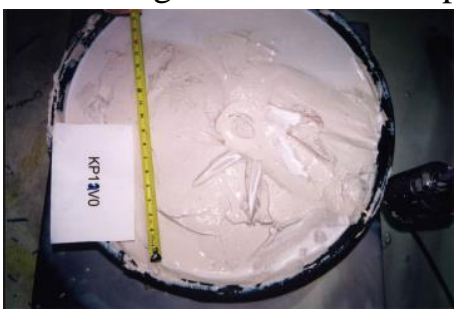

After test conclusion.

Figure 7.12. Test KP31V0 (updated from KP12V0) Sequence June 18, 2002: Kaolin clay simulant, pneumatic conveyance, air, water, head feed, TORE® oriented at vertically with head 0 in. above the simulant.

\subsubsection{KP31VS Observations}
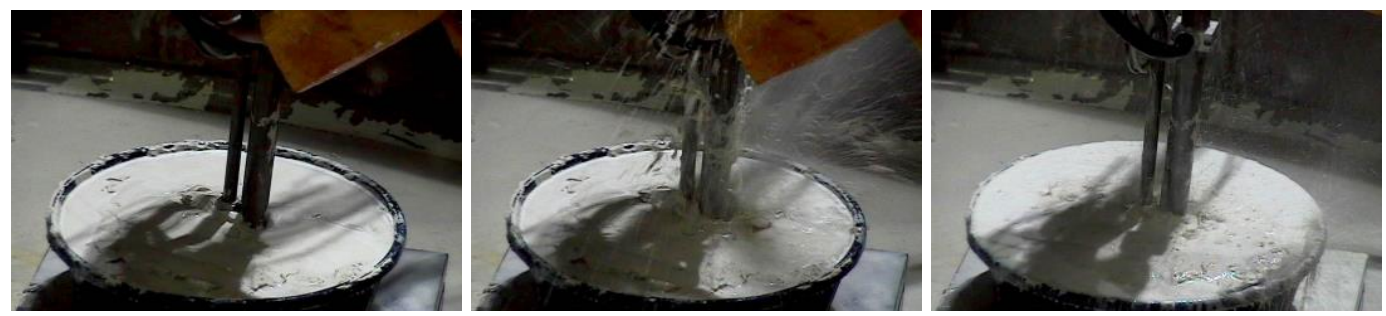

Prior to test start.

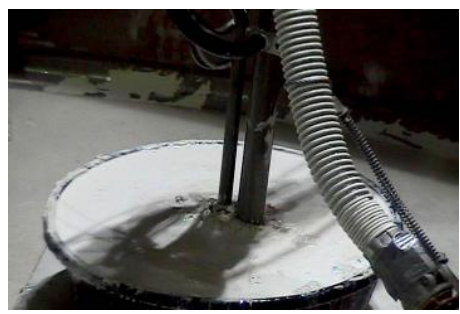

After test conclusion.
During TORE® Lance operation. During TORE® Lance operation.

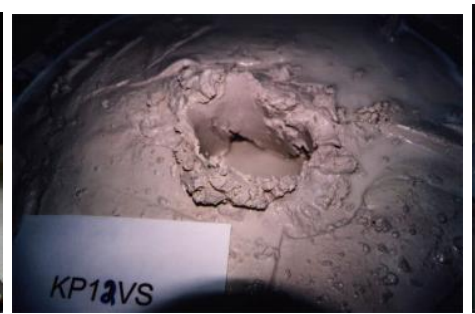

After test conclusion.

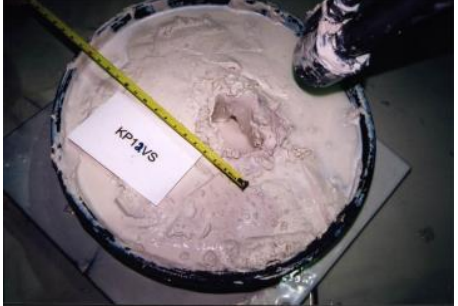

After test conclusion.

Figure 7.13. Test KP31VS (updated from KP12VS) Sequence June 18, 2002: Kaolin clay simulant, pneumatic conveyance, air, water, head feed, TORE® oriented at vertically with head submerged in the simulant.

\subsubsection{KP313S Observations}

During this test water penetration is first visible around the assembly and later at the sludge-container interface. Observations made after the test was completed showed the air-water spray cut or drilled holes in the clay that were observed surfacing around the edges of the container. 


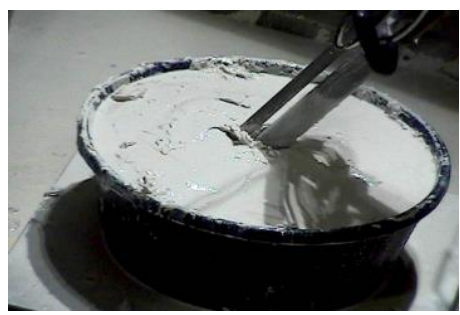

Prior to test start.
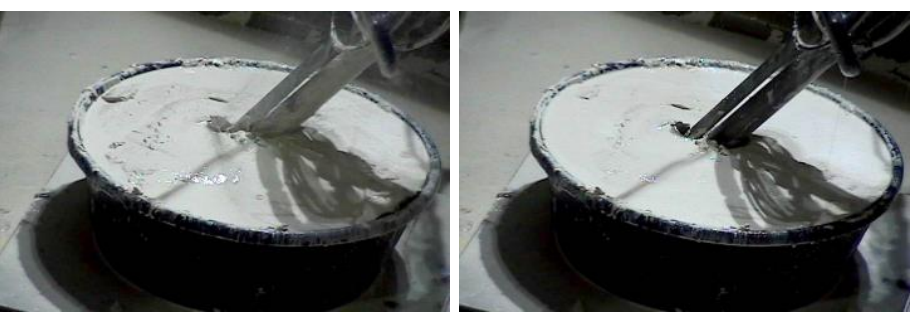

During TORE® Lance operation. After test conclusion.

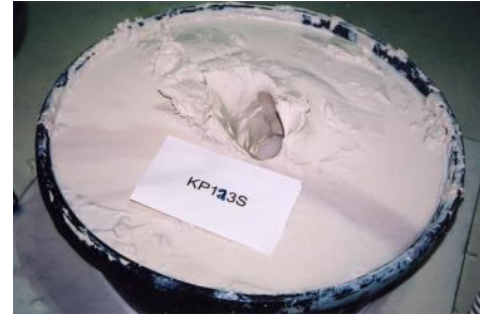

After test conclusion.

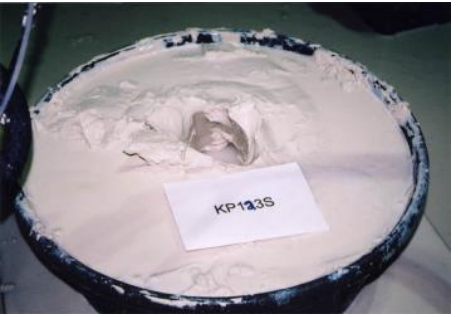

After test conclusion.

Figure 7.14. Test KP313S (updated from KP123S) Sequence June 18, 2002: Kaolin clay simulant, pneumatic conveyance, air, water, head feed, TORE® oriented at $30^{\circ}$ with head submerged in the simulant.

\subsubsection{KP316S Observations}

During this test the operation air and water first penetrated the sludge surface near the TORE® Lance head and soon after penetrated at the sludge container interface.
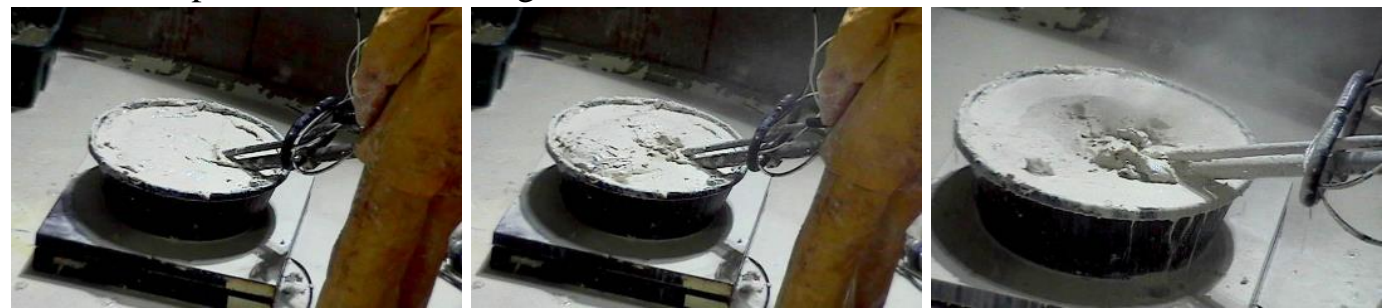

Prior to test start.

During TORE® Lance operation. During TORE® Lance operation.

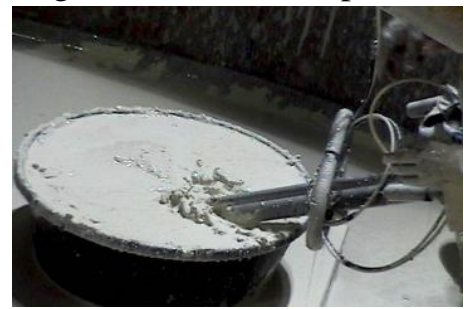

After test conclusion.

Figure 7.15. Test KP316S (updated from KP126S) Sequence June 18, 2002: Kaolin clay simulant, pneumatic conveyance, air, water, head feed, TORE® oriented at $60^{\circ}$ with head submerged in the simulant. 


\subsubsection{KP319S Observations}

During this test the air and water penetrated through the top of the sludge and around the perimeter of the container almost simultaneously.

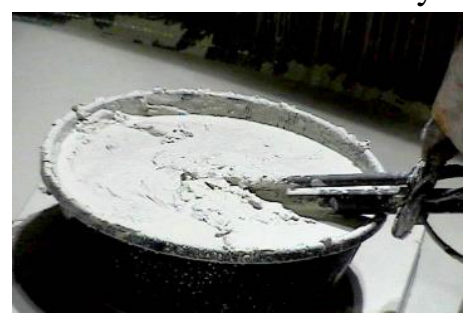

Prior to test start.

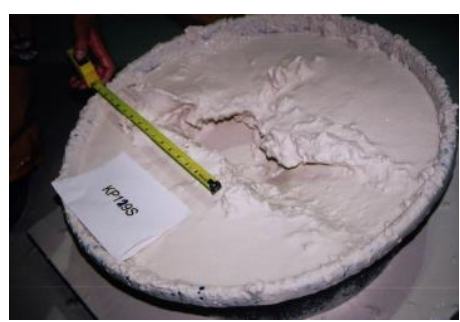

After test conclusion.

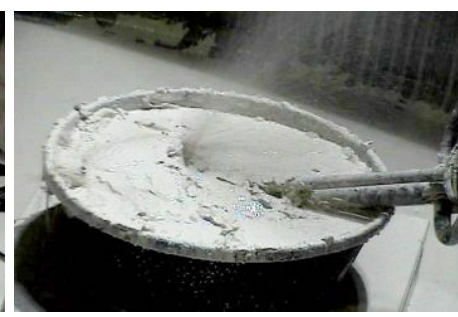

During TORE® Lance operation. After test conclusion

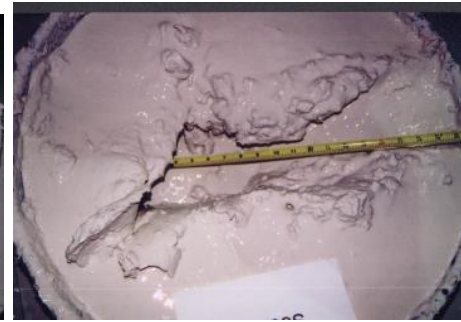

After test conclusion
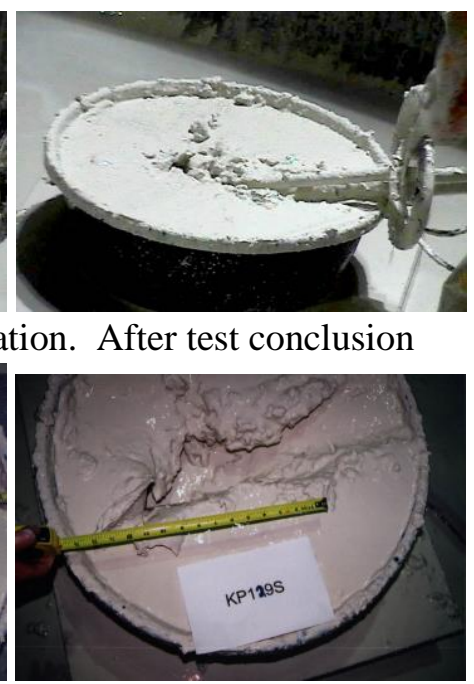

After test conclusion

Figure 7.16. Test KP319S Sequence June 18, 2002: Kaolin clay simulant, pneumatic conveyance, air, water, head feed, TORE® oriented at horizontally $\left(\right.$ at $\left.90^{\circ}\right)$ with head submerged in the simulant.

\subsection{Sludge Test Results}

The kaolin test results showed significantly different behavior based on the fluid used for mobilization: air, water, or an air-water combination.

- The air took the path of least resistance, channeling between the sludge and the assembly or the sludge and container. After this occurred no additional dislodging of the sludge was observed.

- The water also took the path of least resistance; however, some dislodging was observed.

- The air-water combination was able to cut small-diameter channels through the sludge to form a radial cut pattern. Additional dislodging of the sludge occurred along these paths.

When coupled with pneumatic conveyance and eduction the most effective method for sludge dislodging and retrieval turned out to be the air-water combination. The air-water stream was able to penetrate through the sludge; the assist to pneumatic conveyance provided by the compressed air (with some water) enhanced the potential for some retrieval.

The water only dislodging stream provided quite a bit of additional water to be conveyed pneumatically out of the tank. This configuration tended to overload the system retrieval capability and water tended to pool up on the surface of the sludge. With a different retrieval approach or one designed to handle this water flow, the approach may be more effective. The air only dislodging stream is not recommended for dislodging and retrieval of sludge. Details of the test data are listed in Table 7.2. 
Table 7.2. Results of TORE® Lance retrieval of sludge using air, water, and air-water for mobilizing coupled with pneumatic conveyance.

\begin{tabular}{|c|c|c|c|c|c|c|c|c|c|c|c|c|}
\hline \multirow[t]{2}{*}{$\begin{array}{c}\text { Test } \\
\text { Number }\end{array}$} & \multirow[t]{2}{*}{ Data Interval } & \multirow{2}{*}{$\begin{array}{c}\begin{array}{c}\text { Simulant } \\
\text { Mobilized } \\
\text { (LRB) }\end{array} \\
\text { lbm }\end{array}$} & \multirow{2}{*}{$\begin{array}{c}\text { Simulant } \\
\text { Mobilized } \\
\text { lbm }\end{array}$} & \multirow{2}{*}{\begin{tabular}{|c|}
$\begin{array}{c}\text { Water } \\
\text { Flow Rate } \\
\text { Avg }\end{array}$ \\
gpm
\end{tabular}} & \multirow{2}{*}{$\begin{array}{c}\begin{array}{c}\text { Water Std } \\
\text { Dev }\end{array} \\
\text { gpm }\end{array}$} & \multicolumn{2}{|c|}{$\begin{array}{c}\text { Total Water } \\
\text { Consumption } \\
\text { Water }\end{array}$} & \multirow{2}{*}{\begin{tabular}{|c|}
$\begin{array}{c}\text { Material } \\
\text { Collected in } \\
\text { Hopper }\end{array}$ \\
lbm
\end{tabular}} & \multirow{2}{*}{$\begin{array}{c}\begin{array}{c}\text { Air Flow } \\
\text { through } \\
\text { Conveyance } \\
\text { Line Avg }\end{array} \\
\text { scfm }\end{array}$} & \multirow{2}{*}{$\begin{array}{c}\text { TORE® } \\
\text { Head Feed } \\
\text { Pressure } \\
\text { Avg } \\
\text { psi }\end{array}$} & \multirow{2}{*}{$\begin{array}{c}\text { TORE® } \\
\text { Supply } \\
\text { Pressure } \\
\text { Avg } \\
\text { psi }\end{array}$} & \multirow{2}{*}{$\begin{array}{c}\text { Pitot } \\
\text { Probe } \\
\Delta \text { P Avg } \\
\text { psi } \\
\end{array}$} \\
\hline & & & & & & gal & lbm & & & & & \\
\hline \multicolumn{13}{|c|}{$6 / 5 / 2002$} \\
\hline KP11V0 & $11: 17: 28$ to $11: 17: 47$ & 0 & 2 & 0 & 0.0 & 0 & 0.0 & 2 & 441 & 15.7 & 36.2 & 3.8 \\
\hline KP11VS & $11: 21: 55$ to $11: 22: 24$ & 0 & 14 & 0 & 0.0 & 0 & 0.0 & -2 & 362 & 15.5 & 35.9 & 2.6 \\
\hline KP21VS-1 & $14: 49: 17$ to $14: 50: 59$ & -28 & -2 & 97 & 2.1 & 164.1 & 1363.7 & 1101 & 63 & 3.0 & 23.1 & 0.1 \\
\hline KP21VS-2 & $14: 53: 37$ to $14: 55: 10$ & N/A & -10 & 96 & 7.5 & 148.6 & 1234.9 & 1003 & 59 & 2.8 & 22.7 & 0.1 \\
\hline KP21VS-3 & $15: 04: 50$ to $15: 07: 03$ & N/A & 11 & 96 & 0.2 & 213.5 & 1774.2 & $\begin{array}{cl}860 & \text { (limited } \\
\text { out) }\end{array}$ & 58 & 2.1 & 22.3 & 0.1 \\
\hline \multicolumn{13}{|c|}{$6 / 18 / 2002$} \\
\hline KP21VS & $11: 13: 52$ to $11: 15: 00$ & -50 & -54 & 95 & 2.9 & 111.1 & 923.0 & 707 & 62 & 2.2 & 21.9 & 0.1 \\
\hline KP21VSS & $11: 27: 35$ to $11: 28: 45$ & -36 & -54 & 95 & 0.4 & 110.7 & 920.1 & 746 & 63 & 2.0 & 21.7 & 0.1 \\
\hline KP219S & $11: 42: 42$ to $11: 44: 11$ & -31 & -9 & 95 & 18.9 & 140.3 & 1166.1 & 857 & 67 & 2.2 & 21.2 & 0.1 \\
\hline KP216S & $13: 31: 38$ to $13: 32: 37$ & -15 & -16 & 95 & 11.0 & 95.1 & 790.3 & 640 & 67 & 2.4 & 22.1 & 0.1 \\
\hline KP213S & $13: 41: 05$ to $13: 42: 23$ & -18 & -19 & 96 & 1.0 & 124.8 & 1037.1 & 807 & 60 & 2.2 & 21.9 & 0.1 \\
\hline KP31V2 & $14: 21: 46$ to $14: 22: 05$ & -2 & -2 & 8.8 & 5.6 & 2.3 & 19.5 & 8 & 348 & 20.8 & 41.4 & 2.5 \\
\hline KP31V0 & $14: 24: 04$ to $14: 24: 29$ & 2 & 5 & 7.8 & 3.3 & 3.3 & 27.0 & 8 & 323 & 20.9 & 41.7 & 2.1 \\
\hline KP31VS & $14: 27: 47$ to $14: 28: 39$ & -6 & -3 & 7.4 & 2.4 & 6.4 & 53.3 & 27 & 326 & 21.2 & 42.3 & 2.2 \\
\hline KP313S & $14: 38: 35$ to $14: 38: 58$ & -20 & 8 & 7.9 & 4.1 & 3.2 & 26.3 & 12 & 327 & 21.4 & 41.9 & 2.1 \\
\hline KP316S & $14: 47: 27$ to $14: 48: 30$ & -1 & -3 & 7.9 & 2.1 & 8.3 & 68.9 & 29 & 331 & 21.3 & 42.0 & 2.2 \\
\hline KP319S & $14: 57: 28$ to $14: 57: 55$ & -32 & 5 & 13 & 9.5 & 5.6 & 46.7 & 16 & 332 & 21.4 & 41.6 & 2.2 \\
\hline
\end{tabular}





\subsection{Larger-Scale TORE® Lance Evaluations}

To make the transition between the stationary mobilization and retrieval tests described in Sections 5 through 7 and larger scale operations, the TORE® Lance performance was investigated for dislodging and retrieving simulants from larger containers. These tests were conducted retrieving simulant from 55gal. drums, from the tank floor, and from buckets. During these tests the TORE® Lance was moved up and down, back and forth, and forcibly maneuvered to mobilize and retrieve simulant.

\subsection{Test Matrix}

These tests evaluated the TORE® Lance operation at larger scale. To identify each test a unique test number was developed. The components of this number were defined in Section 4.5. Three types of tests were conducted:

- $\quad$ To evaluate the ability of the TORE® Lance to conduct large scale retrieval of solids in a drum. These tests evaluated three combinations at larger scale. Tests were conducted using compressed air, compressed air and pneumatic conveyance, and an air-water mixture coupled with pneumatic conveyance.

- $\quad$ To evaluate the ability of the TORE® Lance to mobilize and retrieve simulant with reduced inlet air pressure, measured at the outlet of the compressor. Inlet pressures of 5,25, 30, and 45 psig were evaluated for mobilization and retrieval of solids from a drum and from the floor. The tests conducted on the floor special permitted visualization of the strength of the vortex.

- $\quad$ To evaluate mobilization by fine tuning the flow to the TORE® Lance head through adjustments to the balance valve. These tests were conducted retrieving solids from the floor and from a bucket.

The test matrix is listed in Table 8.1.

Table 8.1. Test matrix for TORE® Lance larger-scale evaluations.

\begin{tabular}{|l|l|l|l|l|l|l|l|l|}
\hline $\begin{array}{l}\text { Test } \\
\text { Number }\end{array}$ & $\begin{array}{l}\text { Simu- } \\
\text { lant }\end{array}$ & $\begin{array}{l}\text { Conveying } \\
\text { Fluid }\end{array}$ & $\begin{array}{l}\text { Mobilizing } \\
\text { Fluid }\end{array}$ & $\begin{array}{l}\text { Head } \\
\text { Feed }\end{array}$ & $\begin{array}{l}\text { Orien } \\
\text { tation }\end{array}$ & $\begin{array}{l}\text { Stand-off } \\
\text { Distance }\end{array}$ & $\begin{array}{l}\text { Compressor } \\
\text { Air Pressure }\end{array}$ \\
\hline Objective & \multicolumn{2}{|l|}{$\begin{array}{l}\text { To evaluate the ability of the TORE® Lance to conduct large scale retrieval of solids in } a \\
\text { drum. Three combinations were evaluated. }\end{array}$} \\
\hline DSP11VS & Sand & $\begin{array}{l}\text { Air: } \\
\text { pneumatic } \\
\text { conveyance }\end{array}$ & Air & Air & $\begin{array}{l}\text { Verti- } \\
\text { cal }\end{array}$ & $\begin{array}{l}\text { In contact } \\
\text { with solids }\end{array}$ & 100 psig \\
\hline DSP00VS & Sand & $\begin{array}{l}\text { Air: no } \\
\text { conveyance }\end{array}$ & Air & Air & $\begin{array}{l}\text { Verti- } \\
\text { cal }\end{array}$ & $\begin{array}{l}\text { In contact } \\
\text { with solids }\end{array}$ & 100 psig \\
\hline DSP10VS & Sand & $\begin{array}{l}\text { Air: } \\
\text { pneumatic } \\
\text { conveyance }\end{array}$ & Air & Air & $\begin{array}{l}\text { Verti- } \\
\text { cal }\end{array}$ & $\begin{array}{l}\text { In contact } \\
\text { with solids }\end{array}$ & 100 psig \\
\hline DSP31VS & Sand & $\begin{array}{l}\text { Air: } \\
\text { pneumatic }\end{array}$ & $\begin{array}{l}\text { Air and } \\
\text { water }\end{array}$ & $\begin{array}{l}\text { Air } \\
\text { and }\end{array}$ & $\begin{array}{l}\text { Verti- } \\
\text { cal }\end{array}$ & $\begin{array}{l}\text { In contact } \\
\text { with solids }\end{array}$ & 100 psig \\
\hline
\end{tabular}




\begin{tabular}{|c|c|c|c|c|c|c|c|}
\hline $\begin{array}{l}\text { Test } \\
\text { Number }\end{array}$ & $\begin{array}{l}\text { Simu- } \\
\text { lant }\end{array}$ & $\begin{array}{l}\text { Conveying } \\
\text { Fluid }\end{array}$ & $\begin{array}{l}\text { Mobilizing } \\
\text { Fluid }\end{array}$ & $\begin{array}{l}\text { Head } \\
\text { Feed }\end{array}$ & $\begin{array}{l}\text { Orien } \\
\text { tation }\end{array}$ & $\begin{array}{l}\text { Stand-off } \\
\text { Distance }\end{array}$ & $\begin{array}{l}\text { Compressor } \\
\text { Air Pressure }\end{array}$ \\
\hline & & conveyance & & water & & & \\
\hline Objective & \multicolumn{7}{|c|}{$\begin{array}{l}\text { To evaluate the ability of the TORE@ Lance to mobilize and retrieve simulant with reduced } \\
\text { inlet air pressure, measured at the outlet of the compressor. }\end{array}$} \\
\hline DSP11005 & Sand & $\begin{array}{l}\text { Air: } \\
\text { pneumatic } \\
\text { conveyance }\end{array}$ & Air & Air & $\begin{array}{l}\text { Verti- } \\
\text { cal }\end{array}$ & $\begin{array}{l}\text { In contact } \\
\text { with solids }\end{array}$ & 5 psig \\
\hline DSP11025 & Sand & $\begin{array}{l}\text { Air: } \\
\text { pneumatic } \\
\text { conveyance }\end{array}$ & Air & Air & $\begin{array}{l}\text { Verti- } \\
\text { cal }\end{array}$ & $\begin{array}{l}\text { In contact } \\
\text { with solids }\end{array}$ & $25 \mathrm{psig}$ \\
\hline FSP11030 & $\begin{array}{l}\text { Sand on } \\
\text { floor }\end{array}$ & $\begin{array}{l}\text { Air: } \\
\text { pneumatic } \\
\text { conveyance }\end{array}$ & Air & Air & $\begin{array}{l}\text { Verti- } \\
\text { cal }\end{array}$ & $\begin{array}{l}\text { Contacting } \\
\text { floor }\end{array}$ & $30 \mathrm{psig}$ \\
\hline FSP11025 & $\begin{array}{l}\text { Sand on } \\
\text { floor }\end{array}$ & $\begin{array}{l}\text { Air: } \\
\text { pneumatic } \\
\text { conveyance }\end{array}$ & Air & Air & $\begin{array}{l}\text { Verti- } \\
\text { cal }\end{array}$ & $\begin{array}{l}\text { Contacting } \\
\text { floor }\end{array}$ & 25 psig \\
\hline FSP11045 & $\begin{array}{l}\text { Sand on } \\
\text { floor }\end{array}$ & $\begin{array}{l}\text { Air: } \\
\text { pneumatic } \\
\text { conveyance }\end{array}$ & Air & Air & $\begin{array}{l}\text { Verti- } \\
\text { cal }\end{array}$ & $\begin{array}{l}\text { Contacting } \\
\text { floor }\end{array}$ & $45 \mathrm{psig}$ \\
\hline Objective & \multicolumn{7}{|c|}{$\begin{array}{l}\text { To evaluate mobilization by fine tuning the flow to the TORE® Lance head through } \\
\text { adjustments to the balance valve. }\end{array}$} \\
\hline FSZ1145 & $\begin{array}{l}\text { Sand on } \\
\text { floor }\end{array}$ & $\begin{array}{l}\text { Air: } \\
\text { pneumatic } \\
\text { conveyance }\end{array}$ & Air & Air & $\begin{array}{l}\text { Verti- } \\
\text { cal }\end{array}$ & $\begin{array}{l}\text { Contacting } \\
\text { floor }\end{array}$ & 45 psig \\
\hline BSZ1130 & $\begin{array}{l}\text { Sand in } \\
\text { bucket }\end{array}$ & $\begin{array}{l}\text { Air: } \\
\text { pneumatic } \\
\text { conveyance }\end{array}$ & Air & Air & $\begin{array}{l}\text { Verti- } \\
\text { cal }\end{array}$ & $\begin{array}{l}\text { In contact } \\
\text { with solids }\end{array}$ & 30 psig \\
\hline BSZ1145 & $\begin{array}{l}\text { Sand in } \\
\text { bucket }\end{array}$ & $\begin{array}{l}\text { Air: } \\
\text { pneumatic } \\
\text { conveyance }\end{array}$ & Air & Air & $\begin{array}{l}\text { Verti- } \\
\text { cal }\end{array}$ & $\begin{array}{l}\text { In contact } \\
\text { with solids }\end{array}$ & 45 psig \\
\hline FSZ1145 & $\begin{array}{l}\text { Sand on } \\
\text { floor }\end{array}$ & $\begin{array}{l}\text { Air: } \\
\text { pneumatic } \\
\text { conveyance }\end{array}$ & Air & Air & $\begin{array}{l}\text { Verti- } \\
\text { cal }\end{array}$ & $\begin{array}{l}\text { Contacting } \\
\text { floor }\end{array}$ & 45 psig \\
\hline
\end{tabular}

\subsection{Test Observations}

\subsubsection{Initial TORE® Lance Retrieval of Solids from a Drum}

These tests were conducted using compressed air, compressed air and pneumatic conveyance, and an air-water mixture coupled with pneumatic conveyance to mobilize and retrieve solids. 


\subsubsection{DSP11VS Observations Parts 1, 2 and 3}

This was the first test conducted to evaluate large scale mobilization and retrieval. The operator moved the TORE® Lance up and down in the wet sand to facilitate retrieval. Some solids retrieval was observed in the pneumatic conveyance line. Also some solids were thrown out of the drum during the testing. Three separate tests to evaluate this configuration were completed.

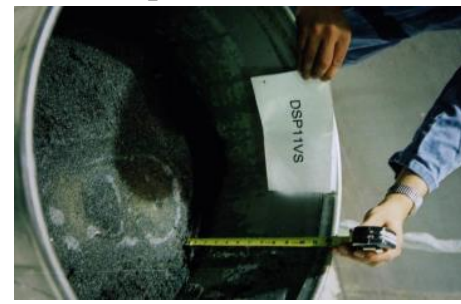

After test conclusion.

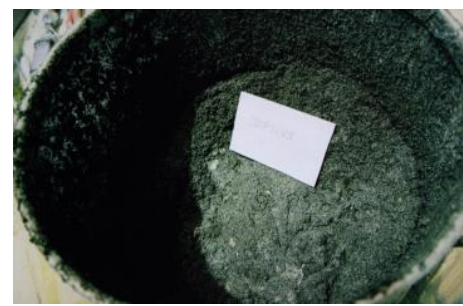

After test conclusion.

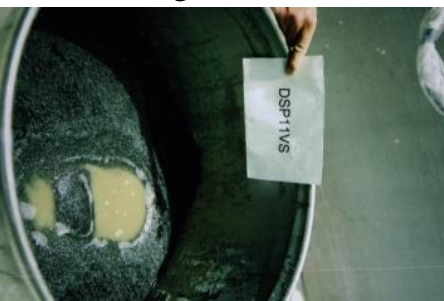

After test conclusion.

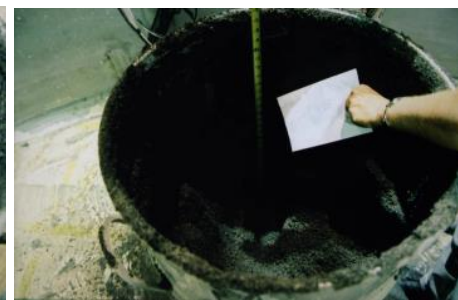

After test conclusion.

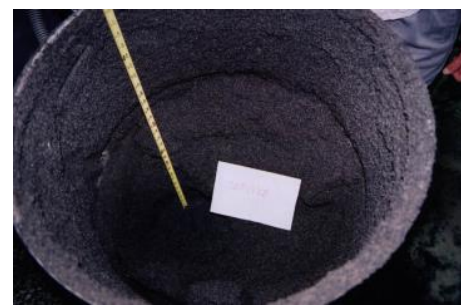

After test conclusion.

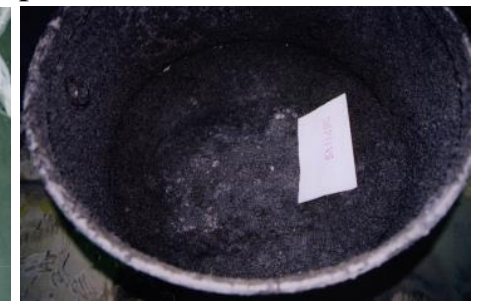

After test conclusion.

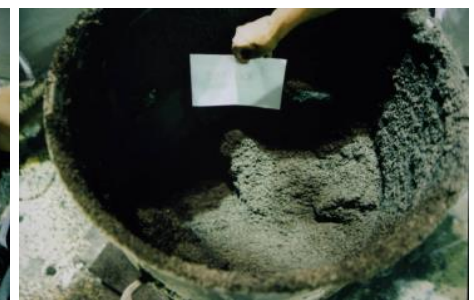

After test conclusion

Figure 8.1. Test DSP11VS ( $a+b)$ Sequence July 22, 2002: Wet sand/water simulant, pneumatic conveyance, air, no water, head feed, TORE® oriented vertically with head submerged into the simulant.

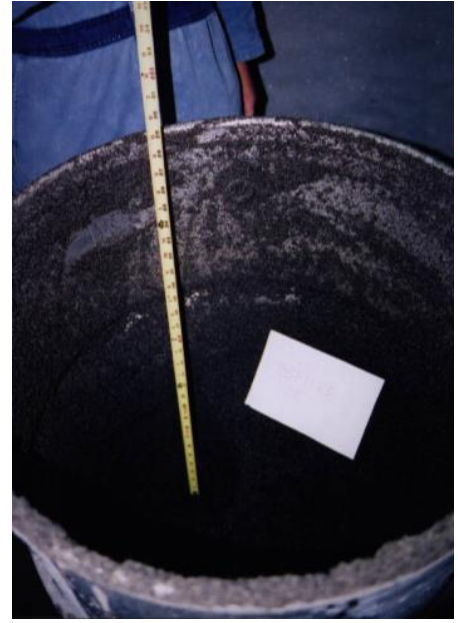

After test conclusion.

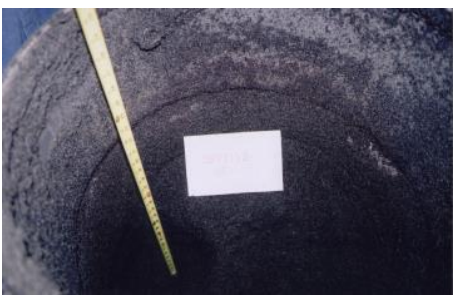

After test conclusion. 
Figure 8.2. Test DSP11VS (c) Sequence July 22, 2002: Wet sand/water simulant, pneumatic conveyance, air, no water, head feed, TORE® oriented vertically with head submerged into the simulant.

\subsubsection{DSP00VS Observations}

The purpose of this test was to determine the type of solids transport from only pneumatic conveyance. The results were similar to the pneumatic conveyance only tests conducted earlier with the solids in the container instead of the drum. Some solids were removed, and also, solids deposited in the conveyance line. The remainder of the transport occurred with a settled solids layer inside the conveyance line. With only pneumatic conveyance and no assist from the TORE® Lance eductor, transport could not be sustained.
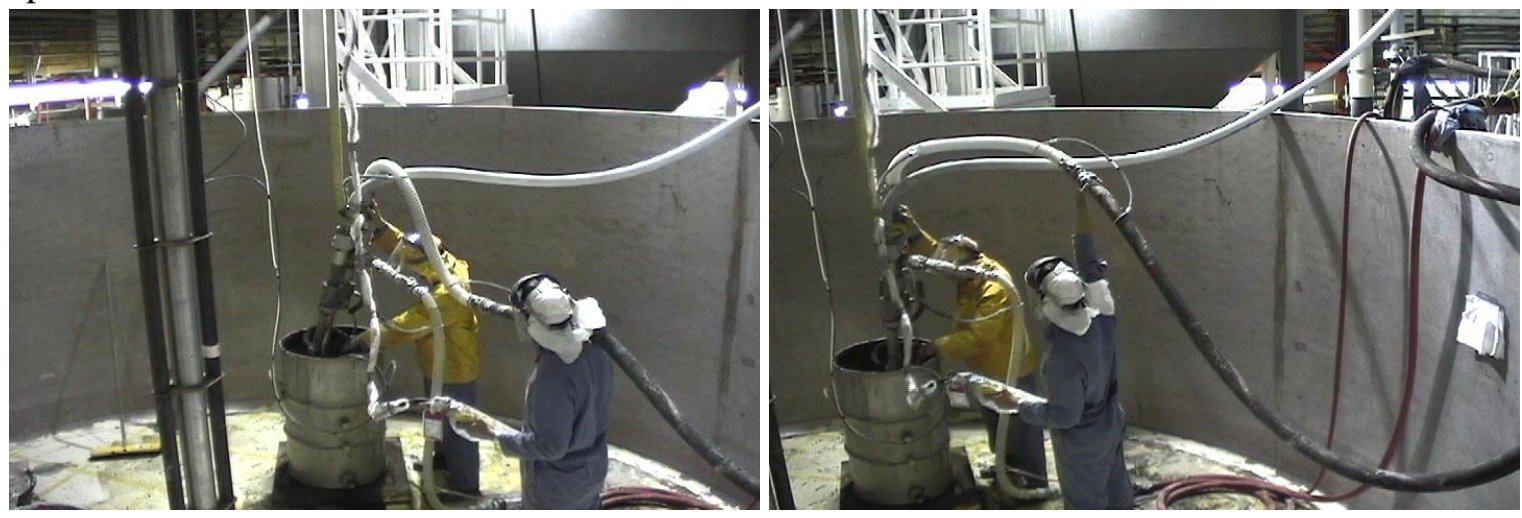

Prior to test start. During TORE® Lance operation.
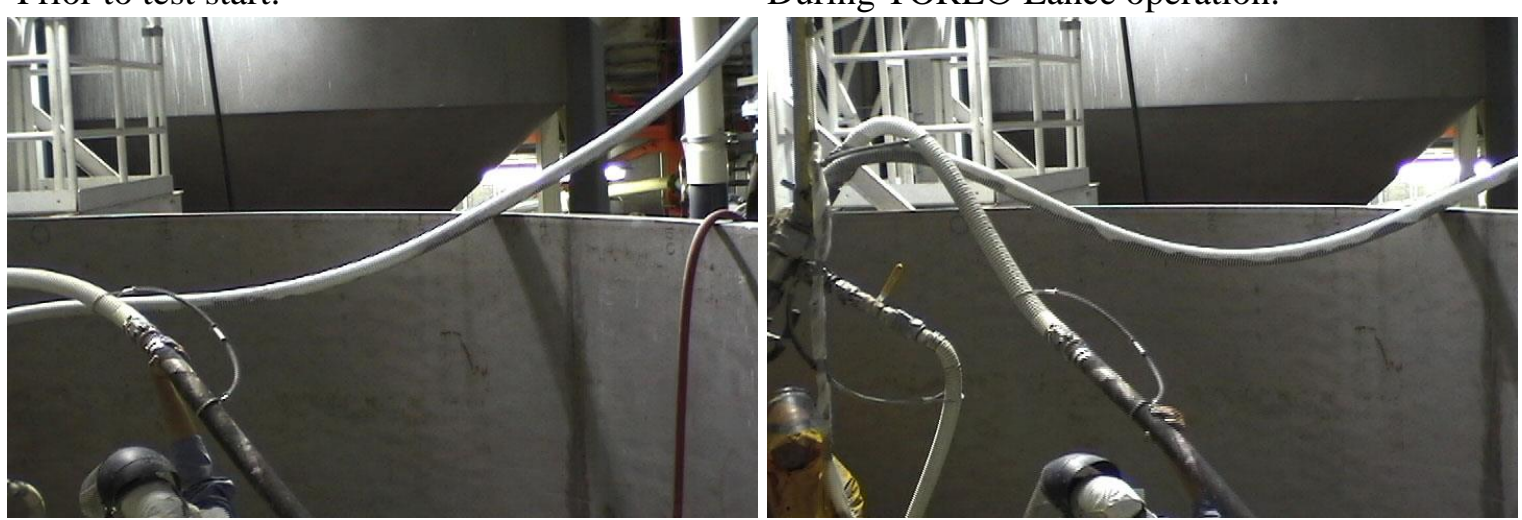

During TORE® Lance operation.

After test conclusion.

Figure 8.3. Test DSP00VS Sequence July 22, 2002: Wet sand/water simulant, pneumatic conveyance, no air, no water, no head feed, TORE® oriented vertically with head submerged into the simulant.

\subsubsection{DSP10VS Observations}

During this run both compressed air to the TORE® Lance eductor and pneumatic conveyance were operating. During the initial trial a slit in the pneumatic conveyance hose occurred due to continued erosion of the sides of the hose from the gravel. The test was stopped and restarted the next day after the hose was replaced. 

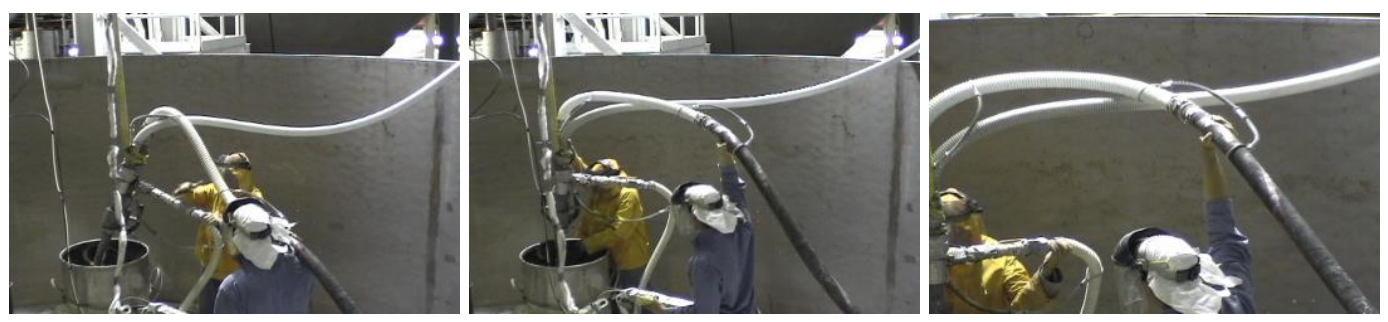

Prior to test start.

During TORE® Lance operation. During TORE® Lance operation.

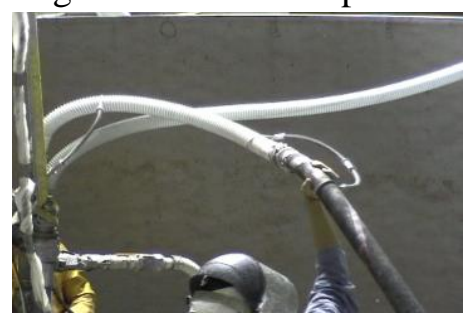

After test conclusion.

Figure 8.4. Test DSP10VS Sequence July 22, 2002: Wet sand/water simulant, pneumatic conveyance, air, no water, no head feed, TORE® oriented vertically with head submerged into the simulant.

\subsubsection{DSP31VS Observations}

During this test a combination of compressed air and pressurized water was used to mobilize the sand. The water flow rate averaged $\sim 5.2 \mathrm{gpm}$. Observations of the conveyance line indicated that mainly water was being retrieved; no solids were visible to darken the flow observed through the conveyance line.

\subsubsection{Evaluating Changes in Inlet Air Pressure}

A series of tests were conducted to determine how the TORE® Lance flow rate was affected by the inlet pressure. Data taken with the compressed air pressure ranging from 5 to $50 \mathrm{psig}$ when measured at the outlet of the compressor. This data was plotted with the data from operation at $100 \mathrm{psig}$ and is shown in Figure 3.6. Based on these results, a series of tests were completed with reduced inlet air pressure.

\subsubsection{DSP1105 Observations}

During this test the inlet air pressure was set at 5 psig at the outlet of the compressor. No solids mobilization were observed at this low inlet pressure to the TORE® Lance head. 


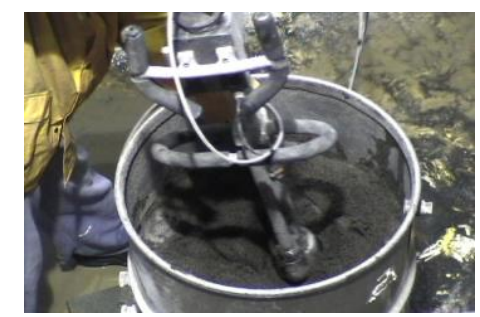

During TORE® Lance operation.

Figure 8.5. Test DSP11005 Sequence July 24, 2002: Wet sand simulant, pneumatic conveyance, air, no water, head feed, TORE® oriented vertically with head submerged into the simulant.

\subsubsection{DSP11025 Observations}

During this test, the inlet air pressure was set at 25 psig at the outlet of the compressor. Some solids mobilization was observed.

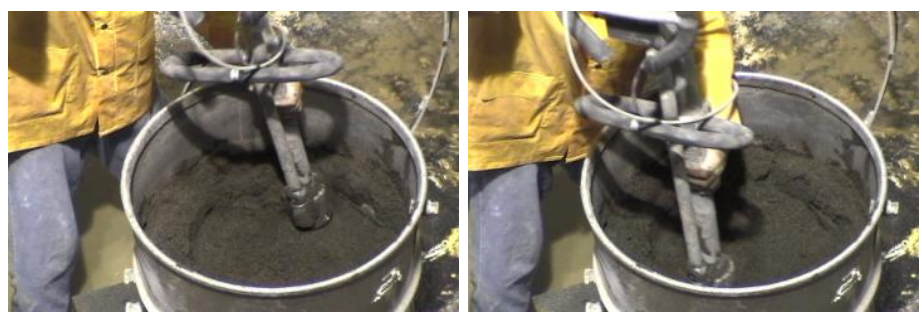

During TORE® Lance operation. During TORE® Lance operation.

Figure 8.6. Test DSP11025 Sequence July 24, 2002: Wet sand/water simulant, pneumatic conveyance, air, no water, head feed, TORE® oriented vertically with head submerged in the simulant.

\subsubsection{FSP11025 Observations}

During this test, the inlet air pressure was set at 25 psig at the outlet of the compressor. This test was similar to DSP11025 with the TORE® Lance oriented above solids on the tank floor. During this test you could see the effects of the precessing vortex moving the solids present on the floor of the tank.
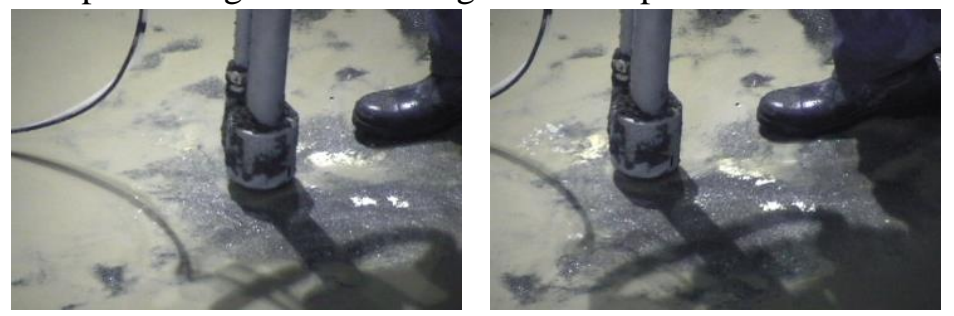

During TORE® Lance operation. During TORE® Lance operation.

Figure 8.7. Test FSP11025 (updated from DSP11025-Floor Sequence) July 24, 2002: Wet sand/water simulant, pneumatic conveyance, air, no water, head feed, TORE® oriented vertically with head 0 in. above the simulant. (25 psig.) 


\subsubsection{FSP11030 Observations}

During this test, the inlet air pressure was set at 30 psig at the outlet of the compressor. This test was conducted in two parts retrieving solids from a pile of sand located on the tank floor and retrieving wet solids from the tank floor. Some mobilization and retrieval was observed.
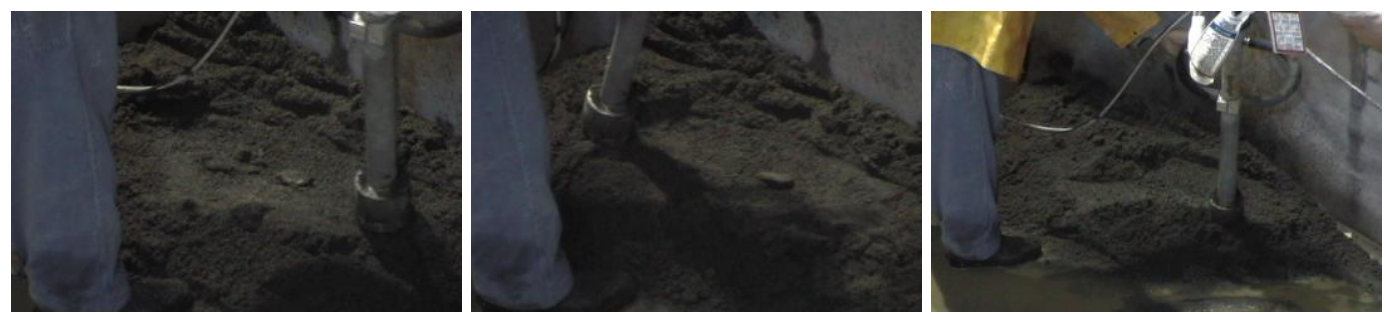

During TORE® Lance operation. During TORE® Lance operation. During TORE® Lance operation.

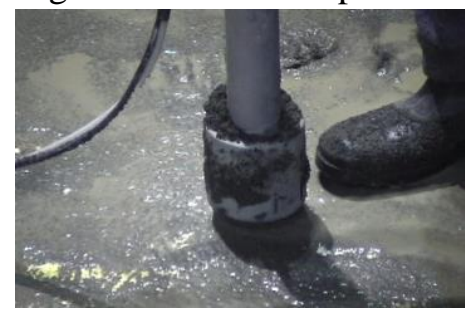

During TORE® Lance operation.

Figure 8.8. Test FSP11030 (updated from DSP11030-Floor Sequence) July 24, 2002: Wet sand/water simulant, pneumatic conveyance, air, no water, head feed, TORE® oriented vertically with head 0 in. above the simulant. (30 psig.)

\subsubsection{FSP11045 Observations}

During this test, the inlet air pressure was set at 45 psig at the outlet of the compressor. At this inlet air pressure setting the mobilization of the precessing vortex and the retrieval action from the eductor and pneumatic conveyance were very visible. As the TORE® Lance head moved across the floor, the solids immediately beneath the head were picked up and a clean path beneath the TORE® Lance head was observed.
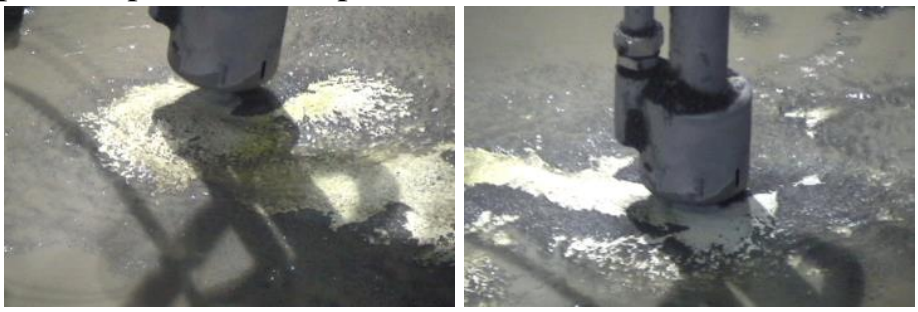

During TORE® Lance operation. During TORE® Lance operation.

Figure 8.9. Test FSP11045 (updated from DSP11045-Floor Sequence) July 24, 2002: Wet sand/water simulant, pneumatic conveyance, air, no water, head feed, TORE® oriented vertically with head 0 in. above the simulant. (45 psig)

\subsubsection{Fine Tuning TORE® Lance Operation}

This series of unconfined tests was conducted based on the following premises: 1) the TORE® Lance head has to be submerged (the slits where the vortex is produced should be covered by simulant) 
and 2) vortexing has to be constrained. To constrain the vortex, the air flow to the TORE® Lance head should be fine tuned, high enough to create a precessing vortex but low enough to keep sand from shooting out of the container. During prior tests the flow was either in $100 \%$ bypass mode with no flow to the TORE® Lance head or in the $0 \%$ bypass mode with all of the allowable flow through the TORE® Lance head. The flow split is controlled by the inlet line pressure and the spacer installed.

\subsubsection{FSZ1145 Test 1 Observations}

During this test, the inlet air pressure was set at 45 psig at the outlet of the compressor and the TORE® Lance unit was disconnected from the pneumatic conveyance line. The objective was to observe the solid exiting the end of the conveyance line and depositing on the floor. Some solids transfer was observed exiting the hose and depositing on the floor.

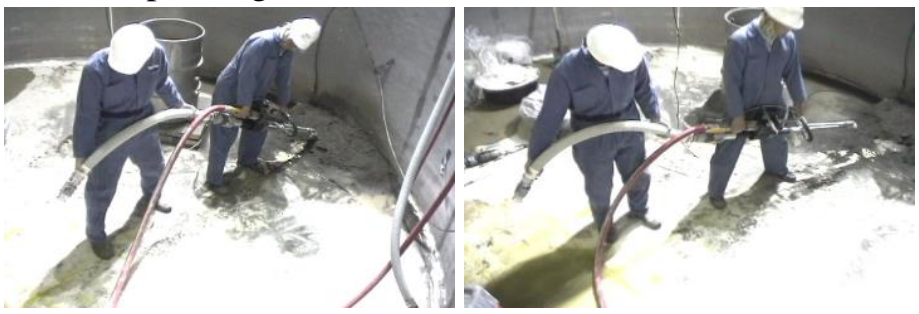

During TORE® Lance operation. After test conclusion.

Figure 8.10. FSZ1145 Test 1 Sequence July 31, 2002: Wet sand/water simulant on floor, no pneumatic conveyance, air, no water, head feed, TORE® operated manually.

\subsubsection{FSZ1145 Test 2 Observations}

This was a repeat of the prior test. During this test, the inlet air pressure was set at 45 psig at the outlet of the compressor and the TORE® Lance unit was disconnected from the pneumatic conveyance line. The objective was to observe the solid exiting the end of the conveyance line and depositing on the floor. Some solids transfer was observed exiting the hose and depositing on the floor.

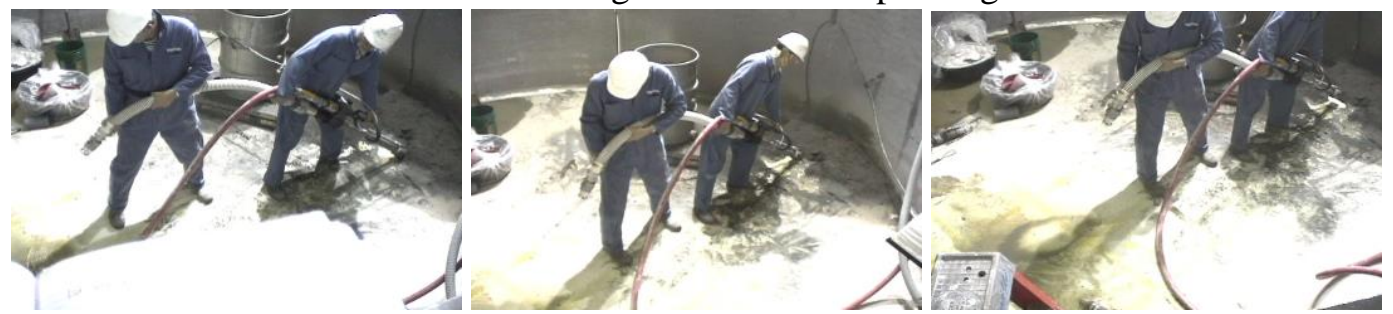

During TORE® Lance operation. During TORE® Lance operation. After test conclusion.

Figure 8.11. FSZ1145 Test 2 Sequence July 31, 2002: Wet sand/water simulant on floor, no pneumatic conveyance, air, no water, head feed, TORE® operated manually.

\subsubsection{FSZ1145 Test 3 Observations}

This was a repeat of the prior two tests. During this test, the inlet air pressure was set at 45 psig at the outlet of the compressor and the TORE® Lance unit was disconnected from the pneumatic conveyance line. The objective was to observe the solid exiting the end of the conveyance line and depositing on the floor. Some solids transfer was observed exiting the hose and depositing on the floor. 

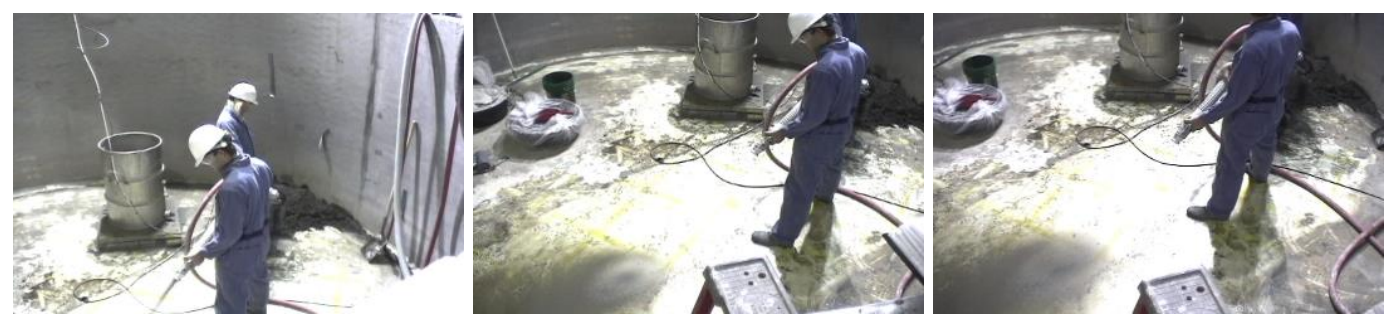

During TORE® Lance operation. During TORE® Lance operation. During TORE® Lance operation.

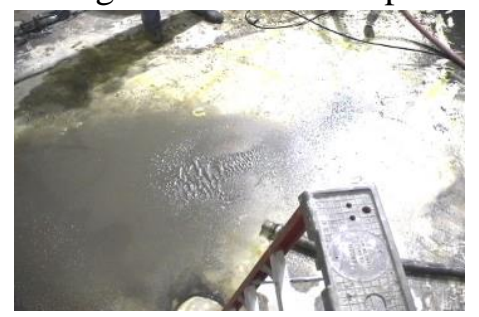

After test conclusion.

Figure 8.12. FSZ1145 Test 3 Sequence July 31, 2002: Wet sand/water simulant on floor, no pneumatic conveyance, air, no water, head feed, TORE® operated manually.

\subsubsection{BSZ1130 Test 4 Observations}

During this test, the inlet air pressure was set at 30 psig at the outlet of the compressor and the TORE® Lance unit was disconnected from the pneumatic conveyance line. The objective was to observe the solid exiting the end of the conveyance line and depositing on the floor. Some pulsating solids transfer was observed through the outlet of the disconnected conveyance line.

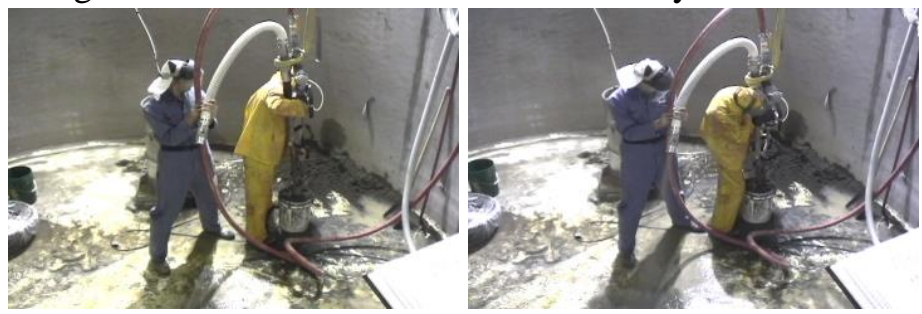

During TORE® Lance operation. During TORE® Lance operation.

Figure 8.13. BSZ1130 Test 4 Sequence July 31, 2002: Wet sand/water simulant in bucket, no pneumatic conveyance, air (at 30psig), no water, head feed, TORE® operated manually.

\subsubsection{BSZ1145 Test 5 Observations}

This test was a repeat of the prior test with the inlet air pressure increased to 45 psig at the outlet of the compressor and the TORE® Lance unit was disconnected from the pneumatic conveyance line. The objective was to observe the solid exiting the end of the conveyance line and depositing on the floor. This configuration worked excellently. A strong continuous stream of solids was observed exiting through the outlet of the disconnected conveyance line. 

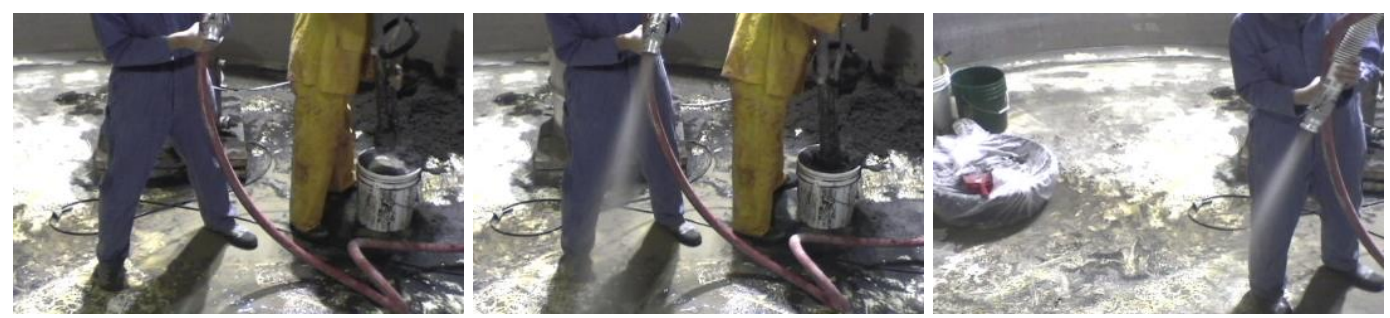

During TORE® Lance operation. During TORE® Lance operation. During TORE® Lance operation.

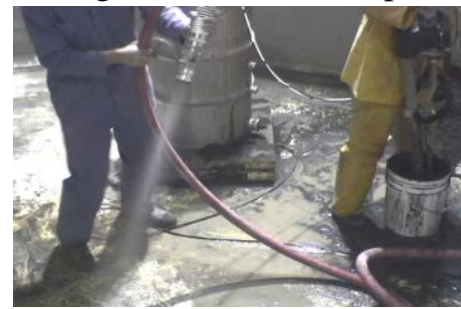

During TORE® Lance operation.

Figure 8.14. BSZ1145 Test 5 Sequence July 31, 2002: Wet sand/water simulant in bucket, no pneumatic conveyance, air (at 45 psig), no water, head feed, TORE® operated manually.

\subsubsection{FSZ1145 Test 6 Observations}

During this test, the inlet air pressure was set at 45 psig at the outlet of the compressor and the TORE® Lance unit was disconnected from the pneumatic conveyance line. The objective was to observe the solid exiting the end of the conveyance line and depositing on the floor. At this configuration steady transfer of solids was observed exiting the conveyance line.
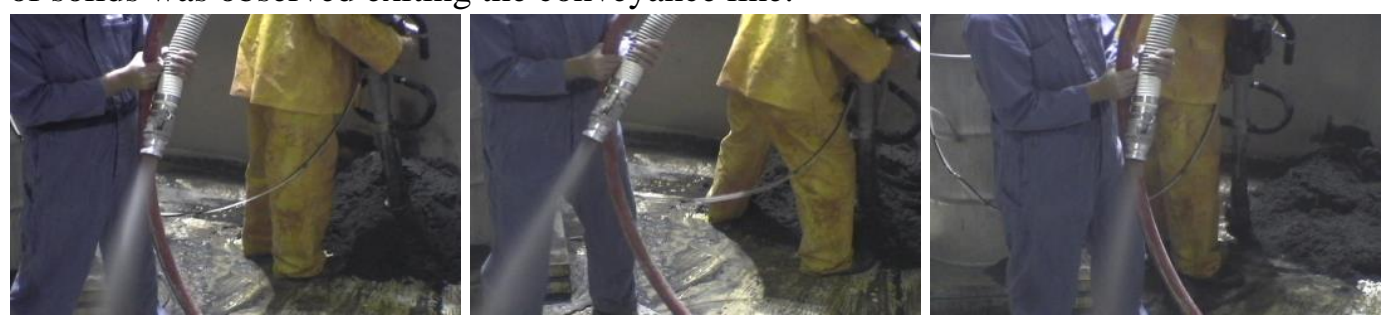

During TORE® Lance operation. During TORE® Lance operation. During TORE® Lance operation.

Figure 8.15. FSZ1145 Test 6 Sequence July 31, 2002: Wet sand/water simulant in pile on floor, no pneumatic conveyance, air, no water, head feed, TORE® operated manually.

\subsubsection{BWZ1045 Test 7 Observations}

The purpose of this test was to observe steady fluid transfer from one location to another using the TORE® Lance. In this configuration, only air eduction was used to support the transfer. The tests showed that air eduction transferred a steady stream of water from the bucket through the TORE® and out the end of the conveyance line. 


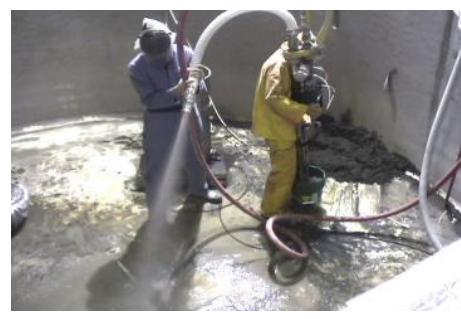

During TORE® Lance operation.
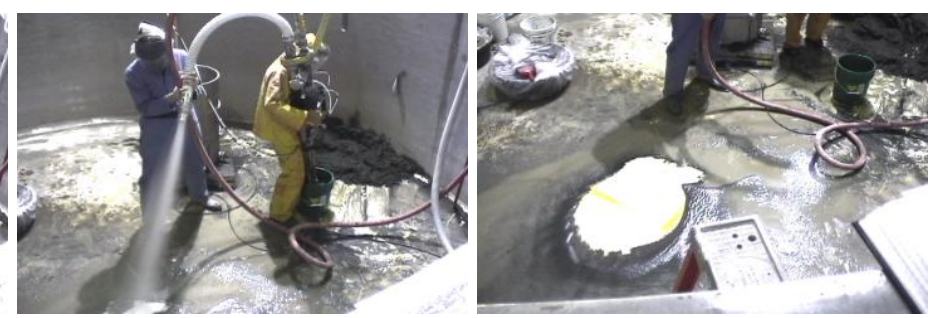

During TORE® Lance operation. After test conclusion

Figure 8.16. BWZ1045 Test 7 Sequence July 31, 2002: Water without solids in bucket, no pneumatic conveyance, air, no water, no head feed, TORE® operated manually.

\subsubsection{BWZ1145 Test 8 Observations}

The purpose of this test was to repeat the prior test with the addition of mobilization air to the TORE® Lance head. The tests showed that air mobilization and eduction also transferred a steady stream of water from the bucket through the TORE® and out the end of the conveyance line. The flow to the head was controlled by the position of the balance valve.
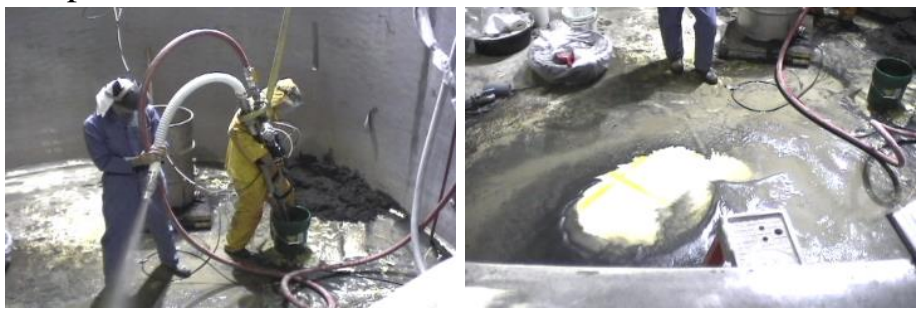

During TORE® Lance operation. After test conclusion

Figure 8.17. BWZ1145 Test 8 Sequence July 31, 2002: Water without solids in bucket, no pneumatic conveyance, air, no water, head feed, TORE® operated manually.

\subsection{Test Results}

This series of tests evaluated mobilization and retrieval of solids from drums, buckets, and on the floor. The efforts focused on fine-tuning the TORE® Lance operation. Operation at lower inlet compressed air pressure especially in the range of $45 \mathrm{psig}$ when measured at the outlet of the compressor worked well for solids mobilization and retrieval. During unconfined tests conducted retrieving sand from the floor permitted visualization of the presence of the precessing vortex by the pickup pattern remaining on the floor. Solids were mobilized and retrieved. Additional fine tuning tests showed that operation at this pressure with and without mobilization was a good combination for water transfer.

Details of the test data are listed in Table 8.2. 
Table 8.2. Results of TORE® Lance mobilizing and retrieval of sand in confined and unconfined configurations

\begin{tabular}{|c|c|c|c|c|c|c|c|c|c|c|c|c|}
\hline \multirow[t]{2}{*}{$\begin{array}{c}\text { Test } \\
\text { Number }\end{array}$} & \multirow[t]{2}{*}{ Data Interval } & \multirow{2}{*}{$\begin{array}{c}\begin{array}{c}\text { Simulant } \\
\text { Mobilized } \\
\text { (LRB) }\end{array} \\
\text { lbm } \\
\end{array}$} & \multirow{2}{*}{$\begin{array}{c}\text { Simulant } \\
\text { Mobilized }\end{array}$} & \multirow{2}{*}{\begin{tabular}{|c|}
$\begin{array}{c}\text { Water } \\
\text { Flow Rate } \\
\text { Avg }\end{array}$ \\
gpm \\
\end{tabular}} & \multirow{2}{*}{$\begin{array}{c}\begin{array}{c}\text { Water Std } \\
\text { Dev }\end{array} \\
\text { gpm } \\
\end{array}$} & \multicolumn{2}{|c|}{$\begin{array}{c}\text { Total Water } \\
\text { Consumption } \\
\text { Water }\end{array}$} & \multirow{2}{*}{$\begin{array}{c}\text { Material } \\
\text { Collected in } \\
\text { Hopper }\end{array}$} & \multirow{2}{*}{$\begin{array}{c}\begin{array}{c}\text { Air Flow } \\
\text { through } \\
\text { Conveyance } \\
\text { Line Avg }\end{array} \\
\text { scfm } \\
\end{array}$} & \multirow{2}{*}{$\begin{array}{c}\text { TORE® } \\
\text { Head Feed } \\
\text { Pressure } \\
\text { Avg } \\
\text { psi } \\
\end{array}$} & \multirow{2}{*}{$\begin{array}{c}\text { TORE® } \\
\text { Supply } \\
\text { Pressure } \\
\text { Avg } \\
\text { psi } \\
\end{array}$} & \multirow{2}{*}{$\begin{array}{c}\text { Pitot } \\
\text { Probe } \\
\Delta \text { P Avg } \\
\text { psi } \\
\end{array}$} \\
\hline & & & & & & gal & lbm & & & & & \\
\hline \multicolumn{13}{|c|}{$7 / 22 / 2002$} \\
\hline DSP11VSa & $13: 33: 24$ to $13: 40: 55$ & 116 & 109 & 0 & 0.0 & 0 & 0.0 & 73 & 389 & 10.6 & 26.5 & 3.0 \\
\hline DSP11VSb & 14:09:57 to $14: 16: 08$ & 143 & 160 & 0 & 0.0 & 0 & 0.0 & 115 & 376 & 10.7 & 26.7 & 2.8 \\
\hline DSP11VSc & $14: 42: 22$ to $14: 47: 47$ & 117 & 189 & 0 & 0.0 & 0 & 0.0 & 105 & 385 & 10.7 & 26.6 & 2.9 \\
\hline DSP00VS & $15: 28: 41$ to $15: 31: 29$ & 28 & 34 & 0 & 0.0 & 0 & 0.0 & 29 & 120 & 0.0 & 0.0 & 0.4 \\
\hline DSP10VS & $15: 50: 21$ to $15: 51: 27$ & 19 & 17 & 0 & 0.0 & 0 & 0.0 & 19 & 453 & 0.3 & 38.1 & 4.0 \\
\hline \multicolumn{13}{|c|}{$7 / 23 / 2002$} \\
\hline DSP10VS & $11: 47: 44$ to $11: 50: 11$ & 26 & Insuff. data & 0 & 0.0 & 0 & 0.0 & 22 & 476 & 0.3 & 37.8 & 4.3 \\
\hline DSP31VSa & $13: 48: 28$ to $13: 50: 41$ & -26 & -38 & 5.1 & 1.4 & 11.8 & 98.1 & 64 & 355 & 16.8 & 32.0 & 2.5 \\
\hline DSP31VSb & $13: 58: 51$ to $14: 00: 39$ & -25 & -10 & 5.3 & 1.3 & 9.5 & 78.9 & 49 & 360 & 16.7 & 32.0 & 2.6 \\
\hline \multicolumn{13}{|l|}{$7 / 24 / 2002$} \\
\hline DSP11005 & $11: 03: 23$ to $11: 03: 51$ & & 1 & 0 & 0.0 & 0 & 0.0 & 2 & 108 & 0.3 & -0.6 & 0.3 \\
\hline DSP11025 & $11: 05: 06$ to $11: 08: 59$ & 64 & 58 & 0 & 0.0 & 0 & 0.0 & 64 & 184 & 0.9 & 2.1 & 0.8 \\
\hline FSP11030 & $11: 26: 28$ to $11: 29: 16$ & N/A & N/A & 0 & 0.0 & 0 & 0.0 & 17 & 206 & 1.0 & 5.9 & 0.9 \\
\hline FSP11025 & $11: 38: 44$ to $11: 40: 49$ & N/A & N/A & 0 & 0.0 & 0 & 0.0 & 0 & 169 & 0.5 & 3.7 & 0.6 \\
\hline FSP11045 & $11: 45: 43$ to $11: 48: 45$ & N/A & N/A & 0 & 0.0 & 0 & 0.0 & 15 & 300 & 2.1 & 10.4 & 1.8 \\
\hline \multicolumn{13}{|c|}{$7 / 31 / 2002$} \\
\hline FSZ1145-1 & $10: 03: 40$ to $10: 06: 22$ & N/A & N/A & 0 & 0 & 0 & 0 & N/A & N/A & 5.2 & 8.1 & 0.0 \\
\hline FSZ1145-2 & $10: 25: 11$ to $10: 26: 50$ & N/A & N/A & 0 & 0 & 0 & 0 & N/A & N/A & 0.5 & 5.1 & 0.0 \\
\hline FSZ1145-3 & $10: 31: 24$ to $10: 32: 33$ & N/A & N/A & 0 & 0 & 0 & 0 & N/A & N/A & 1.1 & 14.6 & 0.0 \\
\hline BSZ1130-4 & $10: 38: 39$ to $10: 39: 35$ & N/A & N/A & 0 & 0 & 0 & 0 & N/A & N/A & 0.6 & 15.6 & 0.0 \\
\hline BSZ1145-5 & $10: 47: 47$ to $10: 48: 14$ & N/A & N/A & 0 & 0 & 0 & 0 & N/A & N/A & 0.1 & 17.5 & 0.0 \\
\hline FSZ1145-6 & $10: 49: 24$ to $10: 49: 39$ & N/A & N/A & 0 & 0 & 0 & 0 & N/A & N/A & 0.7 & 15.9 & 0.0 \\
\hline
\end{tabular}




\subsection{TORE® Lance Retrieval of Bulk Solids from a Drum}

These tests were conducted to integrate all lessons learned regarding TORE® Lance operation to optimize system performance and to duplicate some tests that had been conducted at the vendor's facility. A photo from one of the vendor's tests is shown in Figure 3.10.

\subsection{Test Matrix}

This test series consisted of two parts. To identify each test a unique test number was developed. The components of this number were defined in Section 4.5.

- To evaluate the ability of the TORE® Lance to conduct large scale retrieval of solids in a drum. These tests repeated some earlier tests with a fine tuned operating approach.

- To evaluate the ability of the TORE® Lance to mobilize and retrieve simulant over a range of water flow rates with the pneumatic conveyance line removed. These tests were conducted to duplicate tests witnessed by others at the vendor's facility.

The test matrix is listed in Table 9.1.

Table 9.1. Test matrix for TORE® Lance larger-scale evaluations.

\begin{tabular}{|c|c|c|c|c|c|c|c|}
\hline $\begin{array}{l}\text { Test } \\
\text { Number }\end{array}$ & $\begin{array}{l}\text { Simu- } \\
\text { lant }\end{array}$ & $\begin{array}{l}\text { Conveying } \\
\text { Fluid }\end{array}$ & $\begin{array}{l}\text { Mobilizing } \\
\text { Fluid }\end{array}$ & $\begin{array}{l}\text { Head } \\
\text { Feed }\end{array}$ & $\begin{array}{l}\text { Orien } \\
\text { tation }\end{array}$ & $\begin{array}{l}\text { Stand-off } \\
\text { Distance }\end{array}$ & $\begin{array}{l}\text { Water Flow } \\
\text { Rate }\end{array}$ \\
\hline Objective & \multicolumn{7}{|c|}{$\begin{array}{l}\text { To evaluate the ability of the TORE® Lance to conduct large scale retrieval of solids in a } \\
\text { drum. Three combinations were evaluated. }\end{array}$} \\
\hline DSP11VS & Sand & $\begin{array}{l}\text { Air: } \\
\text { pneumatic } \\
\text { conveyance }\end{array}$ & Air & Air & $\begin{array}{l}\text { Verti- } \\
\text { cal }\end{array}$ & $\begin{array}{l}\text { In contact } \\
\text { with solids }\end{array}$ & $0 \mathrm{gpm}$ \\
\hline DSP11VS & Sand & $\begin{array}{l}\text { Air: } \\
\text { pneumatic } \\
\text { conveyance }\end{array}$ & Air & Air & $\begin{array}{l}\text { Verti- } \\
\text { cal }\end{array}$ & $\begin{array}{l}\text { In contact } \\
\text { with solids }\end{array}$ & $0 \mathrm{gpm}$ \\
\hline DSP31VS & Sand & $\begin{array}{l}\text { Air: } \\
\text { pneumatic } \\
\text { conveyance }\end{array}$ & $\begin{array}{l}\text { Air and } \\
\text { water }\end{array}$ & $\begin{array}{l}\text { Air } \\
\text { and } \\
\text { water }\end{array}$ & $\begin{array}{l}\text { Verti- } \\
\text { cal }\end{array}$ & $\begin{array}{l}\text { In contact } \\
\text { with solids }\end{array}$ & $0 \mathrm{gpm}$ \\
\hline DSP21VS & Sand & $\begin{array}{l}\text { Air: } \\
\text { pneumatic } \\
\text { conveyance }\end{array}$ & Water & Water & $\begin{array}{l}\text { Verti- } \\
\text { cal }\end{array}$ & $\begin{array}{l}\text { In contact } \\
\text { with solids }\end{array}$ & $\sim 50 \mathrm{gpm}$ \\
\hline Objective & \multicolumn{7}{|c|}{$\begin{array}{l}\text { To evaluate the ability of the TORE® Lance to mobilize and retrieve simulant over a range } \\
\text { of water flow rates with the pneumatic conveyance line removed. }\end{array}$} \\
\hline $\begin{array}{l}\text { DSZ21VS } \\
10\end{array}$ & Sand & Water & Water & Water & $\begin{array}{l}\text { Verti- } \\
\text { cal }\end{array}$ & $\begin{array}{l}\text { In contact } \\
\text { with solids }\end{array}$ & $\sim 10 \mathrm{gpm}$ \\
\hline $\begin{array}{l}\text { DSZ21VS } \\
50\end{array}$ & Sand & Water & Water & Water & $\begin{array}{l}\text { Verti- } \\
\text { cal }\end{array}$ & $\begin{array}{l}\text { In contact } \\
\text { with solids }\end{array}$ & $\sim 50 \mathrm{gpm}$ \\
\hline DSZ20VS & Sand & Water & Water & None & Verti- & In contact & $\sim 70 \mathrm{gpm}$ \\
\hline
\end{tabular}




\begin{tabular}{|l|l|l|l|l|l|l|l|}
\hline $\begin{array}{l}\text { Test } \\
\text { Number }\end{array}$ & $\begin{array}{l}\text { Simu- } \\
\text { lant }\end{array}$ & $\begin{array}{l}\text { Conveying } \\
\text { Fluid }\end{array}$ & $\begin{array}{l}\text { Mobilizing } \\
\text { Fluid }\end{array}$ & $\begin{array}{l}\text { Head } \\
\text { Feed }\end{array}$ & $\begin{array}{l}\text { Orien } \\
\text { tation }\end{array}$ & $\begin{array}{l}\text { Stand-off } \\
\text { Distance }\end{array}$ & $\begin{array}{l}\text { Water Flow } \\
\text { Rate }\end{array}$ \\
\hline 70 & & & & & cal & with solids & \\
\hline $\begin{array}{l}\text { DSZ21VS } \\
70\end{array}$ & Sand & Water & Water & Water & $\begin{array}{l}\text { Verti- } \\
\text { cal }\end{array}$ & $\begin{array}{l}\text { In contact } \\
\text { with solids }\end{array}$ & $\sim 70$ gpm \\
\hline
\end{tabular}

\subsection{Test Observations}

\subsubsection{Sand Mobilization and Retrieval from a Drum}

During some of these tests the scale output to the data acquisition system malfunctioned, so weights removed from the container are not available for all tests.

\subsubsection{DSP11VS Observations}

During this test the TORE® Lance was attached to the pneumatic conveyance system. The inlet air pressure was set at $45 \mathrm{psig}$ at the outlet of the compressor. $\sim 35 \mathrm{lbm}$ solids were removed from the drum at a removal rate of $\sim 20 \mathrm{lbm} / \mathrm{min}$.

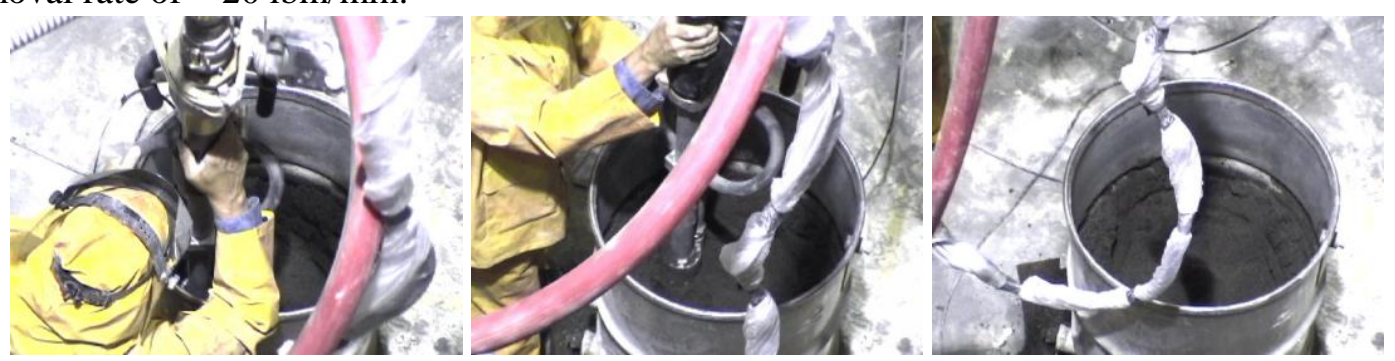

During TORE® Lance operation. During TORE® Lance operation. After test conclusion.

Figure 9.1. Test DSP11VS (updated from DSP01VS) Sequence August 7, 2002: Wet sand/water simulant, pneumatic conveyance, air, no water, head feed, TORE® oriented vertically with head submerged into the simulant.

\subsubsection{DSZ11VS Observations}

During this test the connection to the pneumatic conveyance line was removed; it was replaced with a short line used to direct the transferred material to the floor across the tank. The inlet air pressure was set at $45 \mathrm{psig}$ at the outlet of the compressor. $\sim 42 \mathrm{lbm}$ solids were removed from the drum at a removal rate of $\sim 45 \mathrm{lbm} / \mathrm{min}$. 

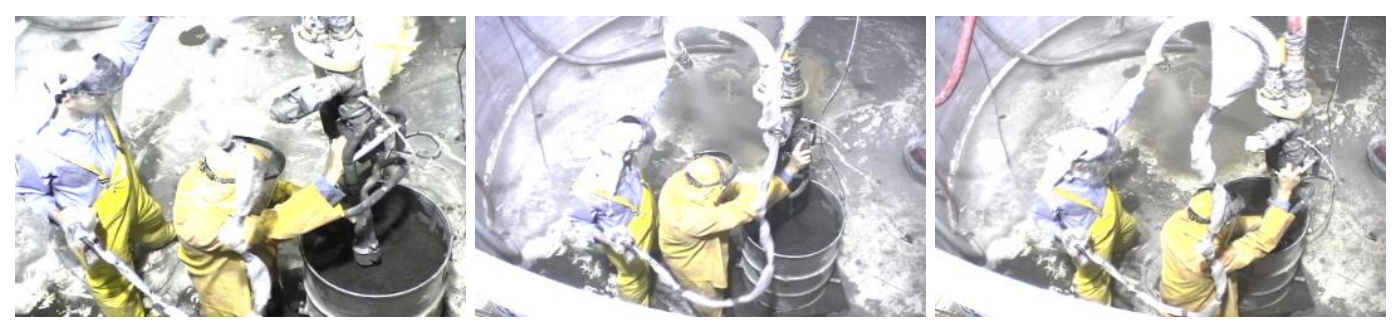

Before test start.

During TORE® Lance operation. During TORE® Lance operation.

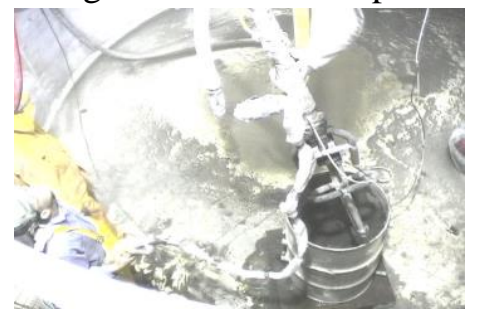

After test conclusion.

Figure 9.2. Test DSZ01VS Sequence August 7, 2002: Wet sand/water simulant, no pneumatic conveyance, air, no water, head feed, TORE® oriented vertically with head submerged into the simulant.

\subsubsection{DSP31VS Observations}

During this test the dislodging stream to the TORE® Lance head included $\sim 5$ gpm of water in addition to the compressed air. The inlet air pressure was set at $45 \mathrm{psig}$ at the outlet of the compressor.
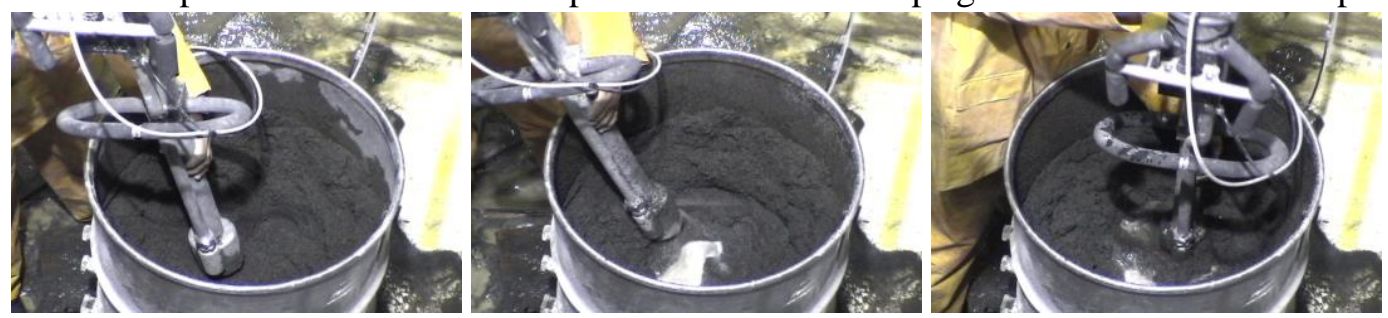

Before test start.

During TORE® Lance operation. During TORE® Lance operation.
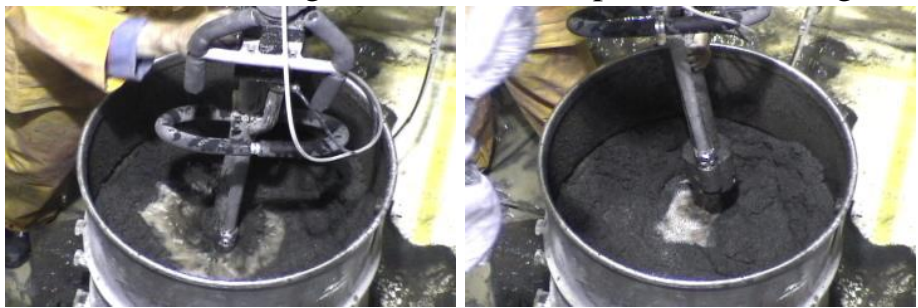

During TORE® Lance operation. After test conclusion.

Figure 9.3. Test DSP31VS (updated from DSP21VS) Sequence August 7, 2002: Wet sand/water simulant, pneumatic conveyance, air, water, head feed, TORE® oriented vertically with head submerged into the simulant. 


\subsubsection{DSP21VS Observations}

During this test only water was supplied to the TORE® Lance for both eduction and head feed. The flow rate was $\sim 50 \mathrm{gpm}$. A significant amount of water filled the drum and overwhelmed the retrieval capability of the combination of pneumatic conveyance and water eduction.
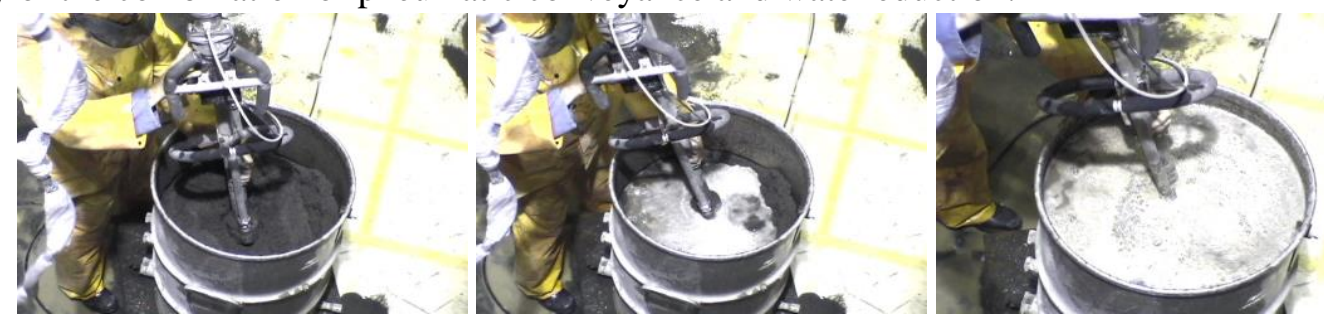

During TORE® Lance operation. During TORE® Lance operation. During TORE® Lance operation
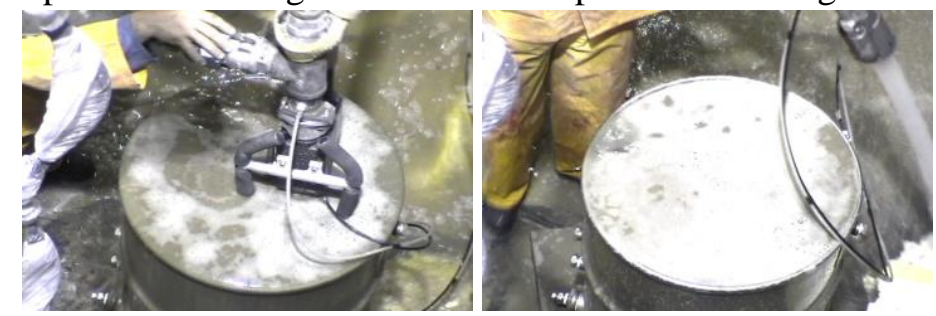

During TORE® Lance operation. After test conclusion.

Figure 9.4. Test DSP21VS (updated from DSP11VS) Sequence August 7, 2002: Wet sand/water simulant, pneumatic conveyance, no air, water, head feed, TORE® oriented vertically with head submerged into the simulant.

\subsubsection{Evaluating Effects of Water Flow Rate on Water-Only Mobilization and Retrieval}

Four tests were conducted evaluating using only water for mobilization and eduction of sand from the drum. During these tests the pneumatic conveyance line was not attached. It was replaced with a short hose used to direct the retrieved flow stream away from the end of the TORE® Lance.

\subsubsection{DSZ21VS10 Observations}

During this test the connection to the pneumatic conveyance line was removed; it was replaced with a short line used to direct the transferred material to the floor across the tank and only water was supplied to the TORE® Lance for both eduction and head feed. For this test the water flow rate was specifically set at $\sim 10 \mathrm{gpm}$, much lower than prior tests. This flow rate was too low to remove much solids from the drum. 


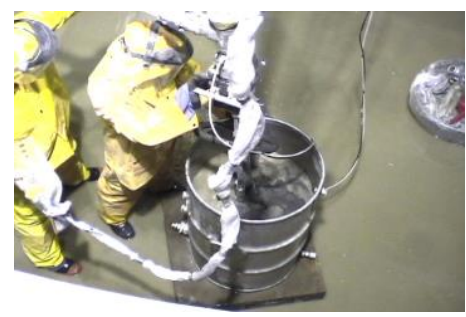

Before test start.

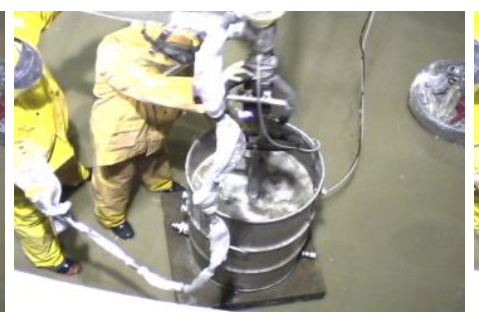

During TORE® Lance operation. After test conclusion.

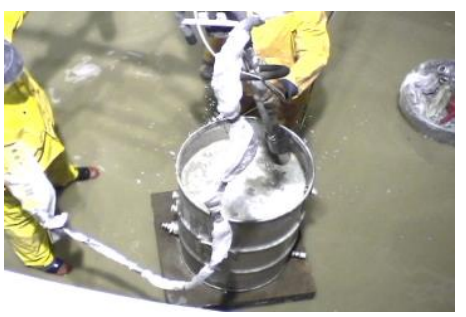

Figure 9.5. Test DSZ21VS10 (updated from DSZ11VS10) Sequence August 7, 2002: Wet sand/water simulant, no pneumatic conveyance, no air, water, head feed, TORE® oriented vertically with head submerged into the simulant. (10 gpm water flow rate.).

\subsubsection{DSZ21VS50 Observations}

This test was a repeat of the prior test but with the water flow rate increased to $\sim 50 \mathrm{gpm}$. During this test the connection to the pneumatic conveyance line was removed; it was replaced with a short line used to direct the transferred material to the floor across the tank and only water was supplied to the TORE® Lance for both eduction and head feed. At the test start some water, visible in the third photo, remained covering the sand in the drum. During this test a steady stream of dark water exited the line attached to the TORE® Lance outlet. This stream of dark colored water is visible in the first and second photos shown below. This is very similar to the type of transport observed by the project sponsor at the vendor's site (Figure 3.10) but (based on the color of the retrieved stream) with significantly more entrained solids.
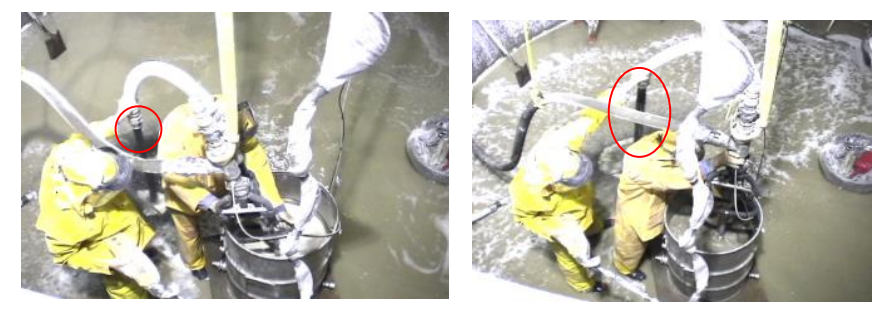

During TORE® Lance operation. During TORE® Lance operation.

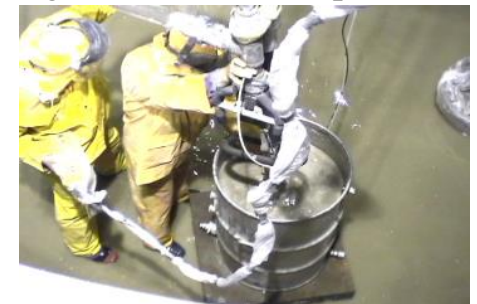

Before test start.

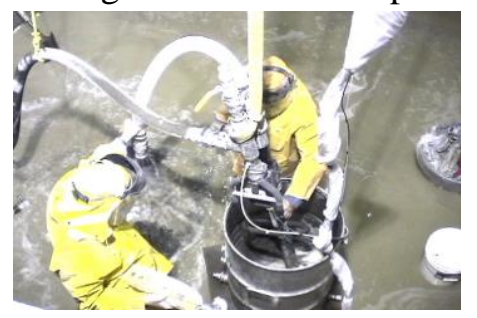

After test conclusion.

Figure 9.6. Test DSZ21VS50 (updated from DSZ11VS50) Sequence August 7, 2002: Wet sand/water simulant, no pneumatic conveyance, no air, water, head feed, TORE® oriented vertically with head submerged into the simulant. (50 gpm water flow rate). 


\subsubsection{DSZ20VS70 Observations}

This test was similar to the prior test; however, the water flow rate was increased to $\sim 70$ gpm with no flow to the TORE® Lance head. Observations of the water stream exiting the TORE® Lance output showed dramatic pulsing changes in color from white to dark as solids were sucked into the TORE® via eduction. The color change was dramatic and the retrieval was not nearly as continuous as seen in the prior test which used water flow through the TORE® Lance head to mobilize solids.
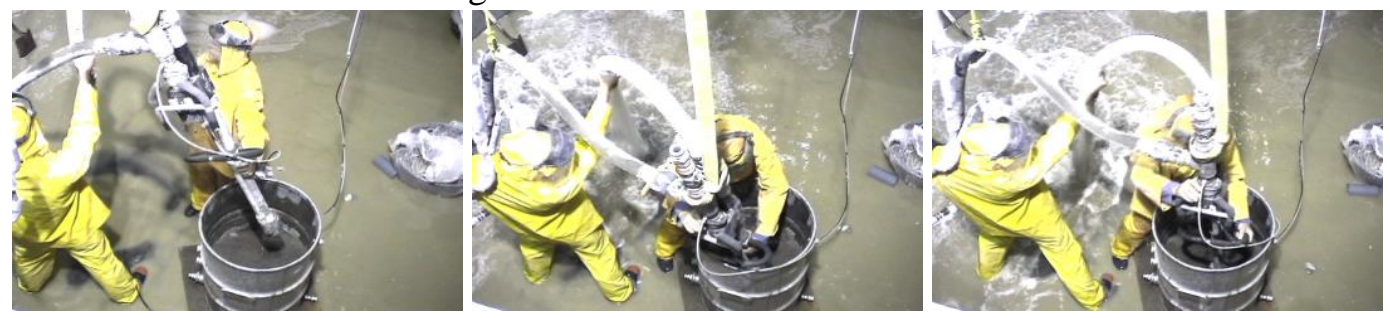

Before test start.

During TORE® Lance operation. During TORE® Lance operation.

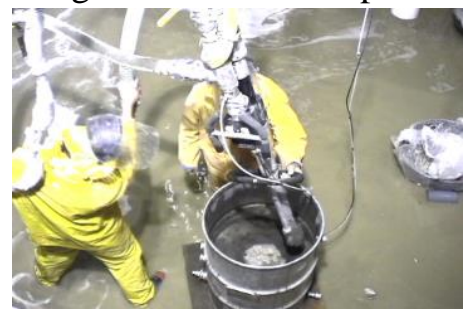

After test conclusion.

Figure 9.7. Test DSZ20VS70 (update of DSZ10VS70) Sequence August 7, 2002: Wet sand/water simulant, no pneumatic conveyance, no air, water, no head feed, TORE® oriented vertically with head submerged into the simulant. (70 gpm).

\subsubsection{DSZ21 VS70 Observations}

This test was similar to the prior test but with water flow to both the eductor and TORE® Lance head. The results from this test were very similar to the significant solids retrieval seen during test DSZ21VS50. In the second photo below the dark color of the solids stream exiting the discharge line is visible above the arm that is holding the outlet line. No pulsation existed in the flow. The combination of mobilization and eduction worked to create a steady retrieved stream of solids laden water. 

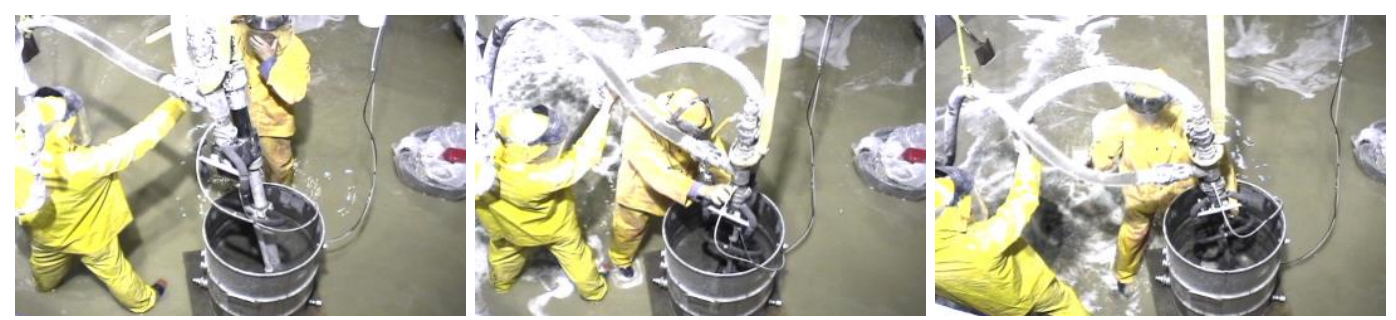

Before test start.

During TORE® Lance operation. During TORE® Lance operation.

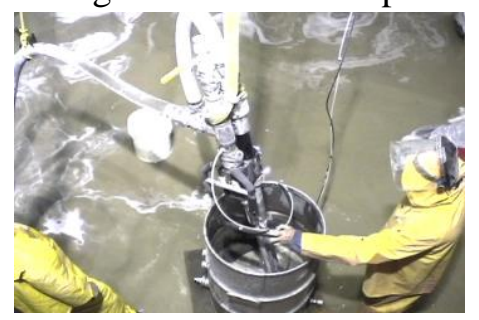

After test conclusion.

Figure 9.8. Test DSZ21VS70 (update of DSZ11VS70) Sequence August 7, 2002: Wet sand/water simulant, no pneumatic conveyance, no air, water, head feed, TORE® oriented vertically with head submerged into the simulant. (70 gpm).

\subsection{Test Results}

The conditions for these tests were selected based on observations from previous tests to fine tune TORE® Lance performance. Tests using compressed air to mobilize and retrieve sand simulant from a drum conducted with the inlet air pressure from the compressor set at 45 psig produced improved solids retrieval rates. The average retrieval rate observed was $\sim 20 \mathrm{lbm} / \mathrm{min}$; the peak retrieval rate obtained was $\sim 45 \mathrm{lbm} / \mathrm{min}$.

Tests using water for solids mobilization and eduction showed that when the retrieval line was attached to the pneumatic conveyance line, the water from the eductor overwhelmed retrieval and water accumulated in the drum. To remove this constraint, the conveyance line was removed and replaced with a short hose to direct the retrieval stream away from the TORE® Lance head. Using this configuration tests were conducted with inlet water flow rates of 10, 50 and $70 \mathrm{gpm}$. Mobilization and retrieval at 50 and $70 \mathrm{gpm}$ water flow rates were excellent. The retrieval was steady and significant amounts of solids were transported as indicated by the extremely dark color of the retrieved fluid. To determine the effect of the precessing vortex on these retrievals, one test with the inlet flow rate at 70 gpm was conducted with no water flow to the TORE® Lance head. Results in this case were definitely not as effective as when mobilization flow was provided. Without mobilization the retrieval flow pulsated between white and black as slugs of solids were intermittently introduced into the retrieval line by eduction. This qualitative comparison demonstrated the importance of the TORE® Lance precessing vortex for solids mobilization.

Details of the test data are listed in Table 9.2. 
Table 9.2. Results of TORE® Lance mobilizing and retrieval of bulk solids from a drum

\begin{tabular}{|c|c|c|c|c|c|c|c|c|c|c|c|c|}
\hline \multirow[t]{2}{*}{$\begin{array}{c}\text { Test } \\
\text { Number }\end{array}$} & \multirow[t]{2}{*}{ Data Interval } & \multirow{2}{*}{$\begin{array}{c}\begin{array}{c}\text { Simulant } \\
\text { Mobilized } \\
\text { (LRB) }\end{array} \\
\text { lbm }\end{array}$} & \multirow{2}{*}{$\begin{array}{c}\text { Simulant } \\
\text { Mobilized } \\
\text { lbm }\end{array}$} & \multirow{2}{*}{\begin{tabular}{|c|}
$\begin{array}{c}\text { Water } \\
\text { Flow Rate } \\
\text { Avg }\end{array}$ \\
gpm \\
\end{tabular}} & \multirow{2}{*}{$\begin{array}{c}\begin{array}{c}\text { Water Std } \\
\text { Dev }\end{array} \\
\text { gpm }\end{array}$} & \multicolumn{2}{|c|}{$\begin{array}{c}\text { Total Water } \\
\text { Consumption } \\
\text { Water }\end{array}$} & \multirow{2}{*}{$\begin{array}{c}\begin{array}{c}\text { Material } \\
\text { Collected in } \\
\text { Hopper }\end{array} \\
\text { lbm }\end{array}$} & \multirow{2}{*}{ 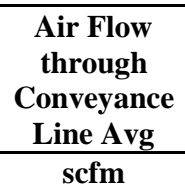 } & \multirow{2}{*}{$\begin{array}{c}\text { TORE® } \\
\text { Head Feed } \\
\text { Pressure } \\
\text { Avg } \\
\text { psi }\end{array}$} & \multirow{2}{*}{$\begin{array}{c}\text { TORE® } \\
\text { Supply } \\
\text { Pressure } \\
\text { Avg } \\
\text { psi }\end{array}$} & \multirow{2}{*}{$\begin{array}{c}\text { Pitot } \\
\text { Probe } \\
\Delta \text { P Avg } \\
\text { psi } \\
\end{array}$} \\
\hline & & & & & & gal & lbm & & & & & \\
\hline $8 / 7 / 1900$ & & & & & & & & & & & & \\
\hline DSP11VS & $13: 31: 24$ to $13: 33: 08$ & 35 & 30 & 0 & 0.0 & 0 & 0.0 & 34 & 295 & 0.4 & 21.6 & 1.8 \\
\hline DSZ11VS & $13: 44: 29$ to $13: 45: 25$ & 42 & NA & 0 & 0.0 & 0 & 0.0 & NA & NA & 0.4 & 22.0 & 0.0 \\
\hline DSP31VS & $14: 05: 04$ to $14: 07: 18$ & 1 & NA & 4.7 & 0.5 & 10.5 & 87.3 & 63 & 281 & 1.6 & 31.8 & 1.6 \\
\hline DSP21VS & $14: 15: 11$ to $14: 17: 21$ & NA & NA & 52 & 0.8 & 112.67 & 936.3 & 462 & 52 & 0.4 & 11.4 & 0.1 \\
\hline DSZ21VS10 & $14: 52: 36$ to $14: 53: 14$ & & -15 & 12 & 2.8 & 6.96 & 57.8 & NA & NA & 0.1 & 0.6 & 0.0 \\
\hline \begin{tabular}{|l} 
DSZ21VS50 \\
\end{tabular} & $14: 54: 05$ to $14: 56: 32$ & 170 & 326 & 51 & 0.6 & 119.23 & 990.8 & NA & NA & 0.0 & 10.3 & 0.0 \\
\hline \begin{tabular}{|l|} 
DSZ20VS70 \\
\end{tabular} & $15: 04: 10$ to $15: 04: 36$ & 16 & 16 & 70 & 0.5 & 30.33 & 252.1 & NA & NA & 0.0 & 27.6 & 0.0 \\
\hline DSZ21VS70 & 15:06:03 to $15: 07: 11$ & & 18 & 71 & 0.3 & 80.92 & 672.4 & NA & NA & 0.0 & 21.2 & 0.0 \\
\hline
\end{tabular}




\subsection{References}

Bamberger, J. A., B. K. Hatchell, B. E. Lewis, and J. D. Randolph. 2001. Evaluation of Technologies for Retrieval of Waste from Leaking Tanks. PNNL-13770. Pacific Northwest National Laboratory, Richland, Washington.

Bamberger, JA, MA McKinnon, DA Alberts, DE Steele, and CT Crowe. 1994. FY93 Summary Report Development of a Multi-Functional Scarifier Dislodger with an Integral Pneumatic Conveyance Retrieval System for Single-Shell Tank Remediation. PNL-8901, Pacific Northwest Laboratory, Richland, Washington.

Chard, S.J., K. Nezhati, J.E. Delves, A.C. Lockier, D.J. Parkinson. 1996. "Evaluation of the TORE ${ }^{\circledR}$ for Hydrotransport and its Application". 13th International Conference on Slurry Handling and Pipeline Transport: HYDROTRANSPORT 13, Johannesburg, South Africa. September 3-5, 1996.

Estey, S. D. 2001. Engineering Calculation: Project W-523, Single-Shell Tank 241-C-104 Mobile Retrieval System Waste Transport Property and Critical Velocity Analysis. RPP-8915, Rev. 0. CH2M Hill Hanford Group, Inc., Richland, Washington.

Estey, S. D. 2001. Engineering Calculation: Project W-523, Single-Shell Tank 241-C-104 Mobile Retrieval System Waste Transport Property and Critical Velocity Analysis. RPP-8915, Rev. 0. CH2M Hill Hanford Group, Inc., Richland, Washington.

Estey, S. D. 2001. Engineering Calculation: Project W-523, Single-Shell Tank 241-C-104 Mobile Retrieval System Waste Transport Property and Critical Velocity Analysis. RPP-8915, Rev. 0A. CH2M Hill Hanford Group, Inc., Richland, Washington.

Estey, S. D. 2001. Engineering Calculation: Project W-523, Single-Shell Tank 241-C-104 Mobile Retrieval System Waste Transport Property and Critical Velocity Analysis. RPP-8915, Rev. 0B. CH2M Hill Hanford Group, Inc., Richland, Washington.

Faram, M.G., N. Syred, T. O’Doherty. 1996. "Studies of Novel Devices for Slurry Transportation”. 13th International Conference on Slurry Handling and Pipeline Transport: HYDROTRANSPORT 13, Johannesburg, South Africa. September 3-5, 1996.

Golcar, G. R., M. R. Powell, J. R. Bontha, P. A. Smith, J. G. Darab, and J. Zhang. 1997. Retrieval Process Development and Enhancements Project Fiscal Year 1995 Simulant Development Technology Task Progress Report. PNNL-11103, Pacific Northwest National Laboratory, Richland, Washington. 
Holm, M. J. 2001. Specification for 241-C-104 Mobile Retrieval System. RPP-7420, Rev. 0. CH2M Hill Hanford Group, Inc., Richland, Washington.

Jewett, J. R., S. D. Estey, L. Jensen, N. W. Kirch, D. A. Reynolds, Y. Onishi. 2002. Values of Particle Size, Particle Density, and Slurry Viscosity to Use in Waste Feed Delivery Transfer System Analysis.RPP-9805, Rev. 1a, Numatec Hanford Corporation, Richland, Washington.

O'Rourke, J. F. 2000. Results of Retrieval Studies with Waste from Tank 241-C-104. RPP_5798, Rev. $0 \mathrm{~A}$.

O'Rourke, J. F. 2000. Results of Retrieval Studies with Waste from Tank 241-C-104. RPP_5798, Rev. $0 \mathrm{~A}$.

O’Rourke, J. F. 2001. Results of Retrieval Studies with Waste from Tank 241-C-104. RPP_5798, Rev. OB.

Parkinson, D., J Delves. 1999. “Continuous TORE ${ }^{\circledR}$ Hydrotransport system”. 14th International Conference on Slurry Handling and Pipeline Transport: HYDROTRANSPORT 14, Maastricht, The Netherlands. September 8-10 1999.

Powell, M. R., G. R. Golcar, and J. G. H. Geeting. 1997. Retrieval Process Development and Enhancements Waste Simulant Compositions and Defensibility. PNNL-11685, Pacific Northwest National Laboratory, Richland, Washington. 


\subsection{Distribution}

No. of

Copies

OFFSITE

1 DOE/Office of Scientific and Technical

Information and Information Release

\section{ONSITE}

1 Tanks Focus Area Program Lead

T. P. Pietrok

K8-50

1 Retrieval Technology Integration

Manager

P. W. Gibbons

K9-91

1 Tanks Focus Area Technical Team

B. J. Williams

K9-69

9 Hanford Site

J. R. Biggs

J. W. Cammann

R4-08

K. E. Carpenter

R2-39

S7-90

P. J. Certa

R3-73

A. F. Choho

K. A. Gasper

M. G. Glasper

D. B. Smet

W. T. Thompson
R3-73

L4-07

K8-50

S7-90

R3-73
No. of

Copies

ONSITE

12 Pacific Northwest National Laboratory

J. A. Bamberger (2) K7-15

C. J. Bates

K7-15

J. M. Bates

K7-15

J. W. Brothers (2)

K7-15

B. K. Hatchell

K5-22

J. L. Huckaby

K7-15

W. L. Kuhn

K7-15

P. A. Meyer

K7-15

M. W. Rinker

K5-22

M. White 
